NBER WORKING PAPER SERIES

\title{
SOVEREIGN DEBT RATCHETS AND WELFARE DESTRUCTION
}

\author{
Peter M. DeMarzo \\ Zhiguo He \\ Fabrice Tourre \\ Working Paper 28599 \\ http://www.nber.org/papers/w28599 \\ NATIONAL BUREAU OF ECONOMIC RESEARCH \\ 1050 Massachusetts Avenue \\ Cambridge, MA 02138 \\ March 2021
}

We would like to thank Mark Aguiar, Fernando Alvarez, Manuel Amador, Jason Donaldson (discussant), Andrea Gamba (discussant), Ben Hebert, Espen Henriksen (discussant), Anil Kashyap, Liu Ping (discussant) and Harald Uhlig for helpful discussions, as well as the seminar participants at Stanford SITE, Arizona State, University of Chicago Booth, Copenhagen Business School, Northwestern University, Boston University, Emory University, CEPR Gerzensee (Corporate Finance session), EFA conference, MFA conference and NBER Summer Institute (Macro Within and Across Borders' session). Zhiguo He acknowledges financial support from the Center for Research in Security Prices at the University of Chicago Booth School of Business. Fabrice Tourre gratefully acknowledges financial support from the Danish Finance Institute as well as the Center for Financial Frictions (FRIC) (grant no. DNRF-102). The views expressed herein are those of the authors and do not necessarily reflect the views of the National Bureau of Economic Research.

NBER working papers are circulated for discussion and comment purposes. They have not been peer-reviewed or been subject to the review by the NBER Board of Directors that accompanies official NBER publications.

(C) 2021 by Peter M. DeMarzo, Zhiguo He, and Fabrice Tourre. All rights reserved. Short sections of text, not to exceed two paragraphs, may be quoted without explicit permission provided that full credit, including $\left({ }^{\circ}\right.$ notice, is given to the source. 
Sovereign Debt Ratchets and Welfare Destruction

Peter M. DeMarzo, Zhiguo He, and Fabrice Tourre

NBER Working Paper No. 28599

March 2021

JEL No. C73,F32,F38,F43,F51,G12

\section{$\underline{\text { ABSTRACT }}$}

An impatient and risk-neutral government can sell bonds at any time to a more patient group of competitive lenders. The key problem: the government cannot commit to either a particular financing strategy, or a default strategy. Despite risk-neutrality, in equilibrium debt adjusts slowly towards a target debt-to-income level, exacerbating booms and busts. Most strikingly, for any debt maturity structure, the gains from trade are entirely dissipated when trading opportunities are continuous, as lenders compete with each other and the government competes with itself. Moreover, citizens who are more patient than their government are strictly harmed by the unrestricted borrowing. We fully characterize debt dynamics, ergodics, and comparative statics when income follows a geometric Brownian motion, and analyze several commitment devices that allow the sovereign to recapture some gains from trade: self-imposed restrictions on debt issuances and levels, as well as "market-imposed" discipline.

Peter M. DeMarzo

Graduate School of Business

Stanford University

Stanford, CA 94305

and NBER

pdemarzo@stanford.edu

Zhiguo He

University of Chicago

Booth School of Business

5807 S. Woodlawn Avenue

Chicago, IL 60637

and NBER

zhiguo.he@chicagobooth.edu
Fabrice Tourre

Finance Department

Copenhagen Business School

Campus Solbjerg Plads 3 - A4.01

2000 Frederiksberg

Denmark

ft.fi@cbs.dk 


\section{Introduction}

Since the seminal work of Eaton and Gersovitz (1981), a large number of articles have studied small open economies issuing defaultable sovereign debt. The theoretical building blocks of this literature include a government that makes financing and default decisions without being able to commit, and competitive creditors that price the sovereign debt rationally. Natural questions to consider include predictions for average debt-to-income ratios, the level of sovereign credit spreads, the behavior of the current account, and the ultimate consequence of external finance on citizen welfare.

While recent work has acknowledged that a sovereign's inability to commit to its future financing policy and indebtedness entails welfare losses, a sharp theoretical characterization of the determinants and magnitude of these losses has not been available. ${ }^{1}$ One challenge is that there are limited theoretical results establishing existence and uniqueness of equilibria in this context. ${ }^{2}$ A related debate has emerged over the optimality of short-term vs. long-term debt, with several articles suggesting that the use of short-term debt provides welfare gains to an optimizing government over the use of long-term debt.

In this paper, we make progress on these questions by taking a standard model of sovereign default and modifying it along two dimensions. First, we assume the government's motive to take on debt purely stems from its impatience relative to international creditors: defaultable debt is used for consumption "tilting" but not for consumption "smoothing" purposes. ${ }^{3}$ This setting is one in which the potential gains from trade are significant and straightforward. Second, we analyze an environment where the time-step between financing decisions - effectively the length of time during which the government can commit - becomes arbitrarily small, by studying a continuous-time model of trading. By doing so we eliminate the implicit (one-period) commitment that arises with discrete trade, thereby allowing us to analyze the consequences of debt maturity separately from commitment timing.

Though these assumptions are admittedly idealized, many important results emerge. First, in the class of Markov perfect equilibria we focus on, debt only adjusts slowly in response to income shocks, exacerbating (and extending) booms and busts. We characterize the bond issuance policy of the government, and show that the issuance rate is equal to (a) the wedge between the government's rate of time preference and debt investors' required rate of return, divided by $(b)$ the marginal percentage decline in the bond price per dollar of new debt issued. Furthermore, sovereign debt is mean reverting; in the special case of geometric Brownian motion income dynamics, the government targets a specific debt-to-income attraction level that we compute analytically.

We demonstrate that supply-side shocks in debt capital markets - whether they are interest rate shocks or risk-price shocks - lead to an adjustment of the government financing policy and corresponding current account adjustments that are qualitatively consistent with empirical studies. ${ }^{4}$ In the particular case where capital markets' investors are risk-neutral, we recover an old result from the sovereign

\footnotetext{
${ }^{1}$ See notably Hatchondo, Martinez and Sosa-Padilla (2016) or Arellano and Ramanarayanan (2012).

${ }^{2}$ Notable exceptions include Chatterjee and Eyigungor (2012), who establish the existence of a Markov perfect equilibrium in the presence of long term debt, and Auclert and Rognlie (2016), who provides a uniqueness result in a model with one-period debt.

${ }^{3}$ The "smoothing" purpose seems at odds with the striking empirical regularity that external borrowing raises consumption growth volatility for emerging market economies relative to their output growth volatility (Aguiar and Gopinath (2004); Neumeyer and Perri (2005).

${ }^{4}$ As shown by Mendoza (2010) or Edwards (2004), during periods of international capital market turbulences, small open economies tend to revert to running current account surpluses.
} 
default literature, first established by Bulow and Rogoff (1989) in the context of a static model: a government should never buy back its own debt. This result is over-turned in the presence of risk-averse debt investors: when bond risk premia demanded by credit market investors are sufficiently high, it becomes optimal for the government to proactively reduce its outstanding debt through bond buy-backs.

Most importantly, and most strikingly, our model produces a sharp welfare result: despite the potential gains from trade, and despite active and consistent borrowing in equilibrium, the government is unable to capture any welfare benefit from external financing. The government's option to borrow from more patient lenders is fully undermined by its inability to commit to a particular fiscal path, and thus, if not initially indebted, does no better than the autarky benchmark. Moreover, despite the extensive borrowing that occurs in equilibrium, its welfare at any point is equal to the present value of future consumption flows computed as if it never trades again in international capital markets. This result echoes the conjecture made by Coase (1972) in the context of a durable goods' monopolist. Section 3 illustrates the economic intuition of this result in a discrete-time setting. There we show that the magnitude of the trading gains is proportional to the product of (i) the wedge between creditors' and the government's discount rate, (ii) the trading time interval $d t$ and (iii) the proceeds raised from bond issuances. Because the price impact of trading implies that the optimal proceeds raised are also of order $d t$, welfare gains per period are of order $d t^{2}$. Lifetime welfare gains thus converge to zero in the continuous-time limit $d t \rightarrow 0$. This welfare result holds independently of the debt maturity, and thus applies even for relatively short-term debt, as long as trading opportunities are sufficiently frequent. ${ }^{5}$

Our no-welfare-gain result is valid for a wide range of assumed income processes for the optimizing government as well as various international credit market specifications. An immediate implication is that equilibrium welfare does not depend on international risk-free rates nor on risk-prices. In equilibrium, the anticipation of future debt issuance by the government drives down the current debt price to the point that the marginal benefit from additional borrowing just equals the marginal cost of the future debt burden. On the other hand, changes in capital market conditions directly affect the issuance strategy of the government - more benign market environments result in a higher rate of debt issuance.

Next we consider the impact on citizens' welfare. Here we make the natural assumption that citizens are more patient than the current government regime. ${ }^{6}$ In that case, while the government does not capture any welfare gains from being able to trade with more patient lenders, we show that citizens will be strictly worse off with open capital markets. Indeed, since the government balances exactly the benefit of borrowing to support current consumption against future default costs, more patient citizens will put higher weight on default costs, making their welfare lower than the no-trade benchmark. Hence, for the citizens of the small open economy, financial autarky is better than trade.

An additional, more technical, contribution of our paper is to show that the smooth Markov perfect equilibrium derived in our model, when it exists, is always unique within the class of smooth Markov perfect equilibria. Furthermore, in the special case of lognormal income dynamics, we are able to establish the uniqueness of our equilibrium among all Markov perfect equilibria (even potentially nonsmooth). While a similar result holds with discrete-time models featuring one-period debt contracts, we

\footnotetext{
${ }^{5}$ Our model thus highlights an important distinction between discrete-time and continuous-time models. With discretetime, one-period debt automatically implies commitment, as there is no opportunity to trade again before the debt matures. With continuous trading, we are able to compare different debt maturities while holding the lack of commitment constant.

${ }^{6}$ For example, the current government may only care about consumption while in power, and anticipate the stochastic arrival of regime change.
} 
are the first paper to our knowledge to establish such a result in the context of long-term defaultable debt.

Finally, our model provides new insight in the role of debt maturity and other features of debt contracts. As mentioned earlier, we show that government welfare is independent of debt maturity. This result even extends to certain types of state contingent bonds (such as GDP-linked debt). In all cases, the inability of the government to commit not to issue additional bonds - even over short time periods prevents it from realizing gains from trade. ${ }^{7}$ But although the government is indifferent, debt maturity does affect the level and dynamics of sovereign debt, and hence can significantly impact citizen welfare.

To provide a concrete illustration of the smooth Markov perfect equilibrium we focus on, we derive a complete analytical characterization of the government value function, debt prices, issuance policy and default policy in the particular case where the small open economy's income process follows geometric Brownian motion dynamics. This analytical characterization allows us to derive explicit comparative statics that are unavailable in most of this literature. ${ }^{8}$ We show that the government financing policy consists in systematically targeting a particular debt-to-income attraction point, and that the speed at which debt adjustments occur following income shocks (a) increases with the discount rate wedge between creditors and the government, and (b) decreases with debt maturity. Finally, we provide an analytic formula for the ergodic debt-to-income density, which facilitates computing the macroeconomic and asset pricing moments of interest to economists. In the paper, we focus specifically on the ergodic default rate, bond credit spread and average debt-to-income ratio.

In the final section of the paper, we introduce different possible frictions or commitment mechanisms that may enable the government to recapture some of the welfare gains from trade. Our analysis demonstrates that the details of the commitment mechanisms matter crucially. For example, trading frictions that allow the government to trade only at stochastically determined points in time does lead to limited welfare gains for the government (while the gains from commitment grow linearly with the expected trading interval, they are ultimately offset by the cost of delaying trade). On the other hand, if trading is possible only in stochastically determined windows of time - such as an environment with sudden stops and starts to international credit markets - the government cannot capture any gains. The contrast between these settings shows that it is critical whether "stops" to trade are perfectly anticipated (and so can provide commitment) or not.

We also investigate commitment devices that have been prevalent in international institutional arrangements. Restrictions on debt issuances once a country is too highly indebted (sometimes called "debt-ceiling" policies) allow the country to recapture some of the welfare gains from trade, but only if the restriction is sufficiently tight, preventing future borrowing while debt levels are relatively low. Instead, restrictions on the rate of debt issuance - a close analog to budget deficit rules or current account deficit limits - always lead to welfare improvements. Our model thus has the policy implication that international organizations should consider more flow-based rather than balance-based interventions.

Our paper is organized as follows. After reviewing the existing literature, we introduce a canonical

\footnotetext{
${ }^{7}$ This also highlights the importance of a continuous-time setting in studying the commitment problem. In a discrete time model with the shortest time interval $h$, debt contracts with a maturity of $h$ resolve the commitment problem completely. In contrast, when time is continuous, the government can always issue more debt before the current debt matures. In this sense, a continuous-time model isolates the debt maturity from time interval of commitment.

${ }^{8}$ See for example Hatchondo, Martinez and Sapriza (2010), Hatchondo and Martinez (2009) and Chatterjee and Eyigungor (2012), which rely on numerical methods.
} 
model of sovereign default in discrete time, and show heuristically the intuition for the results we obtain in the continuous-time limit. We then present our general theory and "no-welfare-gain" result. We then apply these results to a particular income process for which we can obtain an analytical characterization of all equilibrium objects of interest. We then discuss alternative commitment devices that can allow the small open economy to recapture some of the gains from trade.

\section{Related Literature}

Our paper relates to the vast literature on sovereign credit risk, which includes the seminal papers of Eaton and Gersovitz (1981) and Cole and Kehoe (1996), and more recently Aguiar and Gopinath (2004) and Arellano (2008). These original articles focus on discrete-time economies, one-period debt contracts, income risk, and feature impatient governments with finite intertemporal elasticities of substitution. Most of the literature focuses on the quantitative implications of this class of models for consumption, default probabilities, the behavior of the current account, but the authors rarely analyze the welfare costs incurred by a government that lacks a commitment technology. More recently, Rebelo, Wang and Yang (2021) recast the sovereign debt problem in continuous time but continue to assume short-term debt. They focus on a small open economy whose income follows jump diffusive dynamics, and study how the type of debt contract (local currency vs. foreign currency) and the ability to hedge macroeconomic risks influence welfare.

A related literature has analyzed the properties of sovereign default models in the presence of long term debt. Chatterjee and Eyigungor (2012) establish the existence of a Markov perfect equilibrium of their model using fixed-point arguments, while our proof is constructive. They perform a numerical welfare comparison using different types of bond maturities, concluding that short term debt leads to a greater ergodic welfare than long term debt. Arellano and Ramanarayanan (2012) analyze a government that has the option to issue both short-term and long-term debt, and argue that the government policy balances the "hedging benefits" of long-term debt vs. the "incentive benefits" of short-term debt. Those hedging benefits are absent from our paper, given the linear preferences we assume.

Aguiar et al. (2016a) study a model of sovereign default without income risk but with "outside option" risk. Their model is cast in a discrete-time setting, allow for any arbitrary debt maturity structure, and show that debt with long-term maturity-i.e., any maturity that is longer than the smallest time interval in their discrete-time setting - is never traded by the government in equilibrium. The very nature of discrete-time models is that the sovereign's commitment length coincides with the shortest maturity debt contract. In our paper with continuous trade, we decouple the debt maturity structure and commitment length, and argue instead that the lack of ability to commit over any possible time period renders the maturity structure of debt irrelevant for welfare purposes.

We establish a uniqueness result for our constructed Markov Perfect Equilibrium (MPE) among all smooth MPEs, and further show that it is unique among the class of MPE under geometric Brownian motion income processes. Based on a setting of "outside option" risk and linear preference of consumption but with constraints, Aguiar and Amador (2018) show the existence of two equilibria (namely a "borrowing" and a "savings" equilibria). We show in Section A.4 that if we remove the consumption constraints, and if the model is perturbed so that the "outside option" includes some noise, then a unique Smooth MPE emerges in their setting as well. 
Our focus on citizen welfare vs. government welfare is motivated by considerations similar to those in Aguiar, Amador and Fourakis (2020). In that article, welfare losses are incurred by citizens since the country spends a large amount of time in the default state, in which consumption fluctuations are costly for private citizens. In our work, all agents have linear preferences, and citizens are better off in autarky than with trade as soon as they are more patient than their government.

Our result that a government facing risk-neutral lenders never buys back its own bonds echoes a result obtained long ago by Bulow and Rogoff (1988) and Bulow and Rogoff (1989) in the context of a one period model. Our study sheds light on this question under a more general environment where the sovereign and creditors do not necessarily share the same probability measure. This could be related to debt investors having a pricing kernel that correlates with the small open economy's income process (see Borri and Verdelhan (2011) for an example with short-term debt, or Tourre (2017) for a continuoustime example with long-term debt), or disagreements between investors and the government over the future income prospects of the small open economy (see Harrison and Kreps (1978) for the foundational article for the "agree to disagree" framework). In contrast to the Bulow and Rogoff (1988) results, the government might find it optimal to buy back its own debt. This occurs when debt risk-premia required by international creditors are sufficiently high, or when lenders are sufficiently more pessimistic than the government about the small economy's future income growth rate.

A separate literature in corporate finance analyzes bond issuances and default in the presence of long term debt and a lack of commitment. Whereas the incentive to take on debt in the sovereign credit risk literature stems from impatience and consumption smoothing motives, firms' desire to issue debt in capital markets is typically linked to the tax benefits of debt. ${ }^{9}$ Our paper is closest to Admati et al. (2013) and DeMarzo and He (2020), who study the leverage dynamics when shareholders cannot commit to any debt policies and derive a similar welfare destruction effect. ${ }^{10}$ Dangl and Zechner (2021) study the dynamic capital structure decision of a firm that faces issuance costs and covenants that limit the issuance rate of new debt. He and Milbradt (2016) instead study a firm that can commit to keeping a constant amount of debt outstanding but has flexibility to issue short-term or long-term bonds; they show that "shortening" equilibria - equilibria in which the firm close to default chooses to issue shortterm as opposed to long-term bonds - can be Pareto dominated by "lengthening" equilibria.

\section{Model Overview}

We focus our attention on a risk-neutral government which seeks to maximize

$$
\mathbb{E}_{t}\left[\int_{t}^{+\infty} e^{-\delta(s-t)} d C_{s}\right],
$$

\footnotetext{
${ }^{9}$ The dynamic corporate finance literature on credit risk is vast, including Leland (1994), Goldstein, Ju and Leland (2001), and He and Xiong (2012), among others.

${ }^{10}$ DeMarzo and He (2020) point out that their constructed smooth MPE produces the lowest possible equilibrium payoff for the sovereign (Markov or not); as a consequence, all non-MPE equilibria can be supported by using their equilibrium as "grim trigger" punishment in response to an off-equilibrium deviation, as in the folk theorem literature. In the corporate finance literature, Luca et al. (2020) and Malenko and Tsoy (2020) have used these results to support non-Markov strategies in which the firm is "punished" for exceeding a target leverage ratio by reverting to our MPE.
} 
where $d C_{t}$ is consumption on date $t$ and $\delta$ is the government's rate of time preference. ${ }^{11}$ The government earns stochastic income at rate $Y_{t}$ (per unit of time), and therefore, absent borrowing or lending, $d C_{t}=$ $Y_{t} d t$. Because the government is risk-neutral, the incentive to take on debt stems from its high impatience relative to its creditors, who discount cash-flows at a rate $r<\delta .{ }^{12}$

The government can borrow or lend by issuing or repurchasing long-term, exponentially amortizing bonds. For now, assume the bonds have a fixed coupon rate $\kappa$ and amortization rate $m$; given aggregate debt $F$ outstanding, the government must pay interest $\kappa F d t$ and retire bonds by repaying principal $m F d t$ during any time interval $[t, t+d t)$. We can interpret $1 / m$ as the average maturity of the debt.

We focus on Markov perfect equilibria ("MPE") in which the two payoff-relevant state variables are the small open economy's income $Y_{t}$, and the outstanding aggregate debt face value, $F_{t}$, which is an endogenous state variable. The bonds issued by the government are traded in a competitive market at price $D\left(Y_{t}, F_{t}\right)$ (per unit of face value) that will be determined in equilibrium. Such price $D$ should equal the present value of the coupon and principal payments received up until the time $\tau$ of default, plus some final recovery value $\underline{D}\left(Y_{\tau}, F_{\tau}\right):^{13}$

$$
D(Y, F):=\hat{\mathbb{E}}^{Y, F}\left[\int_{0}^{\tau} e^{-(r+m) t}(\kappa+m) d t+e^{-(r+m) \tau} \underline{D}\left(Y_{\tau}, F_{\tau}\right)\right]
$$

The debt price will depend on the government's current income and debt level (which influence the expected time to default) and an appropriate pricing measure $\mathbb{Q}$, with related expectation operator $\hat{\mathbb{E}}$. The pricing measure $\mathbb{Q}$ might differ from the probability measure under which the government discounts consumption streams because either (i) creditors are risk-averse and their marginal utility co-moves with the country's income, or (ii) creditors and the government have different perceptions of the country's expected income growth rate (and they agree to disagree).

While we develop our model in continuous time, it is useful to outline the timing in the model heuristically as though time were discrete, as depicted in Figure 1. Specifically, suppose the government has current income $Y$ and existing debt $F$. If the government chooses not to default, the government will earn income, pay interest and principal on its current outstanding debt, and may issue or repurchase debt to adjust its total debt to $F^{\prime}$. In that case, the government's consumption over this $d t$ interval of time is given by

$$
d C_{t}=\underbrace{Y d t}_{\text {income }}+\underbrace{D\left(Y, F^{\prime}\right)\left(F^{\prime}-(1-m d t) F\right)}_{\text {proceeds from net debt issuance }}-\underbrace{(\kappa+m) F d t}_{\text {interest and principal due }}
$$

Note that the debt price is determined by the government's current income $Y$ and the new debt level $F^{\prime}$,

\footnotetext{
${ }^{11}$ Consumption in our model can be interpreted as government expenditure, and income as tax revenue. Alternatively, once can interpret consumption as the citizen's consumption, under the assumption that the government has sufficient policy instruments to directly control such consumption. In this latter interpretation, income is interpreted as the country's GDP. $\delta$ can be interpreted as an implicit rate of return generated on investment in public goods; alternatively it may correspond to the desire of current politicians to accelerate spending during their time in office.

${ }^{12}$ Our linear preference specification is a departure from a class of models studied by the quantitative sovereign default literature (see Arellano (2008), and Aguiar and Gopinath (2006)), in which the government also has a consumption-smoothing motive to borrow and lend, in addition to an impatience motive.

${ }^{13}$ The recovery value might be specified exogenously as the result of a final settlement agreed between creditors and the debtor at the time of default, or rather endogenously as the result of a renegotiation that leads to a sovereign debt haircut following a debt renegotiation with the government. For the time being, the specific settlement mechanism upon default is not essential.
} 
Figure 1: Model Timeline

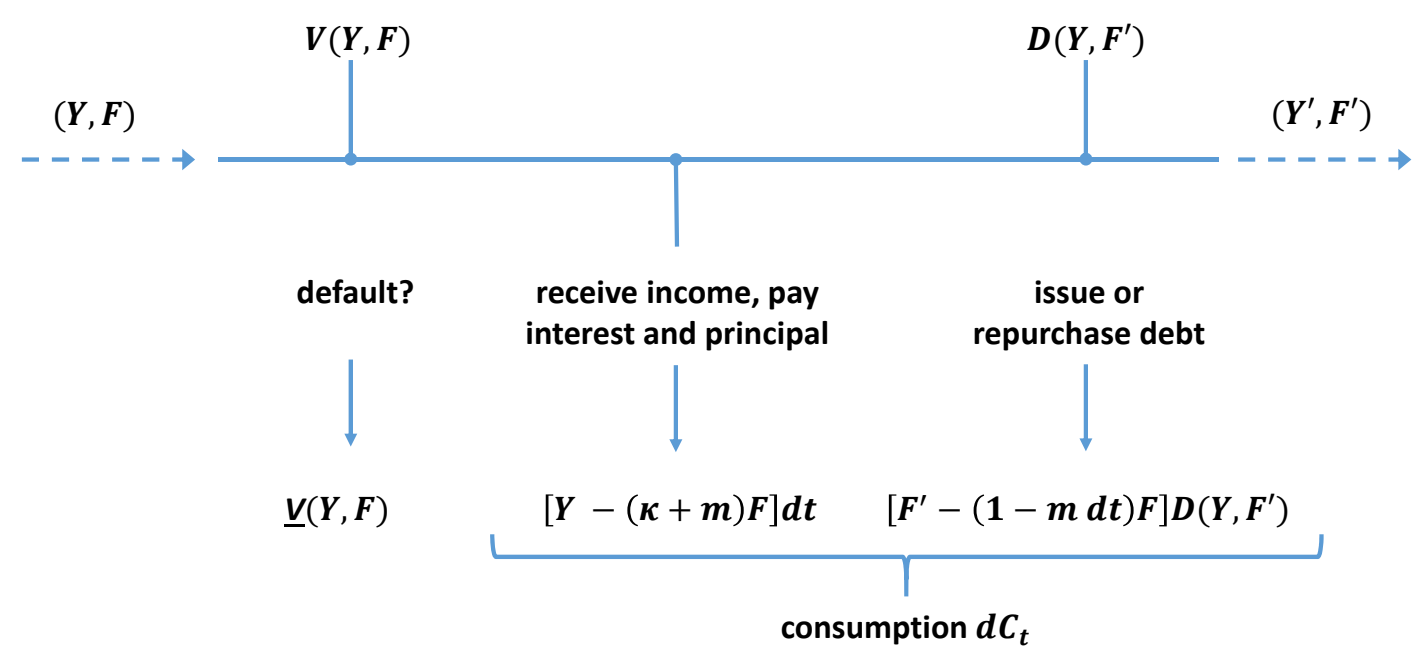

as we should expect the debt price to decline if more debt is issued.

The government has two interrelated commitment problems. First, it cannot commit to always repay its debt, forcing creditors to bear default risk. If the government elects to default, it achieves a default value given by $\underline{V}(Y, F)$ (which we will endogenize in our model, and entails some degree of loss). Second, it cannot commit to a future financing policy - in other words, when issuing bonds at time $t$, the government cannot credibly promise to follow a future path of debt. Thus, creditors must anticipate the government's equilibrium debt issuance behavior and set the debt price $D\left(Y, F^{\prime}\right)$ accordingly. Hence, we can write the corresponding discrete-time government Bellman equation as:

$$
\begin{aligned}
V(Y, F)=\max _{F^{\prime}}\left\{(Y-(\kappa+m) F) d t+D\left(Y, F^{\prime}\right)\left(F^{\prime}-(1-m d t) F\right)\right. & \\
& \left.+e^{-\delta d t} \mathbb{E}^{Y}\left[\max \left(V\left(Y^{\prime}, F^{\prime}\right), \underline{V}\left(Y^{\prime}, F^{\prime}\right)\right)\right]\right\}
\end{aligned}
$$

The continuation value $V(Y, F)$ represents the government's expected payoff given initial income $Y$ and debt $F$ if it chooses not to default. The maximization problem results in an optimal debt adjustment $F^{\prime}(Y, F)$ and a decision to repay versus default which we can represent by the repayment indicator function $\mathcal{R}(Y, F):=\mathbb{1}\{(Y, F): V(Y, F) \geq \underline{V}(Y, F)\}$.

For simplicity (we will relax all these assumptions later), consider for now the case with risk-neutral creditors and common priors, and upon a sovereign default, zero recovery rate for bond holders $(\underline{D}=0)$ and a government value $\underline{V}(Y)$ that is a fraction of its autarky value (which is independent of $F$ and ensures some degree of loss). Then, given the government's optimal decision rules, the debt price can be written recursively as

$$
D\left(Y, F^{\prime}\right)=e^{-r d t} \mathbb{E}^{Y}\left[\mathcal{R}\left(Y^{\prime}, F^{\prime}\right)\left[(\kappa+m) d t+(1-m d t) D\left(Y^{\prime}, F^{\prime \prime}\right)\right]\right]
$$

where $F^{\prime \prime}$ represents the optimal new debt level starting from $\left(Y^{\prime}, F^{\prime}\right)$. Except for our linear preference 
specification for the government, equations (3) and (4) are the two canonical equations of most sovereign default models. An MPE is defined as a pair of functions $(V, D)$ that satisfies these equations.

To understand our main result, note that the government's marginal cost from adding a dollar of outstanding debt today can be calculated as follows:

$$
\begin{aligned}
-\partial_{F^{\prime}}\left[e^{-\delta d t} \mathbb{E}^{Y}\left[\max \left(V\left(Y^{\prime}, F^{\prime}\right), \underline{V}\left(Y^{\prime}\right)\right)\right]\right] & =-e^{-\delta d t} \mathbb{E}^{Y}\left[\mathcal{R}\left(Y^{\prime}, F^{\prime}\right) \partial_{F} V\left(Y^{\prime}, F^{\prime}\right)\right] \\
& =e^{-\delta d t} \mathbb{E}^{Y}\left[\mathcal{R}\left(Y^{\prime}, F^{\prime}\right)\left((\kappa+m) d t+(1-m d t) D\left(Y^{\prime}, F^{\prime \prime}\right)\right)\right] \\
& =e^{(r-\delta) d t} D\left(Y, F^{\prime}\right),
\end{aligned}
$$

which follows from the envelope condition for the Bellman equation (3), used in conjunction with the debt pricing equation (4) and the fact that the sovereign value in default $\underline{V}$ is independent of the face amount of debt $F^{\prime}$. There are two important observations that arise from equation (5). First, because $\delta>r$, the government's marginal cost of debt is always strictly less than the debt price. Thus, regardless of the current debt level, the sovereign's impatience always provides an incentive to issue new debt. Second, the difference between price and marginal cost is proportional to the trading interval $d t$. That is, by the envelope theorem, the valuation differential only accrues until the next opportunity to trade. Denote by $d \Gamma:=F^{\prime}-(1-m d t) F$ the amount of new debt issuance, and let $d \Gamma^{*}$ be the optimal issuance policy. We then have the following central result:

Proposition 1 Suppose an MPE exists in which the debt price is strictly decreasing in the level of government debt $F$. Then for small $d t$, the government's optimal debt issuance is given by

$$
d \Gamma^{*}(Y, F)=\frac{D\left(Y, F^{\prime}\right)}{-\partial_{F} D\left(Y, F^{\prime}\right)}(\delta-r) d t>0,
$$

and the gain from trade over the time interval $d t$ is $O\left(d t^{2}\right)$.

Proof. (Heuristic.) ${ }^{14}$ Using equation (5), the first-order condition with respect to $F^{\prime}$ for (4) is

$$
D\left(Y, F^{\prime}\right)+\partial_{F} D\left(Y, F^{\prime}\right) d \Gamma^{*}=e^{(r-\delta) d t} D\left(Y, F^{\prime}\right),
$$

which states that the marginal revenue from debt issuances equals marginal cost. Then a first-order approximation for $e^{(r-\delta) d t}$ implies $d \Gamma^{*}$. Next note that $\partial_{F} D<0$ implies that the gain from trade is bounded by the quantity traded times the difference between price and marginal cost:

$$
\left(D-e^{(r-\delta) d t} D\right) d \Gamma^{*}=\frac{D^{2}}{-\partial_{F} D}(r-\delta)^{2} d t^{2}+o\left(d t^{2}\right)
$$

Proposition 1 has several key implications. First, because debt issuance is of order $d t$, the debt level

\footnotetext{
${ }^{14}$ While we derive Proposition 1 heuristically here to provide intuition, we will establish these results more formally in the subsequent sections.
} 
Figure 2: Welfare gains vs. trading interval

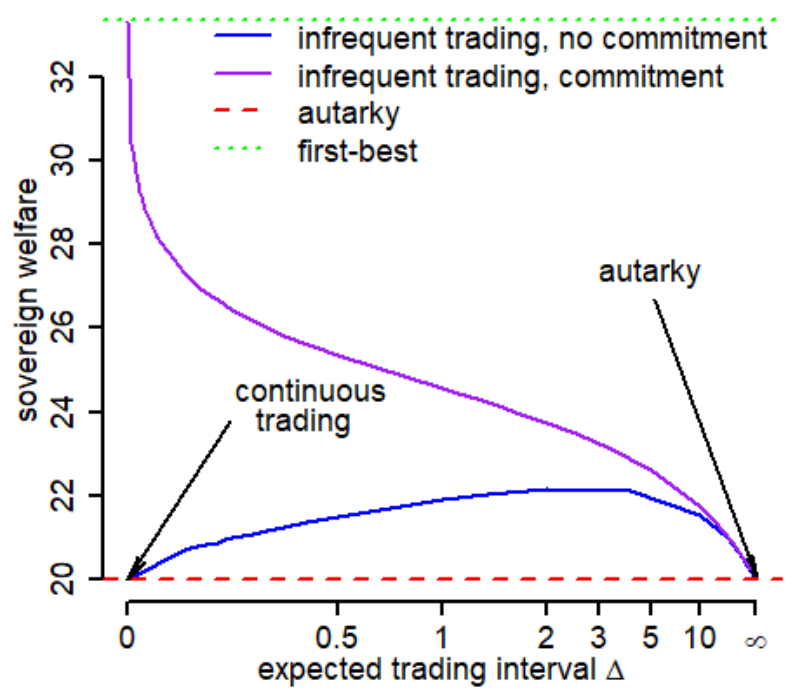

Figure shows sovereign welfare (assuming no initial debt) as a function of the trading interval for the model with infrequent trade developed in Section 6.1. Blue line depicts welfare (per unit of income) for the model without commitment to a future debt policy, and purple depicts welfare with a commitment to return to the optimal debt-to-income level at each trade date (until the government chooses to default). Red dashed line shows the autarky value for the government, and green dotted line shows the first-best value of the government's income process. The plot assumes an income growth rate of $\mu=2 \%$ p.a., volatility of $\sigma=20 \%$ p.a., debt maturity $1 / m=10$ years, zero recovery for creditors and government in default, $r=\kappa=5 \%$ and $\delta=7 \%$; hence autarky welfare is $1 /(7 \%-2 \%)=20$ and the first-best value is $1 /(5 \%-2 \%)=33.3$ (per dollar of income).

will adjust smoothly and we can define the optimal issuance rate of new debt to be

$$
G^{*}(Y, F):=\frac{d \Gamma^{*}}{d t}=\frac{D\left(Y, F^{\prime}\right)}{-\partial_{F} D\left(Y, F^{\prime}\right)}(\delta-r)>0
$$

Because income may fluctuate much faster (e.g. due to the Brownian income shocks we will use in our model), the resulting debt-to-income ratio will be counter-cyclical - falling after large upward income shocks (booms), and rising after large income declines (busts). Second, Proposition 1 implies that even if the government is already highly indebted, its impatience relative to creditors will lead it to continue to issue new debt. Note however, that when the debt price is sufficiently sensitive to the debt level (i.e. debt demand is inelastic), the rate of debt issuance will be below the rate of amortization and total indebtedness will decline; specifically,

$$
\frac{D / F}{-\partial_{F} D}<\frac{m}{\delta-r} \quad \text { implies } \quad G^{*}<m F \quad \text { and thus } \quad \frac{d F}{d t}<0 \text {. }
$$

Indeed, we will show that in the case where income growth is i.i.d., the government's debt-to-income ratio $F / Y$ will slowly mean revert towards a target. This adjustment will lead to consumption booms and busts that are more extreme than the underlying income shocks.

Third, while there are positive gains from trade for any finite trading interval $d t$, because the gains from trade are $O\left(d t^{2}\right)$, as the frequency of trade increases and $d t \rightarrow 0$, the cumulative gains from trading will vanish. Figure 2 illustrates this result by plotting the welfare value for a government without debt 
and subject to i.i.d. income growth shocks when we vary the expected time between trading dates, based on the model fully developed in Section 6.1. The blue line depicts the case of a government who cannot commit to a particular financing strategy, whereas the purple line shows the corresponding welfare for a government who commits to return to a target debt-to-income ratio at each trading date prior to default, where the target is chosen optimally at time zero. As the trading interval shrinks, the welfare of the government who cannot commit converges to the value it would achieve if no further trading of the debt were allowed, whereas the welfare of the government who can commit converges to the first-best value of the government's income process.

Figure 2 thus highlights the combined effect of frequent trading and lack of commitment in destroying welfare. ${ }^{15}$ This welfare destruction occurs because, although creditors are more patient, they anticipate that the uncommitted government will continue to issue new debt and raise the future risk of default. In equilibrium the debt price today falls to the point that it just equals the government's marginal cost of repaying the debt. In the end, the potential gains from trade are fully dissipated by the higher default costs resulting from continued debt issuance. ${ }^{16}$

In the full model we develop in the next section, we extend the above intuition to a general setting where we allow for debt restructuring, as well as risk averse (or pessimistic) creditors. The only qualitative change to the results described above is that when creditors are risk averse, the expected return on the debt will include a risk premium $\pi$. When leverage is sufficiently high and the debt is very risky, it is possible that $r+\pi>\delta$ and the government may find it optimal to repurchase (rather than issue) debt.

A key takeaway from our model is that despite the attractiveness of external debt, a government that can borrow freely and frequently is unable to capture the gains from trade. Furthermore, if citizens are more patient than the government itself, their welfare may be destroyed. Thus, in order to benefit from external debt, some constraints on the government's ability to borrow must be imposed. We examine several natural constraints in the paper and look at their consequences for both sovereign and citizen welfare.

\section{The General Result}

We now generalize the model and results presented in the previous section. To do this, we consider a broad class of income processes for our small open economy of interest, and also introduce risk-averse creditors whose marginal utility process might co-vary with the small open economy's income process.

\footnotetext{
${ }^{15}$ Our result that there is zero gain from trade, which is novel to the canonical sovereign debt literature, is also dependent on the risk-neutrality of our sovereign government. If the government were risk-averse with a concave utility function $u(\cdot)$ over the consumption rate $C_{t}$, we could write the gain from trade on the interval $[t, t+d t)$ as

$$
\begin{array}{r}
{\left[u\left(Y-(\kappa+m) F+G^{*} D\left(Y, F^{\prime}\right)\right)-u(Y-(\kappa+m) F)\right] d t-e^{(r-\delta) d t} G^{*} D\left(Y, F^{\prime}\right) d t=} \\
{\left[u\left(Y-(\kappa+m) F+G^{*} D\left(Y, F^{\prime}\right)\right)-u(Y-(\kappa+m) F)\right] d t+O\left(d t^{2}\right)}
\end{array}
$$

This expression makes clear that gains from trade of order $O(d t)$ only arise from the curvature of the government's utility.

${ }^{16}$ This result is analogous to the Coase conjecture for durable goods monopoly and holds also in the corporate context as shown by DeMarzo and He (2020).
} 


\subsection{Income Process and Sovereign Default}

We specify our small open economy's real income $Y_{t}$ (per unit of time) as an Itô process that takes positive values only. International capital market conditions, which might affect the dynamics of the small open economy's income process, are described by the state variable $s_{t} \in \mathcal{E} \subset \mathbb{R}$. $Y_{t}$ and $s_{t}$ satisfy

$$
\begin{aligned}
d Y_{t} & =\mu_{Y}\left(Y_{t}, s_{t}\right) d t+\sigma_{Y}\left(Y_{t}, s_{t}\right) \cdot d \boldsymbol{B}_{t}, \\
d s_{t} & =\mu_{s}\left(s_{t}\right) d t+\sigma_{s}\left(s_{t}\right) \cdot d \boldsymbol{B}_{t} .
\end{aligned}
$$

Here, $\left\{\boldsymbol{B}_{t}\right\}_{t \geq 0}$ is a multi-dimensional Brownian motion on the underlying probability space $(\Omega, \mathcal{F}, \mathbb{P}) .{ }^{17}$ The multi-dimensional nature of the Brownian shocks could capture country-specific shocks and aggregate shocks, which might also affect the marginal utility of international financial market participants.

Given our small open economy assumption, the income level $Y_{t}$ of our country of focus does not affect the dynamics of the international capital market conditions $s_{t}$. The model specified in (7) can capture a feedback loop between financial market conditions and the country's income process, by allowing the growth rate and volatility of our country of focus to depend on $s_{t} \cdot{ }^{18}$ We assume that the government autarky value is finite.

Assumption 1 The impatience parameter $\delta$, income drift rate $\mu_{Y}(\cdot, \cdot)$, income volatility $\sigma_{Y}(\cdot, \cdot)$, and the stochastic process $\left\{s_{t}\right\}_{t \geq 0}$ are such that for all values of $(Y, s) \in \mathbb{R}_{+} \times \mathcal{E}$, the autarky value satisfies

$$
W(Y, s):=\mathbb{E}^{Y, s}\left[\int_{0}^{+\infty} e^{-\delta t} Y_{t} d t\right]<+\infty
$$

Once the government borrows, there is the possibility of default. Because the government cannot commit to repaying its bonds, it will choose to default strategically once the debt burden is too high. ${ }^{19}$ To analyze the optimal default time, we must specify the consequences of default for creditors and the government. We adopt the following simple framework for clarity, though we show later that our results are robust to alternative default resolution schemes.

Upon a default at time $\tau$, we set the creditors' recovery rate to be a (state dependent) constant $\underline{d}(s)$ and the government's payoff to be a fraction $\alpha \in(0,1)$ of its autarky value net of the payment to

\footnotetext{
${ }^{17}$ Here, $\mathbb{P}$ is the physical probability measure, and $\mathcal{F}_{t}$ the $\sigma$-algebra generated by the Brownian motion $\boldsymbol{B}_{t}$. Our notation will use bold letters for vectors. By convention, we assume that the entries of the volatility vector $\sigma_{Y}$ are positive.

${ }^{18}$ The results presented in this paper are robust to more general specifications of the process $s_{t}$; we could have assumed that $s_{t}$ is a multi-dimensional Itô process, or that its dynamics include a jump component, with a jump measure only dependent on $s_{t}$, without changing any of the results of our paper.

${ }^{19}$ The continuous time setting of this model allows us to abstract from the specific timing assumption of the government bond auction. In discrete time models, Cole and Kehoe (1996), Aguiar and Amador (2013) and Aguiar et al. (2016b) (for example) all assume that the bond auction happens before the default decision is made by the government, while Aguiar and Gopinath (2006), Arellano (2008) and many other quantitative models of sovereign debt assume that the government makes its default decision before the bond auction takes place. The former timing convention allows, in discrete time, for the existence of potentially multiple equilibria, induced by the creditor's self-fulfilling belief that the government will default immediately after debt has been issued, leading to a low auction debt price and a rational decision by the government to default. Those considerations are absent from the continuous time environment, since both timing assumptions become effectively equivalent.
} 
creditors: ${ }^{20}$

$$
\begin{aligned}
& \underline{D}(Y, F, s)=\underline{d}(s)<\frac{\kappa+m}{\delta+m}, \\
& \underline{V}(Y, F, s)=\alpha W(Y, s)-\underline{d}(s) F .
\end{aligned}
$$

The parameter $\alpha$ could be viewed as a reduced form representation of disruptions to trade and financial flows inducing a GDP drop at the time of a sovereign default. Similarly, we can think of $\underline{d}(s)$ as the outcome of a bargaining game between creditors and the sovereign government, once the government has decided to default. Because the strategic interactions between the government in default and its creditors are not a focus of this paper, for now we treat the determination of $\alpha$ and $\underline{d}(s)$ as exogenous. Later, we will endogenize the recovery rate by assuming the debt face value is renegotiated upon default (see Section 4.8.4).

\subsection{Creditors}

International investors purchase the debt issued by the government. We model their marginal utility process $M_{t}$ (which we will also refer to as the stochastic discount factor, or "SDF") as follows:

$$
\frac{d M_{t}}{M_{t}}=-r\left(s_{t}\right) d t-v\left(s_{t}\right) \cdot d \boldsymbol{B}_{t}
$$

The international investors' risk free rate is $r(s)$, while $v(s)$ is the international risk price vector in state $s$. The $j^{\text {th }}$ coordinate of $v(s)$ represents the expected excess return compensation per unit of $j^{\text {th }}$ Brownian shock earned by investors in state $s .{ }^{21}$ Given our assumed investor pricing kernel, any $\mathcal{F}_{t+s}$-measurable amount $A_{t+s}$ received at time $t+s$ will be valued by investors at

$$
\operatorname{Price}_{t}\left(A_{t+s}\right)=\mathbb{E}\left[\frac{M_{t+s}}{M_{t}} A_{t+s} \mid \mathcal{F}_{t}\right]:=\hat{\mathbb{E}}\left[e^{-\int_{0}^{s} r\left(s_{t+u}\right) d u} A_{t+s} \mid \mathcal{F}_{t}\right],
$$

with $\hat{\mathbb{E}}$ being the risk-neutral expectation operator, and $\mathbb{Q}$ the associated measure, under which $\hat{\boldsymbol{B}}_{t}:=$ $\boldsymbol{B}_{t}+\int_{0}^{t} \boldsymbol{v}\left(s_{u}\right) d u$ is a standard multi-dimensional Brownian motion.

Using Girsanov's theorem, there is an alternative interpretation for the behavior of our investors. In that interpretation, risk-neutral creditors have time-varying rate of time preference $\left\{r\left(s_{t}\right)\right\}_{t \geq 0}$, and have beliefs about the growth rate of $Y_{t}$ that are different from that of the sovereign government. When the entries of $\boldsymbol{v}\left(s_{t}\right)$ are negative, investors are more pessimistic relative to the government, whereas when the entries of $\boldsymbol{v}\left(s_{t}\right)$ are positive, investors are more optimistic. Both investors and the government are aware of each other's probability measure, and they simply agree to disagree.

We end this section by introducing the assumption that there are potential gains from trade, which provide the government with an incentive to borrow from international lenders.

\footnotetext{
${ }^{20}$ Note that the upper bound $(\kappa+m) /(\delta+m)$ on the recovery rate assures that the cost to the government in default is less than the cost of simply repaying the debt in perpetuity.

${ }^{21}$ We could have used a more general specification of the stochastic discount factor, by introducing for example jumps, with a jump measure purely dependent on the state variable $s_{t}$. Such addition does not change any of our results.
} 
Assumption 2 The international risk-free rate $r(\cdot)$ satisfies:

$$
r(s)<\delta \quad \forall s \in \mathcal{E}
$$

\subsection{Government Problem and Debt Valuation}

In our model, the payoff-relevant variables for the sovereign government and creditors are $Y_{t}, F_{t}$ and $s_{t}$. The state space will be $\mathbb{R}_{+}^{2} \times \mathcal{E}$, or a subset thereof. Consistent with Maskin and Tirole (2001), we focus on MPEs, where the government's strategy (including both its debt issuance and default timing), and therefore the debt price, only depend on $\left(Y_{t}, F_{t}, s_{t}\right)$.

The sovereign government controls its outstanding debt $F_{t}$ through an endogenous issuance policy $d \Gamma_{t} \in \mathbb{R}$ (repurchase if $d \Gamma_{t}<0$ ) where $\Gamma_{t}$ represents the cumulative debt issuance from time 0 to time t. An admissible debt issuance policy $\Gamma_{t}$ is a right-continuous-left-limit process, so that its increment (i.e., the issuance/repurchase) $d \Gamma_{t}: \mathbb{R}_{+}^{2} \times \mathcal{E} \rightarrow \mathbb{R}$ is measurable with respect to the Markov state vector $\left(Y_{t}, F_{t}, s_{t}\right)$. We will denote $\mathcal{G}$ the set of admissible debt issuance policies.

The government can also default on its debt. An admissible default policy is a stopping time $\tau$, with respect to the filtration $\mathcal{F}_{t}$, that can be written as the first hitting time of a subset of the state space:

$$
\tau=\inf \left\{t \geq 0:\left(Y_{t}, F_{t}\right) \in \mathcal{O}\left(s_{t}\right)\right\}
$$

Here, $\{\mathcal{O}(s)\}_{s \in \mathcal{E}}$ is a family of open sets representing the default regions of the state space. We will note $\mathcal{T}$ the set of admissible default policies. Our formulation of admissible policies leads to a controlled face value process $F_{t}^{(\Gamma)}$ :

$$
F_{t}^{(\Gamma)}=F_{0}+\underbrace{\int_{0}^{t} d \Gamma\left(Y_{u}, F_{u}^{(\Gamma)}, s_{u}\right)}_{\text {debt issuances }}-\underbrace{\int_{0}^{t} m F_{u}^{(\Gamma)} d u}_{\text {principal payments }}
$$

The superscript notation $F_{t}^{(\Gamma)}$ emphasizes the fact that the face value process $F_{t}$ is altered by the issuance policy $\Gamma$. The consumption increment of the sovereign between $t$ and $t+d t$ is:

$$
d C_{t}^{(\Gamma ; D)}:=\left(Y_{t}-(\kappa+m) F_{t}^{(\Gamma)}\right) d t+D\left(Y_{t}, F_{t}^{(\Gamma)}, s_{t}\right) d \Gamma\left(Y_{t}, F_{t}^{(\Gamma)}, s_{t}\right)
$$

Creditors price the newly issued or repurchased debt competitively at some endogenous price $D$ per unit of promised face value. The debt price reflects the information available up to date $t$, including the current debt issuance $d \Gamma_{t}$, and incorporates the price impact of new borrowing. Hence the debt proceeds are determined by the debt price $D\left(Y_{t}, F_{t}, s_{t}\right)$, where the debt amount $F_{t}=F_{t-}+d \Gamma_{t}$ takes into account the amount of debt just issued. Importantly, as we emphasize shortly, in equilibrium $D$ also reflects creditors' expectations regarding future financing decisions.

For creditors, upon a sovereign default at time $\tau$, they realize a recovery rate equal to $\underline{d}\left(s_{\tau}\right)$. Thus 
they will value one unit of sovereign debt as follows:

$$
D(Y, F, s ;(\Gamma, \tau)):=\hat{\mathbb{E}}^{Y, F, s}\left[\int_{0}^{\tau} e^{-\int_{0}^{t}\left(r\left(s_{u}\right)+m\right) d u}(\kappa+m) d t+e^{-\int_{0}^{\tau}\left(r\left(s_{u}\right)+m\right) d u} \underline{d}\left(s_{\tau}\right)\right]
$$

We use a notation that makes the dependence of the debt price function on the anticipated issuance and default policies explicit. Equation (16) can be interpreted as follows: creditors receive cash-flows $\kappa+m$ per unit of time on a debt balance that amortizes exponentially at rate $m$, and they recover $\underline{d}\left(s_{\tau}\right)$ at time of default. The expectations are taken under the pricing measure $Q$.

The government takes as given the debt price function $D$ and chooses its issuance and default policies in order to solve the following problem:

$$
V(Y, F, s ; D):=\sup _{(\Gamma, \tau) \in \mathcal{G} \times \mathcal{T}} \mathbb{E}^{Y, F, s}\left[\int_{0}^{\tau} e^{-\delta t} d C_{t}^{(\Gamma ; D)}\right]
$$

When choosing its issuance policy, the government takes into account the debt price schedule and the impact of the debt pricing on its bond proceeds and thus on its consumption. In equilibrium, creditors price the debt in equation (16) by correctly anticipating the government's equilibrium policies.

\subsection{Smooth Equilibrium}

Following DeMarzo and He (2020) we restrict our attention to a special class of MPEs, in which the sovereign government finds it optimal to adjust its outstanding debt in a "smooth" fashion, i.e., of order " $d t$ ". More specifically, in a smooth MPE, the debt policy $\Gamma$ is characterized by a measurable function $G: \mathbb{R}_{+}^{2} \times \mathcal{E} \rightarrow \mathbb{R}$ such that (with some proper integrability condition on $G$ specified shortly):

$$
d \Gamma_{t}=G\left(Y_{t}, F_{t}, s_{t}\right) d t
$$

The resulting face value and cumulative consumption processes are absolutely continuous. We formally define a "Smooth MPE" as follows.

Definition $1 \mathrm{~A}$ Smooth MPE is a set of Markovian issuance and default policies $\left(G^{*}, \tau^{*}\right) \in \mathcal{G} \times \mathcal{T}$ and a resulting welfare $V$ such that for any initial state $(Y, F, s)$,

$$
\left(G^{*}, \tau^{*}\right)=\arg \max _{(G, \tau) \in \mathcal{G} \times \mathcal{T}} \mathbb{E}^{Y, F, s}\left[\int_{0}^{\tau} e^{-\delta t} d C_{t}^{\left(\Gamma ; D\left(\cdot, \cdot, ;\left(G^{*}, \tau^{*}\right)\right)\right)}\right],
$$

and such that the equilibrium welfare $V$ is twice continuously differentiable.

For a given smooth equilibrium $\left(G^{*}, \tau^{*}\right)$, we will denote $V(\cdot, \cdot, \cdot)$ the government's equilibrium value function, and $D(\cdot, \cdot, \cdot)$ the debt price across the state space. We will show that the resulting smooth MPE is the only equilibrium among the general class of MPEs in the specific Geometric Brownian Motion setting studied in Section 5. 


\subsection{Optimality of Smooth Policies and No Gain from Trade}

We now derive necessary conditions for the Smooth MPE to exist, and show that in equilibrium the sovereign government will just earn its no-trade value despite the potential gains from trade; this echoes the key insight from Section 3. In what follows, for notational convenience, we denote by $X_{t}:=\left(Y_{t}, s_{t}\right)^{\prime}$ the state vector of driving variables, $\mu_{X}:=\left(\mu_{Y}, \mu_{S}\right)^{\prime}$ its related drift vector and $\sigma_{X}:=\left(\sigma_{Y}^{\prime}, \sigma_{s}^{\prime}\right)^{\prime}$ its related diffusion matrix.

In the continuation region (i.e. when the government is servicing its debt), the government value function satisfies the following HJB equation:

$$
\delta V=\sup _{G}\left[Y+G D-(\kappa+m) F+(G-m F) \partial_{F} V+\mu_{X} \cdot \partial_{X} V+\frac{1}{2} \operatorname{tr}\left(\sigma_{X}^{\prime} \partial_{X X^{\prime}} V \sigma_{X}\right)\right] ;
$$

When the government defaults, we have

$$
V(Y, F, s)=\alpha W(Y, s)-\underline{d}(s) F, \quad(Y, F) \in \mathcal{O}(s)
$$

Default optimality gives a smooth pasting condition imposed on the boundaries of the default region:

$$
\partial_{X}[V(Y, F, s)]=\partial_{X}[\alpha W(Y, s)-\underline{d}(s) F], \quad(Y, F) \in \partial \mathcal{O}(s)
$$

Loosely speaking, this condition imposes a minimum amount of "smoothness" of the value function at the boundaries of the default region, and is essential when using verification theorems that establish the optimality of the government decisions.

Finally, notice that for a solution to equation (18) to exist, we must have:

$$
D(Y, F, s)+\partial_{F} V(Y, F, s)=0
$$

Equation (21) is a necessary condition that needs to hold in equilibrium.

As DeMarzo and He (2020) show, the conjectured smooth debt issuance policy is indeed optimal (among a general set of policies that might involve discrete jumps) if and only if the debt price function $D$ is decreasing in the face value $F$ and equation (21) holds. Intuitively, the debt price $D$ faced by the small open economy reflects its current debt issuance and hence incorporates the price impact of new borrowing. When the debt price is decreasing in outstanding debt, then a lumpy issuance or repurchase amount brings an extra penalty due to such price impact (this insight has been discussed in Bulow and Rogoff (1988)).

Reinjecting the optimality condition (21) into equation (18) leads to:

$$
\delta V=Y-(\kappa+m) F-m F \partial_{F} V+\mu_{X} \cdot \partial_{X} V+\frac{1}{2} \operatorname{tr}\left(\sigma_{X}^{\prime} \partial_{X X^{\prime}} V \sigma_{X}\right)
$$

Denote by $G_{0}:=0$ the financing policy with no debt issuances or repurchases, and let $V_{0}(Y, F, s)$ be the corresponding "no-trade" value, which is the government value if it never issues new debt or buys back 
existing debt (but keeps the option to default); that is,

$$
V_{0}(Y, F, s):=\sup _{\tau \in \mathcal{T}} \mathbb{E}^{Y, F, s}\left[\int_{0}^{\tau} e^{-\delta t} d C_{t}^{\left(G_{0} ; D\right)}\right]
$$

Equation (22), in conjunction with equations (19-20), gives us the following proposition:

Proposition 2 In any Smooth MPE, the government welfare is identical to its no-trade value:

$$
V(Y, F, s)=V_{0}(Y, F, s)
$$

In addition, the welfare of a government without debt outstanding is equal to its autarky value:

$$
V(Y, 0, s)=W(Y, s)
$$

Proposition 2 is a formal way to state the no-gain-from-trade result illustrated in Section 3, i.e., the welfare value of a government without any debt outstanding is exactly equal to the autarky welfare. $^{22}$ While there should be gains from trade in this economic environment (since the government is more impatient than its creditors), those gains are entirely dissipated by default costs. Interestingly, the equilibrium welfare of the government is entirely independent of the characteristics of investors in international debt markets-whether risk-free rates are high or low, or whether risk-prices are high or low, the welfare of the government is identical.

The above discussion also suggests a method to construct an MPE for our model, by solving the government problem under the assumption that it does not trade in the future, but retains the option to default on its outstanding debt. The next proposition formalizes this insight.

Proposition 3 If the no-trade value function $V_{0}$ (defined via (23)) is twice continuously differentiable in $F$ and strictly convex in $F$, then a Smooth MPE exists, with debt price $D(Y, F, s)=-\partial_{F} V_{0}(Y, F, s)$ that is strictly decreasing in F.

\subsection{The Optimal Financing Policy}

We now characterize the financing policy of the government, which naturally depends upon the risk premium required by international creditors.

\subsubsection{Risk Premia}

In equilibrium creditors earn a risk-premium as long as the country's income process exhibits nonzero local correlation with investors' pricing kernel. Denote by $\pi\left(Y_{t}, F_{t}, s_{t}\right)$ the instantaneous expected sovereign bond excess return earned by creditors:

$$
\pi\left(Y_{t}, F_{t}, s_{t}\right) d t:=\mathbb{E}\left[\frac{d D_{t}+(m+\kappa) d t-m D_{t} d t}{D_{t}}-r\left(s_{t}\right) d t \mid \mathcal{F}_{t}\right]
$$

\footnotetext{
${ }^{22}$ Note that this indifference between (i) financial autarky and (ii) starting to take on debt leads to an equilibrium indeterminacy at the point $F=0$. Indeed, a "trivial" equilibrium in which the government never borrows, and debt prices are equal to the equilibrium debt prices in our Smooth MPE, still exists.
} 
We show in Section A.1 that

$$
\pi(Y, F, s)=\left(\sigma_{X}(Y, s) v(s)\right) \cdot \partial_{X} \ln D(Y, F, s)
$$

Equation (25) states that the debt investors' required risk premium is proportional to the risk premium of the economy's income process $\left(\sigma_{X} v\right)$ and the beta of the debt $\left(\partial_{X} \ln D\right)$ with respect to income. In particular, the debt beta and thus the required risk premium will vary with the riskiness of the debt.

\subsubsection{Equilibrium Debt Issuance Policy}

We use $D(Y, F, s)+\partial_{F} V(Y, F, s)=0$ and differentiate equation (22) with respect to $F$ to obtain:

$$
(\delta+m) D=\kappa+m+\mu_{X} \cdot \partial_{X} D+\frac{1}{2} \operatorname{tr}\left(\sigma_{X}^{\prime} \partial_{X X^{\prime}} D \sigma_{X}\right)-m F \partial_{F} D
$$

On the other hand, the valuation equation of creditors in (16) implies that

$$
(r+\pi+m) D=\kappa+m+(G(Y, F, s)-m F) \partial_{F} D+\mu_{X} \cdot \partial_{X} D+\frac{1}{2} \operatorname{tr}\left(\sigma_{X}^{\prime} \partial_{X X^{\prime}} D \sigma_{X}\right)
$$

Subtracting one equation from the other allows us to obtain a formula for the optimal Markov issuance policy, as a function of the debt price (which itself can be computed via equation (21)).

Proposition 4 In equilibrium the optimal bond issuance policy of the government is:

$$
G^{*}(Y, F, s)=\frac{\delta-(r(s)+\pi(Y, F, s))}{-\partial_{F} \ln D(Y, F, s)} .
$$

In other words, the bond issuance rate is the wedge between the rate of impatience of the government and the required rate of return of international bond investors, divided by the semi-elasticity of the bond price with respect to the total face value $F$. Upward shocks to risk-free rates $r\left(s_{t}\right)$ or risk-premia $\pi\left(Y_{t}, F_{t}, s_{t}\right)$ cause the government to adjust its bond issuance policy downwards, creating an upward adjustment in the sovereign country's current account, which is defined as $Y_{t}-C_{t}$.

The optimal Markov policy uncovered in equation (26) delivers additional insights. First, when the probability measure $\mathbb{Q}$ of investors and the probability measure $\mathbb{P}$ of the government correspond to each other (in other words, when $v(s)=\mathbf{0}$ for all $s$ ), the bond issuance rate is always positive: in this particular case, it is never efficient for the government to buy back its own debt, as was already hinted at in Section 3. This result echoes an insight from Bulow and Rogoff (1988) who show, in the context of a one-period model of sovereign default with a risk-neutral government and risk-neutral lenders, that it is never welfare-improving for a country to buy back its own debt.

This result breaks down in the presence of risk-averse lenders, whose price of risk has a positive local correlation with the country's endowment process: in such case, equation (26) shows that when sovereign bond risk premia are sufficiently high, the country might find it optimal to buy back its own debt. This result stems from the fact that the measure under which investors discount cash-flows is different from the measure under which the government optimizes. ${ }^{23}$

\footnotetext{
${ }^{23}$ Linking this to the interpretation of belief divergence between creditors and the sovereign, the endogenous risk premium
} 


\subsection{Citizen Welfare: When Autarky is better than Trade}

Our welfare-neutral result is applicable when the preferences of the government correspond to those of the citizens of the small open economy. One could instead imagine, for political economy reasons, that the government has an effective discount rate greater than the discount rate of the citizens of the small open economy; this assumption could be rationalized for example by observing that government officials are elected for short durations. In such case, even if the country's citizens are more impatient than investors in international credit markets, the commitment problem faced by the government brings a worse outcome for citizens' welfare than if they were instead in autarky.

Specifically, suppose that government officials have an effective discount rate $\delta$, while the citizens of the small open economy are more "patient," with a discount rate $\hat{\delta}<\delta$. Consider a simplified economic environment in which, upon default, the entire small open economy's income stream is lost (i.e. $\alpha=0$ ). We also shut down the risk premium channel (i.e., set $v(s)=0$ ) so that the government always issues debt - i.e. so that $G(Y, F, s) \geq 0$ in our Smooth MPE.

Let $\hat{V}(Y, F, s)$ be the indirect utility function of the citizens of the small open economy under the impatient government's financial polices studied in Section 4.6, and $\hat{V}_{0}(Y, F, s)$ the value of citizens if the government refrains from future trading.

Proposition 5 The citizens are strictly worse off when their country has access to international debt markets (and the government makes borrowing and default decisions) than when their country is restricted from future trading, i.e., $\hat{V}(Y, F, s)<\hat{V}_{0}(Y, F, s)$.

Note that this result holds even if citizens discount the future at a rate $\hat{\delta}$ that exceeds the expected return $r(s)$ of the debt. As the proof in Section A.2 shows, for $\hat{\delta}<\delta$, the marginal cost of debt to citizens exceeds the debt price (i.e. $\partial_{F} \hat{V}+D<0$ ). Thus, at the margin, citizens would prefer to buy back bonds and reduce the country's indebtedness. While the government is exactly indifferent between financial autarky and having access to international debt markets, Proposition 5 shows that citizens are strictly worse off, suggesting an economic environment where autarky is better than trade. This result, while surprising, stems from the following simple intuition. The government, with a higher discount rate $\delta$, balances the upside of borrowing to front-load consumption (by issuing debt today) versus its downside of future default (and the permanent loss of income that results). Since the benefits of debt issuances are incurred today, whereas the costs are incurred in the future, citizens of the country with a lower discount rate weigh those benefits less than their related cost, and will thus incur a welfare loss compared to the autarky benchmark. $^{24}$

\subsection{Discussion}

\subsubsection{Connection to Coase Conjecture}

Our "no gain from trade" result is related to the conjecture made in Coase (1972), and formally proven by Stokey (1981) and Gul, Sonnenschein and Wilson (1986), who show that a monopolist with constant

(potentially connected to the endogenous sovereign default policy) can be also viewed as endogenous pessimism of international creditors, and hence the sovereign might buy back the debt from pessimistic creditors.

${ }^{24}$ The argument is more subtle when the country can "restart" after a default. We generalize this result to a range of default regimes in Section 5. 
marginal costs selling a durable good to a continuum of consumers will actually behave competitively, in the continuous-time limit, and not extract any monopoly rent. In the context of our model, the government acts as a monopolist over a durable good - its own sovereign debt. Default risk embedded in the sovereign debt creates a downward sloping bond price schedule, analogous to the downward sloping demand curve arising from the distribution of consumer's private valuations in Coase's model. Without commitment, no matter how many bonds the government sold in the past, the government will sell more bonds if there are marginal gains from doing so (in other words if $D(Y, F)>-\partial_{F} V(Y, F)$ ). In equilibrium, it must thus be the case that $D(Y, F)=-\partial_{F} V(Y, F)$, which makes the government indifferent between any amount of bond issuances (per unit of time), stripping away any potential welfare gain that the government may extract from facing financiers that discount cash flows at a rate strictly lower than the government discount rate. ${ }^{25}$

The risk neutrality of the sovereign implies that its flow payoff is an affine function of the product of (a) the amount of bonds sold, times (b) the price of such bonds. In our smooth equilibrium, the government ends up perfectly indifferent as to the notional amount of bonds sold per unit of time; the costs and benefits of the marginal and infra-marginal units of debt issued are equal. ${ }^{26}$ Our no-gain-fromtrade result is also due to the continuous-time nature of our model, as highlighted by Stokey (1981). As illustrated in Section 3 and Figure 2, the discrete time counterpart to our model yields strictly positive welfare gains for the risk-neutral government, since the government can commit not to issue bonds and not to default during a strictly positive measure of time (which converges to zero in the continuous-time limit). In other words, despite the differing rates of time preference, gains from trade only emerge if there exists some degree of commitment power, either due to limitations on trade or the government's own preference for consumption smoothing.

Our result does not depend either on the assumed maturity profile of the sovereign debt contract. In other words, irrespective of the parameter $m$ governing the average life of long term bonds issued, a small open economy without any debt outstanding does not reap any welfare gains from selling bonds to more "patient" lenders. Our result goes even further: it does not depend on the repayment profile of the bonds issued: those bonds could be "bullet" as opposed to exponentially amortizing, or they could have an arbitrary "sinking fund" schedule. They could even be state-contingent, with a face value indexed to the Brownian vector $\boldsymbol{B}_{t}$ (we investigate this set-up in Section 5.2.5), with an identical outcome for the small open economy.

\footnotetext{
${ }^{25}$ Investors in our model are competitive, and thus do not extract any welfare gains either, despite the fact that trades do occur in equilibrium. Also, unlike in Coase (1972) setting, marginal cost (which is the equilibrium debt price) is endogenous in our model, and investors share a common valuation for the asset. Similar "no-gain-from-trade" results can be found in DeMarzo and Urošević (2006) in the context of trading by a large shareholder, in Daley and Green (2020) where a monopolistic buyer makes frequent offers to a privately informed seller, and more recently in $\mathrm{Hu}$ and Varas (2021) where a bank keeps selling its loans ex post.

${ }^{26}$ If instead the government exhibits some degree of risk aversion or has a finite intertemporal rate of substitution, the result above no longer holds. There, the benefit of the marginal unit of debt sold is no longer equal to the benefit of inframarginal units, and the government will extract welfare gains from issuing bonds to investors whose implied interest rate is lower than the government's rate of time preference. This result is analogous to what is showed theoretically in Kahn (1986) in the context of the durable goods monopoly problem: rents can be extracted by the monopolist if its marginal production costs are increasing.
} 


\subsubsection{Transaction Costs and Non-Pecuniary Benefits}

One can also imagine that the government enjoys additional non-pecuniary benefits when selling bonds in international capital markets, and that those benefits are proportional to either (i) proceeds raised, or (ii) the notional of bonds sold (per unit of time). Those benefits can be motivated by political economy considerations. Using a similar modeling device, one could also consider the case of proportional transaction costs. In both situations, Section A.3 shows that our welfare-neutral result is robust to these alternative assumptions. Non-pecuniary benefits over debt issuance enjoyed by a government will tend to increase bond issuances while decreasing debt prices, while the opposite effects will occur in connection with transaction costs.

\subsubsection{Equilibrium Multiplicity}

The sovereign default literature has struggled with the possibility that the Markov perfect equilibria studied are not unique. In discrete time, while equilibrium uniqueness obtains with one-period defaultable debt, ${ }^{27}$ we are not aware of any paper establishing uniqueness in the presence of long term debt. In fact, a simple reasoning suggests the possibility that we might find multiplicity in this class of models: if creditors price the sovereign bonds issued at a low level, it will be optimal for the government to default "early," i.e. at debt levels that are relatively low and/or income levels that are relatively high. Instead, if creditors price the sovereign bonds issued at a level close to "par," it will be optimal for the government to default at debt levels that are relatively high and/or income levels that are relatively low. Instead, in our particular modeling environment, we can use Proposition 2 to conclude the following:

Corollary 1 If a Smooth MPE exists, then it must be unique within the class of Smooth MPEs.

The proof is immediate, once we notice that in our equilibria of focus, the problem solved by the government is equivalent to a single-agent default problem that is independent of the pricing of debt - neither the HJB equation in the continuation region, nor the value matching condition at the default boundary or the smooth-pasting default optimality condition contain the debt price function. If we further restrict the income process to be the specific Geometric Brownian Motion setting to be studied in Section 5, one then can show that the resulting smooth MPE is the only equilibrium among the general class of MPE (not just Smooth MPEs). ${ }^{28}$

\subsubsection{Default Settlement Mechanisms}

Thus far, we have assumed for simplicity that the payoffs to creditors and the government in the event of default are exogenously given. We could instead endogenize these payoffs by assuming that default involves a restructuring in which the government (i) suffers a permanent loss to its future income, but (ii) is able to write down some portion of the debt. Specifically, for $\alpha, \theta \in(0,1)$,

$$
\underline{V}(Y, F, s)=V(\alpha Y, \alpha \theta F, s),
$$

\footnotetext{
${ }^{27}$ This result was proven rigorously by Auclert and Rognlie (2016) when the default decision is taken before the bond auction.

${ }^{28}$ Adding constraints on consumption can create additional Smooth MPEs, as in Aguiar and Amador (2018). We show in Section A.4 that if these constraints are removed, and if the model is perturbed so that the outside option includes some noise, then a unique Smooth MPE emerges in their setting as well.
} 


$$
\underline{D}(Y, F, s)=\alpha \theta D(\alpha Y, \alpha \theta F, s) \text {. }
$$

Here, $\alpha$ represents the decline in the income process the government suffers in exchange for forgiveness of a fraction $1-\alpha \theta$ of its outstanding debt. We will consider this default process explicitly in Section 5 . More generally, we could allow the government to face a state-dependent menu of alternative default regimes, each with different (and possibly stochastic) default parameters $(\alpha, \theta)$. The only requirement we impose is that in default, the recovery value of creditors is equal to marginal value of the debt to the government:

$$
\underline{D}(Y, F, s)=-\partial_{F} \underline{V}(Y, F, s)
$$

This condition implies that there are no inherent gains from trade introduced in the "default game" itself, and is a natural extension to the framework used throughout Section 4. Absent this condition, then naturally it would be possible for the government to capture some gains from trade simply by defaulting.

\section{Geometric Brownian Motion Income Process}

The results discussed until now are general to an entire class of income and stochastic discount factor processes. In this section, we focus on a particular income process, fully characterize the Smooth MPE, show that it is the unique MPE and provide comparative static results.

We assume that the income process of our small open economy has i.i.d. growth rate innovations:

$$
\frac{d Y_{t}}{Y_{t}}=\mu d t+\sigma \cdot d \boldsymbol{B}_{t}
$$

To insure that Assumption 1 is satisfied, we impose that:

$$
\delta>\mu
$$

Upon default, we assume that the small open economy's income drops by a factor $\alpha \in(0,1)$, that the debt face value suffers a haircut $1-\alpha \theta$ (with $\theta \in(0,1)$ ), and that the government immediately regains access to credit markets after default. These assumptions imply that the debt-to-income is reduced upon default by a factor $\theta \cdot{ }^{29}$ Lastly, we assume that the creditor's SDF features a constant risk-free rate $r$ and a constant risk price vector $v$.

\subsection{Equilibrium with GBM Income Process}

In this setting, the flow payoff and the state dynamics are linear in the state variables $(Y, F)$. This scale invariance property implies that the economically relevant measure of sovereign indebtedness is $x:=F / Y$, i.e. the debt-to-income ratio of our small open economy. Because all subgames with the same

\footnotetext{
${ }^{29}$ Analytic expressions are also available in the case where the income process follows Markov-modulated geometric Brownian motion dynamics. Given the notational complexity of this case, we restrict ourselves in the main body of the paper to the simple geometric Brownian motion case.
} 
initial leverage $x_{t}$ are strategically equivalent, we will look for an MPE in this uni-dimensional state variable, and show that it must be a smooth equilibrium. ${ }^{30}$

Under this observation, the value function $V$ and the optimal issuance policy $G$ are homogeneous of degree 1 in $(Y, F)$, the debt price function is homogeneous of degree 0 in $(Y, F)$, and the default policy will be cutoff (in terms of $x$ ). More specifically,

$$
V(Y, F):=v(x) Y, D(Y, F):=d(x), G(Y, F)=g(x) Y, \text { and } \tau_{k+1}=\inf \left\{t \geq \tau_{k}: x_{t}>\bar{x}\right\}
$$

The debt-to-income ratio $x_{t}^{(g, \tau)}$ is a controlled stochastic process that evolves as follows on $(0, \bar{x})$ :

$$
d x_{t}^{(g, \boldsymbol{\tau})}=\left(g\left(x_{t}^{(g, \boldsymbol{\tau})}\right)-\left(m+\mu-|\boldsymbol{\sigma}|^{2}\right) x_{t}^{(g, \boldsymbol{\tau})}\right) d t-x_{t}^{(g, \boldsymbol{\tau})} \boldsymbol{\sigma} \cdot d \boldsymbol{B}_{t}+(\theta-1) x_{t}^{(g, \boldsymbol{\tau})} d N_{d, t}^{(\boldsymbol{\tau})}
$$

The debt-to-income ratio grows with debt issuances $g(x)$, and otherwise declines at a rate equal to the sum of (i) the debt amortization rate $m$, (ii) the income growth rate $\mu$, corrected by (iii) a convexity term $|\sigma|^{2}$. The government will choose to default as soon as the sovereign's debt-to-income ratio exceeds a certain threshold $\bar{x} ; N_{d, t}^{(\tau)}$ denotes the counting process associated with default decisions of the government.

\subsubsection{Equilibrium Characterization in GBM Case}

The next proposition offers a complete characterization of the Smooth MPE.

Proposition 6 Let $\xi>1$ be the positive root of the characteristic polynomial

$$
\frac{1}{2}|\sigma|^{2} \xi^{2}-\left(m+\mu+\frac{1}{2}|\sigma|^{2}\right) \xi-(\delta-\mu)=0
$$

When the small open economy's income process follows a geometric Brownian motion as in (30), there exists a Smooth MPE where the government's optimal default cutoff $\bar{x}$ is given by

$$
\bar{x}=\frac{\xi}{\xi-1}\left(\frac{\delta+m}{\kappa+m}\right)\left(\frac{1-\alpha}{1-\alpha \theta}\right) \frac{1}{\delta-\mu} .
$$

For $x \in(0, \bar{x}]$, the (scaled) government value function $v(x)$ and the debt price $d(x)$ are

$$
\begin{aligned}
& d(x)=\left(\frac{\kappa+m}{\delta+m}\right)\left[1-\left(\frac{1-\alpha \theta}{1-\alpha \theta \xi}\right)\left(\frac{x}{\bar{x}}\right)^{\xi-1}\right] \\
& v(x)=\frac{1}{\delta-\mu}\left(1-\left(\frac{1-\alpha}{1-\alpha \theta^{\xi}}\right)\left(\frac{x}{\bar{x}}\right)^{\xi}\right)-x d(x)
\end{aligned}
$$

Let $\epsilon(x)$ be the semi-elasticity of the debt price w.r.t. the debt-to-income ratio:

$$
\epsilon(x):=\frac{-d^{\prime}(x)}{d(x)}=\frac{(\xi-1) / x}{\left(\frac{1-\alpha \theta \xi}{1-\alpha \theta}\right)\left(\frac{\bar{x}}{x}\right)^{\xi-1}-1} .
$$

\footnotetext{
${ }^{30}$ Maskin and Tirole (2001) define Markov Perfect Equilibria in terms of the coarsest partition such that equivalent subgames are "strategically equivalent." A sufficient condition for strategic equivalence is that the payoffs are equivalent up to an affine transformation, which is satisfied by this model. DeMarzo and He (2020) follow the same approach.
} 
For $x \in(0, \bar{x}]$, the require bond risk-premium is increasing in $x$ and equal to:

$$
\pi(x):=x \epsilon(x) \sigma \cdot v
$$

The scaled optimal financing policy $g(x)$ has the following expression:

$$
g(x)=\frac{\delta-(r+\pi(x))}{\epsilon(x)}=\frac{\delta-r}{\epsilon(x)}-x \sigma \cdot v .
$$

Figure 3: Value Function and Issuance Policy
(a): Value Function $v(x)$
(b): Issuance Rate $g(x)$
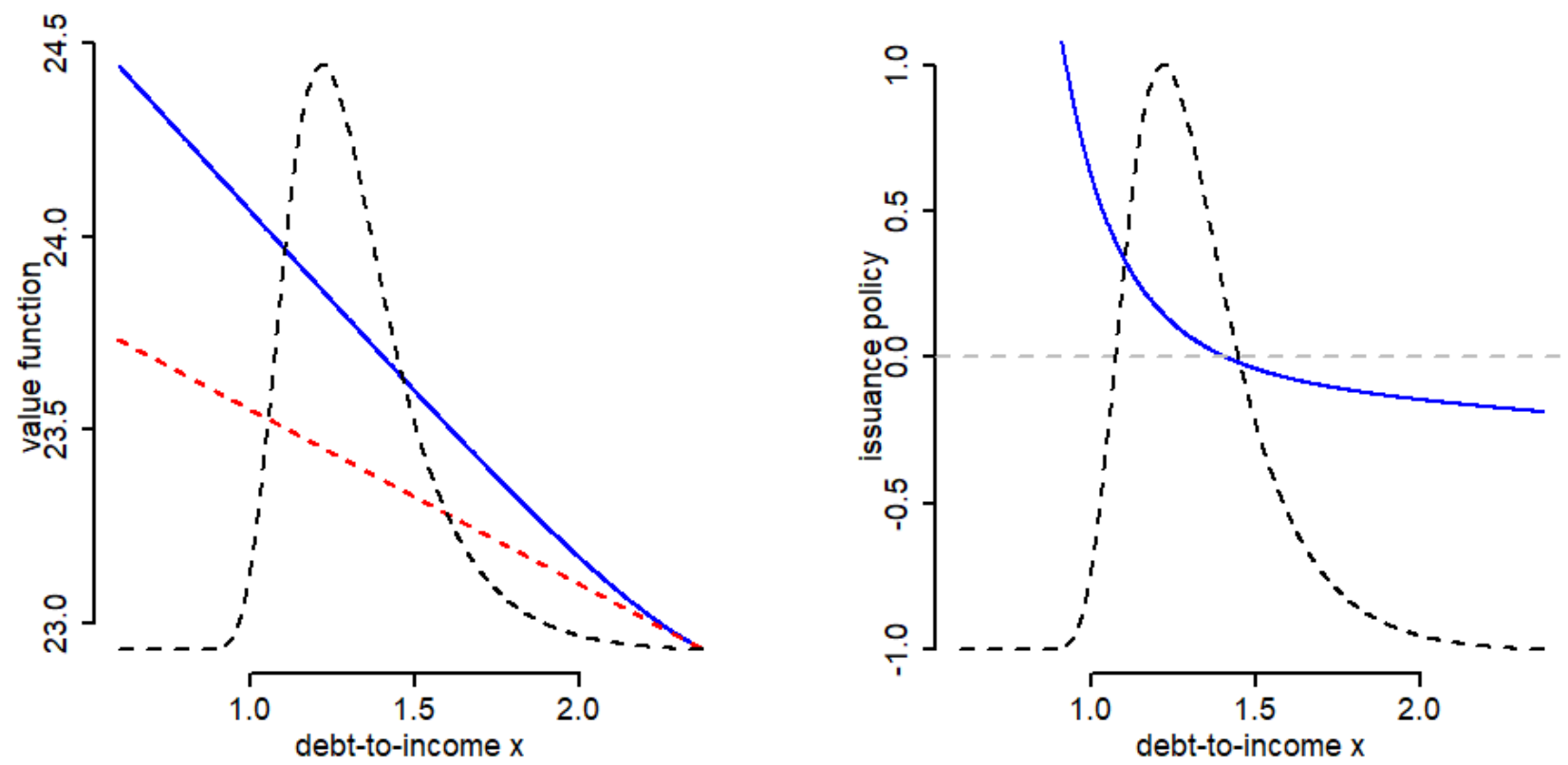

In plot (a) the value function $v(x)$ is depicted in solid blue while the default value $\alpha v(\theta x)$ is depicted in dotted red. In both plots, the dotted black line represents the stationary distribution of the debt-to-income ratio. The plots were computed assuming $\mu=2 \%$ p.a., $\sigma=20 \%$ p.a., $1 / m=10$ years, $\theta=50 \%, \alpha=96 \%, v=40 \%, r=\kappa=5 \%$ and $\delta=6 \%$.

Our proof is detailed in Section A.5. In Figure 3, we provide an illustrative example of the scaled value function $v(x)$ and the issuance policy $g(x)$. Alongside the value function $v(x)$, we also show the "reservation value" $\alpha v(\theta x)$, in other words the value (per unit of output) realized by the government if it was electing to default at that point. One can show that the distance between the value function $v(x)$ and the outside option $\alpha v(\theta x)$ satisfies

$$
v(x)-\alpha v(\theta x)=\tilde{\mathbb{E}}^{x}\left[\int_{0}^{\tau} e^{-(\delta-\mu) t}\left[1-\alpha-(1-\alpha \theta)(\kappa+m) x_{t}\right] d t\right]
$$

In other words, the distance $v(x)-\alpha v(\theta x)$ is equal to the present value (per unit of income) of the flow costs of defaulting $(1-\alpha)$ minus the flow benefits of defaulting $(1-\alpha \theta)(\kappa+m) x_{t}$. At the default boundary $\bar{x}$, the continuation and default values are equal to each other, and both share the same 
sensitivity to the debt-to-income ratio (a requirement for default optimality).

Figure 3 also shows the issuance policy $g(x)$ (per unit of income). When $\xi>2$ (which corresponds to the parameter case $\delta+m>|\sigma|^{2}-(m+\mu)$, the case in our illustration), $g$ is a decreasing and convex function of $x$, with limit $+\infty$ as $x \rightarrow 0$. It is otherwise a concave and hump-shaped function of $x$. In all cases, $g(x)>0$ in the right neighborhood of $x=0$. In Figure 3, the price of risk $v$ is positive, and for high debt-to-income ratios, the bond risk-premia are sufficiently high to push the government to buy back its own debt (i.e. $g(x)<0)$. It can also be shown that the drift rate $g(x)-\left(m+\mu-\sigma^{2}\right) x$ of the state variable $x_{t}$ is downward sloping and intersects zero, meaning that $x_{t}$ is "mean-reverting", and that the government's debt balance systematically "targets" a debt-to-income attraction level $x_{a}$, as the next proposition highlights.

Proposition 7 The debt face value $F_{t}$ satisfies dynamics

$$
d F_{t}^{\xi-1}=-\eta\left[F_{t}^{\xi-1}-\left(x_{a} Y_{t}\right)^{\xi-1}\right] d t-\left(1-(\alpha \theta)^{\xi-1}\right)\left(\bar{x} Y_{t-}\right)^{\xi-1} d N_{d, t}
$$

where $\eta$ represents the speed of reversion of the debt face value towards its target $x_{a} Y_{t}$, and where $x_{a}$, the debt-toincome attraction point, satisfies $g\left(x_{a}\right)=m x_{a}$. Those constants are equal to

$$
\begin{aligned}
\eta & :=\delta-r+(\xi-1)(m+v \cdot \sigma) \\
x_{a} & :=\bar{x}\left[\left(\frac{1-\alpha \theta}{1-\alpha \theta \xi}\right)\left(\frac{\xi-1}{\delta-r}(m+v \cdot \sigma)+1\right)\right]^{\frac{1}{1-\xi}} .
\end{aligned}
$$

Integrating equation (38) yields

$$
F_{t}=\left[e^{-\eta t} F_{0}^{\xi-1}+\eta \int_{0}^{t} e^{\eta(u-t)}\left(x_{a} Y_{u}\right)^{\xi-1} d u-\left(1-(\alpha \theta)^{\xi-1}\right) \int_{0}^{t} e^{\eta(u-t)}\left(\bar{x} Y_{u-}\right)^{\xi-1} d N_{d, u}\right]^{1 /(\xi-1)}
$$

Proposition 7 is proven in Section A.6. As equation (39) suggests, the speed of mean-reversion is high when the impatience wedge $(\delta-r)$ is high, when debt maturity $(1 / m)$ is short, or credit markets' risk prices $(v)$ are high. The first term in equation (41) illustrates the fact that the sovereign debt level at time $t$ can be thought of as a geometric average of past debt targets $\left\{x_{a} Y_{s}\right\}_{s \leq t}$, weighted with an exponential decay with rate $\eta$. The second term in equation (41) takes into account debt adjustments related to past sovereign defaults, which occur when the debt-to-income ratio reaches $\bar{x}$.

In Figure 4, for one realization of the Brownian motion $\boldsymbol{B}$, we show an illustration of the path of output $Y$, as well as the debt face value $F$ and the debt-to-income ratio $x$. We also indicate the default boundary $\bar{x}$ as well as the attraction point $x_{a}$. The no-debt government ramps up its debt very quickly at time zero, since the drift rate of $x_{t}$ turns unbounded when $x \rightarrow 0$. While the country's income $Y$ fluctuates with Brownian income shocks, the aggregate debt face value $F$ evolves smoothly.

Given the debt price $d(x)$, we can define implicitly the sovereign bond spread $\varsigma(x)$ as the yield spread over the risk-free benchmark that is needed to discount the sovereign bond's cash flow stream (assuming away any default risk):

$$
d(x):=\hat{\mathbb{E}}\left[\int_{0}^{\infty} e^{-(r+m+\varsigma(x)) t}(\kappa+m) d t\right]
$$


(a): Debt $F_{t}$ and Income $Y_{t}$

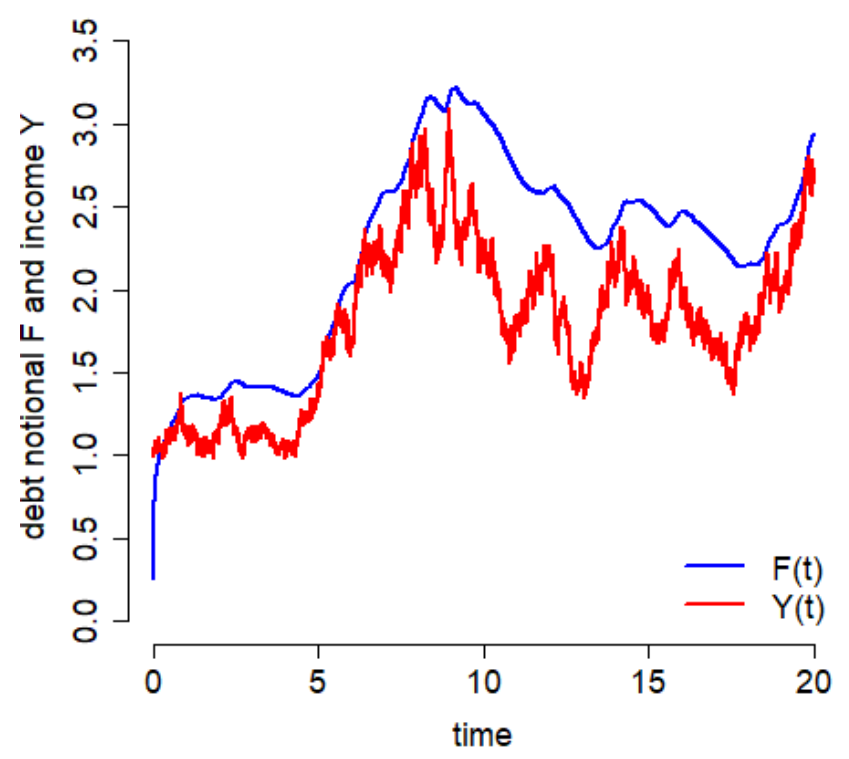

(b): Debt-to-Income ratio $x_{t}$

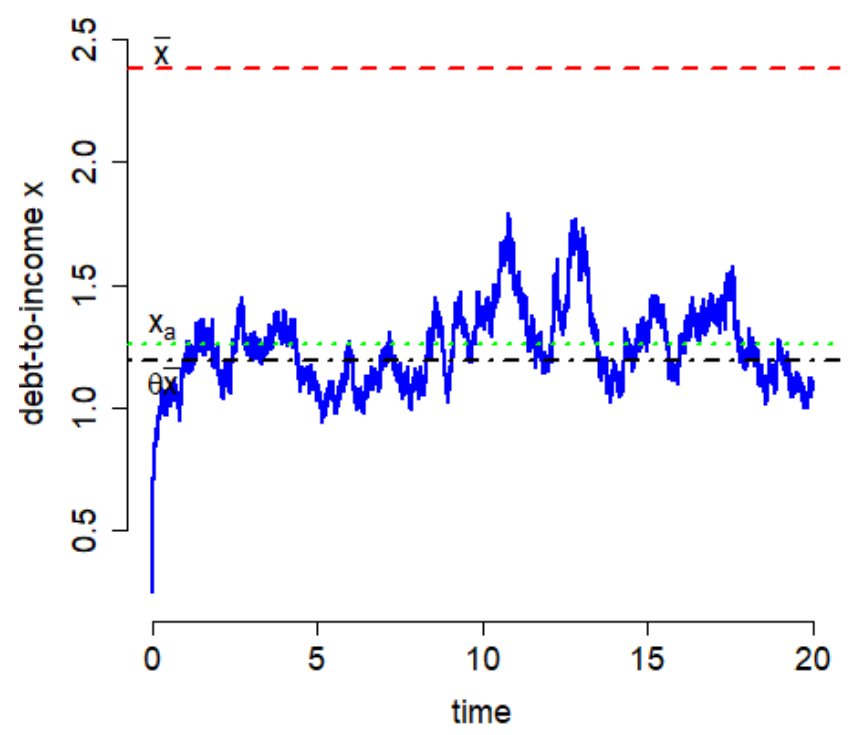

Figure (a) shows the time path of the debt balance $F_{t}$ (in blue) and of income $Y_{t}$ (in red) for one realization of the Brownian motion $B(t)$. Figure (b) shows the resulting debt-to-income ratio, as well as the default boundary $\bar{x}$, the attraction point $x_{a}$, and the reinjection point upon default $\theta \bar{x}$. The plot was computed assuming $\mu=2 \%$ p.a., $\sigma=20 \%$ p.a., $1 / \mathrm{m}=10$ years, $\theta=50 \%$, $\alpha=96 \%, v=40 \%, r=\kappa=5 \%$ and $\delta=6 \%$.

The bond price and bond credit spreads are showed in Figure 5. The bond price is decreasing in the debt-to-income ratio, a necessary condition for the optimality of sovereign's smooth debt issuance policy. The bond credit spread is bounded away from zero: even without debt $(x=0)$, credit spreads are strictly positive and equal to $\delta-r$, as creditors anticipate the dilution risk via future debt issuances. In the same figure we also show the debt price and corresponding credit spread for the equilibrium in which the government can commit never to issue debt in the future. In that latter equilibrium, bond prices are higher at low debt-to-income ratios, but lower at high debt-to-income ratios - due to the fact that in our no-commitment equilibrium, the sovereign is actually buying back its own bonds. In the parameter environment where $v=0$, the government never buys back debt in the no-commitment equilibrium, and the bond price in that case is always strictly lower than the bond price in the equilibrium for which the government can commit to never issue debt in the future.

\subsubsection{Comparative Statics: Analytical Results}

Our model with closed-form expressions allows us to derive comparative static results; we summarize them in Corollary 2 with details provided in Section A.7.1-Section A.7.3.

Corollary 2 The default boundary $\bar{x}$, the speed of reversion $\eta$ and the government value function $v(x)$ (keeping fixed the debt-to-income ratio $x$ ) admit comparative statics with respect to model parameters as given in Table 1.

More impatient governments will default at lower debt-to-income ratios; indeed, they will front- 
Figure 5: Debt Price and Credit Spreads

(a): Debt price $d(x)$

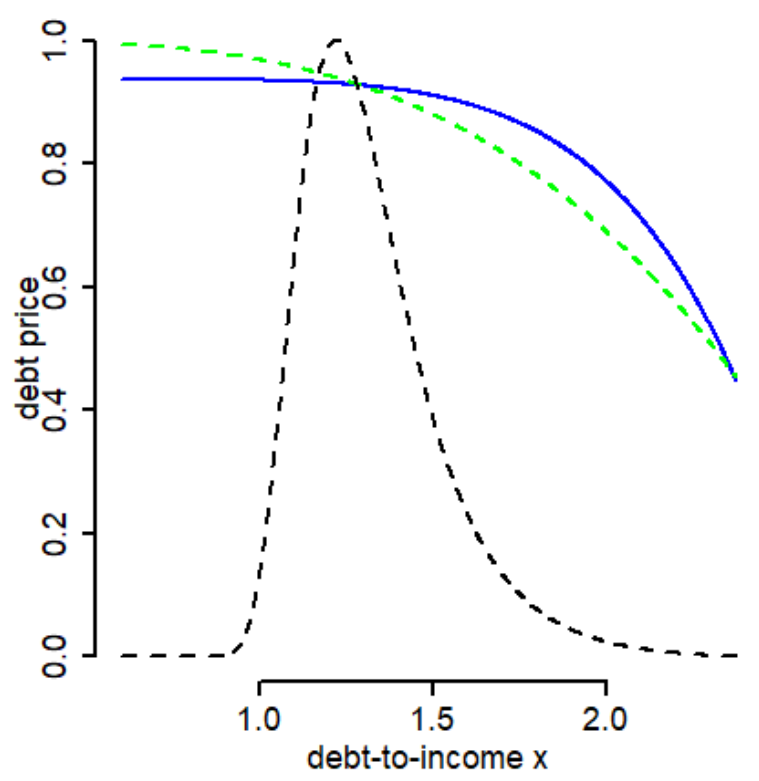

(b): Credit spread $\varsigma(x)$

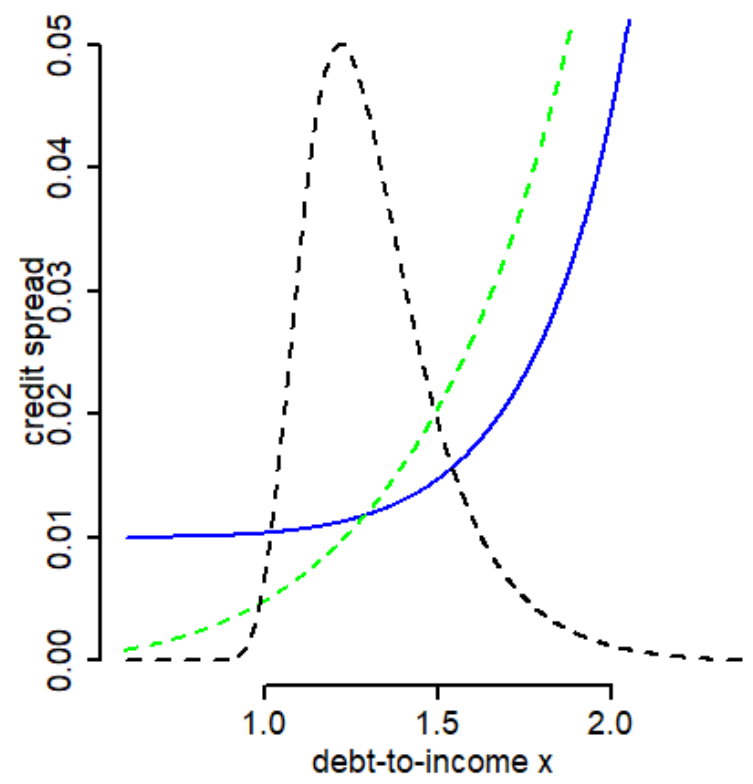

Solid blue line shows the no-commitment bond price and credit spread. Dotted green line shows the bond price and credit spread in the corresponding model where the government can commit to never issue debt in the future. Plots computed assuming $\mu=2 \%$ p.a., $\sigma=20 \%$ p.a., $1 / m=10$ years, $\theta=50 \%, \alpha=96 \%, v=40 \%, r=\kappa=5 \%$ and $\delta=6 \%$. In both plots, the dotted black line represents the stationary distribution of the debt-to-income ratio.

load consumption via large bond issuances, and will adjust their debt level at a faster pace. Since they discount utility flow at higher levels, this leads to lower welfare. On the other side, when we reduce the punishment upon default (i.e. when $1-\alpha$ decreases or $\theta$ decreases), the incentive for the government to default increases (so a lower default boundary in debt-to-income). This also makes the government unconditionally worse off.

An increase in debt interest payments also leads to a lower debt-to-income default boundary as well as a lower welfare. To see the effect of $m$, a higher rate of principal amortization $m$ cuts the government's flow utility today but alleviates the sovereign's future debt burden (the drift of $x_{t}$ decreases in $m$ ); we show that for low values of the coupon rate $\kappa$, the former dominates the latter, pushing the government to default earlier (i.e., a lower $\bar{x}$ ) and to enjoy lower welfare.

The default boundary is increasing in the income volatility of the country; one can think of the indebted government as being long an American put option; since the value of an option increases with volatility (as in the option pricing literature), the incentive to default decreases with higher volatility. This makes both the default boundary and the value of the government increasing functions of the small open economy's income volatility.

Finally, while capital markets' parameters $r$ and $v$ do not influence government welfare or the default boundary, they play an important role in debt dynamics: an increase in $r$ reduces the wedge $\delta-r$, leading to a decrease in the intensity of debt issuance, in the speed of reversion $\eta$ of the debt-to-income ratio and the attraction point $x_{a}$. When we increase the price of risk $v$, the slope of the issuance intensity $g$ 
Table 1: Comparative Static Table

\begin{tabular}{lcccc}
\hline \hline & Parameter & $\bar{x}$ & $\eta$ & $v(x)$ \\
\hline volatility & $|\sigma|$ & + & & + \\
income growth rate & $\mu$ & + & + & + \\
impatience & $\delta$ & - & + & - \\
coupon rate & $\kappa$ & - & $0^{(1)}$ & - \\
debt maturity & $1 / m$ & $+{ }^{(2)}$ & + & $+{ }^{(3)}$ \\
dead-weight costs at default & $1-\alpha$ & + & 0 & - \\
debt restructuring at default & $\theta$ & + & 0 & - \\
risk-free rate & $r$ & 0 & - & 0 \\
risk price & $v$ & 0 & + & 0 \\
\hline (1) 0 indicates that the equilibrium object is independent of the parameter. \\
(2) If and only if $\kappa<\bar{\kappa} \in(\delta,+\infty]$, where $\bar{\kappa}$ depends on all other model parameters. \\
(3) If and only if $\kappa<\delta$.
\end{tabular}

gets steeper, increasing the adjustment speed $\eta$. At the same time, a higher price of risk tends to move bond prices lower, decreasing the incentive for the government to issue debt and ultimately lowering the debt-to-income attraction point $x_{a}$.

\subsubsection{Equilibrium Uniqueness}

Proposition 6 establishes the existence of the Smooth MPE, by construction. One might still wonder whether any other MPE might exist - in which for example the debt face value process was not absolutely continuous everywhere. The next proposition gives a negative answer.

Proposition 8 When the small open economy's income process follows a geometric Brownian motion as in (30), the MPE in the state variable $x=F / Y$ is unique, which is the Smooth MPE described in Proposition 6.

Our proof, detailed in Section A.8, relies on several building blocks. We first show that in any equilibrium, the value function $v$ must be convex, by observing that any point in time the government is free to issue debt. This allows us to show that $v$ is differentiable almost everywhere, and to establish the relationship $v^{\prime}(x)+d(x)=0$ in any MPE. We then partition the state space into two regions, depending on the size of sovereign credit risk-premia - a region where the government always issues debt, and a separate region where the government always buys back debt. This allows us to express the cumulative issuance policy in any MPE as the difference between two monotone processes. We then leverage Lebesgue decomposition theorem to show that in any MPE, it is never optimal for the government to use either an impulse or singular control strategy, which allows us to focus on environments where the debt face value process is absolutely continuous, and conclude that all MPEs must be Smooth MPEs.

\subsubsection{Alternative Default Options}

We conclude this section by noting that we solved our model under a particular set of assumptions following a default: the small open economy's income $Y$ drops by a constant fraction to $\alpha Y$, while the debt face value $F$ is renegotiated to $\alpha \theta F$. One can instead imagine alternative default specifications, under which our Smooth MPE is preserved. In this section, we determine minimum conditions on the 
government payoff upon default $\underline{V}(Y, F)=Y_{\underline{v}}(x)$ and on the debt recovery rate $\underline{d}(x)$ so as to insure that our smooth MPE still exists.

Consider for example an environment where, at default, creditors receive a lump sum payment from the government, whose future income is penalized and who is either (i) allowed to immediately re-enter international credit markets, or (ii) locked out of capital markets forever. It is straightforward to show in such case that our Smooth MPE still exists. In the next lemma, we generalize this discussion, and give conditions that the alternative default specifications must satisfy in order to preserve the Smooth MPE obtained in Proposition 6.

Lemma 3 Assume that upon default creditors receive recovery value $\underline{d}(x)$ and the government receives $\underline{V}\left(Y_{t}, F_{t}\right)=$ $Y_{t} \underline{v}\left(x_{t}\right)$ satisfying, for all $x$,

$$
0 \leq \underline{d}(x)=-\underline{v}^{\prime}(x) \leq \frac{\kappa+m}{\delta+m}
$$

Denote by $\varphi(x)$ the no-default, no-trade, income normalized government welfare, equal to

$$
\varphi(x):=\frac{1}{\delta-\mu}-\frac{\kappa+m}{\delta+m} x
$$

Then the Smooth MPE exists and is unique, with the (income normalized) value function and debt prices satisfying

$$
\begin{aligned}
& d(x)=\frac{\kappa+m}{\delta+m}-\left(\frac{x}{\bar{x}}\right)^{\xi-1}\left[\frac{\kappa+m}{\delta+m}-\underline{d}(\bar{x})\right] \\
& v(x)=\varphi(x)+\left(\frac{x}{\bar{x}}\right)^{\xi}[\underline{v}(\bar{x})-\varphi(\bar{x})]
\end{aligned}
$$

The default boundary $\bar{x}$ solves the implicit equation

$$
\underline{v}(\bar{x})=\varphi(\bar{x})+\frac{1}{\xi}\left(\frac{\kappa+m}{\delta+m}-\underline{d}(\bar{x})\right) \bar{x}
$$

Consider $n$ different alternative default resolution mechanisms $\left\{\underline{v}_{i}, \underline{d}_{i}\right\}_{i \leq n}$, all satisfying the conditions above. An economic environment in which the government has the option to choose from a menu of probability distributions over these $n$ default resolution mechanisms is also consistent with a Smooth MPE.

Condition (42) states that the debt recovery value is less costly to the government than repaying forever, and that there are no gains from trade embedded in the default process itself. Equations (43) and (44) show the the impact of the default option on the debt price and government welfare as the debtto-income level $x$ approaches the default threshold $\bar{x}$. Condition (45) shows that at the default boundary, the gain to the government (relative to the no-default, no-trade outcome) is proportional to its total savings from discharging the debt scaled by the constant $\xi$. Finally, because the required conditions on $\underline{v}$ and $\underline{d}$ are preserved by taking convex combinations or allowing the government a choice of schedules, we can extend this result to alternative menus of stochastic default resolution outcomes. 


\subsection{Model Implications and Extensions}

We next consider a variety of economic implications based on our model. The tractability of our setting allows us to analyze many of these analytically, as opposed to relying on numerical analysis. We then conclude with a number of empirically relevant extensions to the model.

\subsubsection{Citizens vs. Government}

We first investigate the case discussed in Section 4.7, in which citizens have a discount rate $\hat{\delta}$ that is lower than the government discount rate $\delta$. We previously showed, for general income processes, that the citizens' indirect utility function is strictly lower than the indirect utility function if the country was stuck in financial autarky, for the case where default entails full loss for both creditors and the government. In the special case of geometric Brownian motion income dynamics, Section A.2.2 extends our result of Section 4.7 to the present case with "reinjections".

Figure 6: Welfare Losses $\hat{v}(0) / \hat{v}_{0}(0)-1$

(a): As a function of maturity $1 / m$

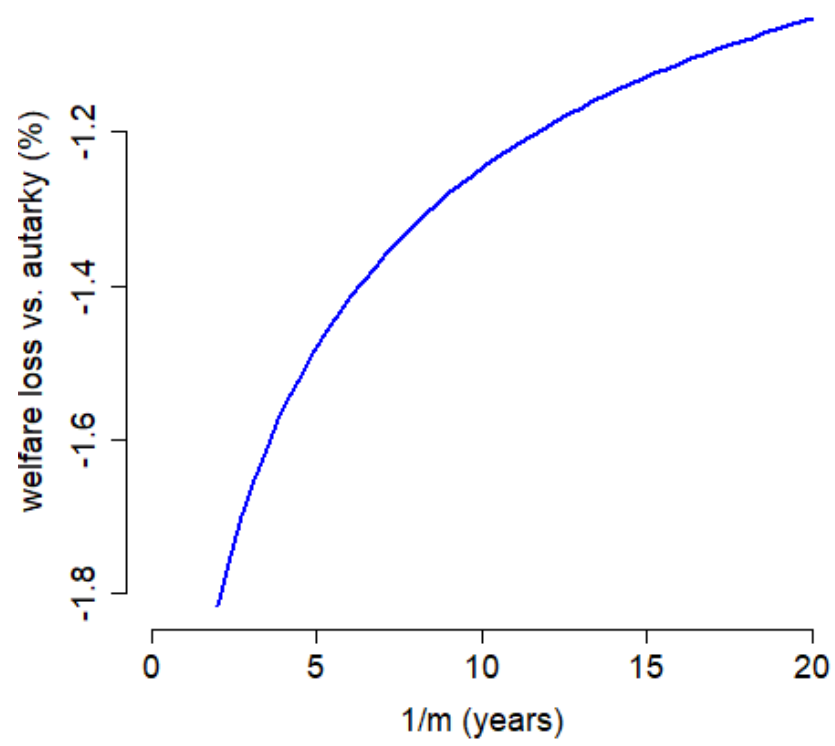

(b): As a function of impatience $\hat{\delta}$

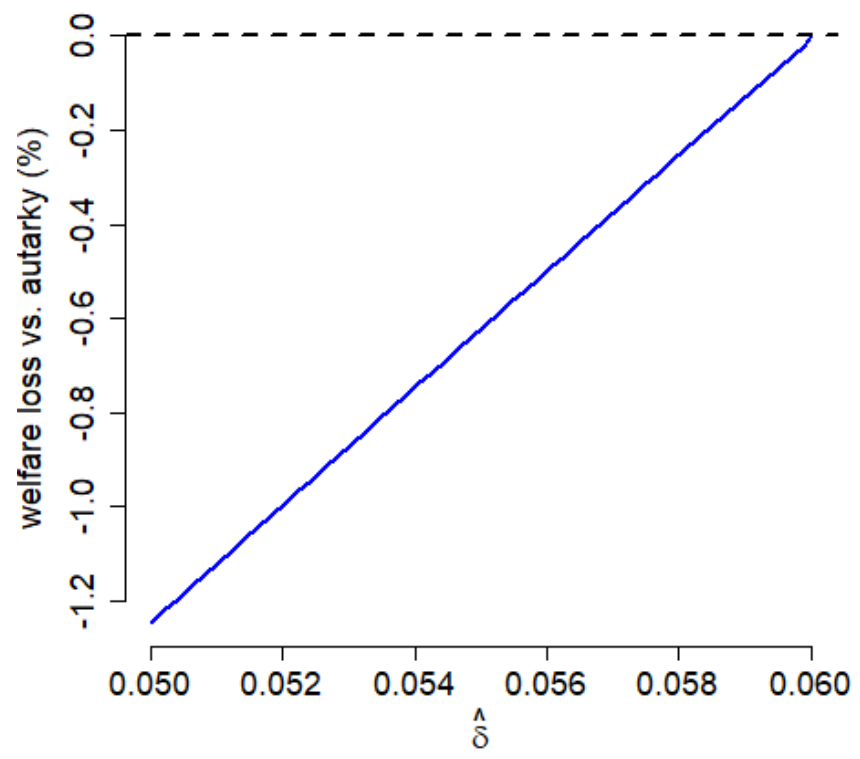

Solid blue line shows the percentage loss in welfare $\hat{v}(0) / \hat{v}_{0}(0)-1$ evaluated when the government has no debt outstanding. Plots assume $\mu=2 \%$ p.a., $\sigma=20 \%$ p.a., $1 / m=10$ years, $\theta=50 \%, \alpha=96 \%, v=40 \%, r=\hat{\delta}=\kappa=5 \%$ and $\delta=6 \%$.

In Figure 6, we plot the percentage loss in welfare for the citizens of the country assuming the country has no initial debt. In the left panel, we assume citizens are as patient as international investors $(\hat{\delta}=r)$ and show that citizen welfare declines as debt maturity shortens. The intuition behind this result is straightforward: with shorter-term debt, the debt price is less sensitive to borrowing, causing the government to borrow more aggressively and target a higher level of leverage. At the same time, high principle payments lead to a lower default threshold (see Corollary 2). As a result, an eventual default becomes more likely with shorter-term debt. For the government, the (future) costs of a default 
are perfectly equalized with the (current) benefits of higher debt-financed consumption, but since citizens are more patient than the government, they weigh the future default costs more than the current consumption benefit. By raising the likelihood of future default, shorter-term debt makes more patient citizens are worse off.

Figure 6 also shows citizens' welfare loss as a function of the discount rate $\hat{\delta}$. Not surprisingly, the closer citizens' discount rate is to the government's, the lower the welfare loss versus the autarky benchmark.

\subsubsection{Current Account and Consumption Growth Volatility}

Our analytical expressions for the debt price $d$ and the issuance policy $g$ allow us to derive the consumptionto-output ratio $c(x):=1+g(x) d(x)-(\kappa+m) x$. The current account-to-income ratio is then simply $1-c(x)$. Some algebra allows us to compute the derivative of the consumption-to-output ratio $c(x)$ :

$$
c^{\prime}(x)=-(\kappa+m)-2(\delta-r) d(x)+(\delta-r)\left(\frac{d(x)}{d^{\prime}(x)}\right)^{2} d^{\prime \prime}(x)-v \cdot \sigma\left(d(x)+x d^{\prime}(x)\right)
$$

Under the parameter restriction $\xi>2$ (i.e. when $\delta+m>|\sigma|^{2}-(\mu+m)$ ), the debt price $d(x)$ is a concave function of the debt-to-income ratio. Thus, so long as $v \cdot \sigma$ is not "too large", the consumption-to-output ratio is strictly decreasing in the debt-to-income ratio. In other words, the current-account is countercyclical- a sequence of good income shocks will push the debt-to-income ratio downwards, causing the small open economy to run a current account deficit; instead, a sequence of bad income shocks will push the small open economy closer to its default boundary, forcing it to run a current account surplus. One can also compute the ratio of consumption growth volatility divided by output growth volatility as follows:

$$
\frac{\operatorname{stdev}_{t}\left(d \ln C_{t}\right)}{\operatorname{stdev}_{t}\left(d \ln Y_{t}\right)}=1-\frac{x_{t} c^{\prime}\left(x_{t}\right)}{c\left(x_{t}\right)}
$$

Since $c^{\prime}(x)<0$, the consumption growth volatility is greater than the output growth volatility across debt-to-income ratios. Our model is thus qualitatively consistent with the empirical evidence of Neumeyer and Perri (2005) or Aguiar and Gopinath (2004), who show that consumption growth volatility for emerging market economies is systematically greater than output growth volatility. ${ }^{31}$

\subsubsection{Ergodic Distribution and Average Default Rate}

Our model admits a stationary distribution $f$ that is relatively straightforward to characterize. Recall that the debt-to-income ratio satisfies the stochastic differential equation

$$
\begin{aligned}
d x_{t} & =\left(g\left(x_{t}\right)-\left(m+\mu-|\sigma|^{2}\right) x_{t}\right) d t-x_{t} \sigma \cdot d B_{t}+(\theta-1) \bar{x} d N_{d, t} \\
& =\mu_{x}\left(x_{t}\right) d t+\sigma_{x}\left(x_{t}\right) d B_{t}+(\theta-1) \bar{x} d N_{d, t},
\end{aligned}
$$

\footnotetext{
${ }^{31}$ Neumeyer and Perri (2005) for example compute ratios of standard deviations of total consumption over GDP for Argentina (1.17), Brazil (1.24), Korea (2.05), Mexico (1.29) and the Philippines (2.78).
} 
where $N_{d, t}$ is the counting process for default events, $\mu_{x}(x)$ is the drift rate of the state variable $x$ and $\sigma_{x}(x)$ its volatility. Let $J(x)$ be the probability flux associated with $f(x)$ :

$$
J(x):=\mu_{x}(x) f(x)-\frac{d}{d x}\left[\frac{\sigma_{x}^{2}(x)}{2} f(x)\right]
$$

The probability flux $J(x)$ can be interpreted as the "mass of particles per unit of time" that crosses at $x^{32}$ and the density function $f(x)$ satisfies the standard Kolmogorov-Forward equation $\frac{d J}{d x}=0$ for $x \in(0, \theta \bar{x})$ and for $x \in(\theta \bar{x}, \bar{x}) . J(\bar{x})$ gives the ergodic average default rate of the sovereign. Given that $\bar{x}$ is an exit point of the system, we have $f(\bar{x})=0$, implying an ergodic default rate $\lambda_{d}=J(\bar{x})=-\frac{\sigma^{2} \bar{x}^{2}}{2} f^{\prime}(\bar{x})$. Introduce the scale function $\omega(x ; y)$, defined via

$$
\omega(x ; y):=\left(\frac{x}{y}\right)^{b} \exp \left(\frac{-a}{1-\xi}\left(x^{1-\xi}-y^{1-\xi}\right)\right)
$$

where two constants $a>0$ and $b$ are given by:

$$
a:=\frac{\delta-r}{\xi-1}\left(\frac{1-\alpha \theta^{\xi}}{1-\alpha \theta}\right) \frac{2 \bar{x}^{\xi-1}}{|\sigma|^{2}}>0 \quad b:=\frac{2}{|\sigma|^{2}}\left(\frac{\delta-r}{\xi-1}+m+\mu+v \cdot \sigma-|\sigma|^{2}\right)
$$

In Section A.9, we solve the Kolmogorov-Forward equation, leading to our next proposition.

Proposition 9 In our Smooth MPE, the boundary $x=0$ is a natural boundary, meaning that it is unattainable. The ergodic density is equal to

$$
f(x)=\lambda_{d} \int_{\theta \bar{x} \vee x}^{\bar{x}} \omega(u ; x) d u
$$

The ergodic default rate $\lambda_{d}$ is the unique positive real number satisfying $\int_{0}^{\bar{x}} f(u) d u=1$.

This expression allows us to easily calculate a variety of model-implied moments of interest to macroeconomists - in Section A.9, we focus on the ergodic default rate, ergodic average bond credit spread, and the ergodic debt-to-income ratio (as a function of various model parameters) as an illustrative example.

Many of the comparative statics we show there are interesting, and several of them deserve our attention. For instance, income volatility $\sigma$ has an ambiguous impact on ergodic average default rates. On the one hand, keeping the government financing policy and the default boundary fixed, the higher the income volatility, the more likely to hit the default barrier, and hence the greater the ergodic default rate. On the other hand, with greater income volatility, the bond price function becomes more elastic, which means that the government tends to issue less debt, and since the government's default option is more valuable, the government defaults "later," pushing the default frequency downwards. For our parameter choice, the two effects almost offset each-other. Instead, ergodic average credit spreads for our parameter choice are downward sloping in $\sigma$, since on average, the government spends more time at lower debt-to-income levels, far away from the default boundary. A shorter maturity $1 / \mathrm{m}$ leads to a lower default boundary (for a sufficiently low coupon rate, as discussed in Section 5.1.2), but a higher average debt-to-income level, and thus higher average default rates and credit spreads.

\footnotetext{
${ }^{32}$ One can interpret our stochastic differential equation for $x_{t}$ as describing the movement of particles getting hit by idiosyncratic Brownian shocks.
} 
In all our results, it is interesting to note that the sensitivity of the ergodic average default rate to any given model parameter is often quite different from the sensitivity of the ergodic average sovereign credit spread to that same parameter due to shifts in equilibrium behavior. These two moments have been the subject of intense focus in the quantitative sovereign default literature, but as our exercise illustrates, they can behave quite differently as we vary our model parameters.

\subsubsection{Time-Varying International Capital Market Conditions}

For simplicity in this section we have so far assumed constant risk-free rates and risk-prices for international creditors. But our model features an interesting result on the effects of the creditors' SDF on our smooth MPE. Suppose now that risk-free rates and risk-prices are time-varying; in particular, they depend on international capital market conditions $s_{t}$ as in equation (12) so that $r_{t}=r\left(s_{t}\right)$ and $\boldsymbol{v}_{t}=\boldsymbol{v}\left(s_{t}\right)$. Using our remark at the end of Section 4.5, the government value function must be independent of the international capital market state $s_{t}$, and thus equal to formula (34). Given the optimality condition (21), the bond price must also be independent of the state $s_{t}$, and thus equal to formula (33). The international capital market state matters only for the sovereign country's debt issuance policy, as shown in Section 4.6.2. We then have the following corollary.

Corollary 4 With time-varying risk-free rates and risk-prices, the government financing policy becomes

$$
g(x, s)=\frac{\delta-r(s)}{\epsilon(x)}-v(s) \cdot \sigma x
$$

Upward shocks to risk-free rates or risk-prices lead the government to adjust its financing policy downwards.

This observation is qualitatively consistent with various sovereign debt crisis episodes and large current account adjustments. As an example, the Latin American sovereign debt crisis, that began in 1982 with the default of Mexico, occurred at a time US interest rates had been increased significantly by Paul Volker. In response, Latin American economies reduced their hard currency bond issuances, with certain countries even buying back their own debt at deep discounts. ${ }^{33}$ Similarly, the Asia Tiger crisis of 1997 could be interpreted, through the lens of our model, as a sudden rise in risk-prices, which led Indonesia, Malaysia and the Philippines to go through a rapid current account adjustment.

\subsubsection{GDP-Linked bonds}

We finally extend our analysis to study an environment where the debt contract has some state-contingency. One such example is GDP-linked bonds, whose principal balance goes up and down with income shocks - and denote $\boldsymbol{\phi}$ the sensitivity of the debt face value to such shocks. In equilibrium the debt face value in such case evolves as follows:

$$
d F_{t}=\left(G\left(Y_{t}, F_{t}, s_{t}\right)-m F_{t}\right) d t+F_{t} \boldsymbol{\phi} \cdot d \boldsymbol{B}_{t}
$$

\footnotetext{
${ }^{33}$ See for example Bulow and Rogoff (1988) for a detailed discussion on such buy-backs and debt-for-equity swaps by Mexico, Chile, Brazil and Bolivia.
} 
For example, a government could issue bonds that "share" some of the small open economy's income risk with international investors, so that $\phi \propto \sigma$. We treat GDP-linked bonds in details in Section A.10, and summarize here the main result.

Proposition 10 The economy where the government issues GDP-linked bonds whose face value follows (48) is isomorphic to an economy in which (a) the government issues non-state-contingent bonds, $(b)$ the country's income growth risk has volatility vector $\boldsymbol{\sigma}-\boldsymbol{\phi}$, and (c) creditor's interest rate is $r(s)+\boldsymbol{\phi} \cdot \boldsymbol{v}(s)$.

This isomorphism is intuitive. A country with income risk $\sigma$, that hedges a component $\phi$ of that risk via GDP-linked bonds, is identical to the one whose income risk is "only" $\sigma-\boldsymbol{\phi}$; since investors pricing kernel might be correlated to the aggregate risk they are now assuming, their cost of capital is distorted upwards by $\boldsymbol{\phi} \cdot \boldsymbol{v}(s)$.

Because the smooth equilibrium remains, our welfare conclusions are unchanged: there is no welfare gain from issuing GDP-linked bonds, i.e., $V(Y, 0, s)=W(Y, s)$. That said, the implied volatility reduction and higher implied cost of capital will influence equilibrium policies, such as the target debtto-income level, speed of adjustment, and default rate, all of which can be solved for using the methods of this section.

\section{The Welfare Benefit of a Commitment Technology}

We now consider different commitment devices and study whether such devices enable the government to re-capture any of the welfare gains from trade. Our study will uncover that the specific commitment technology matters; certain of those technologies will not improve the sovereign's welfare, while others will. To simplify the exposition, we assume going forward that the international risk-free rate is constant equal to $r$, and that aggregate risk is not priced - i.e. $v=0$. We also assume that $\alpha=\theta=0$ : upon default, the small open economy's income falls to zero, and international investors lose their entire investment. Finally, in what follows, we will denote by $v$ (resp. $d$ and $g$ ) the government (income-normalized) welfare value (resp. debt price and issuance policy) in the no-commitment Smooth MPE of Section 5.

\subsection{Infrequent Debt Issuance Opportunities}

A natural place to start our study of commitment devices is an environment almost identical to the heuristic "discrete time" discussion of Section 3. For tractability, and perhaps more realistically, rather than modeling trading times as discrete, suppose the government receives opportunities to trade at Poisson arrival times with intensity $1 / \Delta$ (where $\Delta$ represents the average time interval between two trading dates). In this setup, the country's debt-to-income ratio shrinks at rate $m+\mu$, but at each debt adjustment opportunity, the government can issue (or buy back) "lump" amounts of debt that depend on the level of indebtedness at that time. This trading constraint is thus similar to the "Calvo" friction in the sticky price literature (see Calvo (1983)) or the model of inattentive consumers in the rational inattention literature (see Reis (2006)). The inability of the government to rebalance its debt at any time introduces certain commitment power, and thus welfare gains from trade. In this section, we study the magnitude of those gains from trade in the limiting economy as the average time between trades $\Delta$ changes. 
The MPE is characterized by two delayed differential equations. The first is the government's HJB equation solved by its value function $v_{\Delta}(\cdot)$ in the "continuation region," together with its optimal financing strategy specifying the debt-to-income ratio $n_{\Delta}(x)$ that the government optimally "jumps to" upon a debt adjustment opportunity. The second is an asset pricing equation pinning down the debt price function $d_{\Delta}$, given the sovereign's debt issuance behavior. Those equations are described in Section A.11.

Figure 2 illustrates how government's initial welfare, starting with no debt, varies with the average trading time interval $\Delta$. When $\Delta \rightarrow+\infty$, the government almost never has opportunities to issue bonds, and its no-debt welfare is close to its autarky value. Similarly, as $\Delta \rightarrow 0$, the speed of trading opportunities becomes arbitrarily large, and the lack of commitment again causes government welfare to approach its autarky value. Thus, welfare $v_{\Delta}(0)$ is a hump-shaped function of $\Delta$, and is maximized at a trading frequency that depends upon the debt maturity. Figure 7 highlights this sensitivity; interestingly, as the average debt maturity decreases, the optimal trading frequency and maximum "achievable" welfare both increase. As we shorten the average debt maturity, trade time needs to be even shorter for the commitment cost to have sufficient bite.

To better understand the effect of commitment on welfare, we also show in Figure 2 the welfare that the government could achieve if it could commit to target debt-to-income ratio $x^{*}$ but still retain the option to default. Section A.11.3 characterizes this commitment equilibrium and the target $x^{*}$ which is chosen optimally ex ante. As in our main model, the government can choose to default at any time, but absent default it must rebalance to $x^{*}$ at each trading date. ${ }^{34}$ As Figure 2 highlights, as the frequency of trade increases, commitment leads to substantially higher welfare for the government. In the limit as $\Delta \rightarrow 0$, all gains from trade are extracted as optimal leverage converges to $1 /(r-\mu)$, the first-best value of the government's income stream.

We analyze these settings further in Section A.11. Figure A-13 shows how the default boundaries and target debt-to-income ratios vary across the two models and with the expected trading interval. Figure A-10 illustrates the debt price function for two choices of trading intensity, while Figure A-11 shows the expected issuance rate $\left(n_{\Delta}(x)-x\right) / \Delta$. Finally, in Section A.11.2 we study the asymptotic properties of our model as $\Delta \rightarrow 0$. In particular, we show that under certain conditions, the welfare gains of our discrete trading model vanish at rate $\Delta$, and the magnitude of those gains is proportional to (a) the trading interval $\Delta,(\mathrm{b})$ the discount rate wedge $(\delta-r)$ and (c) the present value of all proceeds raised from debt issuances.

\subsection{Markov-Switching Restricted Issuance}

The previous analysis shows that welfare gains can be reintroduced when the government is only allowed to issue debt at infrequent times - as is the case in discrete time models. We now show that the institutional arrangement of such issuance restrictions is important in obtaining welfare gains.

To illustrate our point, consider the following 2-state Markov-switching economy. In the unrestricted state (state " $u$ "), the government is entirely free to issue debt, while in the constrained state (state " $c$ "), the government is prohibited from issuing any debt. These two Markov states switch back-and-forth at specific Poisson arrival times, with arrival intensities $\lambda_{u}$ and $\lambda_{c}$ respectively. One can also think about

\footnotetext{
${ }^{34}$ In this model, there will be two default boundaries: one that applies between trading dates, and a tighter one that applies on each trading date when the government is forced to rebalance by repurchasing outstanding debt.
} 
Figure 7: Welfare sensitivity to trading time and debt maturity

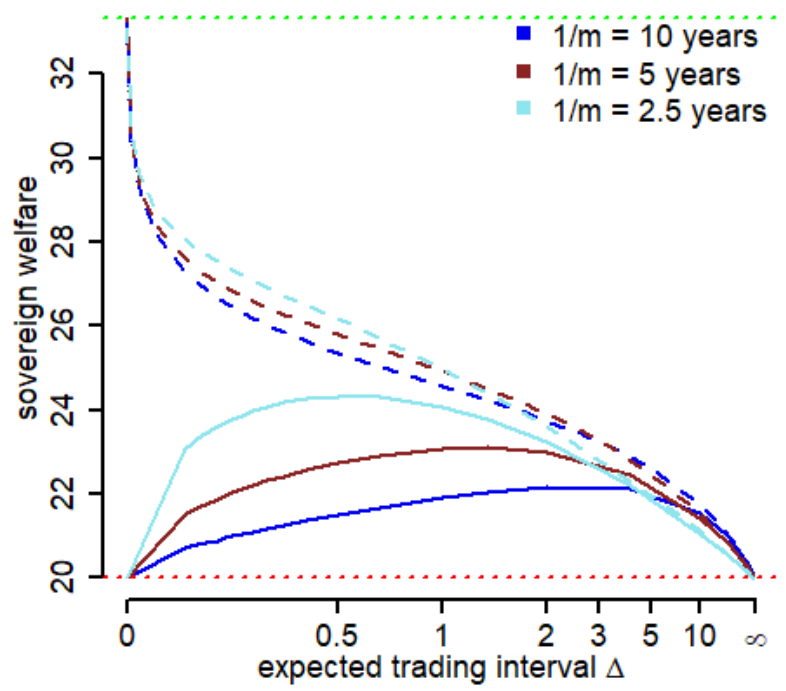

Plot shows sovereign welfare assuming no initial debt and infrequent trading without commitment (solid lines) and with commitment (dotted lines), as a function of the expected trading interval $\Delta$, for different average debt maturity parameters. Plots computed assuming $\mu=2 \%$ p.a., $\sigma=20 \%$ p.a., $\theta=0 \%, \alpha=0 \%, v=0 \%, r=\kappa=5 \%, \delta=7 \%$, and $1 / \mathrm{m}$ equal to 2.5 years, 5 years and 10 years. For these parameters, the first-best value per dollar of government income is $1 /(r-\mu)=33.3$.

this economic environment from a credit supply standpoint: state $c$ can be thought of as a sudden stop state, during which international capital markets are shut for the small open economy, while state $u$ can be thought of as a normal state, during which international capital markets are functioning normally.

Different from Section 6.1 in which the government can issue bonds only at Poisson events (which occur in a discrete fashion), in this setting once international capital markets are in the " $u$ " state, the government can issue sovereign bonds at any time before international capital markets revert back to the " $c$ " state. The next proposition shows that the government receives no gain from trade in equilibrium, just like our no-commitment benchmark, while creditors benefit (i.e. their investment market value increases) in the constrained state "c."

Proposition 11 There exists a Smooth MPE of this economy, where the government value function $v_{c}$ in state " $c$ " and $v_{u}$ in state " $u$ " are equal to the no-commitment value function $v$ :

$$
v_{u}(x)=v_{\mathcal{c}}(x)=v(x)
$$

In such economy, the debt price satisfies (with the exact expression for $d_{c}(x)$ derived in Section A.12):

$$
d_{u}(x)=d(x) \quad \text { and } \quad d_{c}(x)>d(x)
$$

Issuances $g_{u}(x)$ in the unconstrained state are greater than issuances $g(x)$ in the no-commitment MPE:

$$
g_{u}(x)=g(x)+\lambda_{u} \frac{d_{c}(x)-d_{u}(x)}{-d_{u}^{\prime}(x)} \quad \forall x \leq \bar{x}
$$


Figure 8: Debt price and issuance policy in Markov-switching economy

(a): Debt Price

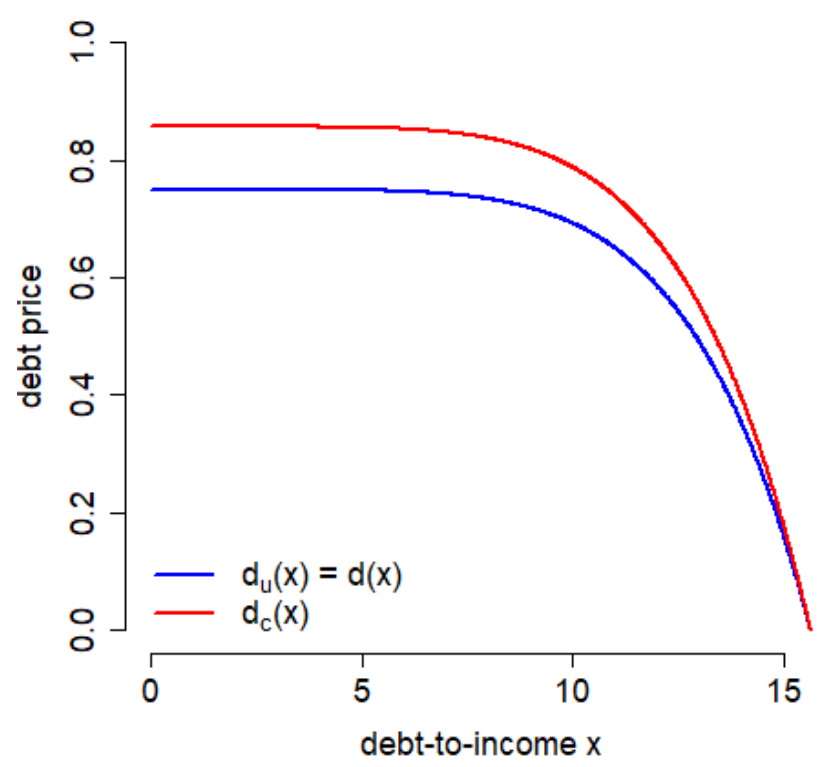

(b): Issuance Policy

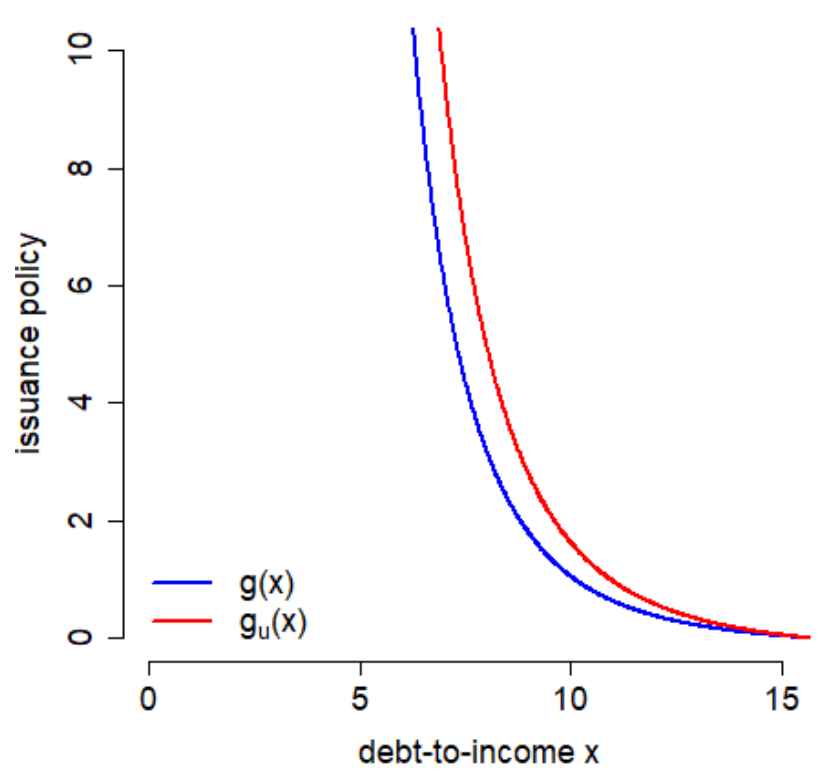

Figure (a) shows the debt price $d_{u}$ (resp. $d_{c}$ ) in the unrestricted (resp. constrained) state. Figure (b) shows the issuance policy $g_{u}$ in the unrestricted state, compared to the issuance policy in the no-commitment equilibrium. The plot was computed assuming $\mu=0 \%$ p.a., $\sigma=20 \%$ p.a., $1 / m=10$ years, $\theta=0 \%, \alpha=0 \%, v=0 \%, r=\kappa=5 \%$ and $\delta=10 \%$.

Proposition 11 is proven in Section A.12. Intuitively, in this environment, while the government is de-facto tying its hands in state $c$, it is totally unpredictable (a) when and whether the government will enter this "commitment" period, and (b) how long such "commitment" period will last. Because the constrained state is unpredictable, the government cannot take advantage of this commitment mechanism. This aspect crucially differs from our previous case of infrequent trading opportunities of Section 6.1 and helps rationalize the complete lack of welfare gains in this setting.

Figure 8 illustrates that the equilibrium debt price $d_{u}$ in the unconstrained state is strictly below the debt price $d_{c}$-creditors understand that in such state $c$, no bond issuances occur, meaning that indebtedness grows slower than in the unconstrained state $u$. From the government's perspective, knowing that it will be limited in its ability to issue bonds in state $c$, the government adjusts its issuance policy $g_{u}(x)$ upward in the unrestricted state compared to the no-commitment economy (i.e., $g_{u}(x)>g(x)$ ). Proposition 11 formally shows that the debt issuances in state $u$ are so large that it completely offsets the gain from commitment (of no debt issuance) in state $c$.

Figure 9 shows the welfare gain/loss vs. the no-commitment MPE for citizens of the small open economy, when their degree of impatience $\hat{\delta}$ varies, and for different levels $x$ of indebtedness. In other words, this figure shows $\hat{v}_{u}(x) / \hat{v}(x)-1$ and $\hat{v}_{c}(x) / \hat{v}(x)-1$ for various parameters $\hat{\delta}$ and various levels of $x$. There are several important take-aways from this figure. First, the figure illustrates that citizens' welfare in the constrained state $\hat{v}_{c}(x)$ is always strictly greater than in the unconstrained state $\hat{v}_{u}(x)$, since those citizens are more patient than the government, and since in state " $c$ ", no debt is issued (which we know is strictly better for citizens than if the government was instead issuing debt). Second, while Proposition 11 shows that our "market-imposed" disciplining device is ineffective at restoring welfare 
Figure 9: Markov-switching economy - welfare gains/losses vs. no-commitment MPE

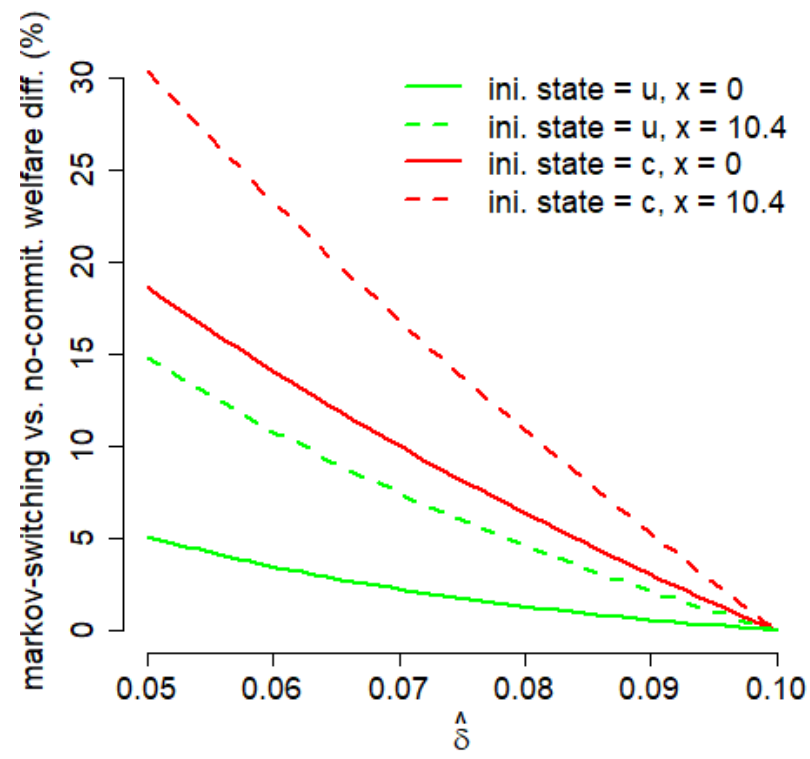

Figure shows the percentage change in welfare for citizens with different discount rates, as measured against the nocommitment MPE. Red lines assume that the game is started when in constrained state " $c$ ", while green lines assumes that the game is started when in unconstrained state " $u$ ". Solid (resp. dash) lines are welfare gains/losses measured at $x=0$ (resp. $x=2 \bar{x} / 3$ ). The plot is computed assuming $\mu=0 \%$ p.a., $\sigma=20 \%$ p.a., $1 / m=10$ years, $\theta=0 \%, \alpha=0 \%, v=0 \%, r=\kappa=5 \%$ and $\delta=10 \%$.

gains for the government, citizens are better off in that economic environment than in our original no-commitment economy; this observation holds across debt-to-income levels $x$ and across patience parameters $\hat{\delta}<\delta$.

Our conclusion of Proposition 11 might seem counter-factual, as the debt price in the sudden-stop state " $c$ " is higher than in the unconstrained state " $u$." This is simply the consequence of our assumption that the market price of risk is constant (and equal to zero) across capital market states. One could instead make the more empirically reasonable assumption that the market price of risk jumps when the economy transitions into the sudden-stop constrained state $c$, as we do in Section A.12. This gives us the following remark.

Remark 5 When the market price of risk in the constrained state " $c$ " is strictly positive, the debt price $d_{c}$ in such state is strictly less than the debt price $d_{u}$ in the unconstrained state $u$ for sufficiently high debt to income ratios.

As a result, if sudden stops coincide with jumps in risk premia, we expect the debt price of highly indebted countries to fall, while those of less indebted countries rise.

So far, we have considered exogenous constraints on trade. In the next sections, we consider financing restrictions that may be adopted as matters of policy, and which the government may help to control or design, such as debt ceilings or issuance constraints.

\subsection{Debt Ceiling Policies}

Imagine that the government alters its constitution, such that it limits future governments from being able to issue additional bonds once the debt-to-income ratio $x_{t}$ exceeds a certain limit $x^{*}$. When $x_{t}<x^{*}$, 
the government has full flexibility to issue additional bonds in international capital markets. But when $x_{t}>x^{*}$, no new debt can be issued (but there is no requirement to immediately reduce debt). Such restrictions can be found in many advanced economies. In the U.S. for example, the debt ceiling is a legislative limit on the notional amount of national debt that can be incurred by the U.S. Treasury. While such limit is not expressed as a percentage of GDP (as it is in our model in order to preserve its homogeneity properties), it achieves a purpose similar to the one we intend to study here. Similarly, under the Maastricht Treaty, member states must maintain their debt-to-GDP ratio below 60\%.

We first show that a "debt ceiling" commitment technology does not always provide welfare gains for the government. If the debt-to-income limit $x^{*}$ is too high, then the improvement in debt prices is not sufficient to allow the government to benefit. In that case, a smooth MPE continues to exist, and the value function $v_{c}$ of the government across the entire state space is identical to the value function $v$ in the no-commitment economy. Creditors, however, do benefit from higher debt prices when the debt-to-income ratio is above the cutoff $x^{*}$.

If the debt ceiling $x^{*}$ is low enough, the government can monetize the welfare benefits from being able to borrow from patient lenders. In this case, once the debt-to-income ratio exceeds $x^{*}$, it varies only with income shocks, except for being reflected - by immediate new debt issuances — at the lower bound $x^{*}$. In that case, the sovereign benefits by being able to issue debt that restores leverage to $x^{*}$ at a higher debt price.

Proposition 12 There exists two cutoffs $\underline{x}^{*}, \bar{x}^{*}$, with $0<\underline{x}^{*} \leq \bar{x}^{*}<\bar{x}$ (with possibly $\underline{x}^{*}=\bar{x}^{*}$ ), such that:

1. Loose debt-ceiling: if $x^{*}>\bar{x}^{*}$, there exists a Smooth MPE in which the government value function $v_{c}(x)=v(x)$ without gain from trade, in which the debt price satisfies $d_{c}(x)=d(x)$ when $x<x^{*}$ and $d_{c}(x)>d(x)$ when $x>x^{*}$. In such MPE, the debt price $d_{c}(x)$ is continuously differentiable on $[0, \bar{x}]$ except at $x=x^{*}$, where it is continuous but exhibits a convex kink.

2. Moderate debt-ceiling: if $x^{*} \in\left[\underline{x}^{*}, \bar{x}^{*}\right]$, there exists a regulated equilibrium of this economy. In such equilibrium, the government uses a singular issuance strategy to maintain its debt-to-income ratio above $x^{*}$. There exists a second endogenous cutoff $\hat{x} \in\left(0, x^{*}\right)$, such that if $x \in(0, \hat{x})$, the government follows a smooth debt issuance strategy, while if $x \in\left(\hat{x}, x^{*}\right)$, the government jumps to $x^{*}$ by issuing a lump amount of debt; the value function $v_{c}(x)>v(x)$ except at $x=0$, where both values coincide;

3. Tight debt-ceiling: if $x^{*}<\underline{x}^{*}$, there exists a regulated equilibrium of this economy. In such equilibrium, the government uses a singular issuance strategy to maintain its debt-to-income ratio above $x^{*}$. The government jumps to the debt-to-income level $x^{*}$ whenever $x \in\left(0, x^{*}\right)$; the government value function $v_{c}(x)>v(x)$ everywhere, achieving a welfare gain compared to its no-trade value.

Closed form expressions are provided in Section A.13.2 for all cases.

Figure 10 illustrates the shape of the debt price function $d_{c}(x)$ for a loose debt-ceiling policy (i.e. $x^{*}>\bar{x}^{*}$, the case where a smooth equilibrium still exists). The debt price $d_{c}(x)$ is identical to the no-commitment debt price $d(x)$ for $x \leq x^{*}$, while $d_{c}(x)>d(x)$ holds for $x>x^{*}$. As discussed in Section A.13.1, the debt price exhibits a convex kink, and the right-derivative of $d_{c}$ at $x=x^{*}$ is strictly greater than the left-derivative. ${ }^{35}$

\footnotetext{
${ }^{35}$ The no-arbitrage condition puts a restriction on the issuance policy at such boundary $x^{*}$, so that the resulting debt-to-
} 
Figure 10: Debt price $d_{c}(x)$ in smooth constrained equilibrium

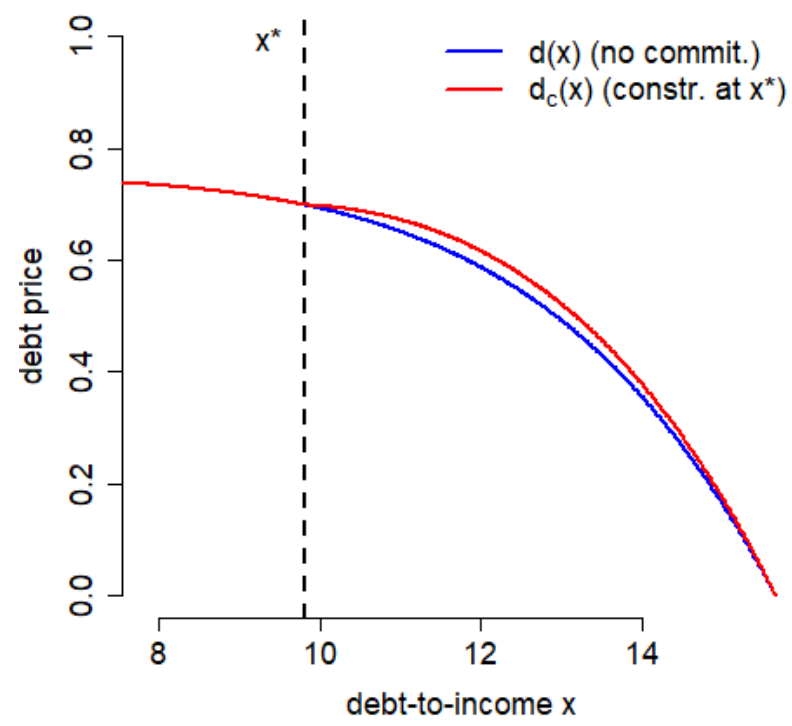

Debt price in the constrained equilibrium (in red) and in the no-commitment equilibrium (in blue). The plot was computed assuming $\mu=0 \%$ p.a., $\sigma=20 \%$ p.a., $1 / m=10$ years, $\theta=0 \%, \alpha=0 \%, v=0 \%, r=\kappa=5 \%$ and $\delta=10 \%$. The threshold $x^{*}$ is set to satisfy $x^{*}=0.05 \bar{x}+0.95 \bar{x}^{*}$, in other words $x^{*}>\bar{x}^{*}$.

\section{Figure 11: Reflecting equilibrium with "moderate" constraint $x^{*}$}

(a): Debt Price

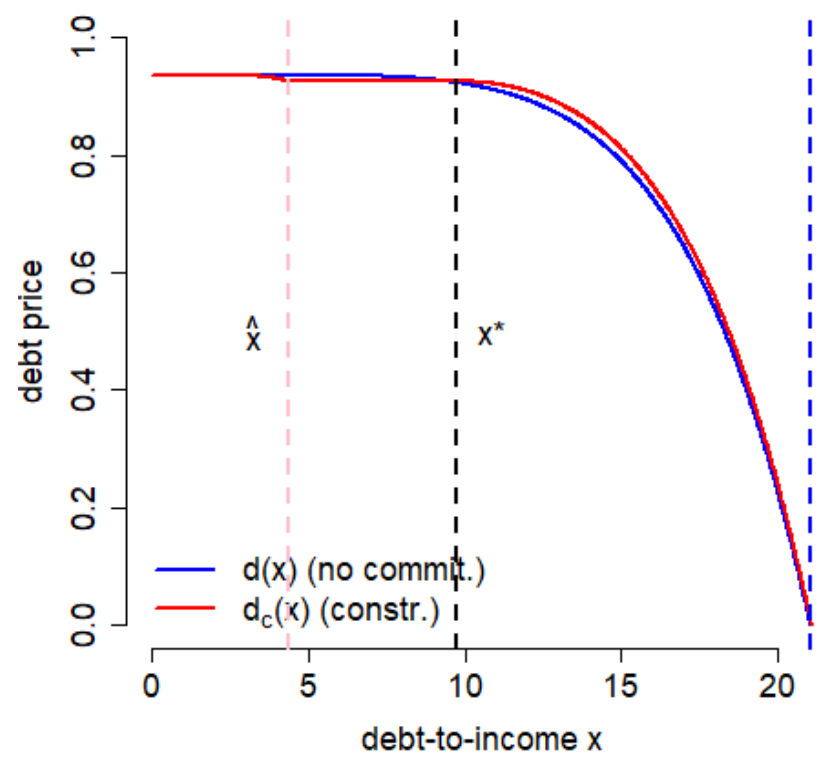

(b): Value Function Difference $v_{c}-v$

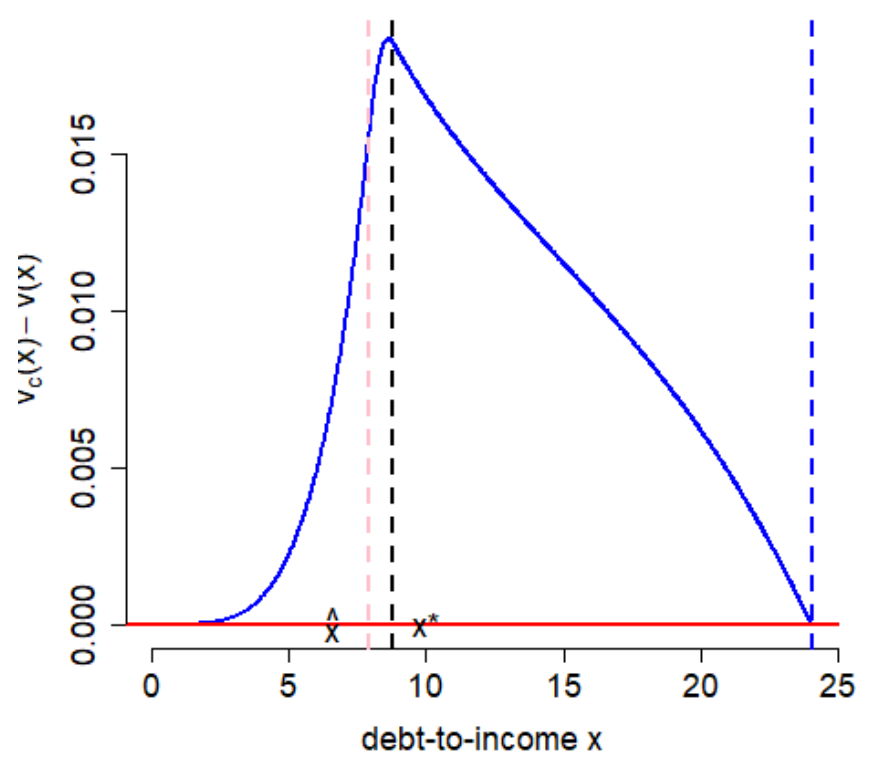

Figure (a) shows the debt price in the constrained equilibrium (in red) and in the no-commitment equilibrium (in blue). Figure (b) shows the (income normalized) difference between (i) the value function $v_{\mathcal{C}}$ in the constrained equilibrium and (ii) the value function $v$ in the no-commitment equilibrium (in blue). The plot was computed assuming $\mu=0 \%$ p.a., $\sigma=20 \%$ p.a., $1 / m=10$ years, $\theta=0 \%, \alpha=0 \%, v=0 \%, r=\kappa=5 \%$ and $\delta=6 \%$. The threshold $x^{*}$ is set to satisfy $x^{*}=0.995 \bar{x}^{*}$, in other words $x^{*} \in\left(\underline{x}^{*}, \bar{x}^{*}\right)$.

income process needs to be a skew-Brownian motion. The debt issuance strategy is such that the excursions of the state variable $x_{t}$ at $x^{*}$ are asymmetric, with probability $\frac{1+\chi}{2}$ to the left and with probability $\frac{1-\chi}{2}$ to the right, where $\chi \in(0,1]$. Note that when $\chi=1$ this boundary corresponds to a reflection bo 39 hdary, while $\chi=0$ corresponds to standard Brownian motion. For more details, see in Harrison and Shepp (1981). 
As we reduce the policy parameter $x^{*}$, the kink in the debt price at $x=x^{*}$ becomes so severe that past the limiting value $\bar{x}^{*}$, the debt price is no longer monotone decreasing in $x$, and our Smooth MPE no longer exists. For $x^{*}<\bar{x}^{*}$, we necessarily have to look for equilibria featuring jumps. In Figure 11, we give an illustration of the value function and debt prices in the MPE for a moderate debt ceiling policy, i.e. $x^{*} \in\left(\underline{x}^{*}, \bar{x}^{*}\right)$. On the interval $x \in\left(\hat{x}, x^{*}\right)$, the value function is linear, the debt price function is flat, with a level $d\left(x^{*}\right)$ that is strictly below the critical value $\frac{\kappa+m}{\delta+m}$, as the government finds it optimal to jump immediately to the debt-to-income level $x^{*}$. On $x \in(0, \hat{x})$, the government follows a smooth debt financing policy, with a value function $v_{\mathcal{C}}(x)$ that is weakly greater than $v(x)$ - both functions are equal when the government is not indebted (i.e. $v(0)=v_{c}(0)$ ).

Figure 12: Reflecting equilibrium with "tight" constraint $x^{*}$

(a): Debt Price

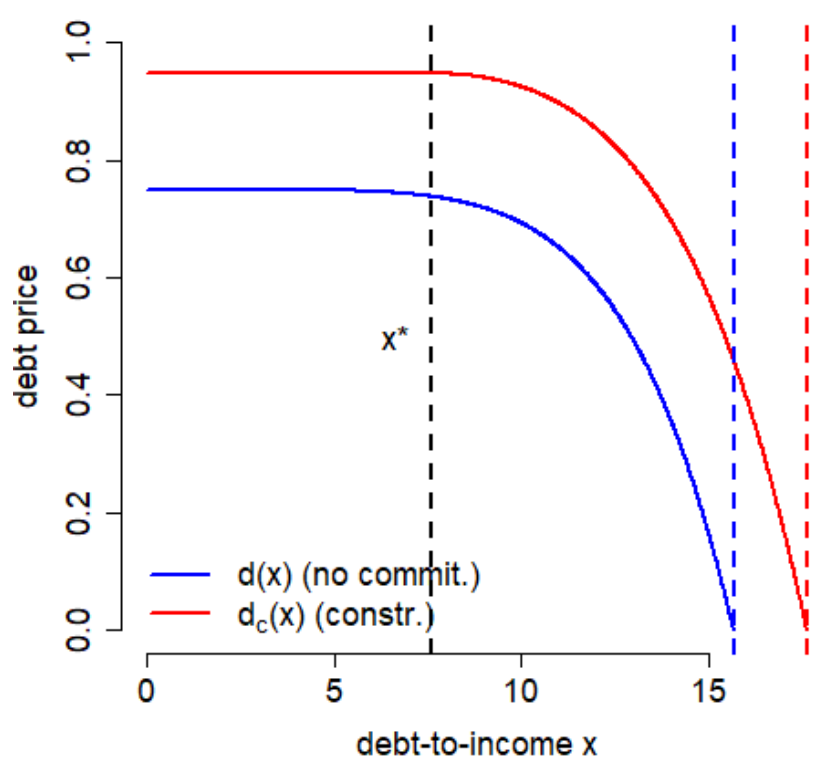

(b): Value Function

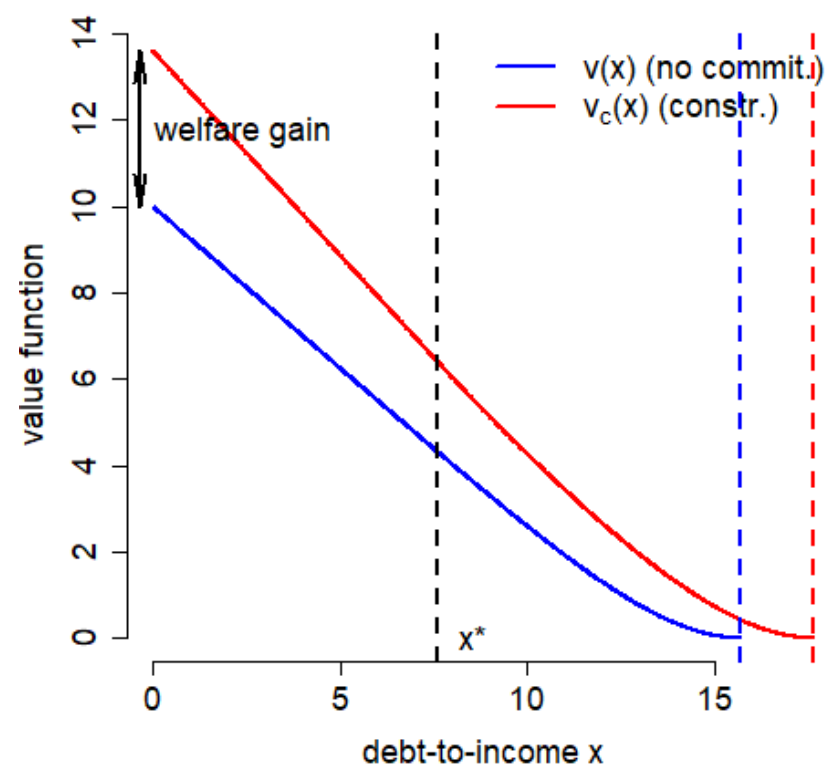

Figure (a) shows the debt price in the constrained equilibrium (in red) and in the no-commitment equilibrium (in blue). Figure (b) shows the (income normalized) value function in the constrained equilibrium (in red) and in the no-commitment equilibrium (in blue). The plot was computed assuming $\mu=0 \%$ p.a., $\sigma=20 \%$ p.a., $1 / m=10$ years, $\theta=0 \%, \alpha=0 \%, v=0 \%$, $r=\kappa=5 \%$ and $\delta=10 \%$. The threshold $x^{*}$ is set to satisfy $x^{*}=0.80 \bar{x}^{*}$, in other words $x^{*}<\underline{x}^{*}$.

Finally, Figure 12 gives an illustration of the MPE given a tight debt ceiling policy $x^{*}<\underline{x}^{*}$. The debt price $d_{c}$ and the government value function $v_{c}$ are uniformly higher than in the no-commitment equilibrium, and one can see the government welfare gain (without debt outstanding) graphically as the distance between $v_{c}(0)$ and $v(0)$. For $x<x^{*}$, the debt price satisfies $d_{c}(x)=d_{c}\left(x^{*}\right)$, since creditors anticipate that the government will issue a lump amount of debt in order achieve a debt-to-income ratio equal to $x^{*}$, while the income-normalized value function satisfies $v_{\mathcal{c}}(x)=v_{\mathcal{c}}\left(x^{*}\right)+\left(x^{*}-x\right) d_{\mathcal{c}}\left(x^{*}\right)-$ in other words the value function is linear in the debt-to-income ratio when $x<x^{*}$.

Figure 13 shows the welfare gains/losses vs. the no-commitment MPE for a range of choices of constraints $x^{*}$, for the government and citizens discounting cashflows at two possible rates: $\hat{\delta}_{1}$ that is equidistant from $r$ and $\delta$, and $\hat{\delta}_{2}=r$. In this figure, the welfare gains and losses are measured either when the government has a low level of debt (in (a)) or a high level of debt (in (b)). 
Figure 13: Debt ceiling policies - welfare gains/losses vs. no-commitment MPE

(a): welfare diff. at "low" $x$

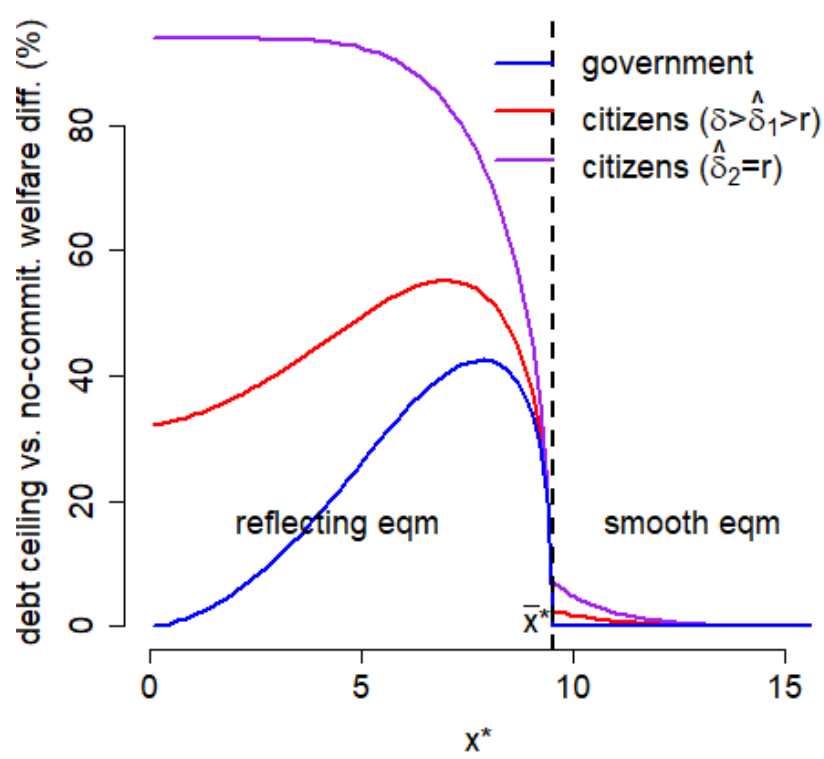

(b): welfare diff. at "high" $x$

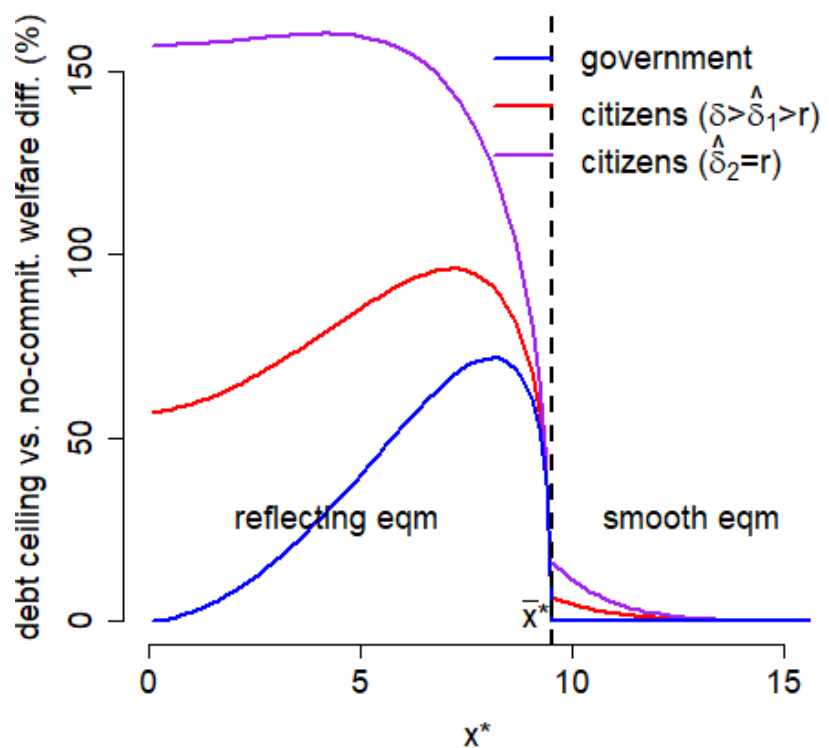

Figure (a) shows the percentage change in welfare (for the government and for citizens with different discount rates) when $x=\bar{x} / 3$, as measured against the no-commitment MPE. Figure (b) shows the same percentage change in welfare, evaluated at $x=2 \bar{x} / 3$ instead. The plot is computed for a range of values for the threshold $x^{*}$, with $\mu=0 \%$ p.a., $\sigma=20 \%$ p.a., $1 / m=10$ years, $\theta=0 \%, \alpha=0 \%, v=0 \%, r=\kappa=5 \%$ and $\delta=10 \%$.

There are several insights we draw from Figure 13. First, when the debt ceiling $x^{*}=0$ and the government commits to never issuing any debt, or $x^{*} \geq \bar{x}^{*}$, i.e. above the limiting case beyond which a Smooth MPE exists, the welfare of the government always equals its autarky (as well as the nocommitment MPE) value. While the government does not gain whenever the policy $x^{*}>\bar{x}^{*}$, citizens instead always increase their welfare, since they are more patient than the government and since those policies end up curbing the government's debt issuance behavior. The more patient citizens are, or the higher the current debt-to-income ratios, the more they gain. Finally, for a given debt-to-income level, our analysis suggests that there exists an optimal debt-to-income limit at which the government welfare improvement is optimal. However, such optimal debt ceiling policy does not correspond to the policy that would be chosen if instead the objective was to maximize citizens' welfare.

\subsection{Cap on Bond Issuance Rate}

In Section 6.3, we analyzed constraints that focus on the stock of government debt. In this section, we instead discuss a commitment device that prevents the government from issuing bonds at an intensity greater than an exogenously specified cap. To accommodate the scale invariance of our model, we focus

on caps of the form $G_{t} \leq \bar{g} Y_{t}$, i.e., the bond issuance rate (per unit of income) $g(x)$ is capped by $\bar{g}>0$. In other words, the government solves the simplified (income-normalized) problem:

$$
v_{\mathcal{c}}(x):=\sup _{(g, \tau) \in \mathcal{I}_{\bar{g}} \times \mathcal{T}} \tilde{\mathbb{E}}^{x}\left[\int_{0}^{\tau} e^{-(\delta-\mu) t}\left(1+g_{t} d\left(x_{t}\right)-(\kappa+m) x_{t}\right) d t\right]
$$




$$
d x_{t}=\left(g_{t}-(m+\mu) x_{t}\right) d t-\sigma x_{t} d \tilde{B}_{t}
$$

The set of admissible issuance policies $\mathcal{I}_{\bar{g}}$ is now the set of Markov controls such that $g_{c}(x) \leq \bar{g}$. This type of policy, targeting the government flow budget constraint rather than the stock of outstanding government debt, has empirical relevance. In a mapping of our model where $C$ is government spending and $Y$ is government tax revenue, a cap on the rate of bond issuances is a close analog to a cap on budget deficits, as is the case under the Maastricht Treaty (where member states must maintain their deficit below $3 \%$ of GDP). In a mapping of our model where $C$ is domestic consumption and $Y$ is GDP, a cap on the rate of bond issuances can be thought of as a limit on the current account deficit (as a fraction of GDP), a measure of economic imbalance frequently targeted by the IMF in connection with emergency lending programs. ${ }^{36}$

Under the parameter restriction $\delta+m>\sigma^{2}-(\mu+m)$, the issuance rate in our no-commitment benchmark is decreasing (as a function of $x$ ), and unbounded as $x \rightarrow 0$. This implies that in the economy with bond issuance caps, the constraint is binding for low debt-to-income states (i.e. for $x \in\left[0, x^{*}\right]$, for some endogenously determined debt-to-income hurdle $x^{*}$ ), but slack for high debt-to-income states (i.e. for $x \in\left[x^{*}, \bar{x}_{c}\right]$, for some endogenously determined default boundary $\bar{x}_{c}$ ). We summarize below our key result.

Figure 14: Cap on bond issuance rate - debt price and value function
(a): Debt Price $d_{c}(x)$
(b): Value Function $v_{c}(x)$
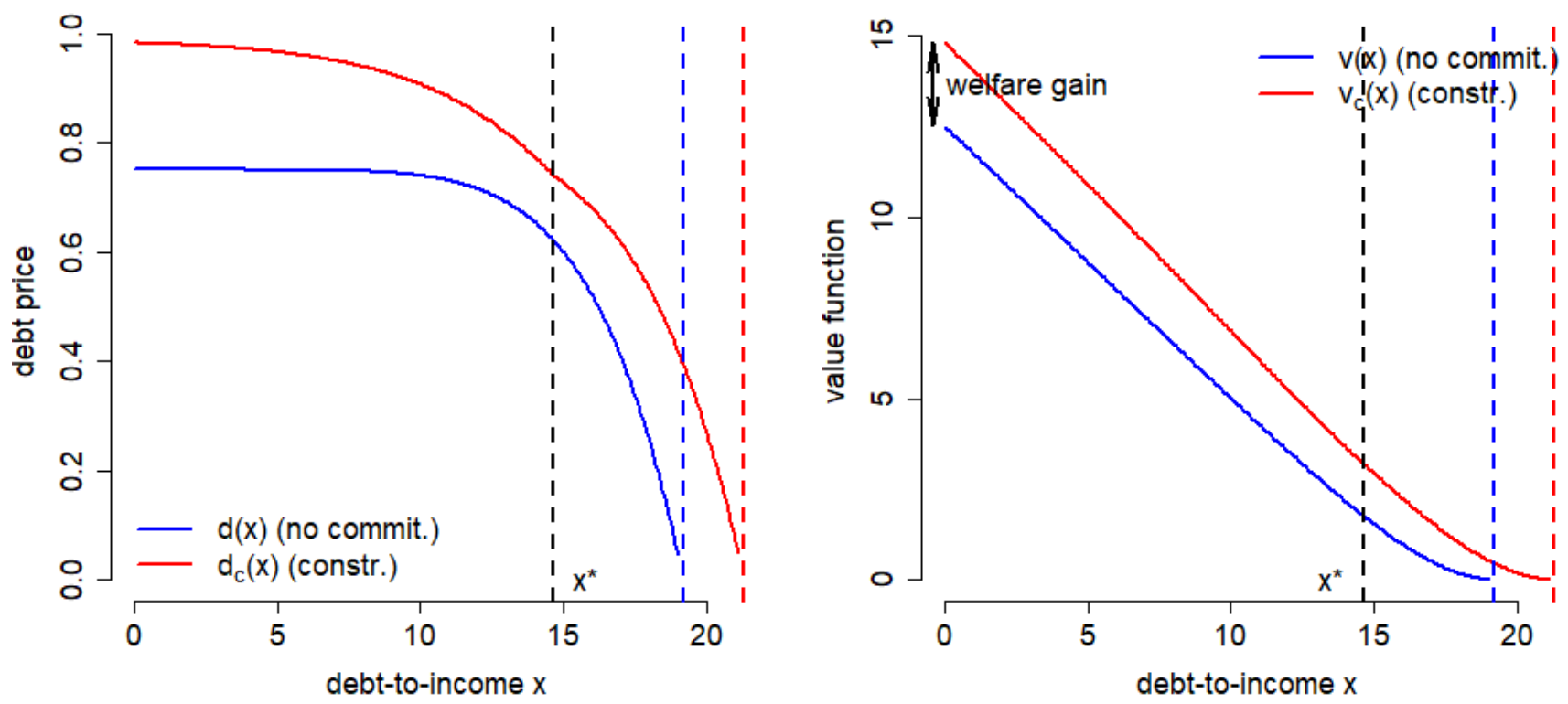

Debt price in (a) and value function in (b), for constrained (in red) and unconstrained equilibrium (in blue). Plot computed with $\mu=2 \%$ p.a., $\sigma=20 \%$ p.a., $1 / m=10$ years, $\theta=0 \%, \alpha=0 \%, v=0 \%, r=\kappa=5 \%, \delta=10 \%$ and $\bar{g}=100 \%$.

\footnotetext{
${ }^{36}$ In both model interpretations, a cap on budget deficit to GDP (or current account deficit to GDP) is not exactly identical to a cap on the bond issuance intensity. A cap on budget deficit as in the Maastrich treaty would be of the form $C-Y \leq b Y$, with $b=0.03$. This constraint is equivalent to a constraint of the form $g_{t} \leq\left(b-(\kappa+m) x_{t}\right) / d_{t}$, which is similar to the constraint studied in this paper when the debt price $d_{t}$ is close to par and when debt service payments to GDP are small vs. $b$.
} 
Proposition 13 Subject to the existence of a solution to a set of 2 algebraic equations in 2 unknowns disclosed in Section A.14, there exists two endogenous cutoffs $x^{*}, \bar{x}_{c}$, with $0<x^{*}<\bar{x}_{c}$ such that:

1. When $x \in\left(0, x^{*}\right)$, the government financing is constrained at $g_{c}(x)=\bar{g}$;

2. When $x \in\left(x^{*}, \bar{x}_{c}\right)$, the government is unconstrained, uses a smooth issuance policy $g_{c}(x)<\bar{g}$, and defaults optimally when $x=\bar{x}_{c}$. On this interval, the debt price satisfies $d_{c}(x)=-v_{c}^{\prime}(x)$.

In both intervals, the debt price and value function are analytic, with expressions given in Section A.14. The no-debt government welfare is strictly greater than the autarky welfare for any $\bar{g} \in(0,+\infty)$.

In Section A.14, we construct the constrained MPE explicitly, by solving the HJB equation satisfied by $v_{c}$ and $d_{c}$ on the constrained and unconstrained domains. Simplifications arise further in the particular case where $\sigma=0$ and $\mu+m<0$. In such case, we show that the default boundary $\bar{x}_{c}=1 /(\kappa+m)$ and the issuance policy is given by

$$
g_{c}(x)= \begin{cases}\bar{g} & \text { if } x \leq x^{*} \\ -\frac{(\delta-\mu)(\mu+m)}{\delta+m}\left[\left(\frac{\bar{x}_{c}}{x}\right)^{-\frac{\delta+m}{\mu+m}}-1\right] x & \text { if } x>x^{*}\end{cases}
$$

The cutoff $x^{*}$ is the unique value guaranteeing that $g_{c}$ is continuous at $x=x^{*}$.

In Figure 14, we plot the debt price and value function together with those in the no-commitment equilibrium. Both the debt price and value function in the constrained equilibrium are uniformly higher than in the no-commitment case, and default occurs at a higher debt-to-income ratio. While the value function is $\mathcal{C}^{1}$ at $x=x^{*}$, the debt price features a kink. In Figure 15, we show the resulting consumptionto-income and issuance-to-income policies. The issuance rate is of course capped at $\bar{g}$ when $x<x^{*}$, and is unconstrained, decreasing (as a function of $x$ ) when $x>x^{*}$. At the default boundary, since the debt price is zero and the gains from trade are proportional to the debt price, there are no incentives to issue debt, which means $g\left(\bar{x}_{c}\right)=0$.

Figure 16 panel (a) shows, given no initial debt, the welfare gains vs. the no-commitment MPE as we vary the policy $\bar{g}$, for the government (discounting cashflows at $\delta$ ) as well as for citizens (discounting cashflows either at rate $\hat{\delta}_{1}$ that is equidistant from $\delta$ and $r$, or at rate $\hat{\delta}_{2}=r$ ). The welfare gains at other debt-to-income ratios have a similar pattern. Panel (b) shows how the default boundary $\bar{x}_{c}$ and the cutoff $x^{*}$ vary with the choice $\bar{g}$. When $\bar{g}$ is small, the government is allowed to issue little debt, implying a government value $v_{\mathcal{C}}(0)$ that is close to the autarky (and no-commitment MPE) benchmark. Welfare gains increase as $\bar{g}$ increases, and those gains peak at around $\bar{g}=1.5$ for the government, but at other levels for citizens who are more patient. For high levels of $\bar{g}$, the constraint becomes more slack, and the government welfare gains drop, to reach zero as $\bar{g} \rightarrow+\infty$, and as the equilibrium gets closer and closer to the no-commitment MPE. For similar reasons, the optimal default boundary $\bar{x}_{c}$ is hump-shaped as a function of the issuance rate cap $\bar{g}$.

Our analysis of debt ceiling policies and caps on debt issuance rates have uncovered strikingly different patterns w.r.t. their efficiency at restoring gains from trade for the government. In particular, debt issuance caps, which only constraint low debt borrowers, are more "reliable" at preserving welfare gains than debt ceiling policies. This insight should push international institutions, such as the IMF, to consider flow-based, rather than stock-based interventions. 
Figure 15: Cap on bond issuance rate - consumption and financing policy

(a): Consumption-to-income $c(x)$

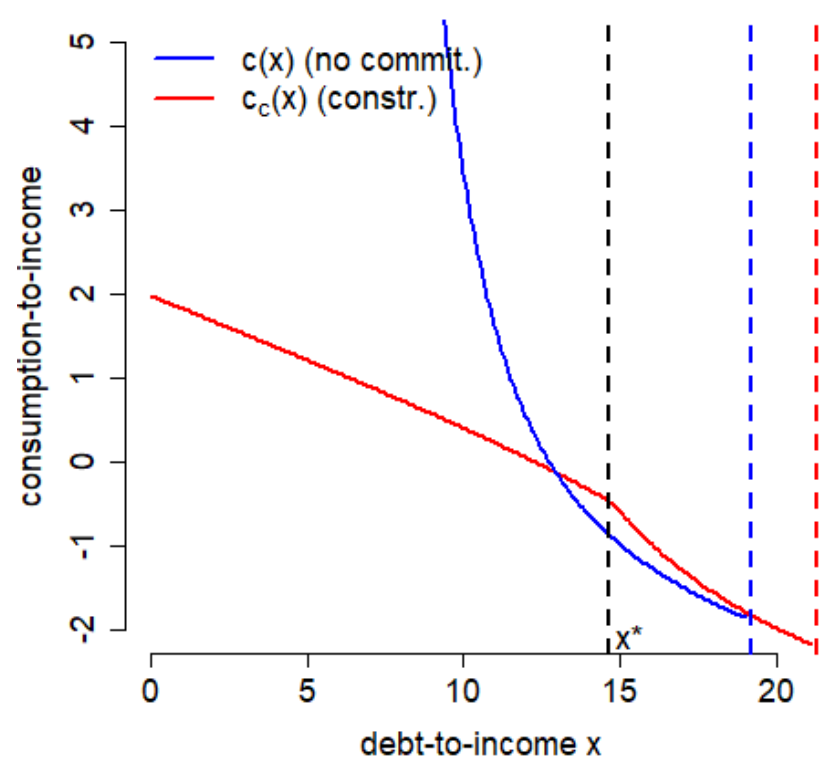

(b): Issuance Rate $g(x)$

Consumption-to-income in (a) and issuance rate in (b), for constrained (in red) and no-commitment equilibrium (in blue). Plot computed with $\mu=2 \%$ p.a., $\sigma=20 \%$ p.a., $1 / m=10$ years, $\theta=0 \%, \alpha=0 \%, v=0 \%, r=\kappa=5 \%, \delta=10 \%$ and $\bar{g}=100 \%$.

Figure 16: Welfare improvement with issuance cap

(a): Welfare gain at $x=0$

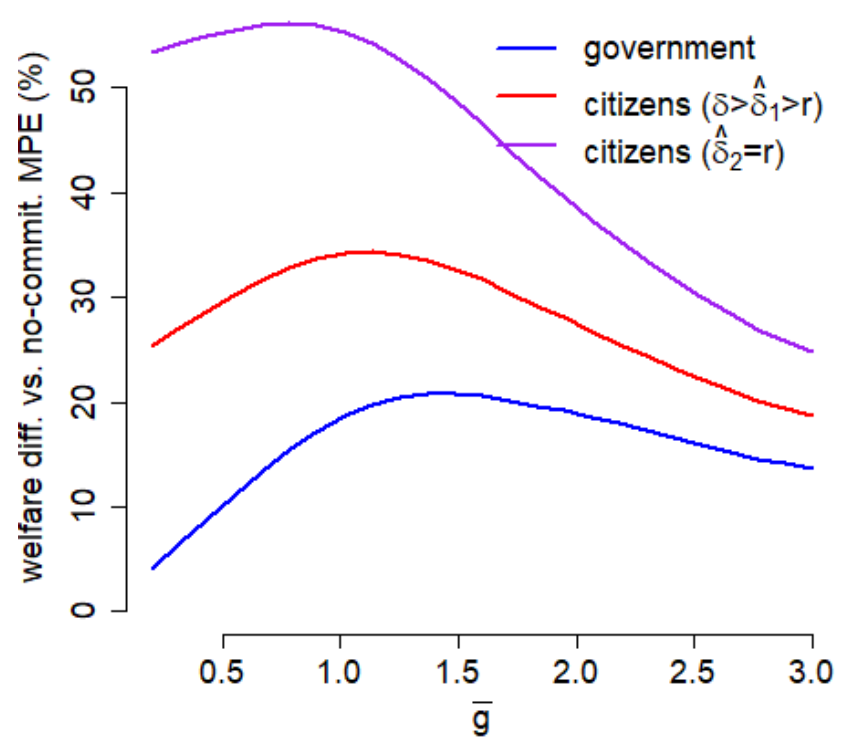

(b): Barriers $x^{*}, \bar{x}_{c}$

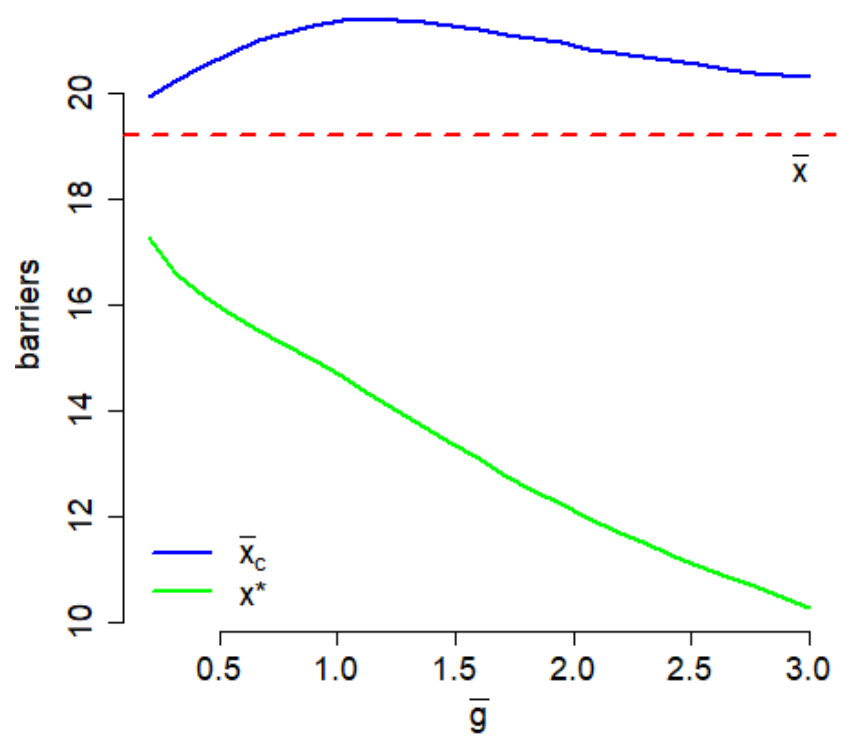

Figure (a) shows the percentage change in welfare (for the government and for citizens with different discount rates) when $x=0$, as measured against the no-commitment MPE. Figure (b) shows the default barrier $\bar{x}_{c}$ (in blue) and the regime switching barrier $x^{*}$ as we change the issuance cap $\bar{g}$. Plot computed with $\mu=2 \%$ p.a., $\sigma=20 \%$ p.a., $1 / m=10$ years, $\theta=0 \%, \alpha=0 \%$, $v=0 \%, r=\kappa=5 \%$ and $\delta=10 \%$. 


\section{Conclusion}

Lack of commitment is a powerful force that can dissipate entirely the gains from trade. We apply this original insight of Coase (1972) to the sovereign default framework to show that a government that can borrow from more patient lenders, but that cannot commit to a financing or default policy, destroys all gains from trade - a no-welfare result familiar from the durable goods' monopoly literature. Our result is general; for a very large class of income processes, and for any debt maturity structure, in the unique smooth MPE the small open economy does not reap the benefits of being able to finance itself with more patient lenders. Not only does lack of commitment destroy gains from trade for the government, it also makes more patient citizens worse off than financial autarky, since the future costs of default exceed, from citizens' perspective, the immediate benefits of current consumption.

Along with these stark welfare results, the model generates realistic and tractable leverage dynamics: debt adjusts slowly towards a target multiple of income, exacerbating consumption booms and busts. With lognormal income, we prove our equilibrium is unique and provide a complete analytical characterization of equilibrium valuations, the speed of adjustment, credit spreads, default rates, and related comparative statics - results that have previously only been obtained numerically in the sovereign default literature. Moreover, our general methodology will hold, and remain tractable, in many other settings (some of which are explored in our appendix).

We also use our model to study alternative commitment devices and evaluate their potential to restore welfare. While unpredictable "sudden stops" to trade provide no commitment benefit, we show that predictable delays in trade can serve as commitment, but have a limited ability to restore welfare since the gains from commitment are offset by a loss in flexibility. Similarly, a debt-ceiling policy can enhance welfare, but only if the ceiling is low enough that it binds immediately. Instead, a policy akin to a limit on public deficits consistently produces welfare gains, though the optimal policy for the government will be "too loose" from citizens' perspective.

Other approaches have been pursued in order to reintroduce gains from trade. Benzoni et al. (2020) for example introduce fixed bond issuance costs, while Malenko and Tsoy (2020) allow for non-Markov equilibria - they study "grim-trigger" strategies from creditors. In these non-Markov equilibrium models, the borrower is punished for past misbehavior by reversion to our smooth MPE.

Our work raises new questions for the sovereign debt literature. It implies that welfare gains from external financing can only arise from the imposition of binding constraints on future trade, or from other motives for trade such as risk sharing. Empirically, however, sovereign borrowers do not appear to be successful at actually "smoothing" consumption. That said, it remains to be seen how our results would change qualitatively with modest inelasticity of intertemporal substitution.

Gains from trade in our framework are systematically destroyed when a government issues sovereign debt, irrespective of the maturity of the debt contract, of its amortization profile, and even when such contract is state contingent. But as DeMarzo (2019) suggests in the context of corporate capital structure decisions, collateral can act as a powerful commitment device; it thus begs the question of the optimal security design for sovereign bonds when the issuing country is able to pledge assets to international creditors. This question has become all the more relevant since the use of collateralized financing transactions has increased in the recent past. ${ }^{37}$

\footnotetext{
${ }^{37}$ See January 2020 IMF report and September 2020 IMF report for example.
} 


\section{References}

Abramowitz, Milton, and Irene A Stegun. 1964. Handbook of mathematical functions: with formulas, graphs, and mathematical tables. Vol. 55, Courier Corporation.

Admati, Anat R, Peter M DeMarzo, Martin F Hellwig, and Paul Pfleiderer. 2013. "The leverage ratchet effect." The Journal of Finance.

Aguiar, Mark A, and Manuel Amador. 2018. "Self-fulfilling debt dilution: Maturity and multiplicity in debt models." National Bureau of Economic Research.

Aguiar, Mark, and Gita Gopinath. 2004. "Emerging market business cycles: The cycle is the trend." National Bureau of Economic Research.

Aguiar, Mark, and Gita Gopinath. 2006. "Defaultable debt, interest rates and the current account." Journal of international Economics, 69(1): 64-83.

Aguiar, Mark, and Manuel Amador. 2013. "Take the Short Route: How to repay and restructure sovereign debt with multiple maturities." National Bureau of Economic Research.

Aguiar, Mark, Manuel Amador, and Stelios Fourakis. 2020. "On the welfare losses from external sovereign borrowing." IMF Economic Review, 68(1): 163-194.

Aguiar, Mark, Manuel Amador, Hugo Hopenhayn, and Iván Werning. 2016a. "Take the short route: Equilibrium default and debt maturity." National Bureau of Economic Research.

Aguiar, Mark, Satyajit Chatterjee, Harold Cole, and Zachary Stangebye. 2016b. “Quantitative Models of Sovereign Debt Crises." National Bureau of Economic Research.

Arellano, Cristina. 2008. "Default risk and income fluctuations in emerging economies." The American Economic Review, 690-712.

Arellano, Cristina, and Ananth Ramanarayanan. 2012. "Default and the maturity structure in sovereign bonds." Journal of Political Economy, 120(2): 187-232.

Auclert, Adrien, and Matthew Rognlie. 2016. "Unique equilibrium in the Eaton-Gersovitz model of sovereign debt." Journal of Monetary Economics, 84: 134-146.

Baxley, John V, and Sarah E Brown. 1981. "Existence and uniqueness for two-point boundary value problems." Proceedings of the Royal Society of Edinburgh Section A: Mathematics, 88(3-4): 219-234.

Benzoni, Luca, Lorenzo Garlappi, Robert S Goldstein, and Chao Ying. 2020. “Optimal debt dynamics, issuance costs, and commitment." Issuance Costs, and Commitment (September 16, 2019).

Borri, Nicola, and Adrien Verdelhan. 2011. "Sovereign risk premia."

Bulow, Jeremy, and Kenneth Rogoff. 1988. "The buyback boondoggle." Brookings Papers on Economic Activity, 1988(2): 675-704.

Bulow, Jeremy, and Kenneth Rogoff. 1989. "Sovereign Debt repurchases: no cure for overhang." National Bureau of Economic Research.

Calvo, Guillermo A. 1983. "Staggered prices in a utility-maximizing framework." Journal of monetary Economics, 12(3): 383-398.

Chatterjee, Satyajit, and Burcu Eyigungor. 2012. "Maturity, indebtedness, and default risk." American Economic Review, 102(6): 2674-99. 
Coase, Ronald H. 1972. "Durability and monopoly." The Journal of Law E Economics, 15(1): 143-149.

Cole, Harold L, and Timothy J Kehoe. 1996. "A self-fulfilling model of Mexico's 1994-1995 debt crisis." Journal of international Economics, 41(3): 309-330.

Daley, Brendan, and Brett Green. 2020. "Bargaining and News." American Economic Review, 110(2): 42874.

Dangl, Thomas, and Josef Zechner. 2021. "Debt maturity and the dynamics of leverage." The Review of Financial Studies.

DeMarzo, Peter M. 2019. "Presidential address: Collateral and commitment." The Journal of Finance, 74(4): 1587-1619.

DeMarzo, Peter M., and Branko Urošević. 2006. “Ownership Dynamics and Asset Pricing with a Large Shareholder." Journal of Political Economy, 114(4): 774-815.

DeMarzo, Peter M, and Zhiguo He. 2020. "Leverage dynamics without commitment." The Journal of Finance.

Eaton, Jonathan, and Mark Gersovitz. 1981. "Debt with potential repudiation: Theoretical and empirical analysis." The Review of Economic Studies, 48(2): 289-309.

Edwards, Sebastian. 2004. "Thirty years of current account imbalances, current account reversals, and sudden stops." IMF staff papers, 51(1): 1-49.

Goldstein, Robert, Nengjiu Ju, and Hayne Leland. 2001. “An EBIT-Based Model of Dynamic Capital Structure*." The Journal of Business, 74(4): 483-512.

Gul, Faruk, Hugo Sonnenschein, and Robert Wilson. 1986. "Foundations of dynamic monopoly and the Coase conjecture." Journal of Economic Theory, 39(1): 155-190.

Harrison, J Michael, and David M Kreps. 1978. "Speculative investor behavior in a stock market with heterogeneous expectations." The Quarterly Journal of Economics, 92(2): 323-336.

Harrison, J. Michael, and Lawrence A. Shepp. 1981. "On Skew Brownian Motion." Annals of Probability, 9(2): 309-313.

Hatchondo, Juan Carlos, and Leonardo Martinez. 2009. "Long-duration bonds and sovereign defaults." Journal of International Economics, 79(1): 117-125.

Hatchondo, Juan Carlos, Leonardo Martinez, and Cesar Sosa-Padilla. 2016. "Debt dilution and sovereign default risk." Journal of Political Economy, 124(5): 1383-1422.

Hatchondo, Juan Carlos, Leonardo Martinez, and Horacio Sapriza. 2010. "Quantitative properties of sovereign default models: solution methods matter." Review of Economic dynamics, 13(4): 919-933.

He, Zhiguo, and Konstantin Milbradt. 2016. "Dynamic debt maturity." The Review of Financial Studies, 29(10): 2677-2736.

He, Zhiguo, and Wei Xiong. 2012. "Rollover Risk and Credit Risk." The Journal of Finance, 67(2): 391-429.

Hu, Yunzhi, and Felipe Varas. 2021. "Intermediary Financing without Commitment." Working paper, Duke University.

Kahn, Charles. 1986. "The durable goods monopolist and consistency with increasing costs." Econometrica: Journal of the Econometric Society, 275-294. 
Leland, Hayne E. 1994. "Corporate debt value, bond covenants, and optimal capital structure." The journal of finance, 49(4): 1213-1252.

Luca, Benzoni, Lorenzo Garlappi, Robert S. Goldstein, Julien Hugonnier, and Chao Ying. 2020. "Optimal debt dynamics, issuance costs, and commitment." Working paper, University of Minnesota.

Malenko, Andrey, and Anton Tsoy. 2020. "Optimal Time-Consistent Debt Policies." Available at SSRN 3588163.

Maskin, Eric, and Jean Tirole. 2001. "Markov perfect equilibrium: I. Observable actions." Journal of Economic Theory, 100(2): 191-219.

Mendoza, Enrique G. 2010. "Sudden stops, financial crises, and leverage." The American Economic Review, 100(5): 1941-1966.

Neumeyer, Pablo A, and Fabrizio Perri. 2005. "Business cycles in emerging economies: the role of interest rates." Journal of monetary Economics, 52(2): 345-380.

Protter, Philip E. 2005. Stochastic Differential Equations. Springer.

Rebelo, Sergio, Neng Wang, and Jinqiang Yang. 2021. "Rare Disasters, Financial Development, and Sovereign Debt." Working paper, Northwestern University.

Reis, Ricardo. 2006. "Inattentive consumers." Journal of monetary Economics, 53(8): 1761-1800.

Stokey, Nancy L. 1981. "Rational expectations and durable goods pricing." The Bell Journal of Economics, 112-128.

Tourre, Fabrice. 2017. "A macro-finance approach to sovereign debt spreads and returns." manuscript, University of Chicago. 


\section{Appendix to Sovereign Debt Ratchets and Welfare Destruction}

Peter DeMarzo, Zhiguo He and Fabrice Tourre 


\section{A.1 Risk Premia}

Remember that $D\left(Y_{t}, F_{t}, s_{t}\right)$ is the price per unit of face value at time $t$. Investors' discounted cumulative gain can be expressed as follows:

$$
\int_{0}^{t} e^{-\int_{0}^{u}\left(r\left(s_{v}\right)+m\right) d v}(\kappa+m) d t+e^{-\int_{0}^{t}\left(r\left(s_{u}\right)+m\right) d u} D\left(Y_{t}, F_{t}, s_{t}\right)
$$

Since the discounted cumulative gain must be a $\mathbb{Q}$-martingale, we must have:

$$
(r+m) D=\kappa+m+\left(\boldsymbol{\mu}_{X}-\boldsymbol{\sigma}_{X} \boldsymbol{v}\right) \cdot \partial_{X} D+\frac{1}{2} \operatorname{tr}\left(\boldsymbol{\sigma}_{X}^{\prime} \partial_{X X^{\prime}} D \sigma_{X}\right)+(G(Y, F, s)-m F) \partial_{F} D
$$

The excess return on holding sovereign bonds between $t$ and $t+d t$ must reflect price changes $d D_{t}$, coupon and principal payments $(\kappa+m) d t$, as well as reinvestment costs $m D_{t} d t$. In other words, those excess returns can be computed as follows:

$$
d R_{t}-r_{t} d t=\frac{d D_{t}+(\kappa+m) d t-m D_{t} d t}{D_{t}}-r_{t} d t
$$

We use Itô formula to compute $d D_{t}$ as follows:

$$
d D_{t}=\left[\boldsymbol{\mu}_{X, t} \cdot \partial_{X} D_{t}+\frac{1}{2} \operatorname{tr}\left(\sigma_{X, t}^{\prime} \partial_{X X^{\prime}} D_{t} \sigma_{X, t}\right)+\left(G_{t}-m F_{t}\right) \partial_{F} D_{t}\right] d t+\left(\sigma_{X, t}^{\prime} \partial_{X} D_{t}\right) \cdot d B_{t}
$$

Reinjecting equation (A1) into our equation for excess returns, and using our martingale condition for $D$, we obtain the following formula for excess returns:

$$
d R_{t}-r_{t} d t=\left(\sigma_{X, t}^{\prime} \partial_{X} \ln D_{t}\right) \cdot v_{t} d t+\left(\sigma_{X, t}^{\prime} \partial_{X} \ln D_{t}\right) \cdot d B_{t}
$$

The second term has zero conditional expectations (under $\mathbb{P}$ ), which leads to the following formula for expected excess returns:

$$
\begin{aligned}
\mathbb{E}\left[d R_{t}-r_{t} d t \mid \mathcal{F}_{t}\right] & =\pi\left(Y_{t}, F_{t}, s_{t}\right) d t \\
\pi(Y, F, s): & =v^{\prime} \sigma_{X}^{\prime} \partial_{X} \ln D
\end{aligned}
$$

\section{A.2 Citizens vs. Government}

Assume that the citizens of the small open economy have linear preferences with discount rate $\hat{\delta}<\delta$, where $\delta$ is the effective discount rate of the government.

\section{A.2.1 General Case - Full Loss Upon Default}

Assume for simplicity that upon default, the small open economy's income is zero forever after, and that creditors lose their entire investment. Let $C(Y, F, s)$ be the resulting country's consumption in state $(Y, F, s)$ resulting from the government optimization outcome. Let $V$ (resp. $\hat{V}$ ) be the indirect utility function of the government (resp. its citizens), and let $\hat{V}_{0}$ be the indirect utility function of citizens of a country that no longer trades in financial markets, and which defaults according to the government 
default stopping rule $\tau$. We then have:

$$
\begin{aligned}
& V(Y, F, S):=\mathbb{E}^{Y, F, S}\left[\int_{0}^{\tau} e^{-\delta t} C\left(Y_{t}, F_{t}, s_{t}\right) d t\right] \\
& \hat{V}(Y, F, S):=\mathbb{E}^{Y, F, S}\left[\int_{0}^{\tau} e^{-\hat{\delta} t} C\left(Y_{t}, F_{t}, s_{t}\right) d t\right] \\
& \hat{V}_{0}(Y, F, S):=\mathbb{E}^{Y, F, S}\left[\int_{0}^{\tau} e^{-\hat{\delta} t}\left(Y_{t}-(\kappa+m) F e^{-m t}\right) d t\right]
\end{aligned}
$$

The equation defining $\hat{V}_{0}$ reflects the fact when the country refrains from future trading in international credit markets, the existing stock of sovereign debt amortizes at rate $m$. In all these indirect utility functions, the stopping time $\tau$ is the same, and is pinned down by the government's optimal behavior.

Our proof strategy will rely on the following key insight: while the government equalizes the marginal benefit of debt issuance $D$ with the marginal cost $-\partial_{F} V$, the citizens of the small open economy, who are more patient than the government, are worse off: the marginal cost $-\partial_{F} \hat{V}$ ends up greater than the marginal benefit $D$. We will then show that the indirect utility differential $\hat{V}-\hat{V}_{0}$ is the expected net present value (at rate $\hat{\delta}$ ) of the product of (a) the utility losses $D+\partial_{F} \hat{V}$, times (b) the issuance rate $G$. Since the issuance rate is positive and the utility losses are negative, this will allow us to conclude that the indirect utility differential $\hat{V}-\hat{V}_{0}$ is always negative.

Remember that the equilibrium consumption is $C(Y, F, s)=Y+G(Y, F, s) D(Y, F, s)-(\kappa+m) F$. The value function for the government satisfies:

$$
\begin{aligned}
\delta V & =C+\mu_{X} \cdot \partial_{X} V+\frac{1}{2} \operatorname{tr}\left(\sigma_{X}^{\prime} \partial_{X X^{\prime}} V \sigma_{X}\right)+(G-m F) \partial_{F} V \\
& =Y-(\kappa+m) F+\mu_{X} \cdot \partial_{X} V+\frac{1}{2} \operatorname{tr}\left(\sigma_{X}^{\prime} \partial_{X X^{\prime}} V \sigma_{X}\right)-m F \partial_{F} V
\end{aligned}
$$

Since $\partial_{F} V+D=0$, this also means that the debt price satisfies:

$$
(\delta+m) D=(\kappa+m)+\boldsymbol{\mu}_{X} \cdot \partial_{X} D+\frac{1}{2} \operatorname{tr}\left(\sigma_{X}^{\prime} \partial_{X X^{\prime}} D \sigma_{X}\right)-m F \partial_{F} D
$$

As a reminder, the (optimal) issuance policy is defined via:

$$
G(Y, F, s)=\frac{\delta-(r(s)+\pi(Y, F, s))}{-\partial_{F} \ln D(Y, F, s)}
$$

The indirect utility function $\hat{V}$ for citizens (who use a discount rate $\hat{\delta}<\delta$ ) satisfies:

$$
\hat{\delta} \hat{V}=C+\mu_{X} \cdot \partial_{X} \hat{V}+\frac{1}{2} \operatorname{tr}\left(\sigma_{X}^{\prime} \partial_{X X^{\prime}} \hat{V} \sigma_{X}\right)+(G-m F) \partial_{F} \hat{V}
$$

First, by subtracting equation (A2) from equation (A5), and by using the boundary condition $\hat{V}(Y, F, s)=$ $V(Y, F, s)=0$ it is immediate to obtain

$$
(\hat{V}-V)(Y, F, S)=\mathbb{E}^{Y, F, S}\left[\int_{0}^{\tau} e^{-\hat{\delta} t}(\delta-\hat{\delta}) V\left(Y_{t}, F_{t}, s_{t}\right) d t\right] \geq 0
$$

This latter inequality comes from the fact that we must have $V(Y, F, s) \geq 0$, since one feasible strategy for the government is to default immediately and obtain 0 . Thus we have proven that $\hat{V}>V$ in the interior of the continuation region (with equality on the default boundary).

Differentiate equation (A5) w.r.t. $F$ to yield: 


$$
\begin{aligned}
(\hat{\delta}+m) \partial_{F} \hat{V}=-(\kappa+m)+\left(D+\partial_{F} \hat{V}\right) \partial_{F} G+G \partial_{F}(D+ & \left.\partial_{F} \hat{V}\right)+\mu_{X} \cdot \partial_{X}\left(\partial_{F} \hat{V}\right) \\
& +\frac{1}{2} \operatorname{tr}\left(\sigma_{X}^{\prime} \partial_{X X^{\prime}}\left(\partial_{F} \hat{V}\right) \sigma_{X}\right)-m F \partial_{F}\left(\partial_{F} \hat{V}\right)
\end{aligned}
$$

Add up equation (A4) to equation (A6), note $H:=D+\partial_{F} \hat{V}$, and notice that:

$$
\left(\hat{\delta}+m-\partial_{F} G\right) H=(\hat{\delta}-\delta) D+\mu_{X} \cdot \partial_{X} H+\frac{1}{2} \operatorname{tr}\left(\sigma_{X}^{\prime} \partial_{X X^{\prime}} H \sigma_{X}\right)+(G-m F) \partial_{F} H
$$

Note that at the default boundary $(Y, F) \in \partial \mathcal{O}(s)$, given the assumed punishment upon default, by continuity we must have

$$
\hat{V}(Y, F, s)=0 \quad D(Y, F, s)=0
$$

Since we have showed that $\hat{V}(Y, F, s) \geq V(Y, F, s) \geq 0$ in the continuation region, it means that at the default boundary $(Y, F) \in \partial \mathcal{O}(s)$, we must have $\partial_{F} \hat{V} \leq 0$. In other words, for $(Y, F) \in \partial \mathcal{O}(s)$, we have

$$
H(Y, F, s) \leq 0
$$

Taken together, equations (A7) and (A8) means that that $H=\partial_{F} \hat{V}+D$ admits an integral representation:

$$
H(Y, F, s)=\mathbb{E}\left[\int_{0}^{\tau} e^{-\int_{0}^{t}\left(\hat{\delta}+m-\partial_{F} G_{u}\right) d u}(\hat{\delta}-\delta) D_{t} d t+e^{-\int_{0}^{\tau}\left(\hat{\delta}+m-\partial_{F} G_{u}\right) d u} H\left(Y_{\tau}, F_{\tau}, s_{\tau}\right)\right]
$$

In the above, we have used the "short" notation $D_{t}=D\left(Y_{t}, F_{t}, s_{t}\right)$ and $G_{t}=G\left(Y_{t}, F_{t}, s_{t}\right)$. Since $\hat{\delta}<\delta$, since the debt price $D$ is strictly positive on the interior of the continuation region, and since $H\left(Y_{\tau}, F_{\tau}, s_{\tau}\right) \leq 0$ at the default boundary, we must have $H(Y, F, s)<0$ for all $(Y, F, S)$ on the interior of the continuation region. Finally, we write down the PDEs statisfied by $\hat{V}$ and $\hat{V}_{0}$ :

$$
\begin{aligned}
& \hat{\delta} \hat{V}=Y-(\kappa+m) F+G H+\mu_{X} \cdot \partial_{X} \hat{V}+\frac{1}{2} \operatorname{tr}\left(\sigma_{X}^{\prime} \partial_{X X^{\prime}} \hat{V} \sigma_{X}\right)-m F \partial_{F} \hat{V} \\
& \hat{\delta} \hat{V}_{0}=Y-(\kappa+m) F+\mu_{X} \cdot \partial_{X} \hat{V}_{0}+\frac{1}{2} \operatorname{tr}\left(\sigma_{X}^{\prime} \partial_{X X^{\prime}} \hat{V}_{0} \sigma_{X}\right)-m F \partial_{F} \hat{V}_{0}
\end{aligned}
$$

Note $\Delta \hat{V}:=\hat{V}-\hat{V}_{0}$, which then satisfies the following PDE:

$$
\hat{\delta} \Delta \hat{V}=G H+\mu_{X} \cdot \partial_{X} \Delta \hat{V}+\frac{1}{2} \operatorname{tr}\left(\sigma_{X}^{\prime} \partial_{X X^{\prime}} \Delta \hat{V} \sigma_{X}\right)-m F \partial_{F} \Delta \hat{V}
$$

At the default boundary $(Y, F) \in \partial \mathcal{O}(s)$ (which, as you might recall, is optimal only from the point of view of the government, discounting cashflows at rate $\delta$ ), we have

$$
\hat{V}(Y, F, s)=0 \quad \hat{V}_{0}(Y, F, s)=0
$$

In other words, for $(Y, F) \in \partial \mathcal{O}(s), \hat{\Delta} V(Y, F, s)=0$. This means that $\hat{\Delta} V(Y, F, s)$ admits the following integral representation:

$$
\Delta \hat{V}(Y, F, s)=\mathbb{E}^{Y, F, S}\left[\int_{0}^{\tau} e^{-\hat{\delta} t} G_{t} H_{t} d t\right]
$$

Since we have focused on an equilibrium where $G_{t} \geq 0$ almost surely, and since we have also proved that $H_{t} \leq 0$ almost surely, it must be the case that $\hat{V}(Y, F, s)<\hat{V}_{0}(Y, F, s)$ for all $(Y, F, s)$ in the interior of the continuation region. 


\section{A.2.2 Geometric Brownian Motion Income and Reinjections}

We now tackle the case where income at default drops from $Y_{\tau-}$ to $Y_{\tau}=\alpha Y_{\tau-}$, and where the debt suffers a haircut $1-\alpha \theta$. When income follows geometric Brownian motion dynamics, we provide a complete analytical characterization of the value function, debt prices and default boundary in Section 5.1.1. In particular, we show that our Smooth MPE exists for any $\delta>r$, and that the default boundary $\bar{x}_{\delta}$ is a decreasing function of $\delta$ (see Corollary 2). We introduce the following notation:

$$
\begin{aligned}
V_{\delta}(Y, F): & =\sup _{\tau} \mathbb{E}^{Y, F}\left[\int_{0}^{+\infty} e^{-\delta t}\left(\alpha^{N_{t}^{(\tau)}} Y_{t}-(\alpha \theta)^{N_{t}^{(\tau)}} e^{-m t}(\kappa+m) F\right) d t\right] \\
& =\mathbb{E}^{Y}\left[\int_{0}^{+\infty} e^{-\delta t} \alpha^{N_{\delta, t}^{*}} Y_{t} d t\right]-F \mathbb{E}\left[\int_{0}^{+\infty}(\alpha \theta)^{N_{\delta, t}^{*}} e^{-(m+\delta) t}(\kappa+m) d t\right]
\end{aligned}
$$

In other words, $V_{\delta}(Y, F)$ is the no-trade value function, using discount rate $\delta$, when the borrower has an option to default at any point time. $N_{\delta, t}^{*}$ is the counting process associated with the sequence $\tau_{\delta}^{*}$ of optimal default times that solves the optimal stopping problem above.

Since a Smooth MPE exists for the discount rate $\delta$, the value function $V_{\delta}$ satisfies the following:

$$
\begin{aligned}
V_{\delta}(Y, F) & =\sup _{\tau} \mathbb{E}^{Y, F}\left[\int_{0}^{+\infty} e^{-\delta t}\left(\alpha^{N_{t}^{(\tau)}} Y_{t}-(\alpha \theta)^{N_{t}^{(\tau)}} e^{-m t}(\kappa+m) F\right) d t\right] \\
& =\sup _{\tau, G} \mathbb{E}^{Y, F}\left[\int_{0}^{+\infty} e^{-\delta t}\left(Y_{t}^{(\boldsymbol{\tau})}+G_{t} D_{\delta}\left(Y_{t}^{(\boldsymbol{\tau})}, F_{t}^{(\boldsymbol{\tau}, G)}\right)-(\kappa+m) F_{t}^{(\tau, G)}\right) d t\right] \\
& =\mathbb{E}^{Y, F}\left[\int_{0}^{+\infty} e^{-\delta t}\left(Y_{t}^{\left(\boldsymbol{\tau}_{\delta}^{*}\right)}+G_{\delta}^{*}\left(Y_{t}^{\left(\boldsymbol{\tau}_{\delta}^{*}\right)}, F_{t}^{\left(\tau_{\delta}^{*}, G_{\delta}^{*}\right)}\right) D_{\delta}\left(Y_{t}^{\left(\boldsymbol{\tau}_{\delta}^{*}\right)}, F_{t}^{\left(\boldsymbol{\tau}_{\delta}^{*}, G_{\delta}^{*}\right)}\right)-(\kappa+m) F_{t}^{\left(\boldsymbol{\tau}_{\delta}^{*}, G_{\delta}^{*}\right)}\right) d t\right]
\end{aligned}
$$

In the above, the Smooth MPE debt price $D_{\delta}$ and the optimal issuance rate $G_{\delta}^{*}$ satisfies

$$
\begin{aligned}
& D_{\delta}(Y, F)=\mathbb{E}^{Y, F}\left[\int_{0}^{+\infty} e^{-(\delta+m) t}(\alpha \theta)^{\left.N_{\delta, t}^{*}(\kappa+m) d t\right]}\right. \\
& G_{\delta}^{*}(Y, F)=(\delta-r) \frac{D_{\delta}(Y, F)}{-\partial_{F} D_{\delta}(Y, F)}
\end{aligned}
$$

Note $C_{\delta}^{*}(Y, F)$ the equilibrium consumption policy when the borrower discounts at rate $\delta$ :

$$
C_{\delta}^{*}(Y, F):=Y+G_{\delta}^{*}(Y, F) D_{\delta}(Y, F)-(\kappa+m) F
$$

Take $\hat{\delta}<\delta$. Since $\bar{x}_{\delta}$ is decreasing in $\delta$, it is straightforward to notice that $D_{\delta}$ is a decreasing function of $\delta$. We can then write

$$
\begin{aligned}
V_{\hat{\delta}}(Y, F) & =\sup _{\tau, G} \mathbb{E}^{Y, F}\left[\int_{0}^{+\infty} e^{-\hat{\delta} t}\left(Y_{t}^{(\boldsymbol{\tau})}+G_{t} D_{\hat{\delta}}\left(Y_{t}^{(\boldsymbol{\tau})}, F_{t}^{(\tau, G)}\right)-(\kappa+m) F_{t}^{(\boldsymbol{\tau}, G)}\right) d t\right] \\
& \geq \mathbb{E}^{Y, F}\left[\int_{0}^{+\infty} e^{-\hat{\delta} t}\left(Y_{t}^{\left(\boldsymbol{\tau}_{\delta}^{*}\right)}+G_{\delta}^{*}\left(Y_{t}^{\left(\boldsymbol{\tau}_{\delta}^{*}\right)}, F_{t}^{\left(\boldsymbol{\tau}_{\delta}^{*}, G_{\delta}^{*}\right)}\right) D_{\hat{\delta}}\left(Y_{t}^{\left(\boldsymbol{\tau}_{\delta}^{*}\right)}, F_{t}^{\left(\boldsymbol{\tau}_{\delta}^{*}, G_{\delta}^{*}\right)}\right)-(\kappa+m) F_{t}^{\left(\boldsymbol{\tau}_{\delta}^{*}, G_{\delta}^{*}\right)}\right) d t\right] \\
& \geq \mathbb{E}^{Y, F}\left[\int_{0}^{+\infty} e^{-\hat{\delta} t}\left(Y_{t}^{\left(\boldsymbol{\tau}_{\delta}^{*}\right)}+G_{\delta}^{*}\left(Y_{t}^{\left(\boldsymbol{\tau}_{\delta}^{*}\right)}, F_{t}^{\left(\boldsymbol{\tau}_{\delta}^{*}, G_{\delta}^{*}\right)}\right) D_{\delta}\left(Y_{t}^{\left(\boldsymbol{\tau}_{\delta}^{*}\right)}, F_{t}^{\left(\boldsymbol{\tau}_{\delta}^{*}, G_{\delta}^{*}\right)}\right)-(\kappa+m) F_{t}^{\left(\boldsymbol{\tau}_{\delta}^{*}, G_{\delta}^{*}\right)}\right) d t\right] \\
& \geq \mathbb{E}^{Y, F}\left[\int_{0}^{+\infty} e^{-\hat{\delta} t} C_{\delta}^{*}\left(Y_{t}^{\left(\boldsymbol{\tau}_{\delta}^{*}\right)}, F_{t}^{\left(\boldsymbol{\tau}_{\delta}^{*}, G_{\delta}^{*}\right)}\right) d t\right]
\end{aligned}
$$

The first inequality is due to the fact that the financing policy $G_{\delta}^{*}$ and the default policy $\tau_{\delta}^{*}$ are feasible but not necessarily optimal for a borrower discounting at rate $\hat{\delta}$. The second inequality is due to the fact that the equilibrium bond price $D_{\hat{\delta}}$ is greater than the equilibrium bond price $D_{\delta}$. Thus, we have proven that 
the no-trade value $V_{\hat{\delta}}$ is greater than the indirect utility function $\mathbb{E}^{Y, F}\left[\int_{0}^{+\infty} e^{-\hat{\delta} t} C_{\delta}^{*}\left(Y_{t}^{\left(\tau_{\delta}^{*}\right)}, F_{t}^{\left(\tau_{\delta}^{*}, G_{\delta}^{*}\right)}\right) d t\right]$, which represents the welfare for citizens (discount at rate $\hat{\delta}$ ) of a country whose government discounts at rate $\delta>\hat{\delta}$.

\section{A.3 Transaction Costs and Non-Pecuniary Benefits}

As discussed in the main text, our results can be extended to the case where the government incurs transaction costs upon the issuance of bonds, or when the government enjoys non-pecuniary benefits. For simplicity, we only cover the case with transaction costs - since the modeling approach is identical to the case with non-pecuniary benefits.

To simplify further the exposition, assume that the exogenous SDF state $s_{t}$ is trivially equal to 1 , and that creditors and the government discount cashflows under the same probability measure (i.e. $v(s)=0$ always). Consider an environment where the government incurs, when issuing bonds, (i) a proportional $\operatorname{cost} \eta \in(0,1)$ on total proceeds raised from issuances, and (ii) a proportional cost $b>0$ on the notional amount of bonds issued. In the case where the government enjoys non-pecuniary benefits over debt issuances, we would instead assume $\eta<0$ and $b<0$.

In an environment without transaction costs, assume that the Smooth MPE exists and assume that the no-trade value function $V_{0}(\cdot, \cdot)$ satisfies, for any $(Y, F)$ on the default boundary $\partial \mathcal{O}$ :

$$
-\partial_{F} V_{0}(Y, F) \geq \frac{1}{\delta-r}\left[\frac{\eta(\kappa+m)}{1-\eta}+\frac{(\delta+m) b}{1-\eta}\right]
$$

Then a Smooth MPE with transaction costs exists. In such equilibrium, the government welfare is equal to its no-trade value $V_{0}$. The default policy of the government is identical in both economic environments. The debt price $D_{t c}$ and optimal bond issuance policy $G_{t c}$ satisfy:

$$
\begin{aligned}
& D_{t c}(Y, F)=\frac{b-\partial_{F} V_{0}(Y, F)}{1-\eta} \\
& G_{t c}^{*}(Y, F)=\frac{(\delta-r) D_{t c}(Y, F)-\frac{\eta}{1-\eta}(\kappa+m)-\frac{(\delta+m) b}{1-\eta}}{-\partial_{F} D_{t c}(Y, F)}
\end{aligned}
$$

Thus, issuance costs decrease the pace of bond issuances, and increase the pricing of debt. To prove the claims above, note that with a smooth issuance strategy and in the presence of proportional transaction costs, the per-period consumption enjoyed by the government is equal to:

$$
C_{t}=Y_{t}-(\kappa+m) F_{t}+(1-\eta) G_{t} D_{t}-b G_{t}
$$

This equation is valid if $G_{t} \geq 0$. The proof of our assertion is a straightforward extension of the argument presented in Section 4.6. Condition (A14) should be viewed as a simple parameter restriction, since it refers to the marginal value of debt $\partial_{F} V_{0}$ in the Smooth MPE without transaction costs, which we know can be computed assuming that the government never trades again in international credit markets. This restriction guarantees that the issuance rate stays weakly positive, even at the default boundary, and thus that the optimality condition $(1-\eta) D_{t c}-b+\partial_{F} V_{t c}=0$ is always satisfied.

\section{A.4 Comparison to Aguiar and Amador (2018)}

The model of Aguiar and Amador (2018) is similar to the general model we present in Section 4, with the following notable differences. First, the government receives a constant flow income $Y$ (per unit of 
time). Second, the government has an outside option to default $\underline{V}$ always available to it. At Poisson times (arrival intensity $\lambda$ ), the government receives a better outside option, with value $\bar{V}>\underline{V}$ (which can be exercised only at the exact time such option is received). For simplicity, we set the coupon rate on the bonds issued to $\kappa=r$. Aguiar and Amador (2018) show that there are parameter configurations under which two MPEs exist.

\section{A.4.1 The Borrowing Equilibrium in Aguiar and Amador (2018)}

In one MPE (called the "borrowing" equilibrium), the government immediately issues a lump amount of debt so as to set its debt balance at $\bar{F}_{b}$, which only depends on model parameters. The government then consumes an amount sufficient to roll-over its debt, stays put at $F=\bar{F}_{b}$, and waits for the outside option $\bar{V}$ to arrive. As soon as $\bar{V}$ is available, the government defaults. The (endogenous) debt level $\bar{F}_{b}$ is the debt level at which the government is indifferent between (a) rolling over its debt and defaulting the first time $\bar{V}$ becomes available, and (b) defaulting immediately in order to receive the outside option $\underline{V}$. In that equilibrium, the debt price is (i) constant and equal to its credit-risky value $\bar{D}$ on $F \leq \bar{F}_{b}$, and (ii) equal to zero for $F>\bar{F}_{b}$. In other words, the (endogenous) debt level $\bar{F}_{b}$ and the credit-risky value $\bar{D}$ are

$$
\bar{F}_{b}=\frac{1}{\bar{D}}\left(\frac{Y+\lambda \bar{V}-(\delta+\lambda) \underline{V}}{r+\lambda}\right) \quad \bar{D}=\frac{\kappa+m}{r+\lambda+m}
$$

The value function is simply linear on $F \in\left[0, \bar{F}_{b}\right]$, with slope $-\bar{D}$. The value function is then equal to $\underline{V}$ for $F \geq \bar{F}_{b}$. Consumption in this model only happens in a lumpy fashion, except when the government is staying put (at $F=\bar{F}_{b}$ ), in which case consumption is smooth (and constant), at rate

$$
C\left(\bar{F}_{b}\right)=Y-(r+m) \bar{F}_{b}+m \bar{F}_{b} D
$$

To summarize, in such equilibrium, we have

$$
\begin{aligned}
& V(F)= \begin{cases}\underline{V}+\left(\bar{F}_{b}-F\right) \bar{D} & \text { if } F \in\left[0, \bar{F}_{b}\right] \\
\underline{V} & \text { if } F>\bar{F}_{b}\end{cases} \\
& D(F)= \begin{cases}\bar{F} & \text { if } F \in\left[0, \bar{F}_{b}\right] \\
0 & \text { if } F>\bar{F}_{b}\end{cases}
\end{aligned}
$$

Finally, for this equilibrium to exist, it must be the case that at the (implicitly defined) debt level $\underline{F}_{b}$ at which $V\left(\underline{F}_{b}\right)=\bar{V}$, it is optimal for the government to jump to the debt level $\bar{F}_{b}$ (as opposed to staying put at $\left.F=\underline{F}_{b}\right)$, in other words parameters must satisfy

$$
\frac{Y-(r+m(1-\bar{D})) \underline{F_{b}}}{\delta}<\bar{V}
$$

\section{A.4.2 The Savings Equilibrium in Aguiar and Amador (2018)}

In their second MPE (called the "borrowing" equilibrium), when the debt level $F$ is high enough (more specifically when $F>\hat{F}_{S}$, where $\hat{F}_{S}$ is an endogenous value), the government issues a lump amount of debt so as to set its debt balance at $\bar{F}_{s}=\bar{F}_{b}$. At that point, the economics of the model are identical to those in the "borrowing" equilibrium - in other words, the government is exactly indifferent between staying "put" at $\bar{F}_{S}$ and waiting for the good outside option $\bar{V}$, or defaulting immediately to obtain $\underline{V}$.

When the debt level satisfies $F<\underline{F}_{S}$ (where $\underline{F}_{S}<\hat{F}_{S}$ is an endogenously determined threshold value), the government issues a lump amount of (risk-free) debt and jumps to $F=\underline{F}_{S}$, where the government rolls over its debt and stays put, indifferent between defaulting when the good outside option $\bar{V}$ comes, and continuing to service its risk-free debt (in which case we break the tie by assuming that the govern- 
ment continues to pay, when indifferent). In other words, $\underline{F}_{S}$ satisfies

$$
\underline{F}_{s}=\frac{Y-\delta \bar{V}}{r}
$$

Finally, when the debt level satisfies $F \in\left(\underline{F}_{s}, \hat{F}_{s}\right)$, the government uses an absolutely continuous debt financing strategy. In other words, the value function satisfies an HJB equation similar to the one we solve in our paper:

$$
(\delta+\lambda) V(F)=Y-(r+m) F-m F \partial_{F} V+\lambda \bar{V}
$$

This is a first order differential equation, that can be solved with the boundary condition $V\left(\underline{F}_{s}\right)=\bar{V}$. Of course on that interval, the bond price satisfies $\partial_{F} V+D=0$. To summarize, in such equilibrium, we have

$$
\begin{aligned}
& V(F)= \begin{cases}\bar{V}+\left(\underline{F}_{s}-F\right) & \text { if } F \in\left[0, \underline{F}_{s}\right] \\
\frac{\gamma+\lambda \bar{V}}{\delta+\lambda}-\left(\frac{r+m}{\delta+m+\lambda}\right) F+\frac{m(\delta+\lambda-r) \underline{F}_{s}}{(\delta+\lambda)(\delta+\lambda+m)}\left(\frac{F}{\underline{F}_{s}}\right)^{-(\delta+\lambda) / m} & \text { if } F \in\left[\underline{F}_{s}, \hat{F}_{s}\right] \\
\underline{V}+\left(\bar{F}_{S}-F\right) \bar{D} & \text { if } F \in\left[\hat{F}_{s}, \bar{F}_{s}\right] \\
\underline{V} & \text { if } F>\bar{F}_{S}\end{cases} \\
& D(F)= \begin{cases}1 & \text { if } F \in\left[0, \underline{F}_{s}\right] \\
\frac{r+m}{\delta+m+\lambda}+\frac{\delta+\lambda-r}{\delta+\lambda+m}\left(\frac{F}{\underline{F}_{s}}\right)^{-(\delta+\lambda) / m-1} & \text { if } F \in\left[\underline{F}_{s}, \hat{F}_{S}\right] \\
\bar{D} & \text { if } F \in\left[\hat{F}_{s}, \bar{F}_{S}\right] \\
0 & \text { if } F>\bar{F}_{S}\end{cases}
\end{aligned}
$$

Finally, the threshold $\hat{V}_{s}$ is such that the value function is continuous at that point, in other words $\hat{V}_{s}$ satisfies

$$
\underline{V}+\left(\bar{F}_{s}-\hat{F}_{s}\right) \bar{D}=\frac{Y+\lambda \bar{V}}{\delta+\lambda}-\left(\frac{r+m}{\delta+m+\lambda}\right) \hat{F}_{s}+\frac{m(\delta+\lambda-r) \underline{F}_{s}}{(\delta+\lambda)(\delta+\lambda+m)}\left(\frac{\hat{F}_{s}}{\underline{F}_{s}}\right)^{-(\delta+\lambda) / m}
$$

\section{A.4.3 The Perturbed Model of Aguiar and Amador (2018)}

In order to study our Smooth MPE in the context of the model of Aguiar and Amador (2018), we perturb the outside option process of their model as follows. Imagine that the default option is always equal to $\underline{V}$, but that at exponentially distributed arrival times, the government receives an option to default at a value $\tilde{V}$, a continuous random variable with unbounded support, expected value $\bar{V}$ and standard deviation $\sigma>0$. Let $G(\cdot)$ be the cumulative distribution function for $\tilde{V}$. The value function solves, in a Smooth MPE, the variational inequality

$$
0=\max \left[\underline{V}-V(F),-(\delta+\lambda) V(F)+Y-(r+m) F-m F \partial_{F} V(F)+\lambda \int \max (V(F), x) d G(x)\right]
$$

In particular, in the continuation region of our game, we must have

$$
\begin{aligned}
(\delta+\lambda(1-G(V(F)))) V(F) & =Y-(r+m) F-m F \partial_{F} V(F)+\lambda \int_{V(F)}^{+\infty} x d G(x) \\
(\delta+m+\lambda(1-G(V(F)))) D(F) & =r+m-m F \partial_{F} D(F)
\end{aligned}
$$

Those equations correspond to the HJB equations of a single-agent optimization problem. Since the outside option $\tilde{V}$ has unbounded support, it must be the case that the debt is always risky, and its price 
will reflect that. One can then introduce $\bar{F}:=\inf \{F \geq 0: V(F)=\underline{F}\}$, the (endogenous) default boundary of our Smooth MPE. Finally, the smooth issuance policy $G(F)$ in this model will satisfy

$$
G(F)=(\delta-r) \frac{D(F)}{-\partial_{F} D(F)}
$$

Figure A-1: Smooth MPE in Aguiar and Amador (2018) Model

(a): Debt Price $D(F)$ (b): Value Function $V(F)$

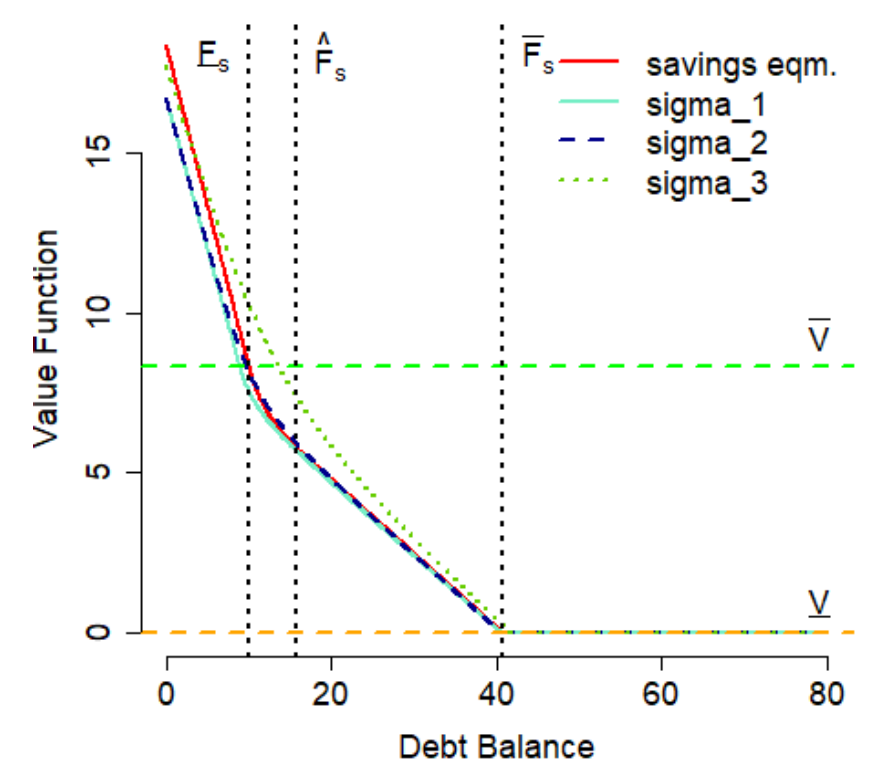

Figure (a) shows debt prices and figure (b) shows value functions. In both plots, the solid red line corresponds to the original "savings" equilibrium in Aguiar and Amador (2018), while the light blue, dark blue and green lines correspond to our Smooth MPE for different standard deviations $\sigma$ of the random variable $\tilde{V}$, which we assume to be double-exponentially distributed, with mean $\bar{V}$. In plot (b), we also show (in orange) the outside option $\underline{V}$ (which is always available) and the expected value $\bar{V}$ (in green) of the outside $\tilde{V}$ (which is only available at Poisson arrival times). The plot was computed assuming $Y=1$ p.a., $r=\kappa=5 \%$ p.a., $\delta=6 \%, 1 / m=10$ years, $\lambda=1 / 2, \underline{V}=0$ and $\bar{V}=0.5 Y / \delta$, so that default entails welfare losses. Our Smooth MPEs are computed for $\left(\sigma_{1}, \sigma_{2}, \sigma_{3}\right)=(0.1,2,5)$.

We compute numerically the value function, debt price and issuance policy, under the assumption that $G(\cdot)$ is a double-exponential distribution with mean $\bar{V}$ and standard deviation $\sigma$, for a range of values $\sigma_{1}<\sigma_{2}<\sigma_{3}$. Our objective is to understand whether our Smooth MPE, at the limit $\sigma \rightarrow 0$, converges to either the borrowing or savings equilibrium of Aguiar and Amador (2018).

Figure A-1 illustrates the debt price and value function in the original "savings" MPE of Aguiar and Amador (2018), as well as the Smooth MPE in our paper. As discussed in Section A.4.2, in the "savings" equilibrium, a low-debt government (for which $F<\underline{F}_{S}$ ) would jump immediately to the debt level $\underline{F}_{S}$, and roll-over its (risk-free) debt indefinitely. Thus, the price of debt up to that debt level is equal to 1. Note that instead, in our Smooth MPE, since we have assumed that the support of $\tilde{V}$ is unbounded from above, the debt is always risky, hence the price of such debt is always strictly below 1, irrespective of $\sigma$. At those debt levels, the value function is linear (for the "savings" equilibrium) and strictly convex (for our Smooth MPE) and decreasing, with slope equal to (minus) the debt price. For $F \in\left[\underline{F}_{s}, \hat{F}_{S}\right]$, in both (i) the "savings" equilibrium and (ii) our Smooth MPEs, the government uses an absolutely continuous face value process, the debt price is strictly decreasing and the value function is strictly convex. Finally, for $F>\hat{F}_{s}$, the government jumps directly to $\bar{F}_{s}$ in the "savings" equilibrium. Instead, in our Smooth $\mathrm{MPE}$, the government continues to use an absolutely continuous face value process up to the maximum 
Figure A-2: Smooth MPE in Aguiar and Amador (2018) Model

(a): Net Issuance Rate $G(F)-m F$

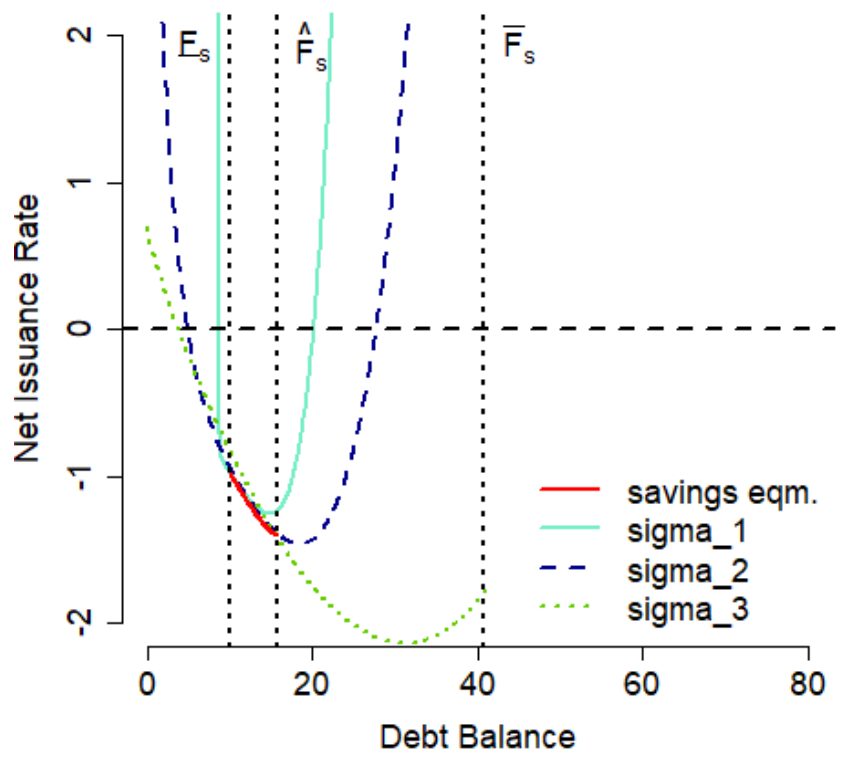

(b): Default Boundary $\bar{F}$

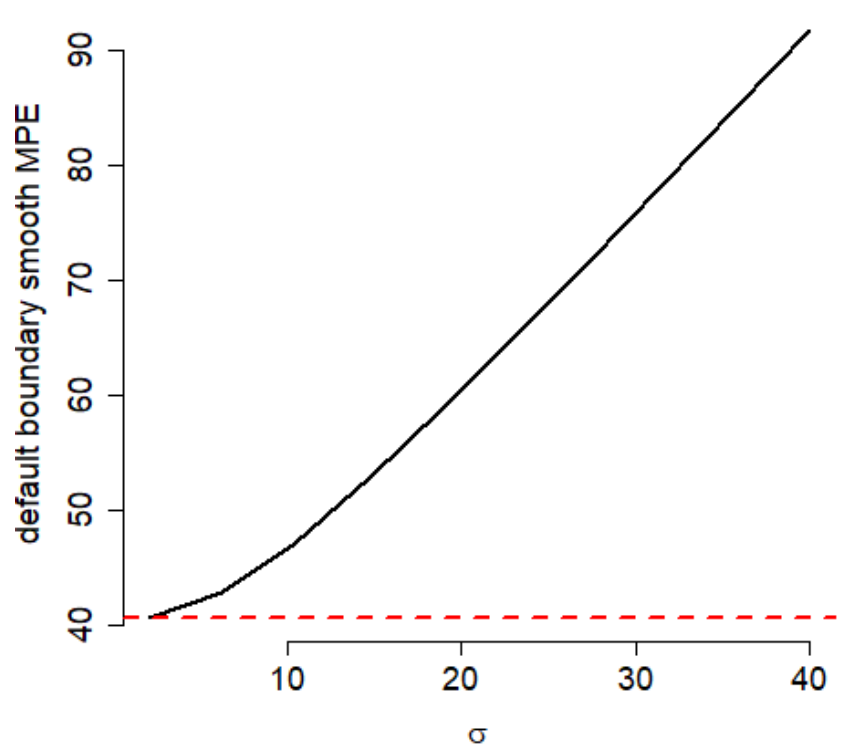

Figure (a) shows the net issuance rate $G(F)-m F$ for the original "savings" equilibrium in Aguiar and Amador (2018) (in red, whenever such rate is defined) and for our Smooth MPE (in light blue, dark blue and green lines for difference values $\sigma_{1}=0.1, \sigma_{2}=2, \sigma_{3}=5$. Figure (b) shows the default boundary $\bar{V}$ of our Smooth MPE (in black) for increasing standard deviations $\sigma$, as well as the default boundary in the "savings" equilibrium of Aguiar and Amador (2018) (in red). The plot was computed assuming $Y=1$ p.a., $r=\kappa=5 \%$ p.a., $\delta=6 \%, 1 / m=10$ years, $\lambda=1 / 2, \underline{V}=0$ and $\bar{V}=0.5 Y / \delta$, so that default entails welfare losses.

debt level $\bar{F}$, the (endogenous) default boundary of our Smooth MPE.

Figure A-2 illustrates the net debt issuance rate in the "savings" MPE of Aguiar and Amador (2018), as well as the Smooth MPE in our paper. Such rate is not defined in the "savings" MPE for $F<\underline{F}_{s}$ (resp. $F>\hat{F}_{s}$ ), since on this interval, the government optimally jumps to $\underline{F}_{s}$ (resp. $\bar{F}_{s}$ ). In our Smooth MPE, the debt dynamics on the interval $[0, \bar{F}]$ are more complex. The net issuance rates for $\sigma_{1}$ and $\sigma_{2}$ are U-shaped and intersect the horizontal axis (set at zero) twice. Thus, for $\sigma_{1}$ and $\sigma_{2}$, three cases arise:

(i) when the dynamic system is started on the left of the left-most intersection, debt increases with time, converges (in infinite time) to the left-most intersection point (and the government defaults if a sufficiently good outside option $\tilde{V}$ presents itself);

(ii) when the dynamic system is started in-between the left-most and right-most intersections, debt decreases with time, converges (in infinite time) to the left-most intersection point (and the government defaults if a sufficiently good outside option $\tilde{V}$ presents itself);

(iii) when the dynamic system is started on the right of the right-most intersection, debt increases with time, converges (in finite time) to the default boundary $\bar{F}$ (and the government defaults if a sufficiently good outside option $\tilde{V}$ presents itself).

For standard deviation $\sigma_{3}$, only cases (i) and (ii) apply. This discussion allows us to conclude that numerically, our Smooth MPE converges, as $\sigma \rightarrow 0$, to the "savings" MPE of Aguiar and Amador (2018). 


\section{A.5 Geometric Brownian Motion Income Process}

For a given admissible default policy $\tau \in \mathcal{T}$, define $N_{d, t}^{(\tau)}:=\max \left\{k \in \mathbb{N}: \tau_{k} \leq t\right\}$ to be the counting process for default events. Using this notation, the dynamic evolution of the controlled stochastic process $Y_{t}^{(\tau)}$ can be expressed as follows:

$$
Y_{t}^{(\tau)}=\alpha^{N_{d, t}^{(\tau)}} Y_{t}
$$

Similarly, the dynamic evolution of the controlled stochastic process $F^{(I, \tau)}$ can be expressed as follows:

$$
F_{t}^{(I, \tau)}=\int_{0}^{t}\left(G\left(Y_{u}^{(\tau)}, F_{u}^{(I, \tau)}, s_{u}\right)-m F_{u}^{(I, \tau)}\right) d u+\int_{0}^{t}(\theta \alpha-1) F_{u-}^{(I, \tau)} d N_{d, u}^{(\tau)}
$$

Armed with those notations, notice that $V$ can be written as follows:

$$
\begin{aligned}
V(Y, F) & =\sup _{(I, \boldsymbol{\tau}) \in \mathcal{I} \times \mathcal{T}} \mathbb{E}^{Y, F}\left[\int_{0}^{+\infty} e^{-\delta t}\left(Y_{t}^{(\boldsymbol{\tau})}+I\left(Y_{t}^{(\boldsymbol{\tau})}, F_{t}^{(I, \boldsymbol{\tau})}, s_{t}\right) D_{t}-(\kappa+m) F_{t}^{(I, \tau)}\right) d t\right] \\
& =Y \sup _{(g, \boldsymbol{\tau}) \in \mathcal{I} \times \mathcal{T}} \mathbb{E}^{x}\left[\int_{0}^{+\infty} \alpha^{N_{d, t}^{\tau}} e^{-\left(\delta-\mu+\frac{\sigma^{2}}{2}\right) t+\sigma B_{t}}\left(1+g\left(x_{t}^{(g, \tau)}, s_{t}\right) D_{t}-(\kappa+m) x_{t}^{(g, \tau)}\right) d t\right] \\
& =Y v(x)
\end{aligned}
$$

In the continuation region $(0, \bar{x})$, the debt-to-income ratio $x_{t}^{(g, \tau)}$ is a controlled stochastic process that evolves as follows:

$$
d x_{t}^{(g, \boldsymbol{\tau})}=\left(g\left(x_{t}^{(g, \boldsymbol{\tau})}, s_{t}\right)-\left(m+\mu-|\boldsymbol{\sigma}|^{2}\right) x_{t}^{(g, \boldsymbol{\tau})}\right) d t-x_{t}^{(g, \boldsymbol{\tau})} \boldsymbol{\sigma} \cdot d \boldsymbol{B}_{t}+(\theta-1) d N_{d, t}^{(\boldsymbol{\tau})}
$$

The normalized value function $v$ is equal to:

$$
\begin{aligned}
v(x) & :=\sup _{(g, \boldsymbol{\tau}) \in \mathcal{I} \times \mathcal{T}} \mathbb{E}^{x}\left[\int_{0}^{+\infty} \alpha^{N_{d, t}^{\tau}} e^{-\left(\delta-\mu+\frac{|\sigma|^{2}}{2}\right) t+\boldsymbol{\sigma} \cdot \boldsymbol{B}_{t}}\left(1+g\left(x_{t}^{(g, \boldsymbol{\tau})}, s_{t}\right) D_{t}-(\kappa+m) x_{t}^{(g, \boldsymbol{\tau})}\right) d t\right] \\
& =\sup _{(g, \boldsymbol{\tau}) \in \mathcal{I} \times \mathcal{T}} \tilde{\mathbb{E}}^{x}\left[\int_{0}^{+\infty} \alpha^{N_{d, t}^{\tau}} e^{-(\delta-\mu) t}\left(1+g\left(x_{t}^{(g, \boldsymbol{\tau})}, s_{t}\right) D_{t}-(\kappa+m) x_{t}^{(g, \boldsymbol{\tau})}\right) d t\right]
\end{aligned}
$$

In equation (A19), we have introduced the measure $\tilde{\operatorname{Pr}}$, defined for any arbitrary Borel set $A \subseteq \mathcal{F}_{t}$ via $\tilde{\operatorname{Pr}}(A)=\mathbb{E}\left[\exp \left(-\frac{|\sigma|^{2}}{2} t+\sigma \cdot B_{t}\right) A\right]$. Under such measure, in the continuation region $(0, \bar{x})$, using Girsanov's theorem, the controlled debt-to-income ratio $x_{t}^{(g, \tau)}$ evolves as follows:

$$
d x_{t}^{(g, \tau)}=\left(g\left(x_{t}^{(g, \tau)}, s_{t}\right)-(m+\mu) x_{t}^{(g, \tau)}\right) d t-x_{t}^{(g, \tau)} \sigma \cdot d \tilde{B}_{t}+(\theta-1) x_{t}^{(g, \tau)} d N_{d, t}^{(\tau)}
$$

$\tilde{\boldsymbol{B}_{t}}:=\boldsymbol{B}_{t}-\sigma t$ is a standard Brownian motion under Pr. As discussed in Section 4.5, the government welfare can be computed as if the government was never issuing debt. Thus, for $x \in(0, \bar{x})$, v satisfies:

$$
(\delta-\mu) v(x)=1-(\kappa+m) x-(\mu+m) x v^{\prime}(x)+\frac{1}{2}|\sigma|^{2} x^{2} v^{\prime \prime}(x)
$$

This is a second order ordinary differential equation, whose general solutions are power functions of $x$. The exponent of the general solutions solves the quadratic equation:

$$
\frac{1}{2}|\sigma|^{2} \xi^{2}-\left(m+\mu+\frac{1}{2}|\sigma|^{2}\right) \xi-(\delta-\mu)=0
$$


Given the parameter restriction (31), this quadratic equation admits one positive, and one negative roots. Since $v$ must be finite as $x \rightarrow 0$, we eliminate the negative root, and note $\xi>1$ the positive one, given by

$$
\xi:=\frac{1}{2}\left(1+\frac{2(m+\mu)}{|\sigma|^{2}}\right)\left[1+\left(1+\frac{8(\delta-\mu)|\sigma|^{2}}{\left(2(m+\mu)+|\sigma|^{2}\right)^{2}}\right)^{1 / 2}\right]
$$

We need one more boundary condition - we will use the fact that upon default, the small open economy suffers a discrete income drop by a factor $\alpha$, and immediately restructure its debt so that its post-default debt-to-income ratio is a fraction $\theta$ of its pre-default value:

$$
v(\bar{x})=\alpha v(\theta \bar{x})
$$

Using these, we can express $v$ as follows on $[0, \bar{x}]$ :

$$
v(x)=\frac{1}{\delta-\mu}\left[1-\left(\frac{1-\alpha}{1-\alpha \theta^{\tau}}\right)\left(\frac{x}{\bar{x}}\right)^{\xi}\right]-\left(\frac{\kappa+m}{\delta+m} x\right)\left[1-\left(\frac{1-\alpha \theta}{1-\alpha \theta^{\tau}}\right)\left(\frac{x}{\bar{x}}\right)^{\xi-1}\right]
$$

For $x>\bar{x}$, let $n(x ; \bar{x}):=1+\left\lfloor\frac{\ln x-\ln \bar{x}}{-\ln \theta}\right\rfloor$ be the number of times the government needs to default consecutively in order to re-enter the continuation region. For $x>\bar{x}$, the value function satisfies:

$$
v(x)=\alpha^{n(x ; \bar{x})} v\left(\theta^{n(x ; \bar{x})} x\right)
$$

We now want to "paste" the solution for $x>\bar{x}$ with the solution for $x \leq \bar{x}$, in such a way that the function $v$ is $\mathcal{C}^{1}$ on $\mathbb{R}^{+}$, so that we can use standard verification arguments. The determination of the optimal default boundary $\bar{x}$ relies on the observation that the government always has the option to default, in other words:

$$
v\left(x_{t}\right) \geq \alpha v\left(\theta x_{t}\right) \quad \forall t
$$

In particular, near the default boundary, for the inequality to be satisfied, we must have:

$$
\lim _{t \nearrow \tau} \operatorname{var}\left[d\left(v\left(x_{t}\right)-\alpha v\left(\theta x_{t}\right)\right)\right]=0
$$

This leads to the smooth pasting condition:

$$
v^{\prime}(\bar{x})=\alpha \theta v^{\prime}(\theta \bar{x})
$$

Collecting these together, we compute the following default boundary $\bar{x}$ :

$$
\bar{x}=\frac{\xi}{\xi-1}\left(\frac{\delta+m}{\kappa+m}\right)\left(\frac{1-\alpha}{1-\alpha \theta}\right) \frac{1}{\delta-\mu}
$$

The debt price $d$ per unit of debt outstanding can be computed by leveraging equation (21), which becomes in this particular case $d(x)=-v^{\prime}(x)$. In other words, for $x \in[0, \bar{x}]$, we have:

$$
d(x)=\left(\frac{\kappa+m}{\delta+m}\right)\left[1-\left(\frac{1-\alpha \theta}{1-\alpha \theta^{\tau}}\right)\left(\frac{x}{\bar{x}}\right)^{\xi-1}\right]
$$

For $x>\bar{x}, d$ is determined via the number of consecutive times the sovereign will default in order to reenter the continuation region:

$$
d(x)=(\alpha \theta)^{n(x ; \bar{x})} d\left(\theta^{n(x ; \bar{x})} x\right)
$$


Note that in the continuation region, the value function $v$ takes the following form:

$$
v(x)=\frac{1}{\delta-\mu}\left(1-\left(\frac{1-\alpha}{1-\alpha \theta^{\tau}}\right)\left(\frac{x}{\bar{x}}\right)^{\tilde{\zeta}}\right)-x d(x)
$$

The required expected excess return on the sovereign debt can be easily computed:

$$
\begin{aligned}
\pi(x, s) & =-\frac{x d^{\prime}(x)}{d(x)} \sigma \cdot v(s) \\
& =\frac{\xi-1}{\left(\frac{1-\alpha \theta \tilde{\xi}}{1-\alpha \theta}\right)\left(\frac{\bar{x}}{x}\right)^{\tilde{\xi}-1}-1} \sigma \cdot \boldsymbol{v}(s)
\end{aligned}
$$

The issuance policy thus takes the following form:

$$
\begin{aligned}
g^{*}(x, s) & =\frac{d(x)}{-d^{\prime}(x)}(\delta-r(s)-\pi(s)) \\
& =\frac{\delta-r(s)}{\xi-1}\left[\left(\frac{1-\alpha \theta^{\xi}}{1-\alpha \theta}\right)\left(\frac{\bar{x}}{x}\right)^{\xi-1}-1\right] x-x \sigma \cdot v(s)
\end{aligned}
$$

We are not quite done with our proof. We still need to establish that no other admissible policy can achieve a higher welfare for the government, via a standard verification theorem. Let $(g, \tau) \in \mathcal{I} \times \mathcal{T}$ be an arbitrary issuance and default policy. We introduce the infinitessimal generator $\mathcal{L}^{(g)}$, defined for any function $f \in \mathcal{C}^{2}(\mathbb{R})$ as follows:

$$
\mathcal{L}^{(g)} f(x):=(g(x, s)-(\mu+m) x) f^{\prime}(x)+\frac{1}{2} x^{2}|\sigma|^{2} f^{\prime \prime}(x)
$$

Note that the function $v$ constructed above is defined on $\mathbb{R}_{+}$, and is $\mathcal{C}^{2}$ on $\mathbb{R} \backslash\left\{\theta^{k} \bar{x} ; k \in \mathbb{N}\right\}$. At $x=\theta^{k} \bar{x}$ $(k \in \mathbb{N})$, the function $v$ is $\mathcal{C}^{1}$ by construction. The function $v$ also satisfies the variational inequality:

$$
0=\max \left[\sup _{g}\left[-(\delta-\mu) v(x)+1+g d(x)-(\kappa+m) x+\mathcal{L}^{(g)} v(x)\right] ; \alpha v(\theta x)-v(x)\right]
$$

Given the dynamic evolution of the controlled stochastic process $x_{t}^{(g, \tau)}$ (as described by equation (A20)), we have the following Itô formula:

$$
\begin{aligned}
& \alpha^{N_{d, t}^{(\tau)}} e^{-(\delta-\mu) t} v\left(x_{t}^{(g, \tau)}\right)=v(x)-\int_{0}^{t} \alpha^{N_{d, z}^{(\tau)}} e^{-(\delta-\mu) z} x_{z}^{(g, \tau)} v^{\prime}\left(x_{z}^{(g, \tau)}\right) \sigma \cdot d \tilde{\boldsymbol{B}_{z}} \\
+ & \int_{0}^{t} \alpha^{N_{d, z}^{(\boldsymbol{\tau})}} e^{-(\delta-\mu) z}\left[\mathcal{L}^{(g)} v\left(x_{z}^{(g, \tau)}\right)-(\delta-\mu) v\left(x_{z}^{(g, \tau)}\right)\right] d z+\int_{0}^{t} \alpha^{N_{d, z-}^{(\boldsymbol{\tau})}} e^{-(\delta-\mu) z}\left[\alpha v\left(\theta x_{z-}^{(g, \boldsymbol{\tau})}\right)-v\left(x_{z-}^{(g, \tau)}\right)\right] d N_{d, z}^{(\boldsymbol{\tau})}
\end{aligned}
$$

See for example Protter (2005). We then use our variational inequality (A24) to obtain:

$$
\begin{aligned}
\alpha^{N_{d, t}^{(\tau)}} e^{-(\delta-\mu) t} v\left(x_{t}^{(g, \tau)}\right) \leq v(x)-\int_{0}^{t} \alpha^{N_{d, z}^{\tau}} e^{-(\delta-\mu) z}\left[1+g\left(x_{z}^{(g, \tau)},\right.\right. & \left.\left.s_{z}\right)-(\kappa+m) x_{z}^{(g, \tau)}\right] d z \\
& -\int_{0}^{t} \alpha^{N_{d, z}^{(\boldsymbol{\tau})}} e^{-(\delta-\mu) z} x_{z}^{(g, \tau)} v^{\prime}\left(x_{z}^{(g, \tau)}\right) \sigma \cdot d \tilde{\boldsymbol{B}_{z}}
\end{aligned}
$$


The stochastic integral in the second line of the equation above is a martingale since $x v^{\prime}(x)$ is bounded. Thus, taking expectations on both sides of this equality, we obtain:

$$
\tilde{\mathbb{E}}^{x, s}\left[\int_{0}^{t} \alpha^{N_{d, z}^{(\tau)}} e^{-(\delta-\mu) z}\left[1+g\left(x_{z}^{(g)}, s_{z}\right)-(\kappa+m) x_{z}^{(g)}\right] d z+\alpha^{N_{d, t}^{(\tau)}} e^{-(\delta-\mu) t} v\left(x_{t}\right)\right] \leq v(x)
$$

When we take $t \rightarrow+\infty, \alpha^{N_{d, t}^{(\tau)}} e^{-(\delta-\mu) t} v\left(x_{t}\right) \rightarrow 0$. Using the dominated convergence theorem, we then obtain the desired result: for any admissible policy $(g, \tau)$, we have

$$
v(x) \geq \tilde{\mathbb{E}}^{x}\left[\int_{0}^{+\infty} \alpha^{N_{d, t}^{\tau}} e^{-(\delta-\mu) t}\left(1+g\left(x_{t}^{(g, \tau)}, s_{t}\right) D_{t}-(\kappa+m) x_{t}^{(g, \tau)}\right) d t\right]
$$

The bound is achieved for our issuance policy $g^{*}$ and default policy $\tau^{*}$, and the proof relies on steps identical to those described above, except that inequalities are now replaced by equalities.

\section{A.6 Attraction Point}

Note that the dynamics of debt can be specified via

$$
\frac{d F_{t}}{F_{t-}}=\left[\left(\frac{\delta-r}{\xi-1}\right)\left(\frac{1-\alpha \theta^{\tau}}{1-\alpha \theta}\right) \bar{x}^{\xi-1}\left(\frac{F_{t}}{Y_{t}}\right)^{1-\xi}-\left(\frac{\delta-r}{\xi-1}+m+v \cdot \sigma\right)\right] d t-(1-\alpha \theta) d N_{d, t}
$$

Thus, we have

$$
\begin{aligned}
\frac{d F_{t}^{\xi-1}}{F_{t-}^{\xi-1}} & =(\xi-1)\left[\left(\frac{\delta-r}{\xi-1}\right)\left(\frac{1-\alpha \theta^{\xi}}{1-\alpha \theta}\right) \bar{x}^{\xi-1}\left(\frac{F_{t}}{Y_{t}}\right)^{1-\xi}-\left(\frac{\delta-r}{\xi-1}+m+v \cdot \sigma\right)\right] d t-\left(1-(\alpha \theta)^{\xi-1}\right) d N_{d, t} \\
d F_{t}^{\xi-1} & =-\eta\left[F_{t}^{\xi-1}-\left(x_{a} Y_{t}\right)^{\xi-1}\right] d t-\left(1-(\alpha \theta)^{\xi-1}\right)\left(\bar{x} Y_{t-}\right)^{\xi-1} d N_{d, t} \\
d\left(e^{\eta t} F_{t}^{\xi-1}\right) & =\eta e^{\eta t}\left(x_{a} Y_{t}\right)^{\xi-1} d t-e^{\eta t}\left(1-(\alpha \theta)^{\xi-1}\right)\left(\bar{x} Y_{t-}\right)^{\xi-1} d N_{d, t} \\
F_{t} & =\left[e^{-\eta t} F_{0}^{\xi-1}+\eta \int_{0}^{t} e^{\eta(u-t)}\left(x_{a} Y_{u}\right)^{\xi-1} d u-\left(1-(\alpha \theta)^{\xi-1}\right) \int_{0}^{t} e^{\eta(u-t)}\left(\bar{x} Y_{u-}\right)^{\xi-1} d N_{d, u}\right]^{1 /(\xi-1)}
\end{aligned}
$$

In the above, we have introduced the speed of mean-reversion $\eta$, and the debt-to-income attraction point $x_{a}$, defined via

$$
\begin{aligned}
\eta & :=\delta-r+(\xi-1)(m+v \cdot \sigma) \\
x_{a} & :=\bar{x}\left[\left(\frac{1-\alpha \theta}{1-\alpha \theta \xi}\right)\left(\frac{\xi-1}{\delta-r}(m+v \cdot \sigma)+1\right)\right]^{\frac{1}{1-\tilde{\xi}}}
\end{aligned}
$$




\section{A.7 Comparative Statics}

\section{A.7.1 Default Boundary}

For the comparative static with respect to $\sigma$, note that:

$$
\frac{\partial \xi}{\partial \sigma^{2}}=\frac{-(\xi-1) \xi^{2}}{\sigma^{2} \xi^{2}+2(\delta-\mu)}<0
$$

Since $\frac{\partial \bar{x}}{\partial \bar{\xi}}<0$, it means that the default boundary $\bar{x}$ is increasing as output volatility increases. For the comparative static w.r.t. $\mu$, notice that:

$$
\frac{\partial \xi}{\partial \mu}=\frac{\xi(\xi-1)}{\frac{\sigma^{2}}{2} \xi^{2}+\delta-\mu}>0
$$

Thus, we can write:

$$
\frac{d \bar{x}}{d \mu}=\frac{\partial \bar{x}}{\partial \mu}+\frac{\partial \bar{x}}{\partial \xi} \frac{\partial \xi}{\partial \mu}=\bar{x}\left[\frac{1}{\delta-\mu}-\frac{1}{\frac{\sigma^{2}}{2} \xi^{2}+\delta-\mu}\right]>0
$$

In other words, $\bar{x}$ is increasing in $\mu$. For the comparative static w.r.t. $\delta$, notice that:

$$
\frac{d \bar{x}}{d \delta}=\frac{\partial \bar{x}}{\partial \xi} \frac{\partial \xi}{\partial \delta}+\frac{\partial \bar{x}}{\partial \delta}
$$

$\xi$ is clearing increasing in $\delta$, and $\bar{x}$ is clearing decreasing in $\xi$. Similarly, keeping $\xi$ constant, $\bar{x}$ is decreasing in $\delta$. This means that $\bar{x}$ is decreasing in $\delta$. For the comparative static w.r.t. $\alpha$ and $\theta$, notice that $\xi$ does not depend on those parameters, while $\bar{x}$ is decreasing in $\alpha$ and increasing in $\theta$, delivering the result stated. The threshold $\bar{x}$ is trivially decreasing in $\kappa$, since $\xi$ is independent of $\kappa$. For the comparative static w.r.t. $m$, note that:

$$
\frac{\partial \xi}{\partial m}=\frac{\xi^{2}}{\frac{\sigma^{2}}{2} \xi^{2}+\delta-\mu}>0
$$

This means that

$$
\frac{d \bar{x}}{d m}=\frac{\partial \bar{x}}{\partial \bar{\xi}} \frac{\partial \xi}{\partial m}+\frac{\partial \bar{x}}{\partial m}=-\bar{x}\left[\frac{1}{\xi(\xi-1)} \frac{\partial \xi}{\partial m}+\frac{\delta-\kappa}{(\delta+m)(\kappa+m)}\right]
$$

Note that $\xi$ does not depend on $\kappa$, meaning that the term in brackets above is decreasing in $\kappa$. In other words, there exists $\bar{\kappa}>\delta$ (with $\bar{\kappa}$ potentially infinite) such that $\frac{d \bar{x}}{d m}<0$ if and only if $\kappa<\bar{\kappa}$.

\section{A.7.2 Speed of Reversion}

As a reminder, the speed of reversion $\eta=\delta-r+(\xi-1)(m+v \cdot \sigma)$. Since $\xi$ is increasing in $\mu$, it must be case that $\eta$ is increasing in $\mu$. Similarly, since $\xi$ is increasing in $\delta$, it must be case that $\eta$ is increasing in $\delta$. Note that $\alpha, \theta$ and $\kappa$ do not have any effect on $\xi$ and thus on the speed of mean reversion $\eta$. We have established that $\xi$ is increasing in $m$, which means that $\eta$ must also be increasing in $m$. Finally, the comparative static w.r.t. $\sigma$ cannot be signed. 


\section{A.7.3 Comparative Statics - Value Function}

To perform those comparative statics, we leverage extensively Feynman-Kac and the integral representation of second order differential equations. Let us look at the comparative static w.r.t. $\kappa$ for example. Remember that the value function $v$ satisfies the following:

$$
\begin{aligned}
(\delta-\mu) v(x ; \kappa) & =1-(\kappa+m) x-(\mu+m) x v_{x}(x ; \kappa)+\frac{1}{2}|\sigma|^{2} x^{2} v_{x x}(x ; \kappa) \\
v(\bar{x} ; \kappa) & =\alpha v(\theta \bar{x} ; \kappa) \\
v_{x}(\bar{x} ; \kappa) & =\alpha \theta v_{x}(\theta \bar{x} ; \kappa)
\end{aligned}
$$

In the above, we have used a notation that emphasizes that the value function depends on the parameter $\kappa$. Differentiate the first two equations above w.r.t $\kappa$ to obtain:

$$
\begin{aligned}
(\delta-\mu) v_{\mathcal{K}}(x ; \kappa) & =-x-(\mu+m) x v_{\kappa x}(x ; \kappa)+\frac{1}{2}|\sigma|^{2} x^{2} v_{\kappa x x}(x ; \kappa) \\
\frac{\partial \bar{x}}{\partial \kappa} v_{x}(\bar{x} ; \kappa)+v_{\kappa}(\bar{x} ; \kappa) & =\alpha \theta \frac{\partial \bar{x}}{\partial \kappa} v_{x}(\theta \bar{x} ; \kappa)+\alpha v_{\kappa}(\theta \bar{x} ; \kappa)
\end{aligned}
$$

Use the fact that $v_{x}(\bar{x} ; \kappa)=\alpha \theta v_{x}(\theta \bar{x} ; \kappa)$ to obtain the boundary condition $v_{\mathcal{K}}(\bar{x} ; \kappa)=\alpha v_{\mathcal{K}}(\theta \bar{x} ; \kappa)$. In other words, $v_{\kappa}$ admits the following integral representation:

$$
v_{\mathcal{K}}(x)=\tilde{\mathbb{E}}^{x}\left[\int_{0}^{\infty} \alpha^{N_{d, t}^{(\tau)}} e^{-(\delta-\mu) t}\left(-x_{t}\right) d t\right]
$$

In other words, $v_{\mathcal{K}}(x)<0$. A similar method leads to the other comparative statics:

$$
\begin{aligned}
v_{|\sigma|^{2}}(x) & =\frac{1}{2} \tilde{\mathbb{E}}^{x}\left[\int_{0}^{\infty} \alpha^{N_{d, t}^{(\tau)}} e^{-(\delta-\mu) t} x_{t}^{2} v^{\prime \prime}\left(x_{t}\right) d t\right]>0 \\
v_{\delta}(x) & =-\tilde{\mathbb{E}}^{x}\left[\int_{0}^{\infty} \alpha^{N_{d, t}^{(\tau)}} e^{-(\delta-\mu) t} v\left(x_{t}\right) d t\right]<0 \\
v_{\mu}(x) & =\tilde{\mathbb{E}}^{x}\left[\int_{0}^{\infty} \alpha^{N_{d, t}^{(\tau)}} e^{-(\delta-\mu) t}\left(v\left(x_{t}\right)-x_{t} v^{\prime}\left(x_{t}\right)\right) d t\right]>0 \\
v_{m}(x) & =-\tilde{\mathbb{E}}^{x}\left[\int_{0}^{\infty} \alpha^{N_{d, t}^{(\tau)}} e^{-(\delta-\mu) t} x_{t}\left(1+v^{\prime}\left(x_{t}\right)\right) d t\right]
\end{aligned}
$$

To sign $v_{m}$, it suffices to look at the behavior of the function $1+v^{\prime}(x)$. Note that $v^{\prime}(0)=-\frac{\kappa+m}{\delta+m}$, and since $v$ is convex, we must have $v^{\prime}(x) \geq-\frac{\kappa+m}{\delta+m}$ for all $x \in[0, \bar{x}]$. Thus, if $\kappa<\delta, v^{\prime}(x)+1>0$ for all $x \in[0, \bar{x}]$, meaning that $v_{m}<0$. Finally, a slight modification of our proof is needed for the comparative statics w.r.t. $\alpha$ and $\theta$. For $\alpha$ for example, note that we have the following:

$$
\begin{aligned}
(\delta-\mu) v_{\alpha}(x ; \alpha) & =-(\mu+m) x v_{\alpha x}(x ; \alpha)+\frac{1}{2}|\sigma|^{2} x^{2} v_{\alpha x x}(x ; \alpha) \\
\frac{\partial \bar{x}}{\partial \alpha} v_{x}(\bar{x} ; \alpha)+v_{\alpha}(\bar{x} ; \alpha) & =\alpha \theta \frac{\partial \bar{x}}{\partial \alpha} v_{x}(\theta \bar{x} ; \alpha)+\alpha v_{\alpha}(\theta \bar{x} ; \alpha)+v(\theta \bar{x} ; \alpha)
\end{aligned}
$$

Use the smooth-pasting condition $v_{x}(\bar{x} ; \alpha)=\alpha \theta v_{x}(\theta \bar{x} ; \alpha)$ to obtain the boundary condition $v_{\alpha}(\bar{x} ; \alpha)=$ $\alpha v_{\alpha}(\theta \bar{x} ; \alpha)+v(\theta \bar{x} ; \alpha)$. In other words, $v_{\alpha}$ admits the following representation:

$$
v_{\alpha}(x)=\tilde{\mathbb{E}}^{x}\left[\sum_{k=1}^{\infty} e^{-(\delta-\mu) \tau_{k}} \alpha^{k} v(\theta \bar{x})\right]>0
$$


Similarly, one can show that

$$
v_{\theta}(x)=\tilde{\mathbb{E}}^{x}\left[\sum_{k=1}^{\infty} e^{-(\delta-\mu) \tau_{k}} \alpha^{k+1} \bar{x} v^{\prime}(\theta \bar{x})\right]<0
$$

\section{A.8 Uniqueness of the MPE under GBM}

Our proof strategy largely follows DeMarzo and He (2020), with the important extension of possible buybacks along the equilibrium path in Section A.8.10.

\section{A.8.1 Setup}

We note $\Gamma_{t}$ the cumulative bond issuance process, with $\Gamma_{0}=0 . \Gamma_{t}$ is a stochastic process that must be adapted to the filtration $\mathcal{F}_{t}, \sigma$-algebra generated by $\left\{B_{s}, 0 \leq s \leq t\right\}$. The face value $F_{t}^{(\Gamma)}$ resulting from such bond issuance process is:

$$
F_{t}^{(\Gamma)}=e^{-m t} F_{0}+\int_{0}^{t} e^{m(s-t)} d \Gamma_{s}
$$

This implies that $d F_{t}=d \Gamma_{t}-m F_{t-} d t$. For any policy $(\Gamma, \tau)$ followed by the government, the debt price is defined via:

$$
D(Y, F)=\hat{\mathbb{E}}^{Y, F}\left[\int_{0}^{\tau} e^{-(r+m) t}(\kappa+m) d t+e^{-(r+m) \tau} \underline{D}\left(Y_{\tau}, F_{\tau}\right)\right]
$$

Under the probability measure $\hat{\operatorname{Pr}}, \hat{B}_{t}:=B_{t}-v t$ is a Brownian motion. The government solves the following problem:

$$
V(Y, F)=\sup _{(\Gamma, \tau) \in \mathcal{G} \times \mathcal{T}} \mathbb{E}^{Y, F}\left[\int_{0}^{\tau} e^{-\delta t}\left(\left(Y_{t}-(\kappa+m) F_{t}^{(\Gamma)}\right) d t+D\left(Y_{t}, F_{t}^{(\Gamma)}\right) d \Gamma_{t}\right)+e^{-\delta \tau} \underline{V}\left(Y_{\tau}, F_{\tau}\right)\right]
$$

\section{A.8.2 Scalability}

Let $x_{t}$ be the debt-to-income ratio: $x_{t}:=F_{t} / Y_{t}$. We restrict ourselves to the study of Markov equilibria in the state variable $x_{t}$. Note that $x_{t}^{(\gamma)}$ is equal to:

$$
x_{t}^{(\gamma)}=x_{0}+\gamma_{t}-\int_{0}^{t}\left(m+\mu-\sigma^{2}\right) x_{s}^{(\gamma)} d s-\int_{0}^{t} \sigma x_{s}^{(\gamma)} d B_{s}
$$

In the above, we have introduced $\gamma_{t}$, defined as follows:

$$
\gamma_{t}:=\int_{0}^{t} \frac{d \Gamma_{s}}{Y_{s}}
$$

It is easy to notice that if the debt price is homogenous of degree zero in $(Y, F)$, then it is optimal for the government to follow a financing and default policies that are homogeneous of degree 1, since:

$$
V(Y, F)=\sup _{(\Gamma, \tau) \in \mathcal{G} \times \mathcal{T}} \mathbb{E}^{Y, F}\left[\int_{0}^{\tau} e^{-\delta t}\left(\left(Y_{t}-(\kappa+m) F_{t}^{(\Gamma)}\right) d t+D\left(Y_{t}, F_{t}^{(\Gamma)}\right) d \Gamma_{t}\right)+e^{-\delta \tau} \underline{V}\left(Y_{\tau}, F_{\tau}\right)\right]
$$




$$
\begin{aligned}
& =Y \sup _{(\gamma, \tau) \in \mathcal{G} \times \mathcal{T}} \mathbb{E}^{x}\left[\int_{0}^{\tau} \frac{M_{t}}{M_{0}} e^{-(\delta-\mu) t}\left(\left(1-(\kappa+m) x_{t}^{(\gamma)}\right) d t+d\left(x_{t}^{(\gamma)}\right) d \gamma_{t}\right)+\frac{M_{\tau}}{M_{0}} e^{-(\delta-\mu) \tau} \underline{v}\left(x_{\tau}^{(\gamma)}\right)\right] \\
& =Y \sup _{(\gamma, \tau) \in \mathcal{G} \times \mathcal{T}} \tilde{\mathbb{E}}^{x}\left[\int_{0}^{\tau} e^{-(\delta-\mu) t}\left(\left(1-(\kappa+m) x_{t}^{(\gamma)}\right) d t+d\left(x_{t}^{(\gamma)}\right) d \gamma_{t}\right)+e^{-(\delta-\mu) \tau} \underline{v}\left(x_{\tau}^{(\gamma)}\right)\right],
\end{aligned}
$$

where the second equality follows from $\frac{Y_{t}}{Y_{0}}=\frac{M_{t}}{M_{0}} e^{\mu t}$, where $M_{t}=\exp \left(-\frac{\sigma^{2}}{2} t+\sigma B_{t}\right)$ is a strictly positive martingale that induces the usual change in measure. This allows us to define the income-normalized value function:

$$
v(x):=\sup _{(\gamma, \tau) \in \mathcal{G} \times \mathcal{T}} \tilde{\mathbb{E}}^{x}\left[\int_{0}^{\tau} e^{-(\delta-\mu) t}\left(\left(1-(\kappa+m) x_{t}^{(\gamma)}\right) d t+d\left(x_{t}^{(\gamma)}\right) d \gamma_{t}\right)+e^{-(\delta-\mu) \tau} \underline{v}\left(x_{\tau}^{(\gamma)}\right)\right]
$$

Under the change of measure $\tilde{\operatorname{Pr}}, \tilde{B}_{t}=B_{t}-\sigma t$ is a Brownian motion, and $x_{t}$ follows

$$
x_{t}^{(\gamma)}=x_{0}+\gamma_{t}-\int_{0}^{t}(m+\mu) x_{s}^{(\gamma)} d s-\int_{0}^{t} \sigma x_{s}^{(\gamma)} d \tilde{B}_{s}
$$

Similarly, if the default and issuance policies are homogeneous of degree 1, the debt price is homogeneous of degree zero. The debt price can then be written:

$$
d(x)=\hat{\mathbb{E}}^{x}\left[\int_{0}^{\tau} e^{-(r+m) t}(\kappa+m) d t+e^{-(r+m) \tau} \underline{d}\left(x_{\tau}^{(\gamma)}\right)\right]
$$

\section{A.8.3 Inequalities satisfied by $d$ and $v$}

We then note that we must have:

$$
0 \leq d(x) \leq \frac{\kappa+m}{r+m} \quad \forall x
$$

In any equilibrium, we must also have:

$$
\begin{aligned}
& v(x) \geq \underline{v}(x) \\
& v(x) \geq \max _{x^{\prime}} v\left(x^{\prime}\right)+\left(x^{\prime}-x\right) d\left(x^{\prime}\right)
\end{aligned}
$$

The first inequality is simply saying that the government always has the option to default. The second inequality says that the government can always jump to a debt-to-income ratio $x^{\prime}$.

\section{A.8.4 Convexity of $v$}

The inequality (A29) leads us to conclude that $v$ must be convex. Indeed, take two arbitrary debt-toincome ratios $x_{1}, x_{2}$, and $\lambda \in[0,1]$, with $x_{\lambda}:=\lambda x_{1}+(1-\lambda) x_{2}$. Consider feasible policies that make the government jump from $x_{1}$ to $x_{\lambda}$, or from $x_{2}$ to $x_{\lambda}$. Then we have:

$$
\begin{aligned}
& v\left(x_{1}\right) \geq v\left(x_{\lambda}\right)+\left(x_{\lambda}-x_{1}\right) d\left(x_{\lambda}\right) \\
& v\left(x_{2}\right) \geq v\left(x_{\lambda}\right)+\left(x_{\lambda}-x_{2}\right) d\left(x_{\lambda}\right)
\end{aligned}
$$

Take a weighted average of these two inequalities to obtain:

$$
\lambda v\left(x_{1}\right)+(1-\lambda) v\left(x_{2}\right) \geq v\left(x_{\lambda}\right)
$$




\section{A.8.5 Monotonicity of $v$ and Cutoff Policy for Default}

Take $x^{\prime}>x$. Using inequality (A29) we know $v$ is non-increasing:

$$
v(x) \geq v\left(x^{\prime}\right)+\left(x^{\prime}-x\right) d\left(x^{\prime}\right) \geq v\left(x^{\prime}\right)
$$

The second inequality follows from $x^{\prime}>x$ and the non-negativity of debt price $d\left(x^{\prime}\right)$ in (A27). Thus $v$ is non-increasing in $x$. Finally, note that on the subset $\{x>0: d(x)>\underline{d}(x)\}$, the value function $v$ is strictly decreasing. As a result, in any equilibrium there exists $\bar{x}<\infty$ such that $d(x)=\underline{d}(x)$ and the government defaults at $x$ if and only if $x \geq \bar{x}$.

\section{A.8.6 No Convex Kinks}

Define the left and right derivatives of $v$, noted $v_{-}^{\prime}$ and $v_{+}^{\prime}$ respectively, as follows:

$$
v_{+}^{\prime}(x):=\lim _{h \downarrow 0} \frac{v(x+h)-v(x)}{h} \quad v_{-}^{\prime}(x):=\lim _{h \uparrow 0} \frac{v(x+h)-v(x)}{h}
$$

We know that $v_{+}^{\prime}\left(x_{1}\right) \leq v_{-}^{\prime}\left(x_{2}\right) \leq v_{+}^{\prime}\left(x_{2}\right)$ for all $x_{1}<x_{2}$, thanks to the convexity of $v$ shown in Section A.8.4. We want to show that $v$ cannot have a convex kink; this implies that $v$ is differentiable everywhere. Intuitively, suppose that $v$ had a convex kink at $x_{0}$, then $v_{+}^{\prime}\left(x_{0}\right)>v_{-}^{\prime}\left(x_{0}\right)$. In such case, the government could be better off by not issuing any bonds in the neighborhood of $x_{0}$.

To show this formally, we need to introduce the second derivative measure $v(\cdot)$, defined for $x_{1}<x_{2}$ via:

$$
v\left(\left[x_{1}, x_{2}\right)\right):=v_{-}^{\prime}\left(x_{2}\right)-v_{-}^{\prime}\left(x_{1}\right)
$$

If $v^{\prime \prime}$ exists at $x$, then $v(d x)=v^{\prime \prime}(x) d x$. Finally, we remind the reader that the local time $L_{t}(x)$ is defined via:

$$
L_{t}(x):=\lim _{\epsilon \downarrow 0} \frac{1}{2 \epsilon} \int_{0}^{t} 1_{\left\{\left|x_{t}-x\right|<\epsilon\right\}} d s
$$

We have established that $v$ is convex, and thus $\mathcal{C}^{1}$ except maybe at a countable number of points. Assume that $v$ is not differentiable at $x_{0}$, and take $\epsilon$ small enough that $v$ is $\mathcal{C}^{1}$ everwhere on $\left[x_{0}-\epsilon, x_{0}+\epsilon\right]$, except at $x_{0}$. Consider once again the strategy $\gamma_{0}$, of not issuing any bonds until the first time $x_{t}$ hits either $x_{0}-\epsilon$ or $x_{0}+\epsilon$. We then have the generalized Ito-Tanaka formula for convex functions (see Karatzas and Shreve, Theorem 6.22 and its generalization by Elworthy et al):

$$
\begin{gathered}
e^{-(\delta-\mu) \tau_{\epsilon}} v\left(x_{\tau_{\epsilon}}^{\left(\gamma_{0}\right)}\right)=v\left(x_{0}\right)-\int_{0}^{\tau_{\epsilon}} e^{-(\delta-\mu) s}\left[(m+\mu) x_{s}^{\left(\gamma_{0}\right)} v_{-}^{\prime}\left(x_{s}^{\left(\gamma_{0}\right)}\right)+(\delta-\mu) v\left(x_{s}^{\left(\gamma_{0}\right)}\right)\right] d s \\
+\int_{x_{0}-\epsilon}^{x_{0}+\epsilon} \int_{0}^{\tau_{\epsilon}} e^{-(\delta-\mu) s} \frac{\sigma^{2} y^{2}}{2} L_{s}(y) v(d y) d s \\
-\sigma \int_{0}^{\tau_{\epsilon}} e^{-(\delta-\mu) s} x_{s} v_{-}^{\prime}\left(x_{s}^{\left(\gamma_{0}\right)}\right) d \tilde{B}_{s}
\end{gathered}
$$

Note that if $v$ was twice differentiable on $\left[x_{0}-\epsilon, x_{0}+\epsilon\right]$, the formula above would become:

$$
\begin{aligned}
e^{-(\delta-\mu) \tau_{\epsilon}} v\left(x_{\tau_{\epsilon}}^{\left(\gamma_{0}\right)}\right)=v\left(x_{0}\right) & +\int_{0}^{\tau_{\epsilon}} e^{-(\delta-\mu) s}(\hat{\mathcal{A}}-(\delta-\mu)) v\left(x_{s}^{\left(\gamma_{0}\right)}\right) d s \\
& +\frac{\sigma^{2} x_{0}^{2}}{2}\left(v_{+}^{\prime}\left(x_{0}\right)-v_{-}^{\prime}\left(x_{0}\right)\right) \int_{0}^{\tau_{\epsilon}} d L_{t}\left(x_{0}\right)-\sigma \int_{0}^{\tau_{\epsilon}} e^{-(\delta-\mu) s} x_{s}^{\left(\gamma_{0}\right)} v^{\prime}\left(x_{s}^{\left(\gamma_{0}\right)}\right) d \tilde{B}_{s}
\end{aligned}
$$


Take expectations of (A30) to obtain:

$$
\begin{aligned}
\mathbb{E}\left[e^{-(\delta-\mu) \tau_{\epsilon}} v\left(x_{\tau_{\epsilon}}^{\left(\gamma_{0}\right)}\right)\right]=v\left(x_{0}\right)+\mathbb{E}\left[\int_{x_{0}-\epsilon}^{x_{0}+\epsilon}\right. & \int_{0}^{\tau_{\epsilon}} e^{-(\delta-\mu) s} \frac{\sigma^{2} y^{2}}{2} L_{s}(y) v(d y) d s \\
& \left.-\int_{0}^{\tau_{\epsilon}} e^{-(\delta-\mu) s}\left[(m+\mu) x_{s}^{\left(\gamma_{0}\right)} v_{-}^{\prime}\left(x_{s}^{\left(\gamma_{0}\right)}\right)+(\delta-\mu) v\left(x_{s}^{\left(\gamma_{0}\right)}\right)\right] d s\right]
\end{aligned}
$$

By taking $\epsilon$ small enough, we can make the left-handside of the equation above strictly greater than the right-handside, as the first term in the above expectation ends up dominating the second term. This would lead to the desired contradiction.

\section{A.8.7 No-trade value as a lower bound on $v$}

Remember that $x_{t}^{\left(\gamma_{0}\right)}$ is the no-trade debt-to-income ratio, defined via:

$$
x_{t}^{\left(\gamma_{0}\right)}:=x \exp \left(-\left(m+\mu+\frac{\sigma^{2}}{2}\right) t-\sigma \tilde{B}_{t}\right)
$$

Let $v_{0}$ be the government no-trade value, defined via:

$$
\begin{aligned}
v_{0}(x): & =\sup _{\tau \in \mathcal{T}} \tilde{\mathbb{E}}\left[\int_{0}^{\tau} e^{-(\delta-\mu) t}\left(1-(\kappa+m) x_{t}^{\left(\gamma_{0}\right)}\right) d t+e^{-(\delta-\mu) \tau} \underline{v}\left(x_{\tau}^{\left(\gamma_{0}\right)}\right)\right] \\
& =\varphi(x)+\left(\frac{x}{\bar{x}_{0}}\right)^{\xi}\left[\underline{v}\left(\bar{x}_{0}\right)-\varphi\left(\bar{x}_{0}\right)\right]
\end{aligned}
$$

$\bar{x}_{0}$ is the optimal debt-to-income default boundary under the assumption that no bond is ever issued, satisfying $v_{0}^{\prime}\left(\bar{x}_{0}\right):=\underline{v}^{\prime}\left(\bar{x}_{0}\right) \cdot \varphi(x)$ is the no-trade, no default value, which satisfies

$$
\varphi(x):=\frac{1}{\delta-\mu}-\left(\frac{\kappa+m}{\delta+m}\right) x
$$

In any equilibrium, for any $x$, we have the following inequality:

$$
v(x) \geq v_{0}(x)
$$

In other words, the government can simply "do nothing," and not issue any bond ever again. Finally, this must also mean that $\bar{x} \geq \bar{x}_{0}$.

\section{A.8.8 Equilibrium debt pricing $d(x)+v^{\prime}(x)=0$}

For any $x, x_{0}<\bar{x}$, from equation (A29) we must have

$$
v(x)-v\left(x_{0}\right) \geq\left(-d\left(x_{0}\right)\right)\left(x-x_{0}\right)
$$

In other words, $-d\left(x_{0}\right)$ belongs to the subdifferential of $v$ at $x_{0}$. Since $v$ is differentiable everywhere, it must be the case that the subdifferential of $v$ is made up of only one point, i.e., $d(x)=-v^{\prime}(x)$.

\section{A.8.9 Monotonicity and Differentiability of $d$}

From Rademacher theorem, the gradient $-d$ of $v$ must be continuous on the set of points where $v$ is differentiable. Since $v$ is differentiable everywhere, it follows that $d$ is continuous for $x \leq \bar{x}$. The convexity of $v$ then implies the monotonicity of $v^{\prime}$, meaning that $d$ must be monotone weakly decreasing 
in $x$. From Lebesgue's theorem for the differentiability of monotone functions, $d$ must be differentiable almost everywhere (which also means that $v^{\prime}$ is differentiable almost everywhere).

\section{A.8.10 Issuance and Buy-Backs}

In this section, we rule out Brownian shocks for the cumulative debt process $d \Gamma_{t}$ based on the optimality of the government problem. To do this, we create two regions of the state space forming a partition, and show that in each such region, it is either (a) never optimal to buy back debt (when the risk-premium earned by international investors is sufficiently low), or (b) never optimal to issue debt (when the riskpremium earned by international investors is sufficiently high); at the boundary, debt risk-premia are exactly equal to the wedge $\delta-r$ and the government is indifferent between any type of issuance strategy. This means that the cumulative debt issuance process, in each region of the partition, is monotone and the Lebesgue decomposition theorem applies region by region, ruling out Brownian shocks to the cumulative issuance process $\Gamma_{t}$.

As a reminder, for any issuance policy $\Gamma$, the risk-premium earned by international debt investors is defined via:

$$
\pi\left(Y_{t}, F_{t}^{(\Gamma)}\right) d t:=\mathbb{E}_{t}\left[\frac{d D_{t}^{(\Gamma)}+(\kappa+m) d t}{D_{t}^{(\Gamma)}}\right]-(r+m) d t
$$

The condition above is equivalent to the martingale condition under the risk-neutral measure

$$
\hat{\mathbb{E}}_{t}\left[\frac{d D_{t}^{(\Gamma)}+(\kappa+m) d t}{D_{t}^{(\Gamma)}}\right]-(r+m) d t=0
$$

Consider the sets $\mathcal{O}_{+}, \mathcal{O}_{-}, \mathcal{O}_{0}$, defined as follows:

$$
\begin{aligned}
\mathcal{O}_{+}: & =\{(Y, F): \delta-r>\pi(Y, F)\} \\
\mathcal{O}_{-}: & =\{(Y, F): \delta-r<\pi(Y, F)\} \\
\mathcal{O}_{0}: & =\{(Y, F): \delta-r=\pi(Y, F)\}
\end{aligned}
$$

Note that $\left(\mathcal{O}_{+}, \mathcal{O}_{-}, \mathcal{O}_{0}\right)$ form a partition of the state space. We will show by contradiction that in $\mathcal{O}_{+}$, the government always wants to issue debt, whereas in $\mathcal{O}_{-}$the government always wants to buy back debt, and in $\mathcal{O}_{0}$ the government is always staying put.

1. Consider the set $\mathcal{O}_{+}$, we claim that on that set, the optimal issuance policy is such that the government never repurchases debt. Assume (by contradiction) that the optimal strategy $\Gamma$ is such that there exists a point $(Y, F) \in \mathcal{O}_{+}$for which we have $d \Gamma_{t}<0$. Consider the optimal default time $\tau_{d}$ (associated with the original policy $\Gamma$ ). Define the stopping time $\tau$ as follows

$$
\tau:=\tau_{d} \wedge \inf \left\{t \geq 0:\left(Y_{t}, F_{t}^{(\Gamma)}\right) \notin \mathcal{O}_{+}\right\}
$$

$\tau$ is either (a) the first time the state leaves the region $\mathcal{O}_{+}$, or $(b)$ the default time under the original default policy, whichever occurs earlier. Consider an alternative strategy $\hat{\Gamma}$, such that the resulting face value process satisfies

$$
F_{t}^{(\hat{\Gamma})}=\sup _{s \leq t}\left\{e^{-m(t-s)} F_{t}^{(\Gamma)}\right\} \quad t<\tau, \quad F_{\tau}^{(\hat{\Gamma})}=F_{\tau}^{(\Gamma)} .
$$

Strategy $\hat{\Gamma}$ and the associate debt face value process $F_{t}^{(\hat{\Gamma})}$ are illustrated in Figure A-3. It is straightforward to notice that $d \hat{\Gamma}_{t}=\max \left(0, F_{t}^{(\Gamma)}-F_{t-}^{(\hat{\Gamma})}\right)$, and that the difference $\Delta F_{t}:=F_{t}^{(\hat{\Gamma})}-F_{t}^{(\Gamma)} \geq 0$ 
satisfies

$$
\begin{aligned}
\Delta F_{0} & =\Delta F_{\tau}=0 \\
d \Delta F_{t} & =d \Delta \Gamma_{t}-m \Delta F_{t} d t,
\end{aligned}
$$

where we have noted $\Delta \Gamma_{t}:=\hat{\Gamma}_{t}-\Gamma_{t}$. Note that at any time $t<\tau$ at which debt is issued under $\hat{\Gamma}$, debt is also issued under $\Gamma$, such that the post-issuance debt level is identical. Note also that it is possible that at time $\tau$, under strategy $\hat{\Gamma}$ debt must be repurchased in order to ensure that $F_{\tau}^{(\hat{\Gamma})}=F_{\tau}^{(\Gamma)}$. In all cases however, we must have

$$
D\left(Y_{t}, F_{t}^{(\hat{\Gamma})}\right) d \hat{\Gamma}_{t}=D\left(Y_{t}, F_{t}^{(\Gamma)}\right) d \hat{\Gamma}_{t}
$$

Consider the difference in payoffs $\Delta V_{[0 ; \tau]}$ between using strategy $\Gamma$ and using strategy $\hat{\Gamma}$, over the time interval $[0, \tau)$. We claim that this payoff difference $\Delta V_{[0 ; \tau]}>0$, providing a contradiction.

$$
\begin{aligned}
\Delta V_{[0 ; \tau]}: & =\mathbb{E}^{Y, F}\left[\int_{0}^{\tau} e^{-\delta t}\left[(\kappa+m)\left(F_{t}^{(\Gamma)}-F_{t}^{(\hat{\Gamma})}\right) d t+D\left(Y_{t}, F_{t}^{(\hat{\Gamma})}\right) d \hat{\Gamma}_{t}-D\left(Y_{t}, F_{t}^{(\Gamma)}\right) d \Gamma_{t}\right]\right] \\
& =\mathbb{E}^{Y, F}\left[\int_{0}^{\tau} e^{-\delta t}\left[-(\kappa+m) \Delta F_{t} d t+D\left(Y_{t}, F_{t}^{(\Gamma)}\right) d \Delta \Gamma_{t}\right]\right] \\
& =\mathbb{E}^{Y, F}\left[\int_{0}^{\tau} e^{-\delta t}\left[-(\kappa+m) \Delta F_{t} d t+D\left(Y_{t}, F_{t}^{(\Gamma)}\right)\left(d \Delta F_{t}+m \Delta F_{t} d t\right)\right]\right]
\end{aligned}
$$

Integrating by parts, using (A33) and the fact that $\Delta F_{\tau}=\Delta F_{0}=0$, we obtain

$$
\Delta V_{[0 ; \tau]}=\mathbb{E}^{Y, F}\left[\int_{0}^{\tau} e^{-\delta t}\left(\delta-r-\pi\left(Y_{t}, F_{t}^{(\Gamma)}\right)\right) \Delta F_{t} D_{t}^{(\Gamma)} d t\right]>0
$$

The latter inequality comes from the fact that the debt price $D_{t}^{(\Gamma)}$ is positive, that $\Delta F_{t} \geq 0$, and that on the set $\mathcal{O}_{+}$, we have $\delta-r-\pi\left(Y_{t}, F_{t}^{(\Gamma)}\right)>0$. Thus, we just constructed a profitable deviation, contradicting our original assumption.

2. Consider now the set $\mathcal{O}_{-}$, we claim that on that set, the optimal issuance policy is such that the government never issues debt. Assume (by contradiction) that the optimal strategy $\Gamma$ is such that there exists a point $(Y, F) \in \mathcal{O}_{-}$for which we have $d \Gamma_{t}>0$. We will construct a deviating strategy that improves upon $\Gamma$ by following steps almost identical to the previous section. This time however, we will use the stopping time $\tau$, defined via

$$
\tau:=\tau_{d} \wedge \inf \left\{t \geq 0:\left(Y_{t}, F_{t}^{(\Gamma)}\right) \notin \mathcal{O}_{-}\right\}
$$

The alternative strategy $\hat{\Gamma}$ will instead be

$$
F_{t}^{(\hat{\Gamma})}=\inf _{s \leq t}\left\{e^{-m(t-s)} F_{t}^{(\Gamma)}\right\} \quad t<\tau, \quad F_{\tau}^{(\hat{\Gamma})}=F_{\tau}^{(\Gamma)} .
$$

Strategy $\hat{\Gamma}$ and the associated debt face value process $F_{t}^{(\hat{\Gamma})}$ are illustrated in Figure A-3. It is straightforward to then notice that $d \hat{\Gamma}_{t}=\min \left(0, F_{t}^{(\Gamma)}-F_{t-}^{(\hat{\Gamma})}\right)$, and that the difference $\Delta F_{t}:=$ $F_{t}^{(\hat{\Gamma})}-F_{t}^{(\Gamma)} \leq 0$ satisfies

$$
\Delta F_{0}=\Delta F_{\tau}=0
$$




$$
d \Delta F_{t}=d \Delta \Gamma_{t}-m \Delta F_{t} d t
$$

where we have denoted $\Delta \Gamma_{t}:=\hat{\Gamma}_{t}-\Gamma_{t}$. At any time $t<\tau$ at which debt is bought back under $\hat{\Gamma}$, debt is also bought back under $\Gamma$, such that the post-repurchase debt level is identical. Note also that it is possible that at time $\tau$, under strategy $\hat{\Gamma}$ debt must be issued in order to ensure that $F_{\tau}^{(\hat{\Gamma})}=F_{\tau}^{(\Gamma)}$. In all cases however, we must have

$$
D\left(Y_{t}, F_{t}^{(\hat{\Gamma})}\right) d \hat{\Gamma}_{t}=D\left(Y_{t}, F_{t}^{(\Gamma)}\right) d \hat{\Gamma}_{t}
$$

Consider the difference in payoffs $\Delta V_{[0 ; \tau]}$ between using strategy $\Gamma$ and using strategy $\hat{\Gamma}$, over the time interval $[0, \tau)$. Using calculations almost identical to those in the previous section leads us to the following:

$$
\begin{aligned}
\Delta V_{[0 ; \tau]}: & =\mathbb{E}^{Y, F}\left[\int_{0}^{\tau} e^{-\delta t}\left[(\kappa+m)\left(F_{t}^{(\Gamma)}-F_{t}^{(\hat{\Gamma})}\right) d t+D\left(Y_{t}, F_{t}^{(\hat{\Gamma})}\right) d \hat{\Gamma}_{t}-D\left(Y_{t}, F_{t}^{(\Gamma)}\right) d \Gamma_{t}\right]\right] \\
& =\mathbb{E}^{Y, F}\left[\int_{0}^{\tau} e^{-\delta t}\left(\delta-r-\pi\left(Y_{t}, F_{t}^{(\Gamma)}\right)\right) \Delta F_{t} D_{t}^{(\Gamma)} d t\right]>0
\end{aligned}
$$

Thus, we just constructed a profitable deviation, contradicting our original assumption.

Figure A-3: Issuances and Buy-Backs

(a): $F_{t}$ and $\hat{F}_{t}$ when buy-back is not optimal

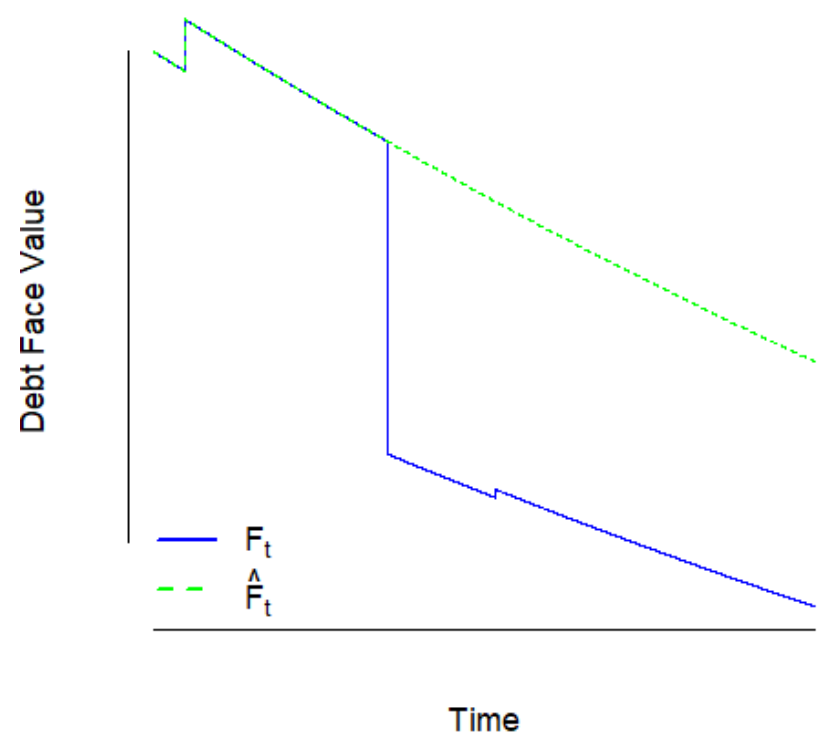

(b): $F_{t}$ and $\hat{F}_{t}$ when issuance is not optimal

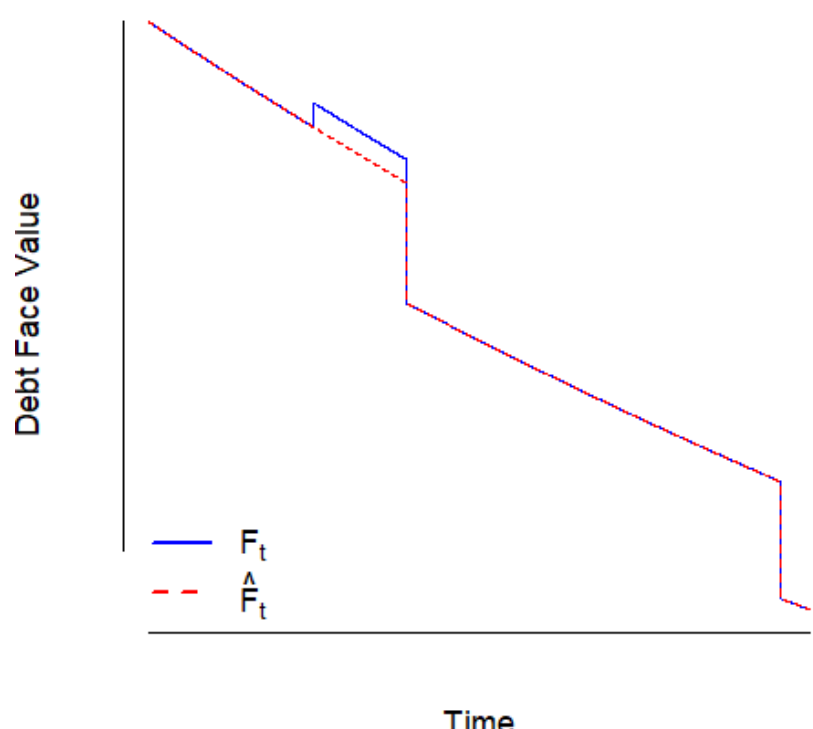

Time

Finally, the arguments above also justify our assertion that whenever $(Y, F) \in \mathcal{O}_{0}$, the government is indifferent between any type of issuance policy. We can then conclude, in the general case $v \neq 0$, that the optimal policy $\Gamma$ can be written as the difference between two monotone increasing processes $\Gamma^{+}$and $\Gamma^{-}$. The increasing process $\Gamma^{+}$represents bond issuances whenever $(Y, F) \in \mathcal{O}_{+}$, while the increasing process $\Gamma^{-}$represents bond repurchases whenever $(Y, F) \in \mathcal{O}_{-}$. Thus, $\Gamma^{-} \Gamma^{+}-\Gamma^{-}$. We then use Lebesgue decomposition theorem for monotone functions to express $\Gamma^{+}$and $\Gamma^{-}$as follows:

$$
\Gamma_{t}^{+}=\Gamma_{t}^{a c+}+\Gamma_{t}^{p p+}+\Gamma_{t}^{\text {sing+ }}
$$




$$
\Gamma_{t}^{-}=\Gamma_{t}^{a c-}+\Gamma_{t}^{p p-}+\Gamma_{t}^{s i n g-}
$$

$\Gamma^{p p+}\left(\operatorname{resp} . \Gamma^{p p-}\right)$ is the pure point part of $\Gamma^{+}\left(\operatorname{resp} . \Gamma^{-}\right)$, wile $\Gamma^{\text {sing }}+\left(\operatorname{resp} . \Gamma^{\text {sing- }}\right)$ is the singular continuous part of $\Gamma^{+}$(resp. $\Gamma^{-}$). Finally $\Gamma_{t}^{a c+}$ and $\Gamma_{t}^{a c-}$ are two absolutely continuous and increasing processes. The debt-to-income process $x_{t}$ must then satisfy:

$$
x_{t}^{(\gamma)}=x_{0}+\int_{0}^{t}\left(\gamma_{s}-\left(m+\mu-\sigma^{2}\right) x_{s}^{(\gamma)}\right) d s-\int_{0}^{t} \sigma x_{s}^{(\gamma)} d B_{s}+\int_{0}^{t}\left(d \gamma_{t}^{p p+}-d \gamma_{t}^{p p-}\right)+\int_{0}^{t}\left(d \gamma_{t}^{\text {sing }+}-d \gamma_{t}^{\text {sing- }}\right)
$$

\section{A.8.11 Hamilton Jacobi Bellman Equation in Smooth Region}

The preceding results show that whenever the state variable $x$ is not at a point of singular issuance or buy-back (i.e. at a point where $d \gamma_{t}^{\text {sing }+}=d \gamma_{t}^{\text {sing- }}=0$ ) or at a point where a jump is optimal (i.e. at a point where $\left.d \gamma_{t}^{p p+}=d \gamma_{t}^{p p-}=0\right)$, the following Hamilton Jacobi Bellman must hold:

$$
1-(\kappa+m) x+(\mathcal{A}-(\delta-\mu)) v(x)=0,
$$

where the operator $\mathcal{A}$ is defined for any $f \in \mathcal{C}^{2}$ via:

$$
\mathcal{A} f(x):=-(m+\mu) x f^{\prime}(x)+\frac{\sigma^{2} x^{2}}{2} f^{\prime \prime}(x)
$$

In the interior of any interval where equation (A34) holds, $v$ must be $\mathcal{C}^{\infty}$, since one can express $v^{(k+2)}$ as a function of $v^{(k+1)}$ and $v^{(k)}$ for any $k \geq 0$. When differentiating equation (A34) w.r.t. $x$, we obtain (equivalently, using $v^{\prime}(x)+d(x)=0$ )

$$
\begin{aligned}
& (\delta+m) v^{\prime}(x)=-(\kappa+m)-\left(m+\mu-\sigma^{2}\right) x v^{\prime \prime}(x)+\frac{\sigma^{2} x^{2}}{2} v^{\prime \prime \prime}(x) \\
& (\delta+m) d(x)=\kappa+m-\left(m+\mu-\sigma^{2}\right) x d^{\prime}(x)+\frac{\sigma^{2} x^{2}}{2} d^{\prime \prime}(x)
\end{aligned}
$$

\section{A.8.12 Lumpy Debt Issuances and Repurchases}

We now study lumpy debt trading decisions and show that at a debt-to-income ratio $\hat{x}$ at which the government ends up following such lumpy trading decision, $v$ must be $\mathcal{C}^{2}$ and we must have $d^{\prime}(\hat{x})=$ $v^{\prime \prime}(\hat{x})=0$.

Without loss of generality, consider a lumpy issuance. Consider $x_{0}<\hat{x}$, where $\hat{x}$ is the point at which the government ends up after the lumpy issuance, and $x_{0}$ is such that at time $t$, starting at a debt-to-income level $x_{t} \in\left[x_{0}, \hat{x}\right]$, the government jumps to $x_{t+}=\hat{x}$. We must have $d(x)=d(\hat{x})=d\left(x_{0}\right)$ for all $x \in\left[x_{0}, \hat{x}\right]$ thanks to creditor's rational expectation. It must then exist $x_{2}>\hat{x}$ such that $x_{t}$ evolves continuously on $\left[\hat{x}, x_{2}\right]$, otherwise $x_{t+} \neq \hat{x}$. $\hat{x}$ must then be a reflecting barrier when the process $x_{t}$ starts at $x \geq \hat{x}$. In that case, equation (A34) must hold for all $x \in\left(\hat{x}, x_{2}\right)$. We must also have $d^{\prime}(\hat{x})=0$. Indeed, $d^{\prime}(\hat{x}-)=0$ since $d(x)=d(\hat{x})$ for all $x \in\left[x_{0}, \hat{x}\right]$, and $d^{\prime}(\hat{x}+)=0$ given the reflecting barrier. Finally, for $x \in\left(x_{0}, \hat{x}\right), d$ is constant and $v$ is an affine function, meaning that $v^{\prime \prime}(x)=0$ on that interval. Finally, it must be the case that $v$ is $\mathcal{C}^{2}$ at $x=\hat{x}$. Indeed, since $v$ is convex, if for some reason $v$ was not $\mathcal{C}^{2}$ at $x=\hat{x}$, this would mean that $v^{\prime \prime}(\hat{x}+)>v^{\prime \prime}(\hat{x}-)=0$. But since $v^{\prime}(x)+d(x)=0$, differentiating this equation and evaluating it at $x=\hat{x}+$ leads to $v^{\prime \prime}(\hat{x}+)+d^{\prime}(\hat{x}+)=v^{\prime \prime}(\hat{x}+)>0$, where we have used the fact that $d^{\prime}(\hat{x}+)=0$. This is a contradiction, since we must have $v^{\prime \prime}(\hat{x}+)+d^{\prime}(\hat{x}+)=0$. Thus $v^{\prime \prime}(\hat{x}+)=v^{\prime \prime}(\hat{x}-)=0$ and $v$ is $\mathcal{C}^{2}$ at $x=\hat{x}$. A similar reasoning (omitted here) can be used in connection with lumpy debt buy-backs. Thus, on any jump interval $\left[x_{0}, \hat{x}\right]$, the value function $v$ is affine in $x$, the debt price $d$ is constant and strictly positive, $v$ is $\mathcal{C}^{2}$ and $d$ is $\mathcal{C}^{1}$ at the arrival point $x=\hat{x}$. 


\section{A.8.13 Isolated Point of Singular Trading Intensity}

In this section, we show that at any singular trading intensity point $\hat{x}$, the value function $v$ is $\mathcal{C}^{2}$ and we must have $d^{\prime}(\hat{x})=v^{\prime \prime}(\hat{x})=0$. Consider such a point $\hat{x}$ of singular trading intensity. This means that on an open ball around $\hat{x}$, the state variable $x_{t}$ satisfies

$$
\begin{aligned}
x_{t}^{(\gamma)} & =x_{0}+\int_{0}^{t}\left(\gamma_{s}-\left(m+\mu-\sigma^{2}\right) x_{s}^{(\gamma)}\right) d s-\int_{0}^{t} \sigma x_{s}^{(\gamma)} d B_{s}+\int_{0}^{t}(2 p-1) d \gamma_{s}^{(\hat{x})}\left(x_{s}^{(\gamma)}\right) \\
\gamma_{t}^{(\hat{x})}\left(x_{t}^{(\gamma)}\right): & =\lim _{\epsilon \searrow 0} \frac{1}{2 \epsilon} \int_{0}^{t} 1_{\left\{\hat{x}-\epsilon<x_{t}^{(\gamma)}<\hat{x}+\epsilon\right\}} d s
\end{aligned}
$$

The probability $p \in[0,1], p \neq 1 / 2$ is the probability of "moving to the right", and it must satisfy

$$
p d^{\prime}(\hat{x}+)=(1-p) d^{\prime}(\hat{x}-)
$$

see the concept of "skew Brownian motion" in Harrison and Shepp (1981). The point $\hat{x}$ must be isolated, which means that on a left and right neighborhood of $\hat{x}$, equation (A34) must hold. This means in particular that $v^{\prime \prime}(\hat{x}+)=v^{\prime \prime}(\hat{x}-)$, which means that $d^{\prime}(\hat{x}+)=d^{\prime}(\hat{x}-)$. Thus, in order for equation (A37) to hold, it must be the case that $d^{\prime}(\hat{x}+)=d^{\prime}(\hat{x}-)=0$, which must mean that $v^{\prime \prime}$ is continuous at $\hat{x}$, with $v^{\prime \prime}(\hat{x})=0$.

\section{A.8.14 No Debt Welfare equals Autarky Value}

We are now going to show that in any equilibrium, the sovereign does not achieve gains from trade when not indebted. Said another way, we are going to show that $v(0)=1 /(\delta-\mu)$, the autarky value. We will also show that in any equilibrium, the debt price is always weakly less than $\frac{\kappa+m}{\delta+m}$. Consider $x=0$ - i.e. when the government is not indebted. Three cases can then arise.

- If the financing policy is absolutely continuous at $x=0$, equations (A35) and (A36) hold, and if we take the limit of such equations when $x \rightarrow 0$, we obtain

$$
v(0)=\frac{1}{\delta-\mu} \quad d(0)=\frac{\kappa+m}{\delta+m}
$$

- Imagine instead that at $x=0$, the optimal financing policy is an impulse control, from $x=0$ to $\hat{x}$. In such case, we know that the value function is linear on $x \in[0, \hat{x}]$ and we know that the debt price is constant on such interval. We also know, from the previous section, that we must have $v^{\prime \prime}(\hat{x})=d^{\prime}(\hat{x})=0$. For $x>\hat{x}$ and in the neighbourhood of $\hat{x}, v$ must be strictly convex, i.e. $v^{\prime \prime}(x)>0$, meaning that we must have $v_{+}^{\prime \prime \prime}(\hat{x}) \geq 0$. Thus, if one were to evaluate equation (A36) at $x=\hat{x}+$, we would obtain

$$
(\delta+m) d(\hat{x})=\kappa+m+\frac{\sigma^{2} \hat{x}^{2}}{2} d^{\prime \prime}(\hat{x})=\kappa+m-\frac{\sigma^{2} \hat{x}^{2}}{2} v_{+}^{\prime \prime \prime}(\hat{x}) \leq \kappa+m
$$

In other words, in such case, we have

$$
d(\hat{x})=d(0) \leq \frac{\kappa+m}{\delta+m}
$$

Since equation (A34) holds in the (right) neighbourhood of $\hat{x}$, we must have

$$
\begin{aligned}
(\delta-\mu) v(\hat{x}) & =1-(\kappa+m) \hat{x}-(\mu+m) \hat{x} v^{\prime}(\hat{x}) \\
& =1-(\kappa+m) \hat{x}+(\mu+m) \hat{x} d(\hat{x})
\end{aligned}
$$


But since the optimal policy is assumed to be an impulse control, it means that $v(0)=v(\hat{x})+\hat{x} d(\hat{x})$, which we can use in the previous equation to obtain:

$$
(\delta-\mu) v(0)=1+(\delta+m) \hat{x}\left[d(\hat{x})-\frac{\kappa+m}{\delta+m}\right] \leq 1
$$

In other words, it must be the case that $v(0) \leq 1 /(\delta-\mu)$. But of course we know that the value function must be bounded below by the autarky value, which means that we must have $v(0)=1 /(\delta-\mu)$.

- Lastly, imagine that at $x=0$, the optimal financing policy is singular control. This means that in the right neighbourhood of $x=0$, equation (A34) holds. Taking the limit of that equation as $x \rightarrow 0$, keeping in mind that $v^{\prime}(x)=-d(x)$ must be bounded, and that $v^{\prime \prime}(0)=0$ (using results from the previous section), we immediately reach the conclusion that $v(0)=1 /(\delta-\mu)$. We can then take the limit of equation (A36) as $x \rightarrow 0$, use the fact that $d^{\prime}(0)=0$ and that $d^{\prime}(0+)<0$, which means that $d^{\prime \prime}(0+)<0$ to conclude that $d(0) \leq \frac{\kappa+m}{\delta+m}$.

The reasoning above also shows that $d(0) \leq \frac{\kappa+m}{\delta+m}$. Since $d$ is decreasing, it then means that $d(x) \leq \frac{\kappa+m}{\delta+m}$ for all $x$. Thus, we have established that the value function for a government without debt is equal to the autarky value.

\section{A.8.15 No Singular or Impulse Control in Equilibrium Financing Strategy}

We end our proof by showing that in any equilibrium, the government always uses an absolutely continuous face value process, which of course leads to the conclusion that the equilibrium must be unique, and that it must correspond to the equilibrium we characterized in Section 5. As a preliminary calculation, note $z(x)$ the value (per unit of income) if a no-debt government was immediately jumping from $x=0$ to $x>0$ :

$$
z(x)=v(x)+x d(x)=v(x)-x v^{\prime}(x)
$$

Note that $z^{\prime}(x)=-x v^{\prime \prime}(x) \leq 0$, which means that $z$ is decreasing, and that

$$
z(x) \leq z(0)=\frac{1}{\delta-\mu}
$$

Now let us prove that there can be no jump or points of singularity in our equilibrium. By way of contradiction, imagine $\hat{x}$ was a point of singular issuance intensity or arrival point of an issuance jump. 3 cases need to be considered:

- Imagine a jump occurs immediately when the sovereign has no debt. Let $\hat{x}$ be the arrival point of such initial jump. Then we have, for $x \leq \hat{x}$

$$
\frac{1}{\delta-\mu}-\frac{\kappa+m}{\delta+m} x \leq v(x)=v(\hat{x})+(\hat{x}-x) d(\hat{x})=z(\hat{x})-x d(\hat{x}),
$$

where the first inequality comes from the fact that $v$ is bounded from below by the no-default, notrade value, and where the second equality comes from the fact that the government jumps from any point $x \leq \hat{x}$ to $\hat{x}$. But since $d(\hat{x}) \leq \frac{\kappa+m}{\delta+m}$, this means that $\frac{1}{\delta-\mu} \leq z(\hat{x})$, which is a contradiction.

- Imagine instead that a jump occurs between $x_{1}>0$ and $x_{2}>x_{1} ; x_{2}$ is the arrival debt-to-income ratio, and we know from previous sections that we must then have $v^{\prime \prime}\left(x_{2}\right)=0$. Since we have a jump between $x_{1}$ and $x_{2}$, this also means that $v\left(x_{1}\right)=v\left(x_{2}\right)+\left(x_{1}-x_{2}\right) v^{\prime}\left(x_{1}\right)$. Consider the HJB 
equation satisfied by $v$ at both $x_{1}-$ and $x_{2}+$ :

$$
\begin{aligned}
& (\delta-\mu) v\left(x_{1}\right)=1-(\kappa+m) x_{1}-(\mu+m) x_{1} v^{\prime}\left(x_{1}\right)+\frac{\sigma^{2} x_{1}^{2}}{2} v^{\prime \prime}\left(x_{1}-\right) \\
& (\delta-\mu) v\left(x_{2}\right)=1-(\kappa+m) x_{2}-(\mu+m) x_{2} v^{\prime}\left(x_{2}\right)
\end{aligned}
$$

Note that the second order derivative $v^{\prime \prime}$ does not appear for the second HJB since $v^{\prime \prime}\left(x_{2}+\right)=0$. Take the difference between those two HJBs, use $v\left(x_{1}\right)=v\left(x_{2}\right)+\left(x_{1}-x_{2}\right) v^{\prime}\left(x_{1}\right)$ and $v^{\prime}\left(x_{1}\right)=$ $v^{\prime}\left(x_{2}\right)$ to obtain

$$
(\delta-\mu)\left(x_{1}-x_{2}\right) v^{\prime}\left(x_{1}\right)=-(\kappa+m)\left(x_{1}-x_{2}\right)-(\mu+m) v^{\prime}\left(x_{1}\right)\left(x_{1}-x_{2}\right)+\frac{\sigma^{2} x_{1}^{2}}{2} v^{\prime \prime}\left(x_{1}-\right)
$$

After simplification and division by $\left(x_{2}-x_{1}\right)$ we obtain

$$
d\left(x_{1}\right)=-v^{\prime}\left(x_{1}\right)=\frac{\kappa+m}{\delta+m}+\frac{\sigma^{2} x_{1}^{2} v^{\prime \prime}\left(x_{1}-\right)}{2\left(x_{2}-x_{1}\right)} \geq \frac{\kappa+m}{\delta+m},
$$

where the inequality comes from the fact that $v^{\prime \prime}\left(x_{1}-\right) \geq 0$. But since $x_{1}>0$ and since the financing strategy for the government is absolutely continuous on an non-empty interval in the left neighborhood of $x_{1}$, it must be the case that $d\left(x_{1}\right)<\frac{\kappa+m}{\delta+m}$, thus we have a contradiction.

- Finally, let us assume that $\hat{x}>0$ is a point of singular trading intensity. We then know that $v^{\prime \prime}(\hat{x})=d^{\prime}(\hat{x})=0$. Since $d$ is decreasing and $d^{\prime}(\hat{x}-) \leq 0$, it must be the case that $d^{\prime \prime}(\hat{x}-) \geq 0$. Consider equation (A36), satisfied by $d$ at $\hat{x}-$ :

$$
\begin{aligned}
(\delta+m) d(\hat{x}) & =\kappa+m-\left(\mu+m-\sigma^{2}\right) \hat{x} d^{\prime}(\hat{x}-)+\frac{\sigma^{2} \hat{x}^{2}}{2} d^{\prime \prime}(\hat{x}-) \\
& =\kappa+m+\frac{\sigma^{2} \hat{x}^{2}}{2} d^{\prime \prime}(\hat{x}-) \\
& \geq \kappa+m,
\end{aligned}
$$

where the second equality uses $d^{\prime}(\hat{x})=0$ and the last inequality stems from $d^{\prime \prime}(\hat{x}-) \geq 0$. Thus, $d(\hat{x}) \geq \frac{\kappa+m}{\delta+m}$, which is a contradiction - for the same reason as in the previous case.

All the cases considered above show that the equilibrium financing strategy of the government cannot feature any singular point of trading intensity, or any impulse control. Thus, the financing strategy of the government must be absolutely continuous, and the MPE must be unique.

\section{A.9 Ergodic Distribution and Average Default Rate}

The drift rate $\mu_{x}(x)$ of the state variable $x$ and the volatility $\sigma_{x}(x)$ are equal to:

$$
\begin{aligned}
\mu_{x}(x): & =g(x)-\left(m+\mu-|\sigma|^{2}\right) x \\
& =\left[\left(\frac{\delta-r}{\xi-1}\right)\left(\frac{1-\alpha \theta^{\xi}}{1-\alpha \theta}\right)\left(\frac{\bar{x}}{x}\right)^{\xi-1}-\left(m+\mu+v \cdot \sigma-|\sigma|^{2}+\frac{\delta-r}{\xi-1}\right)\right] x \\
\sigma_{x}(x): & =\sigma x
\end{aligned}
$$


The stationary distribution $f$ of the state variable $x_{t}$ under the measure $\mathbb{P}$ solves the KolmogorovForward equation:

$$
0=\frac{d J}{d x}=-\frac{d}{d x}\left[\mu_{x}(x) f(x)\right]+\frac{d^{2}}{d x^{2}}\left[\frac{\sigma_{x}^{2}(x)}{2} f(x)\right]
$$

\section{A.9.1 Is the boundary $x=0$ ever reached?}

What is the behavior of $x_{t}$ at the boundary $x=0$ ? To understand this question better, we need to determine whether such boundary is a regular, entrance, exit or natural boundary. Thus, define the scale density by:

$$
\omega\left(x ; x_{0}\right):=\exp \left[-\int_{x_{0}}^{x} \frac{2 \mu_{x}(t)}{\left|\sigma_{x}(t)\right|^{2}} d t\right]=\left(\frac{x}{x_{0}}\right)^{b} \exp \left(\frac{-a}{1-\xi}\left(x^{1-\xi}-x_{0}^{1-\xi}\right)\right),
$$

with the constant $a>0$ and $b$ defined via

$$
a:=\frac{\delta-r}{\xi-1}\left(\frac{1-\alpha \theta^{\xi}}{1-\alpha \theta}\right) \frac{2 \bar{x}^{\xi-1}}{|\sigma|^{2}} \quad b:=\frac{2}{|\sigma|^{2}}\left(\frac{\delta-r}{\xi-1}+m+\mu+v \cdot \sigma-|\sigma|^{2}\right)
$$

Compute the following:

$$
\begin{aligned}
& A\left(x^{*}\right):=\int_{x^{*}}^{x_{0}}\left(\int_{x^{*}}^{t} \omega\left(z ; x_{0}\right) d z\right) \frac{2}{\omega\left(t ; x_{0}\right)\left|\sigma_{x}(t)\right|^{2}} d t \\
& B\left(x^{*}\right):=\int_{x^{*}}^{x_{0}}\left(\int_{t}^{x^{*}} \omega\left(z ; x_{0}\right) d z\right) \frac{2}{\omega\left(t ; x_{0}\right)\left|\sigma_{x}(t)\right|^{2}} d t
\end{aligned}
$$

The boundary $x^{*} \in\{0, \bar{x}\}$ is classified depending on the finiteness of these integrals:

1. $x^{*}$ is regular if $A\left(x^{*}\right)<+\infty$ and $B\left(x^{*}\right)<+\infty$

2. $x^{*}$ is entrance if $A\left(x^{*}\right)=+\infty$ and $B\left(x^{*}\right)<+\infty$

3. $x^{*}$ is exit if $A\left(x^{*}\right)<+\infty$ and $B\left(x^{*}\right)=+\infty$

4. $x^{*}$ is natural if $A\left(x^{*}\right)=+\infty$ and $B\left(x^{*}\right)=+\infty$

Entrance and natural boundaries are inaccessible, meaning they are never reached; regular and exit boundaries are accessible. Clearly, the boundary $\bar{x}$ is regular and thus accessible. In addition, $\omega\left(x ; x_{0}\right) \rightarrow$ $+\infty$ as $x \rightarrow 0$. This means that the quantities $A(0)$ and $B(0)$ are not finite: $x=0$ is a natural boundary, and is thus not accessible. Said differently, an indebted government can never entirely repay back its entire existing stock of debt.

\section{A.9.2 Solution to the KF equation}

Remember that the probability flux $J(x)$ is defined via

$$
J(x):=\mu_{x}(x) f(x)-\frac{d}{d x}\left[\frac{\sigma_{x}^{2}(x)}{2} f(x)\right]
$$

The ergodic density satisfies $d J / d x=0$. We can integrate this equation on $[\theta \bar{x}, \bar{x}]$ to obtain $J(x)=\lambda_{d}$, where $\lambda_{d}:=J(\bar{x})$ is the ergodic default rate. Thus, for $x \in[\theta \bar{x}, \bar{x}], f$ satisfies

$$
\mu_{x}(x) f(x)-\frac{d}{d x}\left[\frac{\sigma_{x}(x)^{2}}{2} f(x)\right]=\lambda_{d}
$$


With the boundary condition $f(\bar{x})=0$ (since $\bar{x}$ is an exist point), the solution to this first order ODE is

$$
f(x)=\lambda_{d} \int_{x}^{\bar{x}} \exp \left(-\int_{x}^{u} \frac{2 \mu_{x}(s)}{\sigma_{x}^{2}(s)} d s\right) d u=\lambda_{d} \int_{x}^{\bar{x}} \omega(u ; x) d u
$$

For $x \in(0, \theta \bar{x}]$, the probability flux is constant and equal to zero given that $x=0$ is an unattainable boundary. Thus,

$$
\mu_{x}(x) f(x)-\frac{d}{d x}\left[\frac{\sigma_{x}(x)^{2}}{2} f(x)\right]=0
$$

Given that $f$ is continuous at $x=\theta \bar{x}$, the solution to this first order ODE is

$$
f(x)=\lambda_{d} \int_{\theta \bar{x}}^{\bar{x}} \omega(u ; x) d u
$$

Figure A-4: Sensitivities to $m$

(a): debt-to-income

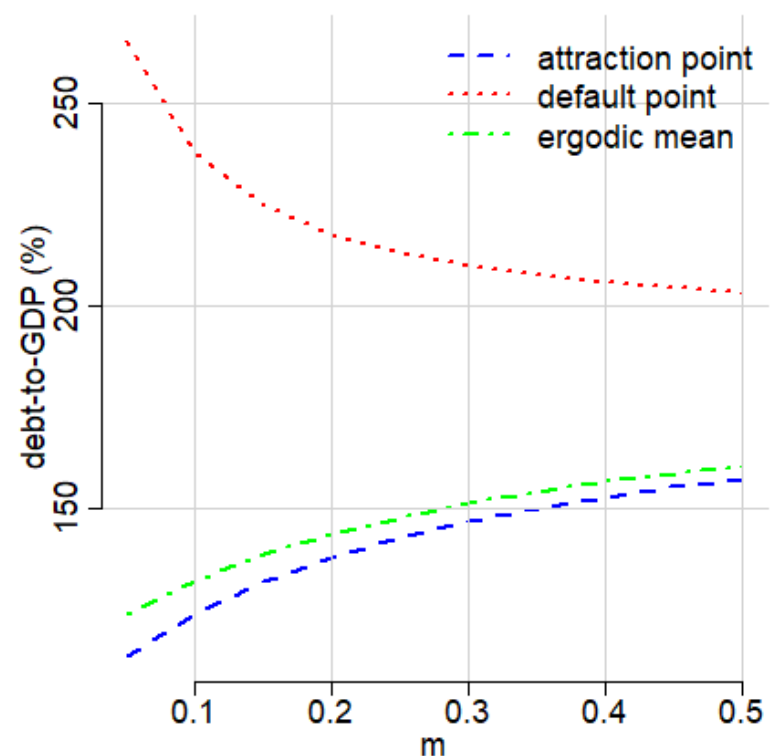

(b): Default rate and credit spreads

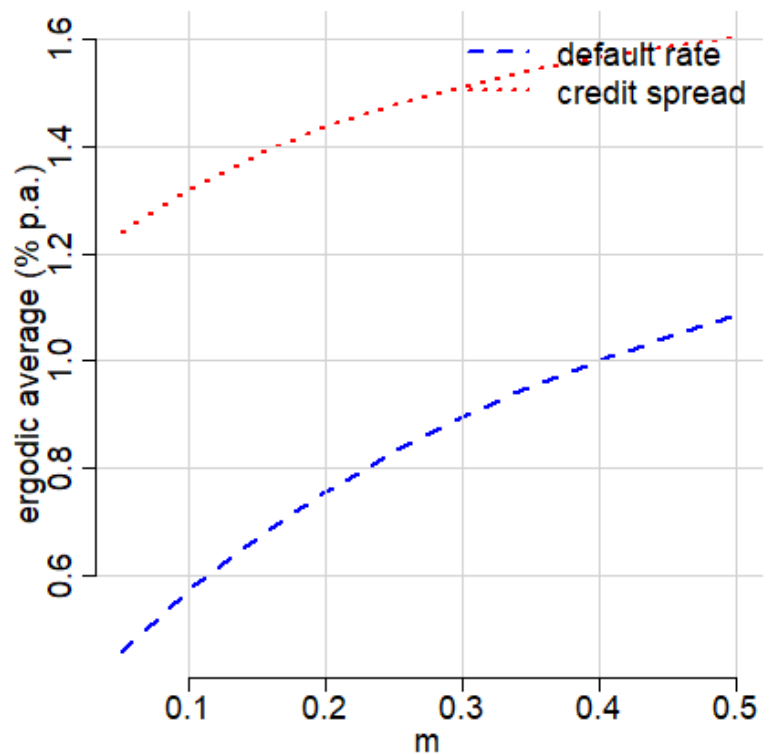

Plots computed assuming $\mu=2 \%$ p.a., $\sigma=20 \%$ p.a., $1 / m=10$ years, $\theta=50 \%, \alpha=96 \%, v=40 \%, r=\kappa=5 \%$ and $\delta=6 \%$.

\section{A.10 GDP-Linked Bonds}

Our proof follows closely Section A.5. The bonds issued by the government are now GDP-linked, with weighting vector $\zeta$, such that the debt face value $F_{t}$ follows:

$$
F_{t}^{(I, \boldsymbol{\tau})}=\int_{0}^{t}\left(G\left(Y_{u}^{(\boldsymbol{\tau})}, F_{u}^{(I, \boldsymbol{\tau})}, s_{u}\right)-m F_{u}^{(I, \boldsymbol{\tau})}\right) d u+\int_{0}^{t} F_{u}^{(I, \boldsymbol{\tau})} \boldsymbol{s} \cdot d \boldsymbol{B}_{u}+\int_{0}^{t}(\theta \alpha-1) F_{u-}^{(I, \boldsymbol{\tau})} d N_{d, u}^{(\boldsymbol{\tau})}
$$


Figure A-5: Sensitivities to $r$

(a): debt-to-income

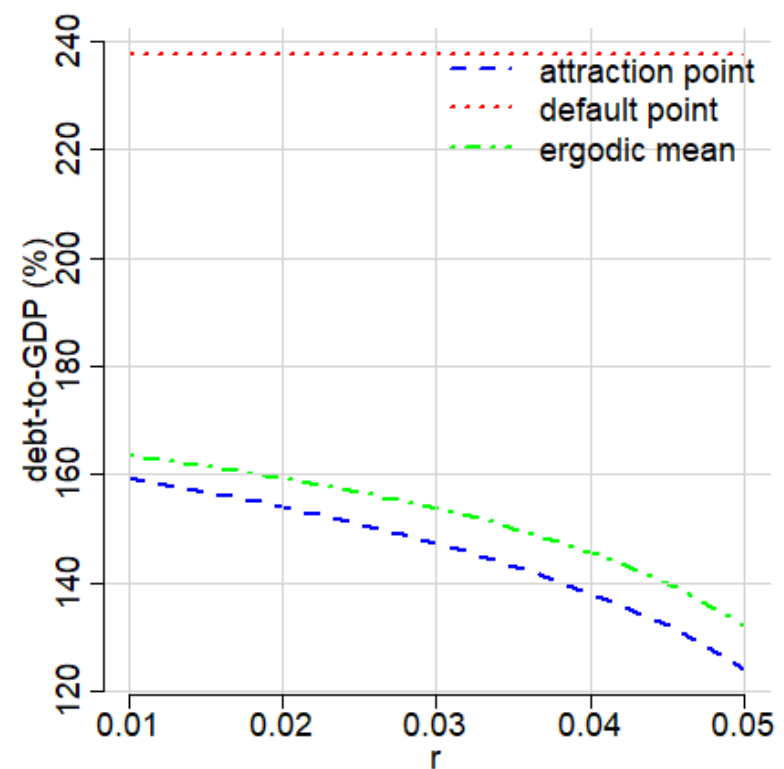

(b): Default rate and credit spreads

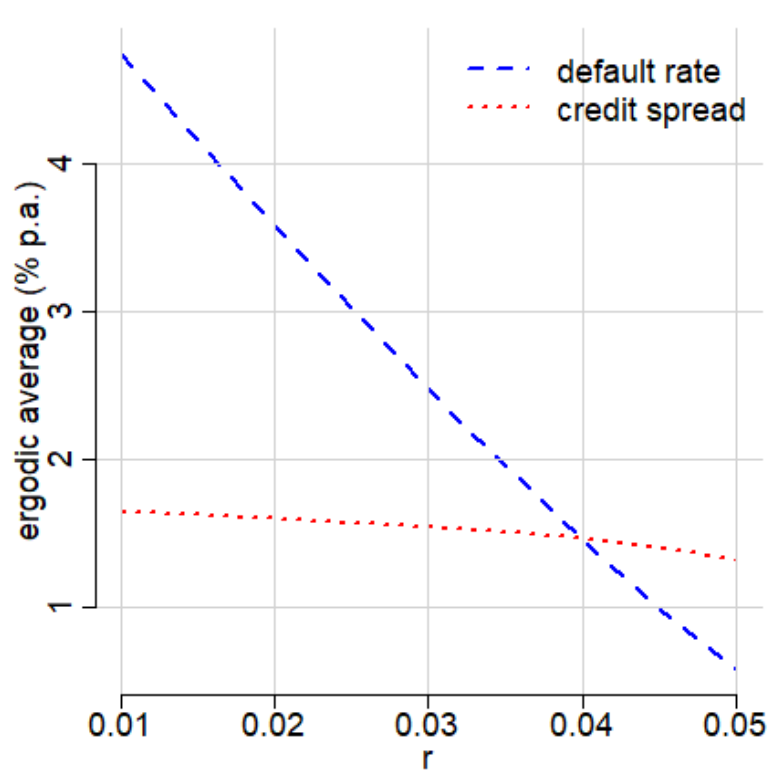

Plots computed assuming $\mu=2 \%$ p.a., $\sigma=20 \%$ p.a., $1 / m=10$ years, $\theta=50 \%, \alpha=96 \%, v=40 \%, r=\kappa=5 \%$ and $\delta=6 \%$.

Figure A-6: Sensitivities to $\alpha$

(a): debt-to-income

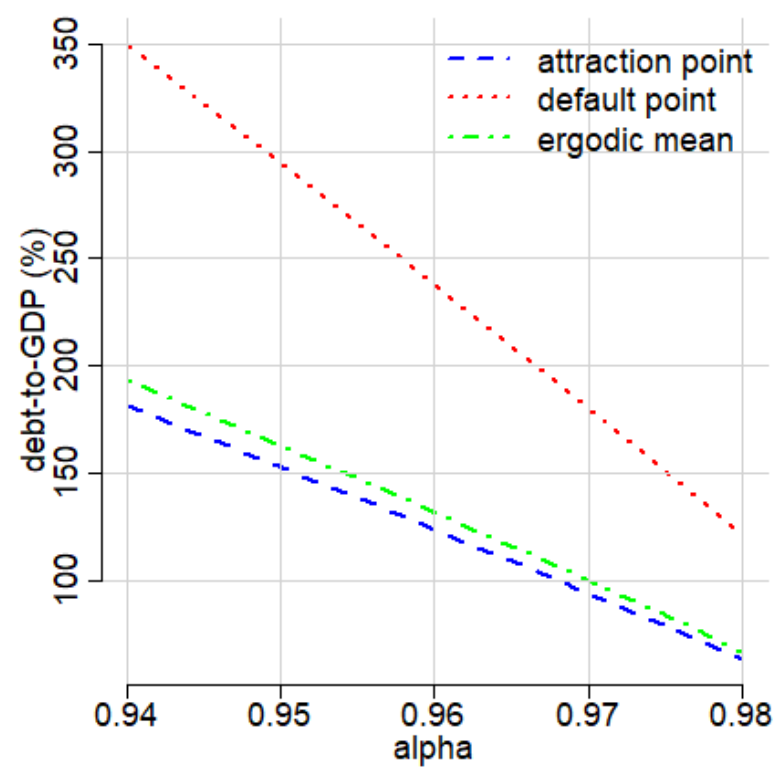

(b): Default rate and credit spreads

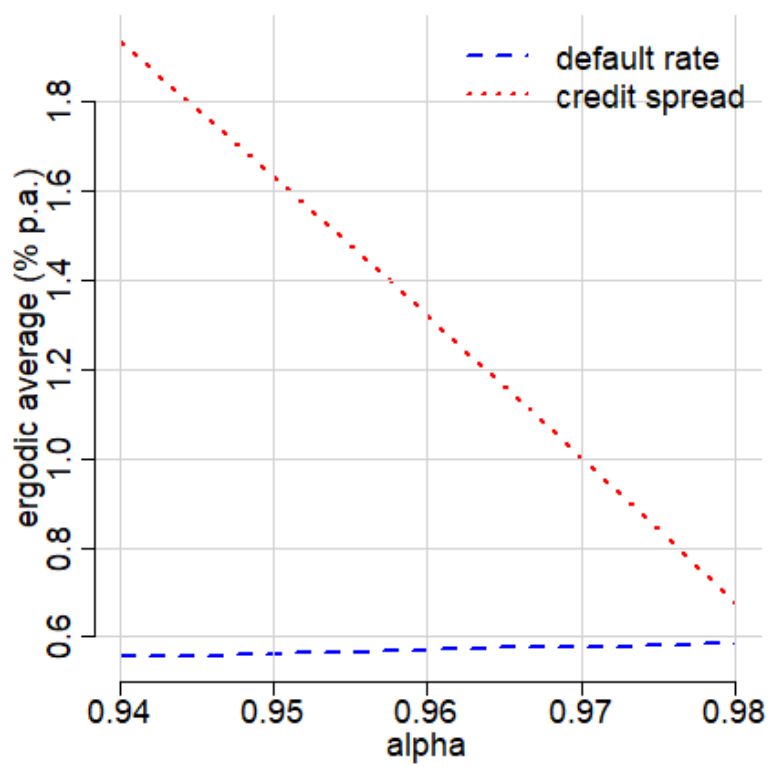

Plots computed assuming $\mu=2 \%$ p.a., $\sigma=20 \%$ p.a., $1 / m=10$ years, $\theta=50 \%, \alpha=96 \%, v=40 \%, r=\kappa=5 \%$ and $\delta=6 \%$.

The value function $V$ can still be written $V(Y, F)=Y v(x)$. Under Pr and Pr, the debt-to-income ratio follows:

$$
d x_{t}^{(g, \boldsymbol{\tau})}=\left(g\left(x_{t}^{(g, \boldsymbol{\tau})}, s_{t}\right)-(m+\mu-\boldsymbol{\sigma} \cdot(\boldsymbol{\sigma}-\boldsymbol{\varsigma})) x_{t}^{(g, \boldsymbol{\tau})}\right) d t-x_{t}^{(g, \boldsymbol{\tau})}(\boldsymbol{\sigma}-\boldsymbol{\varsigma}) \cdot d \boldsymbol{B}_{t}+(\theta-1) x_{t}^{(g, \boldsymbol{\tau})} d N_{d, t}^{(\boldsymbol{\tau})}
$$


Figure A-7: Sensitivities to $\theta$

(a): debt-to-income

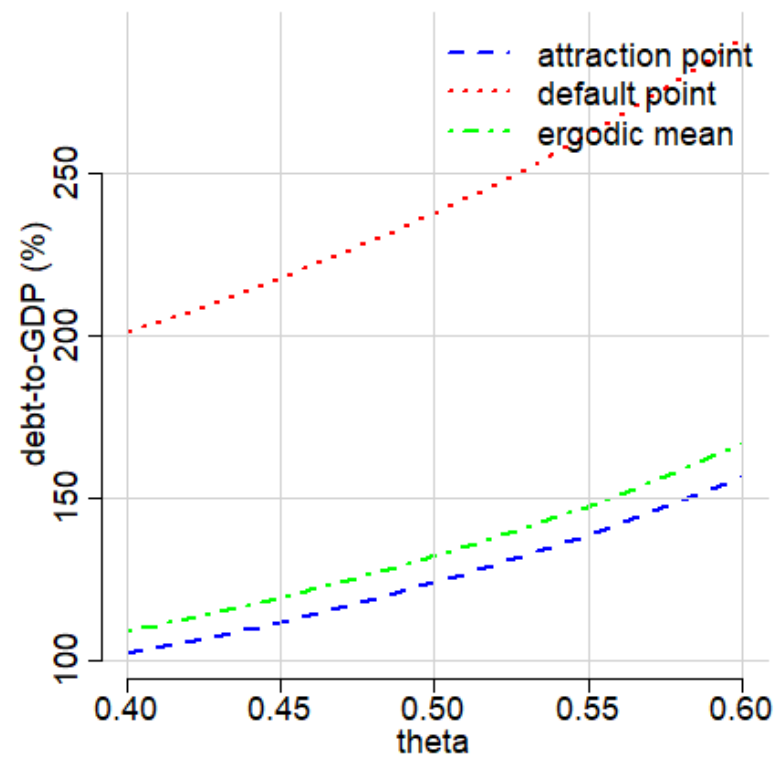

(b): Default rate and credit spreads

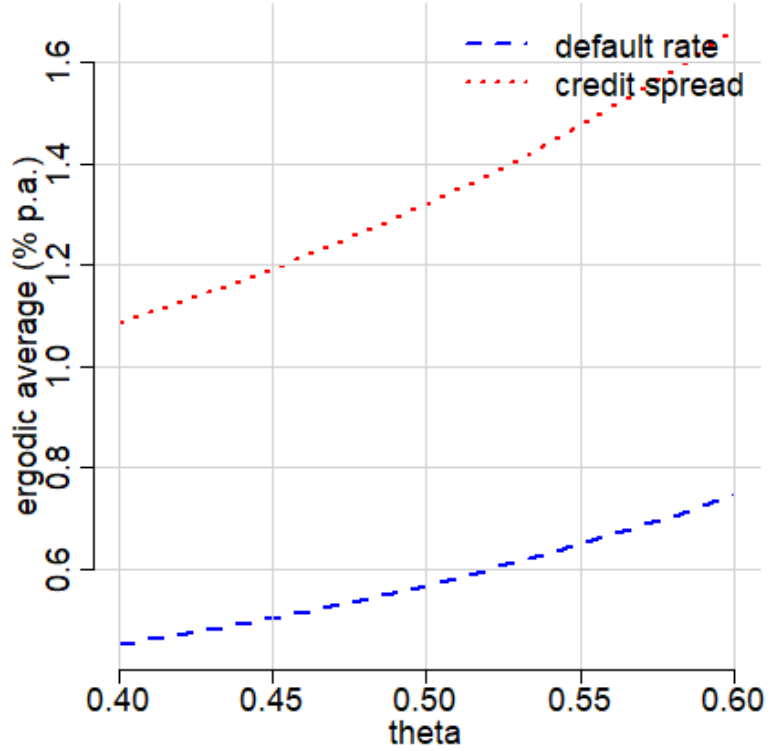

Plots computed assuming $\mu=2 \%$ p.a., $\sigma=20 \%$ p.a., $1 / m=10$ years, $\theta=50 \%, \alpha=96 \%, v=40 \%, r=\kappa=5 \%$ and $\delta=6 \%$.

Figure A-8: Sensitivities to $\mu$

(a): debt-to-income

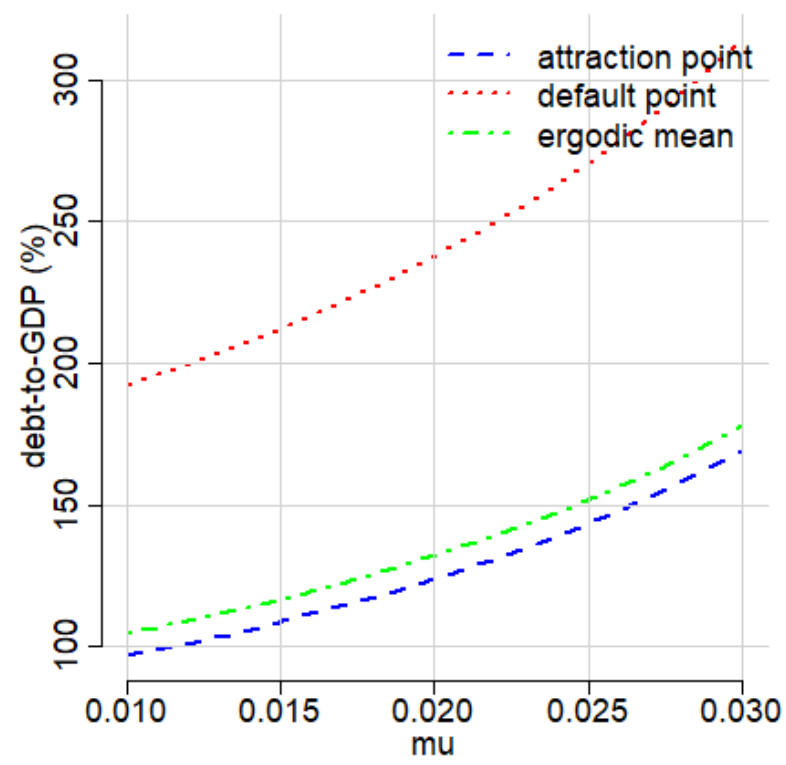

(b): Default rate and credit spreads

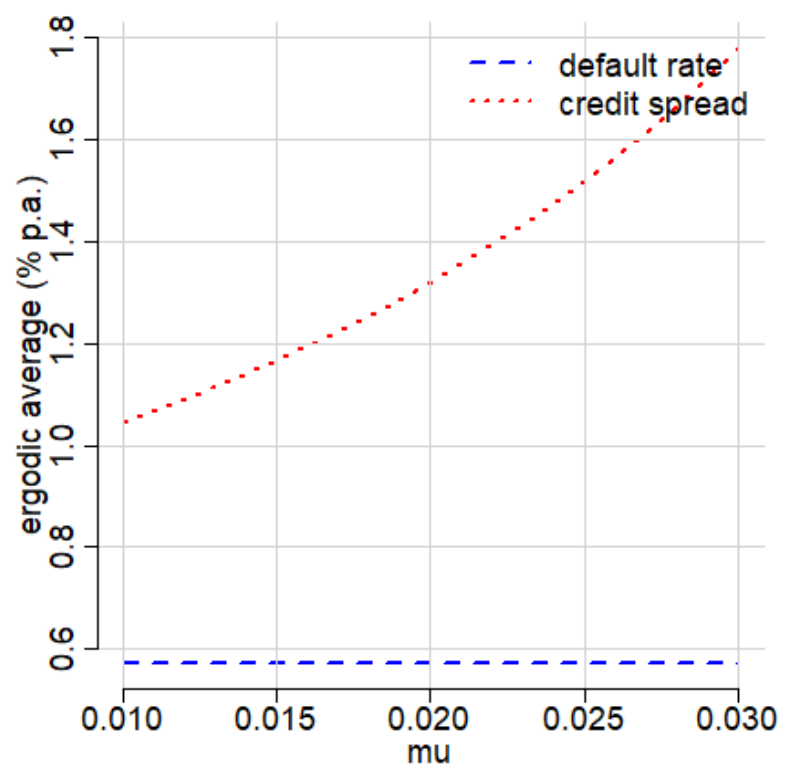

Plots computed assuming $\mu=2 \%$ p.a., $\sigma=20 \%$ p.a., $1 / m=10$ years, $\theta=50 \%, \alpha=96 \%, v=40 \%, r=\kappa=5 \%$ and $\delta=6 \%$.

$$
d x_{t}^{(g, \boldsymbol{\tau})}=\left(g\left(x_{t}^{(g, \tau)}, s_{t}\right)-(m+\mu) x_{t}^{(g, \tau)}\right) d t-x_{t}^{(g, \tau)}(\sigma-\varsigma) \cdot d \tilde{\boldsymbol{B}}_{t}+(\theta-1) x_{t}^{(g, \boldsymbol{\tau})} d N_{d, t}^{(\boldsymbol{\tau})}
$$


Figure A-9: Sensitivities to $\sigma$

(a): debt-to-income

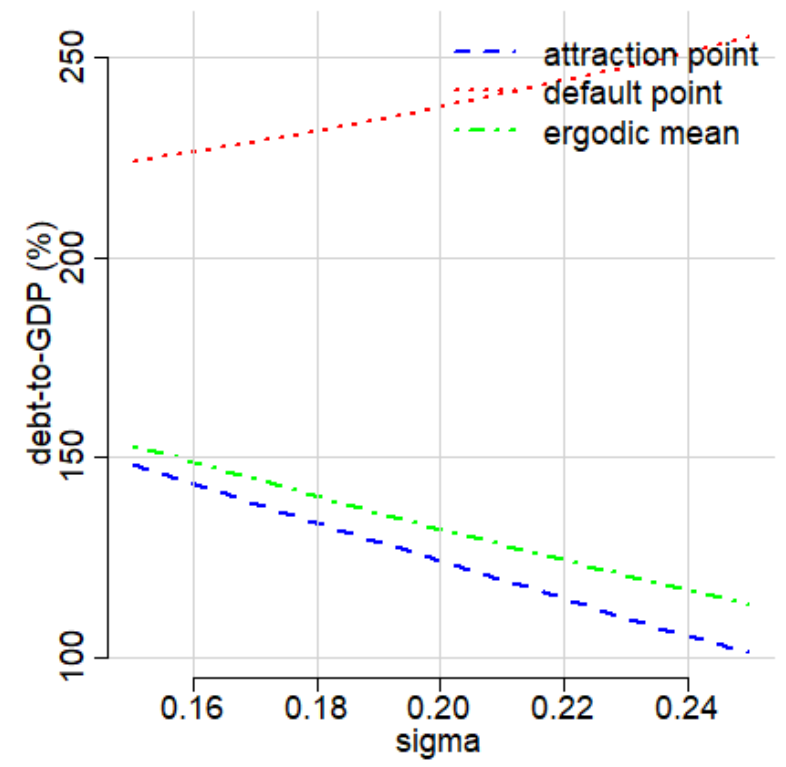

(b): Default rate and credit spreads

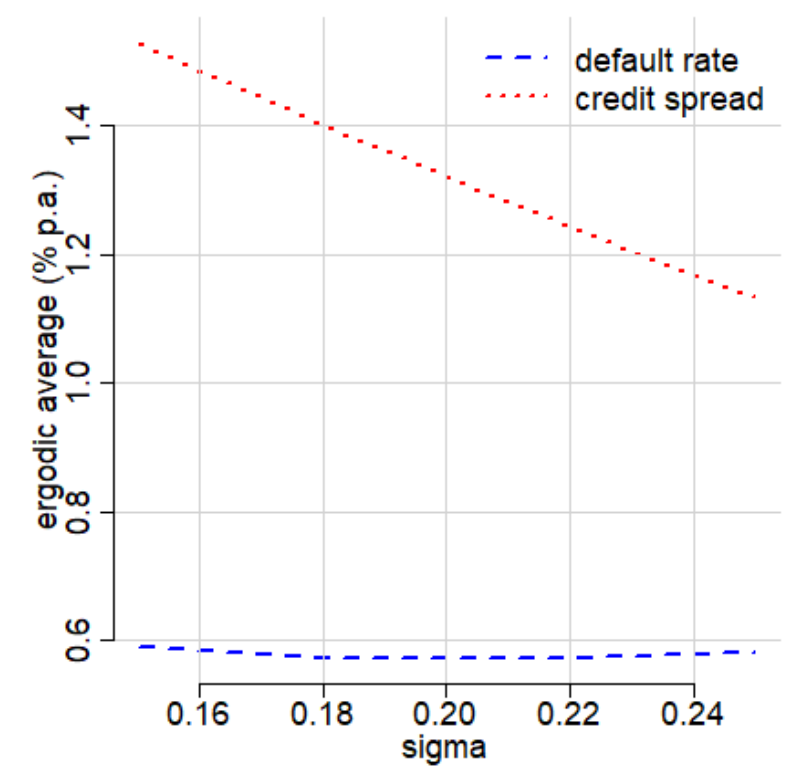

Plots computed assuming $\mu=2 \%$ p.a., $\sigma=20 \%$ p.a., $1 / m=10$ years, $\theta=50 \%, \alpha=96 \%, v=40 \%, r=\kappa=5 \%$ and $\delta=6 \%$.

In the continuation region $(0, \bar{x}), v$ satisfies:

$$
(\delta-\mu) v(x)=1-(\kappa+m) x-(\mu+m) x v^{\prime}(x)+\frac{1}{2}|\sigma-\varsigma|^{2} x^{2} v^{\prime \prime}(x)
$$

This is a second order ordinary differential equation, whose general solutions are power functions of $x$. The exponent of the general solutions solves the quadratic equation:

$$
\frac{1}{2}|\sigma-\varsigma|^{2} z_{\varsigma}^{2}-\left(m+\mu+\frac{1}{2}|\sigma-\varsigma|^{2}\right) \xi_{\varsigma}-(\delta-\mu)=0
$$

Given the parameter restriction (31), this quadratic equation admits one positive, and one negative roots. We also know that $\xi_{\varsigma}>1$. Since $v$ must be finite as $x \rightarrow 0$, we eliminate the negative root, and note $\xi_{\zeta}$ the positive one. Our second boundary condition uses the fact that upon default, the small open economy suffers a discrete income drop by a factor $\alpha$, and immediately emerges from autarky with a debt-to-income ratio that is a fraction $\theta$ of its pre-default debt-to-income ratio:

$$
v\left(\bar{x}_{\zeta}\right)=\alpha v\left(\theta \bar{x}_{\zeta}\right)
$$

Using these, we can express $v$ as follows on $[0, \bar{x}]$ :

$$
v(x)=\frac{1}{\delta-\mu}\left[1-\left(\frac{1-\alpha}{1-\alpha \theta^{\tilde{\zeta}_{\varsigma}}}\right)\left(\frac{x}{\bar{x}_{\varsigma}}\right)^{\tilde{\zeta}_{\varsigma}}\right]-\left(\frac{\kappa+m}{\delta+m} x\right)\left[1-\left(\frac{1-\alpha \theta}{1-\alpha \theta^{\tau_{\varsigma}}}\right)\left(\frac{x}{\bar{x}_{\varsigma}}\right)^{\tilde{\zeta}_{\varsigma}-1}\right]
$$

The smooth-pasting condition takes the usual form:

$$
v^{\prime}\left(\bar{x}_{\varsigma}\right)=\alpha \theta v^{\prime}\left(\theta \bar{x}_{\varsigma}\right)
$$


Collecting these together, we compute the following default boundary $\bar{x}_{\varsigma}$ :

$$
\bar{x}_{\varsigma}=\frac{\xi_{\zeta}}{\xi_{\varsigma}-1}\left(\frac{\delta+m}{\kappa+m}\right)\left(\frac{1-\alpha}{1-\alpha \theta}\right) \frac{1}{\delta-\mu}
$$

The debt price $d$ per unit of debt outstanding can be computed by leveraging equation (21), which becomes in this particular case $d(x)=-v^{\prime}(x)$. In other words, for $x \in\left[0, \bar{x}_{\varsigma}\right]$, we have:

$$
d(x)=\left(\frac{\kappa+m}{\delta+m}\right)\left[1-\left(\frac{1-\alpha \theta}{1-\alpha \theta^{\xi_{\varsigma}}}\right)\left(\frac{x}{\bar{x}_{\varsigma}}\right)^{\xi_{\varsigma}-1}\right]
$$

Note that in the continuation region, the value function $v$ takes the following form:

$$
v(x)=\frac{1}{\delta-\mu}\left(1-\left(\frac{1-\alpha}{1-\alpha \theta^{\xi_{\varsigma}}}\right)\left(\frac{x}{\bar{x}_{\zeta}}\right)^{\xi_{\varsigma}}\right)-x d(x)
$$

The required expected excess return on the sovereign debt can be easily computed:

$$
\begin{aligned}
\pi(x, s) & =-\frac{x d^{\prime}(x)}{d(x)}(\sigma-\varsigma) \cdot v(s) \\
& =\frac{\xi_{\varsigma}-1}{\left(\frac{1-\alpha \theta^{\xi_{\zeta}}}{1-\alpha \theta}\right)\left(\frac{\bar{x}_{\varsigma}}{x}\right)^{\xi_{\zeta}-1}-1}(\sigma-\varsigma) \cdot \boldsymbol{v}(s)
\end{aligned}
$$

The issuance policy now takes a different form. Indeed, note that the debt price satisfies:

$$
\begin{aligned}
d(x) & =\hat{\mathbb{E}}^{x, s}\left[\int_{0}^{\infty} e^{-\int_{0}^{t}\left(r\left(s_{u}\right)+m+\frac{1}{2}|\varsigma|^{2}\right) d u+\int_{0}^{t} \varsigma \cdot d \boldsymbol{B}_{u}}(\alpha \theta)^{N_{d, t}^{(\tau)}}(\kappa+m) d t\right] \\
& =\stackrel{\circ}{\mathbb{E}}^{x, s}\left[\int_{0}^{\infty} e^{-\int_{0}^{t}\left(r\left(s_{u}\right)+m+\varsigma \cdot v\left(s_{u}\right)\right) d u}(\alpha \theta)^{N_{d, t}^{(\boldsymbol{\tau})}}(\kappa+m) d t\right]
\end{aligned}
$$

In the above, we have introduced the measure Prr, defined for any arbitrary Borel set $A \subseteq \mathcal{F}_{t}$ via $\operatorname{Pr}(A)=\mathbb{E}\left[\exp \left(-\frac{\mid \boldsymbol{s}^{2}}{2} t+\boldsymbol{\varsigma} \cdot \tilde{\boldsymbol{B}}_{t}\right) A\right] . \stackrel{\circ}{\boldsymbol{B}}_{t}:=\hat{\boldsymbol{B}}_{t}-\boldsymbol{\varsigma} t$ is a standard Brownian motion under Pr, and under such measure the debt-to-income ratio follows:

$$
\begin{array}{r}
d x_{t}^{(g, \boldsymbol{\tau})}=\left(g\left(x_{t}^{(g, \boldsymbol{\tau})}, s_{t}\right)-\left(m+\mu-|\boldsymbol{\sigma}-\boldsymbol{\varsigma}|^{2}-\boldsymbol{v}(s) \cdot(\boldsymbol{\sigma}-\boldsymbol{s})\right) x_{t}^{(g, \boldsymbol{\tau})}\right) d t \\
\quad-x_{t}^{(g, \boldsymbol{\tau})}(\boldsymbol{\sigma}-\boldsymbol{\varsigma}) \cdot d{\stackrel{\circ}{\boldsymbol{B}_{t}}}+(\theta-1) x_{t}^{(g, \boldsymbol{\tau})} d N_{d, t}^{(\boldsymbol{\tau})}
\end{array}
$$

The debt price thus satifies the following Feynman-Kac equation:

$(r(s)+m+\boldsymbol{s} \cdot \boldsymbol{v}(s)) d(x)=\kappa+m+\left[g(x, s)-\left(m+\mu-|\sigma-\varsigma|^{2}-\boldsymbol{v}(s) \cdot(\sigma-\varsigma)\right) x\right] d^{\prime}(x)+\frac{|\sigma-\varsigma|^{2}}{2} x^{2} d^{\prime \prime}(x)$

The issuance policy thus takes the following form:

$$
\begin{aligned}
g^{*}(x, s) & =\frac{d(x)}{-d^{\prime}(x)}(\delta-r(s)-\boldsymbol{s} \cdot \boldsymbol{v}(s))-x(\sigma-\boldsymbol{s}) \cdot \boldsymbol{v}(s) \\
& =\frac{\delta-(r(s)+\boldsymbol{s} \cdot \boldsymbol{v}(s))}{\xi_{\varsigma}-1}\left[\left(\frac{1-\alpha \theta^{\xi_{\varsigma}}}{1-\alpha \theta}\right)\left(\frac{\bar{x}_{\varsigma}}{x}\right)^{\xi_{\varsigma}-1}-1\right] x-x(\sigma-\boldsymbol{s}) \cdot \boldsymbol{v}(s)
\end{aligned}
$$




\section{A.11 Infrequent Trading Opportunities}

In this section, the government can issue debt only at Poisson arrival times (parameter $1 / \Delta$ ). We assume that in default, the government loses its entire income stream (i.e. $\alpha=0$ ), while creditors lose their entire investment (i.e. $\theta=0$ ). In the discussion that follows, we will assume the existence of an MPE characterized by the set of equations (A39), (A42) and (A40), to be described shortly.

\section{A.11.1 Results Applicable for any $\Delta$ and No Commitment}

In an MPE, the income-normalized value function for the government satisfies

$$
\begin{aligned}
\left(\delta+\frac{1}{\Delta}-\mu\right) v_{\Delta}(x)=1-(\kappa+m) x-(\mu+m) x v_{\Delta}^{\prime}(x)+\frac{\sigma^{2} x^{2}}{2} v_{\Delta}^{\prime \prime}(x) & \\
& +\frac{1}{\Delta} \max _{y}\left[v_{\Delta}(y)+(y-x) d_{\Delta}(y)\right]
\end{aligned}
$$

Equation (A39) is identical to equation (A21), except for the terms involving $1 / \Delta$ and related to the infrequent debt rebalancing opportunities. Let $n_{\Delta}(x)$ be the "jump-to" state, in other words

$$
n_{\Delta}(x)=\arg \max _{y}\left[v_{\Delta}(y)+(y-x) d_{\Delta}(y)\right]
$$

The "jump-to" state satisfies the optimality condition

$$
v_{\Delta}^{\prime}\left(n_{\Delta}(x)\right)+d_{\Delta}\left(n_{\Delta}(x)\right)+\left(n_{\Delta}(x)-x\right) d_{\Delta}^{\prime}\left(n_{\Delta}(x)\right)=0
$$

Optimality at the default boundary yields the standard smooth pasting condition $v_{\Delta}^{\prime}\left(\bar{x}_{\Delta}\right)=0$. The debt price satisfies the usual Feynman-Kac equation

$$
\left(\frac{1}{\Delta}+r+m\right) d_{\Delta}(x)=\kappa+m-\left(\mu+m-\sigma^{2}\right) x d_{\Delta}^{\prime}(x)+\frac{\sigma^{2} x^{2}}{2} d_{\Delta}^{\prime \prime}(x)+\frac{1}{\Delta} d_{\Delta}\left(n_{\Delta}(x)\right)
$$

At the default boundary, we must also have $d_{\Delta}\left(\bar{x}_{\Delta}\right)=0$. If we differentiate equation (A39) and use the envelop theorem, we obtain

$$
\left(\frac{1}{\Delta}+\delta+m\right) v_{\Delta}^{\prime}(x)=-(\kappa+m)-\left(\mu+m-\sigma^{2}\right) x v_{\Delta}^{\prime \prime}(x)+\frac{\sigma^{2} x^{2}}{2} v_{\Delta}^{\prime \prime \prime}(x)-\frac{1}{\Delta} d_{\Delta}\left(n_{\Delta}(x)\right)
$$

We add (A42) to this latter equation, and obtain a differential equation for $h_{\Delta}(x):=v_{\Delta}^{\prime}(x)+d_{\Delta}(x)$ :

$$
\left(\frac{1}{\Delta}+\delta+m\right) h_{\Delta}(x)=(\delta-r) d_{\Delta}(x)-\left(\mu+m-\sigma^{2}\right) x h_{\Delta}^{\prime}(x)+\frac{\sigma^{2} x^{2}}{2} h_{\Delta}^{\prime \prime}(x)
$$

Combine this with the boundary condition $h_{\Delta}\left(\bar{x}_{\Delta}\right)=0$, and we obtain

$$
h_{\Delta}(x)=\hat{\mathbb{E}}^{x}\left[\int_{0}^{\tau} e^{-(\delta+m+1 / \Delta) s}(\delta-r) d_{\Delta}\left(x_{s}\right) d s\right]
$$

$\hat{\mathbb{E}}$ is the expectation operator related to the probability measure $\hat{\operatorname{Pr}}$, under which $x_{t}$ satisfies

$$
d x_{t}=-\left(m+\mu-\sigma^{2}\right) x_{t} d t-\sigma x_{t} d \hat{Z}_{t}
$$

with $\hat{Z}_{t}$ a Brownian motion. This is the dynamic equation for the debt-to-income ratio under the assumption that the government never issues debt in the future. Several observations arise from this equation. 
First, $h_{\Delta}(x)$ represents the marginal gains from issuing one unit of debt. Equation (A43) shows that $h_{\Delta}(x)>0$; in other words, if the government was able to, it would always try to issue more debt. Since $h_{\Delta}(x)>0$, since the debt price should be a decreasing function in any MPE, we can use equation (A41) to conclude that $n_{\Delta}(x)>x$. Whenever the government has the Poisson opportunity to adjust its debt balance, it will choose to issue more debt.

Figure A-10: Debt price vs. $\Delta$

(a): debt price with high $\Delta$

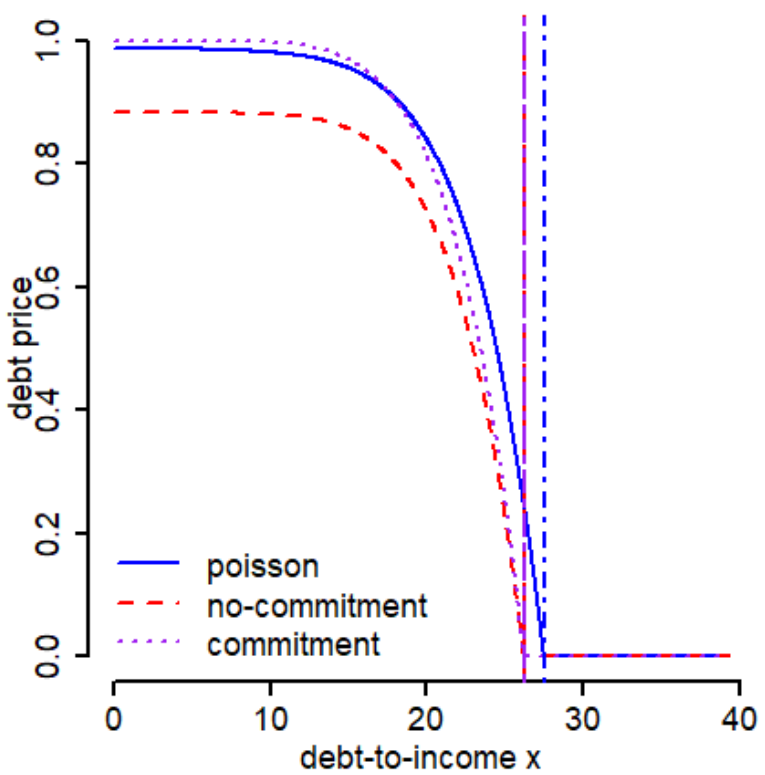

(b): debt price with low $\Delta$

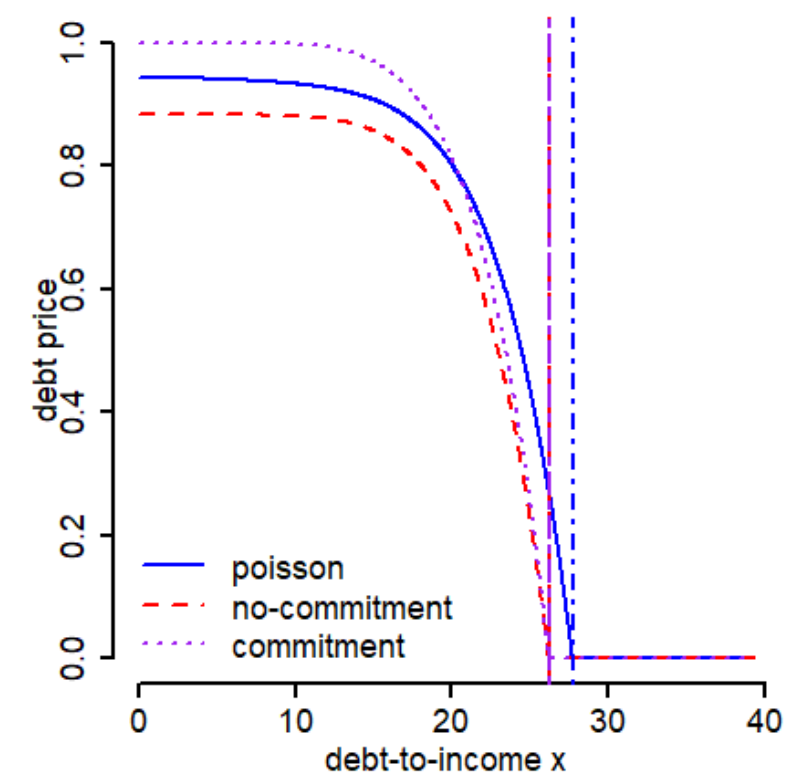

Plots show the debt price (blue solid line) for two different values of the expected trading interval $\Delta$, equal to 10 (left hand side) and 1 (right hand side). We also show (red dotted line) the debt price in our no-commitment Smooth MPE, and (purple dotted line) the debt price in the equilibrium where the government can commit never to issue any debt. Plots computed assuming $\mu=2 \%$ p.a., $\sigma=20 \%$ p.a., $1 / m=10$ years, $\theta=0 \%, \alpha=0 \%, v=0 \%, r=\kappa=5 \%$ and $\delta=7 \%$.

\section{A.11.2 Asymptotic Results when $\Delta \rightarrow 0$}

Since $d_{\Delta}(x) \in[0,1]$, equation (A43) makes it clear that for any $x, h_{\Delta}(x) \rightarrow 0$ as $\Delta \rightarrow 0$. More precisely, we can state that $h_{\Delta}(x)=O(\Delta)$. In other words, as the speed at which opportunities to issue debt increases, the sequence of functions $\left\{d_{\Delta}(x)+v_{\Delta}^{\prime}(x)\right\}_{\Delta \geq 0}$ (indexed by $\Delta$ ) converges to zero at rate $\Delta$. Using equation (A41), this also means that, as $\Delta \rightarrow 0$, we have for all $x$

$$
\left(n_{\Delta}(x)-x\right) d_{\Delta}^{\prime}\left(n_{\Delta}(x)\right) \rightarrow 0
$$

Thus, it must be the case that $n_{\Delta}(x) \rightarrow x$ as $\Delta \rightarrow 0$.

Under the assumption that the sequence of equilibrium functions $\left\{v_{\Delta}, d_{\Delta}, n_{\Delta}\right\}$ is continuous and differentiable in $\Delta$ as $\Delta \rightarrow 0$, the previous remarks allow us to perform an asymptotic expansion of our MPE as follows:

$$
\begin{aligned}
v_{\Delta}(x) & =v(x)+v_{1}(x) \Delta+o(\Delta) \\
d_{\Delta}(x) & =d(x)+d_{1}(x) \Delta+o(\Delta) \\
n_{\Delta}(x) & =x+n_{1}(x) \Delta+o(\Delta) \\
\bar{x}_{\Delta} & =\bar{x}+\bar{x}_{1} \Delta+o(\Delta)
\end{aligned}
$$


Figure A-11: Expected issuance rate vs. $\Delta$

(a): expected issuance rate with high $\Delta$

(b): expected issuance rate with low $\Delta$
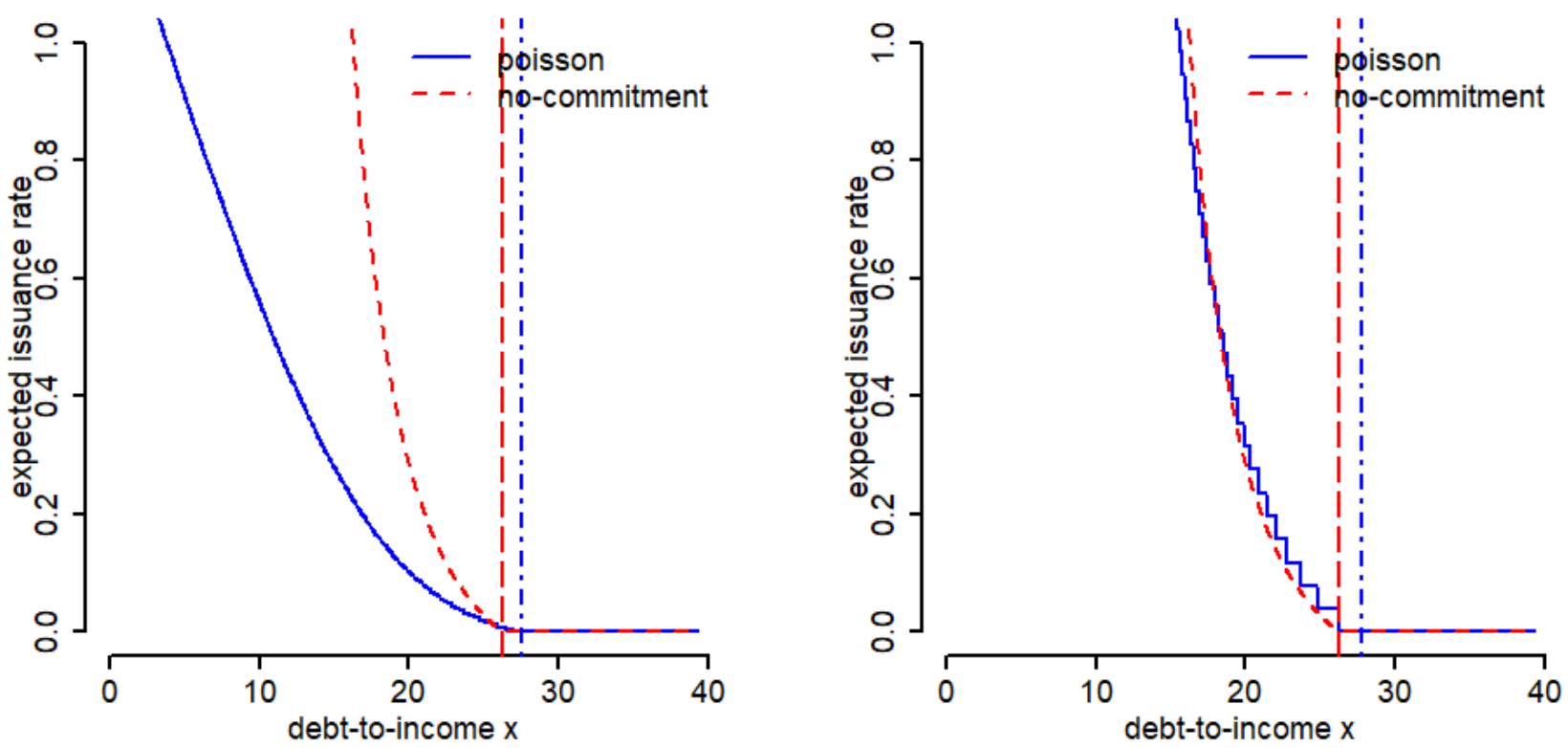

Plots show (blue solid line) the expected issuance rate $\left(n_{\Delta}(x)-x\right) / \Delta$ for two different expected trading intervals $\Delta$, equal to 10 years (left hand side) and 1 year (right hand side). We also show (red dotted line) the issuance rate $g(x)$ in our nocommitment Smooth MPE. Plots computed assuming $\mu=2 \%$ p.a., $\sigma=20 \%$ p.a., $1 / m=10$ years, $\theta=0 \%, \alpha=0 \%, v=0 \%$, $r=\kappa=5 \%$ and $\delta=7 \%$.

In the above, $v$ (resp. $d$ ) is the no-commitment value function (resp. no-commitment debt price), and $d(x)=-v^{\prime}(x)$. The asymptotic expansion of equation (A41) delivers the following equation

$$
v_{1}^{\prime}(x)+d_{1}(x)+n_{1}(x) d^{\prime}(x)=0
$$

Let us then notice the following

$$
\begin{aligned}
& v_{\Delta}\left(n_{\Delta}(x)\right)+\left(n_{\Delta}(x)-x\right) d_{\Delta}\left(n_{\Delta}(x)\right)-v_{\Delta}(x)=\Delta\left[v_{1}(x)+n_{1}(x) v^{\prime}(x)+n_{1}(x) d(x)-v_{1}(x)\right] \\
+ & \Delta^{2}\left[v_{2}(x)+n_{1}(x) v_{1}^{\prime}(x)+n_{2}(x) v^{\prime}(x)+\frac{n_{1}^{2}(x)}{2} v^{\prime \prime}(x)+n_{1}^{2}(x) d^{\prime}(x)+n_{2}(x) d(x)+n_{1}(x) d_{1}(x)-v_{2}(x)\right]
\end{aligned}
$$

When taking into account the fact that $v^{\prime}(x)+d(x)=0$, and when taking into account equation (A45), the above equation simplifies to

$$
v_{\Delta}\left(n_{\Delta}(x)\right)+\left(n_{\Delta}(x)-x\right) d_{\Delta}(x)-v_{\Delta}\left(n_{\Delta}(x)\right)=\Delta^{2} \frac{n_{1}^{2}(x)}{2} v^{\prime \prime}(x)+o\left(\Delta^{2}\right)
$$

The asymptotic expansion of equation (A39) delivers the following equation for the first order correction term

$$
(\delta-\mu) v_{1}(x)=\frac{n_{1}^{2}(x)}{2} v^{\prime \prime}(x)-(\mu+m) x v_{1}^{\prime}(x)+\frac{\sigma^{2} x^{2}}{2} v_{1}^{\prime \prime}(x)
$$

The expansion of the value matching condition $v_{\Delta}\left(\bar{x}_{\Delta}\right)=0$ yields (taking into account the optimality 
condition $\left.v^{\prime}(\bar{x})=0\right)$ :

$$
v_{1}(\bar{x})=0
$$

Thus, we have the following integral representation for $v_{1}$ :

$$
v_{1}(x)=\tilde{\mathbb{E}}^{x}\left[\int_{0}^{\tau} e^{-(\delta-\mu) t}\left(\frac{n_{1}^{2}\left(x_{t}\right)}{2}\right) v^{\prime \prime}\left(x_{t}\right) d t\right]>0
$$

$\tilde{\mathbb{E}}$ is the expectation operator related to the probability measure $\tilde{\operatorname{Pr}}$, under which $x_{t}$ satisfies

$$
d x_{t}=-(m+\mu) x_{t} d t-\sigma x_{t} d \tilde{Z}_{t}
$$

with $\tilde{Z}_{t}$ a Brownian motion. Thus, the first order correction term $v_{1}(x)$ must be positive. Welfare gains from trade exist when the government trades at Poisson arrival times, and those welfare gains vanish at rate $\Delta$ as $\Delta \rightarrow 0$. The expansion of the optimality condition $v_{\Delta}^{\prime}\left(\bar{x}_{\Delta}\right)=0$ yields:

$$
v_{1}^{\prime}(\bar{x})+\bar{x}_{1} v^{\prime \prime}(\bar{x})=0
$$

In particular, this means that

$$
\bar{x}_{1}=\frac{v_{1}^{\prime}(\bar{x})}{d^{\prime}(\bar{x})}
$$

We know that $d^{\prime}(\bar{x})<0$. Since $v_{1}(x)>0$ for $x<\bar{x}$ and since $v_{1}(\bar{x})=0$, it must be the case that $v_{1}^{\prime}(\bar{x})<0$. Thus, we know that $\bar{x}_{1}>0$. In other words, whenever trading is infrequent, the government will default on its debt at a higher debt-to-income ratio than when trading is continuous. The asymptotic expansion of equation (A42) delivers the following equation for the zero order correction term

$$
(r+m) d(x)=\kappa+m+\left[n_{1}(x)-\left(\mu+m-\sigma^{2}\right) x\right] d^{\prime}(x)+\frac{\sigma^{2} x^{2}}{2} d^{\prime \prime}(x)
$$

Thus, it must be the case that $n_{1}(x)=g(x)=(\delta-r) d(x) /\left(-d^{\prime}(x)\right)$, the optimal financing policy of the model with continuous trading. This result makes sense. Indeed, with adjustments at Poisson times, we have

$$
d x_{t}=-\left(m+\mu-\sigma^{2}\right) x_{t-} d t-\sigma x_{t-} d Z_{t}+\left(n_{\Delta}\left(x_{t-}\right)-x_{t-}\right) d N_{t}^{(\Delta)},
$$

with $N_{t}^{(\Delta)}$ a Poisson counting process with intensity $1 / \Delta$. Given our postulated asymptotic expansion, the last term in the dynamic equation above is

$$
\left(n_{\Delta}\left(x_{t-}\right)-x_{t-}\right) d N_{t}^{(\Delta)} \approx \Delta n_{1}\left(x_{t-}\right) d N_{t}^{(\Delta)}=n_{1}\left(x_{t-}\right) d t+\Delta n_{1}\left(x_{t-}\right)\left(d N_{t}^{(\Delta)}-\frac{1}{\Delta} d t\right)
$$

Taken together, these results show that the first order correction term $v_{1}(x)$ is equal to

$$
v_{1}(x)=\left(\frac{\delta-r}{2}\right) \hat{\mathbb{E}}^{x}\left[\int_{0}^{\tau} e^{-(\delta-\mu) t} g\left(x_{t}\right) d\left(x_{t}\right) d t\right]
$$

Finally, using the fact that $n_{1}(x)=g(x)$ and using equation (A45), it means that

$$
v_{1}^{\prime}(x)+d_{1}(x)=(\delta-r) d(x)
$$

Let $p(x):=g(x) d(x)$ be proceeds raised from bond issuances per unit of time in the no-commitment 
equilibrium. If we differentiate equation (A46), and if we leverage the fact that $n_{1}^{2}(x) v^{\prime \prime}(x)=(\delta-r) p(x)$, we obtain

$$
(\delta+m) v_{1}^{\prime}(x)=\left(\frac{\delta-r}{2}\right) p^{\prime}(x)-\left(\mu+m-\sigma^{2}\right) x v_{1}^{\prime \prime}(x)+\frac{\sigma^{2} x^{2}}{2} v_{1}^{\prime \prime \prime}(x)
$$

In other words, $v_{1}^{\prime}(x)$ admits the integral representation

$$
v_{1}^{\prime}(x)=\mathbb{E}^{x}\left[\int_{0}^{\tau} e^{-(\delta+m) t}\left(\frac{\delta-r}{2}\right) p^{\prime}\left(x_{t}\right) d t+e^{-(\delta+m) \tau} v_{1}^{\prime}(\bar{x})\right]<0
$$

The inequality above stems from the fact that we showed previously that $v_{1}^{\prime}(\bar{x})<0$, and that

$$
p^{\prime}(x)=-d(x)+\left(\frac{d(x)}{d^{\prime}(x)}\right)^{2} d^{\prime \prime}(x)<0
$$

Thus, $d_{1}$ admits the integral representation

$$
d_{1}(x)=(\delta-r) \mathbb{E}^{x}\left[\int_{0}^{\tau} e^{-(\delta+m) t}\left(\kappa+m-\frac{p^{\prime}\left(x_{t}\right)}{2}\right) d t\right]-\mathbb{E}^{x}\left[e^{-(\delta+m) \tau} \bar{x}_{1} d^{\prime}(\bar{x})\right]
$$

\section{A.11.3 Commitment}

Imagine now that the government can commit to a particular capital structure strategy. In particular, we assume that at each debt financing opportunity, the government rebalances its debt towards a debt-toincome target $x^{*}$. At time zero, when the government is not indebted, it chooses the optimal leverage $x^{*}$ at which it commits to releverage, when given the opportunity to do so in the future. Note $v_{\Delta, c}\left(\cdot ; x^{*}\right)$ (resp. $\left.d_{\Delta, c}\left(\cdot ; x^{*}\right)\right)$ the income-normalized value function given our commitment assumption. In this commitment MPE, the income-normalized value function for the government satisfies

$$
\begin{aligned}
\left(\frac{1}{\Delta}+\delta-\mu\right) v_{\Delta, c}\left(x ; x^{*}\right)=1-(\kappa+m) x-(\mu & +m) x v_{\Delta, c}^{\prime}\left(x ; x^{*}\right)+\frac{\sigma^{2} x^{2}}{2} v_{\Delta, c}^{\prime \prime}\left(x ; x^{*}\right) \\
& +\frac{1}{\Delta} \max \left[0, v_{\Delta, c}\left(x^{*} ; x^{*}\right)+\left(x^{*}-x\right) d_{\Delta, c}\left(x^{*} ; x^{*}\right)\right]
\end{aligned}
$$

The maximum operator indicates that at the time the government has the opportunity to adjust its debtto-income ratio to $x^{*}$, it can choose to default rather than change its indebtedness. In equilibrium, this may happen when the government has to buy back its own debt, and finds it more appealing to default. Note $\mathbb{J}_{c}\left(x ; x^{*}\right):=\mathbb{1}\left\{v_{\Delta, c}\left(x^{*} ; x^{*}\right)+\left(x^{*}-x\right) d_{\Delta, c}\left(x^{*} ; x^{*}\right) \geq 0\right\}$ the "survival" indicator, equal to 1 whenever a trading opportunity occurs and the government prefers to change its leverage rather than default. The debt price must then satisfy

$$
\begin{aligned}
\left(\frac{1}{\Delta}+r+m\right) d_{\Delta, c}\left(x ; x^{*}\right)=\kappa+m-\left(\mu+m-\sigma^{2}\right) x d_{\Delta, c}^{\prime}\left(x ; x^{*}\right) & +\frac{\sigma^{2} x^{2}}{2} d_{\Delta, c}^{\prime \prime}\left(x ; x^{*}\right) \\
& +\frac{1}{\Delta} \mathbb{J}_{c}\left(x ; x^{*}\right) d_{\Delta, c}\left(x^{*} ; x^{*}\right)
\end{aligned}
$$

It is thus natural to postulate an equilibrium with 2 default boundaries $\bar{x}_{c}\left(x^{*}\right)$ and $\bar{x}_{c}\left(x^{*}\right)>\bar{x}_{c}\left(x^{*}\right)>x^{*}$.

- When $x \leq \bar{x}_{c}\left(x^{*}\right)$, the debt-to-income ratio evolves with Brownian shocks only, except at Poisson arrival times, points at which the government issues (or buys back) a lump amount of debt to reach 
the debt-to-income ratio $x^{*}$;

- When $x \in\left(\bar{x}_{c}\left(x^{*}\right), \overline{\bar{x}}_{c}\left(x^{*}\right)\right)$, the debt-to-income ratio evolves with Brownian shocks only, except at Poisson arrival times, points at which the government finds it optimal to default rather than to buy back a lump amount of debt to reach the debt-to-income ratio $x^{*}$;

- When $x$ reaches $\overline{\bar{x}}_{c}\left(x^{*}\right)$, the government elects to default.

At the boundary $\bar{x}_{c}\left(x^{*}\right)$, the value function and debt price must be $\mathcal{C}^{1}$. At the default boundary $\overline{\bar{x}}_{c}\left(x^{*}\right)$, we have the following value matching and smooth pasting conditions for the debt price and value function:

$$
d_{\Delta, c}\left(\overline{\bar{x}}_{c}\left(x^{*}\right) ; x^{*}\right)=0 \quad v_{\Delta, c}\left(\overline{\bar{x}}_{c}\left(x^{*}\right) ; x^{*}\right)=0 \quad v_{\Delta, c}^{\prime}\left(\overline{\bar{x}}_{c}\left(x^{*}\right) ; x^{*}\right)=0
$$

One can solve for the debt prices, using $\eta_{2}>0>\eta_{1}$ for the roots of the characteristic polynomial

$$
\frac{\sigma^{2}}{2} \eta^{2}-\left(m+\mu-\frac{\sigma^{2}}{2}\right) \eta-\left(r+m+\frac{1}{\Delta}\right)=0
$$

Denote $d^{*}:=d\left(x^{*} ; x^{*}\right)$, and $\bar{d}:=d\left(\bar{x}_{c}\left(x^{*}\right) ; x^{*}\right)$. The debt price satisfies

$$
\begin{aligned}
& d\left(x ; x^{*}\right)=\frac{\kappa+m+d^{*} / \Delta}{r+m+1 / \Delta}-\left[\frac{\kappa+m+d^{*} / \Delta}{r+m+1 / \Delta}-\bar{d}\right]\left(\frac{x}{\bar{x}_{c}\left(x^{*}\right)}\right)^{\eta_{2}}, \quad x \in\left(0, \bar{x}_{c}\left(x^{*}\right)\right) \\
& d\left(x ; x^{*}\right)=\frac{\kappa+m}{r+m+1 / \Delta}+d_{1}\left(\frac{x}{\overline{\bar{x}}_{c}\left(x^{*}\right)}\right)^{\eta_{1}}+d_{2}\left(\frac{x}{\overline{\bar{x}}_{c}\left(x^{*}\right)}\right)^{\eta_{2}}, \quad x \in\left(\bar{x}_{c}\left(x^{*}\right), \overline{\bar{x}}_{c}\left(x^{*}\right)\right)
\end{aligned}
$$

Given $x^{*}, \bar{x}_{c}\left(x^{*}\right)$ and $\overline{\bar{x}}_{c}\left(x^{*}\right)$, we have 4 unknown constants $\left(d^{*}, \bar{d}, d_{1}, d_{2}\right)$ to determine. The requirement that $d\left(x^{*} ; x^{*}\right)=d^{*}$ delivers one equation. The requirement that $d$ be $\mathcal{C}^{1}$ at $x=\bar{x}_{c}\left(x^{*}\right)$ delivers two more equations. The requirement that $d\left(\overline{\bar{x}}_{c}\left(x^{*}\right) ; x^{*}\right)=0$ delivers one last equation. Note that this system of 4 equations in 4 unknown is a linear system.

We can also solve for the value function. Let $\xi_{2}>0>\xi_{1}$ be the roots of the characteristic polynomial

$$
\frac{\sigma^{2}}{2} \xi^{2}-\left(m+\mu+\frac{\sigma^{2}}{2}\right) \eta-\left(\delta+\frac{1}{\Delta}-\mu\right)=0
$$

The value function takes the following form

$$
\begin{aligned}
& v_{\Delta, c}\left(x ; x^{*}\right)=\left[\frac{1+\left(v^{*}+x^{*} d^{*}\right) / \Delta}{\delta+1 / \Delta-\mu}\right]\left[1-\left(\frac{x}{\bar{x}_{c}\left(x^{*}\right)}\right)^{\xi_{2}}\right]-x\left[\frac{\kappa+m+d^{*} / \Delta}{\delta+m+1 / \Delta}\right]\left[1-\left(\frac{x}{\bar{x}_{c}\left(x^{*}\right)}\right)^{\xi_{2}-1}\right]+\bar{v}\left(\frac{x}{\bar{x}_{c}\left(x^{*}\right)}\right)^{\xi_{2}}, \\
& x \in\left(0, \bar{x}_{c}\left(x^{*}\right)\right) \\
& v_{\Delta, c}\left(x ; x^{*}\right)=\frac{1}{\delta+1 / \Delta-\mu}-\frac{\kappa+m}{\delta+m+\Delta} x+v_{1}\left(\frac{x}{\overline{\bar{x}}_{c}\left(x^{*}\right)}\right)^{\xi_{1}}+v_{2}\left(\frac{x}{\overline{\bar{x}}_{c}\left(x^{*}\right)}\right)^{\xi_{2}} \\
& x \in\left(\bar{x}_{c}\left(x^{*}\right), \overline{\bar{x}}_{c}\left(x^{*}\right)\right)
\end{aligned}
$$

Given $x^{*}, \bar{x}_{c}\left(x^{*}\right)$ and $\overline{\bar{x}}_{c}\left(x^{*}\right)$, we have 4 unknown constants $\left(v^{*}, \bar{v}, v_{1}, v_{2}\right)$ to determine. The requirement that $v\left(x^{*} ; x^{*}\right)=v^{*}$ delivers one equation. The requirement that $v$ be $\mathcal{C}^{1}$ at $x=\bar{x}_{c}\left(x^{*}\right)$ delivers two more equations. The requirement that $v\left(\bar{x}_{c}\left(x^{*}\right) ; x^{*}\right)=0$ delivers one last equation. Note that this system of 4 equations in 4 unknown is a linear system.

For a given $x^{*}$, we are left with only $\bar{x}_{c}\left(x^{*}\right)$ and $\overline{\bar{x}}_{c}\left(x^{*}\right)$ to determine. These barriers solve a system of 2 non-linear equations. The first non-linear equation comes from the fact that for $x=\bar{x}_{c}\left(x^{*}\right)$, the government who has an opportunity to change its debt-to-income ratio is exactly indifferent between (a) buying back its bonds to jump back to a debt-to-income ratio $x^{*}$, or (b) defaulting. In other words,

$$
v_{\Delta, c}\left(x^{*} ; x^{*}\right)+\left(x^{*}-\bar{x}_{c}\left(x^{*}\right)\right) d_{\Delta, c}\left(x^{*} ; x^{*}\right)=0
$$


Figure A-12: Value function and debt price with infrequent trades and commitment

(a): value function $v_{\Delta, c}$

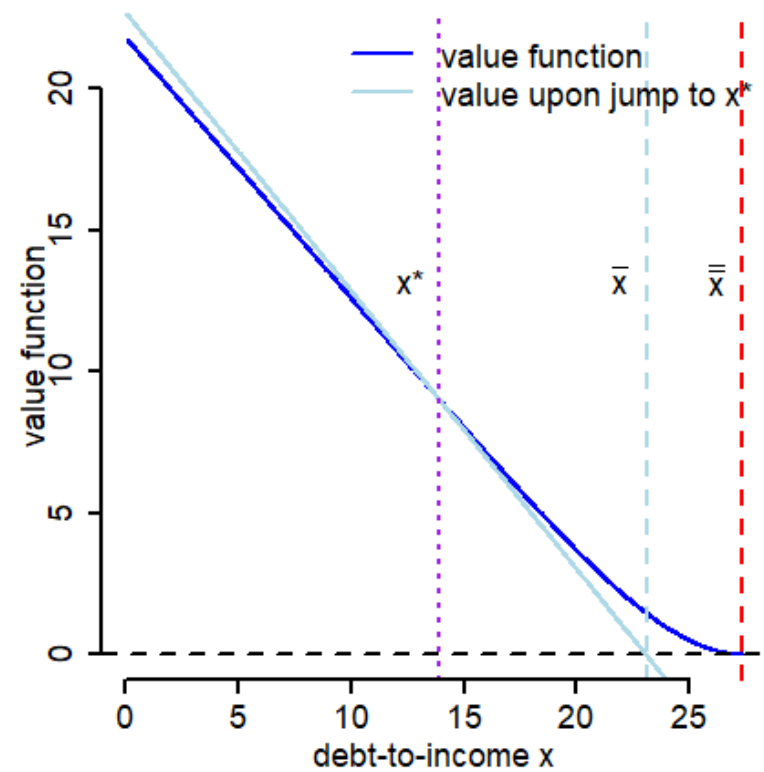

(b): debt price $d_{\Delta, c}$

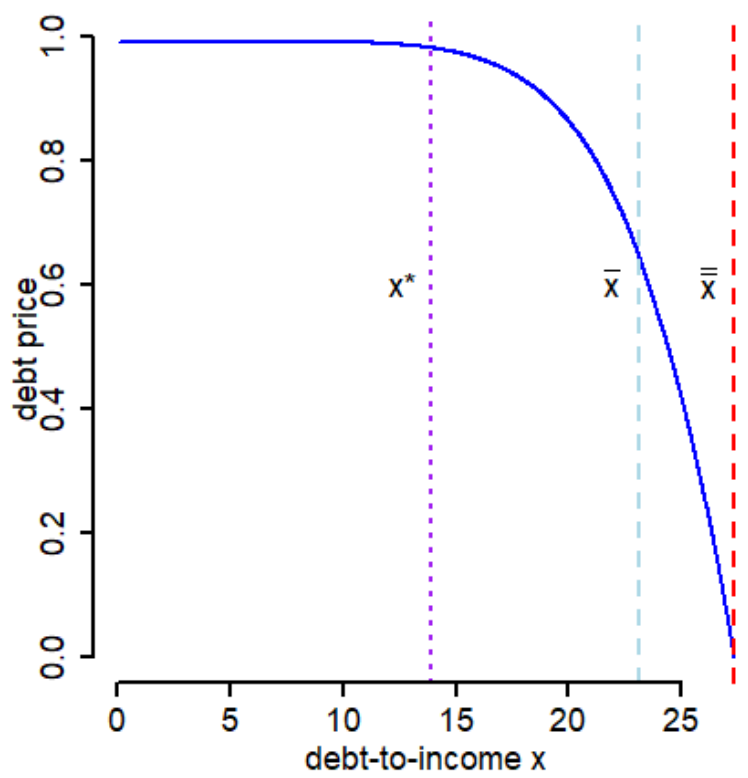

Plots show the value function and debt price for an expected trading interval $\Delta=1$ year, in the case where the government can commit to always returning to a debt-to-income ratio $x^{*}$. Plots computed assuming $\mu=2 \%$ p.a., $\sigma=20 \%$ p.a., $1 / m=10$ years, $\theta=0 \%, \alpha=0 \%, v=0 \%, r=\kappa=5 \%$ and $\delta=7 \%$.

Finally, default optimality yields the smooth pasting condition

$$
v_{\Delta, c}^{\prime}\left(\overline{\bar{x}}_{c}\left(x^{*}\right) ; x^{*}\right)=0
$$

These last two equations allow us to pin down $\bar{x}_{c}\left(x^{*}\right)$ and $\overline{\bar{x}}_{c}\left(x^{*}\right)$ given a choice of debt-to-income commitment $x^{*}$. At time zero, the government chooses the optimal leverage $x^{*}$ to commit to, in other words the government solves

$$
\max _{x^{*}} v_{\Delta, c}\left(x^{*} ; x^{*}\right)+x^{*} d_{\Delta, c}\left(x^{*} ; x^{*}\right)
$$

Figure A-12 illustrates the value function and debt price for a particular choice of $\Delta$. In the region $x<\bar{x}_{c}$, the debt-to-income ratio of the sovereign moves only due to income shocks, and due to Poisson adjustment events. When the debt-to-income ratio is located on $\left(\bar{x}_{c}, \overline{\bar{x}}_{c}\right)$, Poisson arrivals of trading opportunities introduce jump-to-default risk for creditors. At $x=\bar{x}_{c}$, upon the arrival of an adjustment opportunity, the government is exactly indifferent between defaulting and adjusting its debt-to-income ratio to $x^{*}$.

Finally, Figure A-13 illustrates how the optimal default boundaries and optimal initial leverage change with the trading time interval $\Delta$. As expected, the lower the expected trading interval, the closer the default boundaries $\bar{x}_{c}, \overline{\bar{x}}_{c}$ and $x^{*}$ are from each other, and the closer they are to the full-commitment optimal policy we characterize in our conclusion. Similarly, the greater the trading time interval, the lower the optimal leverage $x^{*}$. 
Figure A-13: Optimal boundaries in infrequent trading models

(a): Optimal default boundaries

(b): Target debt-to-income ratios
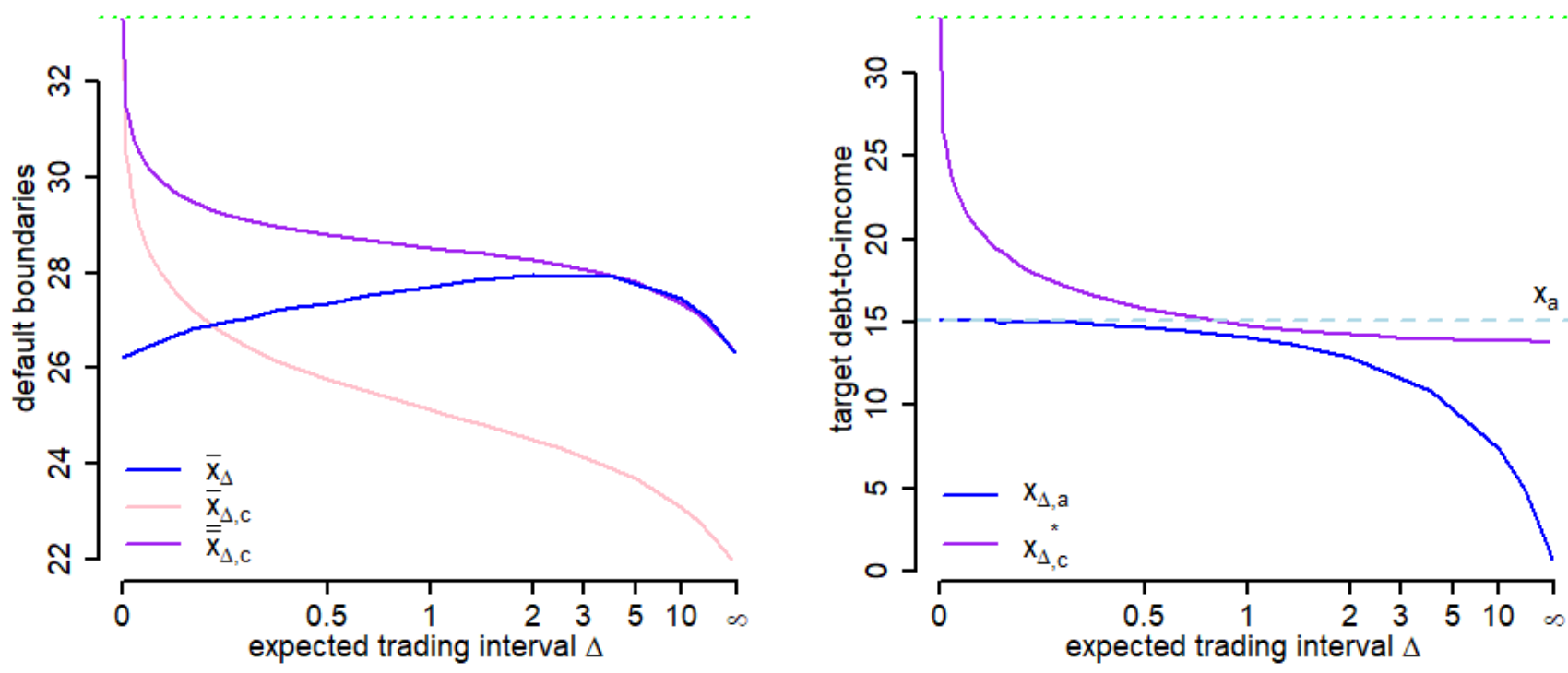

Figure (a) shows (i) the default boundary $\bar{x}_{\Delta}$ of the no-commitment model developed in Section A.11.1 (blue line) and (ii) the default boundaries $\bar{x}_{\Delta, c}$ and $\overline{\bar{x}}_{\Delta, c}$ of corresponding model with commitment and developed in Section A.11.3 (pink and purple lines). Figure (b) shows (i) the debt-to-income attraction point $x_{\Delta, a}$ of the no-commitment model (blue line) and (ii) the optimal commitment debt-to-income $x^{*}$ in the corresponding model with commitment (purple line). The dotted light blue line is the attraction point $x_{a}$ in the continuous trading no-commitment model of Section 5 . The plot is computed assuming $\mu=2 \%$ p.a., $\sigma=20 \%$ p.a., $1 / m=10$ years, $\theta=0 \%, \alpha=0 \%, v=0 \%, r=\kappa=5 \%$ and $\delta=7 \%$.

\section{A.12 Markov Switching Issuance Constraint}

In this section, the government alternates between a constrained and unconstrained state at Poisson arrival times. When unconstrained (state " $u$ "), the regime transitions to the constrained regime (state "c") with intensity $\lambda_{u}$. When constrained, the regime transitions to the unconstrained regime with intensity $\lambda_{c}$. We note $v_{u}$ (resp. $d_{u}$ ) the value function for the government (resp. the debt price) when unconstrained, and $v_{c}$ (resp. $d_{c}$ ) the value function for the government (resp. the debt price) when constrained.

In this setup, we postulate that a Smooth MPE exists, in which, when in the unconstrained state " $u$ ", the government uses an absolutely continuous debt face value policy as in the Smooth MPE of Section 5. This must then mean that the value functions in the constrained and unconstrained states $v_{c}$ and $v_{u}$ are equal to the value function in the no-commitment MPE $v: v_{u}(x)=v_{c}(x)=v(x)$ for all $x \in[0, \bar{x}]$. In such case, we know the debt price in state " $u$ " satisfies:

$$
d_{u}(x)=-v_{u}^{\prime}(x)=\frac{\kappa+m}{\delta+m}\left[1-\left(\frac{x}{\bar{x}}\right)^{\xi-1}\right]
$$

In the constrained regime " $c$ ", the debt price $d_{c}$ satisfies the following Feynman-Kac equation:

$$
\left(r+m+\lambda_{c}\right) d_{c}(x)=\kappa+m-\left(m+\mu-\sigma^{2}\right) x d_{c}^{\prime}(x)+\frac{\sigma^{2} x^{2}}{2} d_{c}^{\prime \prime}(x)+\lambda_{c} d_{u}(x)
$$


Note $\eta>0$ the positive root of the quadratic equation:

$$
\frac{\sigma^{2}}{2} \eta^{2}-\left(m+\mu-\frac{\sigma^{2}}{2}\right) \eta-\left(r+m+\lambda_{c}\right)=0
$$

Note that $\eta<\xi-1$ if and only if $\delta>r+\lambda_{c}$. Since $d_{c}$ must be finite when $x=0$ and since $d_{c}(\bar{x})=0$, we can compute the debt price $d_{c}$ as follows:

$$
\begin{aligned}
d_{c}(x)=\frac{\kappa+m}{r+m+\lambda_{c}}\left(1+\frac{\lambda_{c}}{\delta+m}\right)+\frac{\lambda_{c}}{\delta-\left(r+\lambda_{c}\right)} \frac{\kappa+m}{\delta+m}\left(\frac{x}{\bar{x}}\right)^{\xi-1} & \\
& -\left[\frac{\kappa+m}{r+m+\lambda_{c}}\left(1+\frac{\lambda_{c}}{\delta+m}\right)+\frac{\lambda_{c}}{\delta-\left(r+\lambda_{c}\right)} \frac{\kappa+m}{\delta+m}\right]\left(\frac{x}{\bar{x}}\right)^{\eta}
\end{aligned}
$$

Note that irrespective of the parameter $\lambda_{c}>0, d_{c}^{\prime}(x)<0$ as $x \rightarrow 0$. This is a sufficient condition to guarantee that $d_{c}$ is decreasing on $[0, \bar{x}]$. Finally, note that we can combine the differential equation satisfied by $v^{\prime}$ with the differential equation satisfied by $d_{u}$ :

$$
\begin{aligned}
& (\delta+m) v^{\prime}(x)=-(\kappa+m)-\left(m+\mu-\sigma^{2}\right) x v^{\prime \prime}(x)+\frac{\sigma^{2} x^{2}}{2} v^{\prime \prime \prime}(x) \\
& (r+m) d_{u}(x)=\kappa+m+\left[g_{u}(x)-\left(m+\mu-\sigma^{2}\right) x\right] d_{u}^{\prime}(x)+\frac{\sigma^{2} x^{2}}{2} d_{u}^{\prime \prime}(x)+\lambda_{u}\left(d_{c}(x)-d_{u}(x)\right)
\end{aligned}
$$

Adding up those two equations and remembering that $d_{u}(x)+v^{\prime}(x)=0$ yields the issuance policy $g_{u}$ in the unconstrained state " $u$ ":

$$
g_{u}(x)=(\delta-r) \frac{d_{u}(x)}{-d_{u}^{\prime}(x)}+\lambda_{u} \frac{d_{c}(x)-d_{u}(x)}{-d_{u}^{\prime}(x)}
$$

This issuance policy is positive across the state space. Indeed, $\delta>r, d_{u}$ is strictly decreasing in $x$ and it is easy to verify that $\Delta d(x):=d_{c}(x)-d_{u}(x)>0$, since $\Delta d(x)$ satisfies the ODE:

$$
\left(r+m+\lambda_{c}\right) \Delta d(x)=(\delta-r) d_{u}(x)-\left(m+\mu-\sigma^{2}\right) x \Delta d^{\prime}(x)+\frac{\sigma^{2}}{2} x^{2} \Delta d^{\prime \prime}(x)
$$

The boundary condition is $\Delta d(\bar{x})=0$, suggesting that $\Delta d(x)$ admits the Feynman-Kac integral representation:

$$
\Delta d(x)=\mathbb{E}^{x}\left[\int_{0}^{\tau} e^{-\left(r+m+\lambda_{c}\right) t}(\delta-r) d_{u}\left(x_{t}\right) d t\right] \geq 0
$$

Notice finally that if we include risk-premia such that $v_{u}<v_{c}$ (in other words such that in the sudden stop constrained state " $c$ ", credit market risk premia increase vs. the unconstrained state " $u$ "), then Feynman-Kac equations satisfied by the debt prices are

$$
\begin{aligned}
& (\delta+m) d_{u}(x)=\kappa+m-\left(m+\mu-\sigma^{2}\right) x d_{u}^{\prime}(x)+\frac{\sigma^{2} x^{2}}{2} d_{u}^{\prime \prime}(x) \\
& (r+m) d_{c}(x)=\kappa+m-\left(m+\mu-\sigma^{2}-v_{c} \sigma\right) x d_{c}^{\prime}(x)+\frac{\sigma^{2} x^{2}}{2} d_{c}^{\prime \prime}(x)+\lambda_{c}\left(d_{u}(x)-d_{c}(x)\right)
\end{aligned}
$$

Subtracting one equation from the other, our previous equation (A51) becomes

$$
\left(r+m+\lambda_{c}\right) \Delta d(x)=(\delta-r) d_{u}(x)+v_{c} \sigma x d_{c}^{\prime}(x)-\left(m+\mu-\sigma^{2}\right) x \Delta d^{\prime}(x)+\frac{\sigma^{2}}{2} x^{2} \Delta d^{\prime \prime}(x),
$$


which means that its integral representation is now

$$
\Delta d(x)=\mathbb{E}^{x}\left[\int_{0}^{\tau} e^{-\left(r+m+\lambda_{c}\right) t}\left[(\delta-r) d_{u}\left(x_{t}\right)+v_{c} \sigma x d_{c}^{\prime}(x)\right] d t\right]
$$

Thus, if the risk premium $v_{c}$ is large enough, it is easy to obtain $\Delta d(x)<0$ for some debt to income levels. We emphasize that that we cannot have $d_{c}(x)<d_{u}(x)$ for all $x \in[0, \bar{x}]$, since at $x=0$, we have

$$
d_{u}(0)=\frac{\kappa+m}{\delta+m} \quad d_{c}(0)=\frac{\kappa+m}{\delta+m} \frac{\delta+m+\lambda_{c}}{r+m+\lambda_{c}}>d_{u}(0)
$$

but for $x$ sufficiently high, since $d_{u}(\bar{x})=0$ and since $d_{c}^{\prime}(\bar{x})<0$, it must be the case that $d_{c}(x)<d_{u}(x)$. Note finally that in such case, the financing policy becomes

$$
g_{u}(x)=\left(\delta-\left(r+\pi_{u}(x)\right)\right) \frac{d_{u}(x)}{-d_{u}^{\prime}(x)}+\lambda_{u} \frac{d_{c}(x)-d_{u}(c)}{-d_{u}^{\prime}(x)} \quad \pi_{u}(x):=-v_{u} \sigma x d_{u}^{\prime}(x)
$$

\section{A.13 Debt Ceiling Policies}

In this section, we assume that there is a debt-to-income limit $x^{*}<\bar{x}$ such that if the small open economy's debt-to-income is above such threshold, the government is prevented from issuing any debt.

\section{A.13.1 Smooth Equilibrium}

We derive a condition on $x^{*}$ such that our Smooth MPE still exists. When that is the case, the value function $v_{c}$ is identical to the value function $v$ in the unconstrained economy. The debt price $d_{c}$ is such that when $x<x^{*}$, the debt price satisfies:

$$
d_{c}(x)=\frac{\kappa+m}{\delta+m}\left[1-\left(\frac{x}{\bar{x}}\right)^{\xi-1}\right]
$$

When $x \in\left(x^{*}, \bar{x}\right)$, the debt price satisfies the following ODE:

$$
(r+m) d_{c}(x)=\kappa+m-\left(m+\mu-\sigma^{2}\right) x d_{c}^{\prime}(x)+\frac{\sigma^{2} x^{2}}{2} d_{c}^{\prime \prime}(x)
$$

with two boundary conditions $d_{c}(\bar{x})=0$ and $d_{c}\left(x^{*}\right)=\frac{\kappa+m}{\delta+m}\left[1-\left(\frac{x^{*}}{\bar{x}}\right)^{\xi-1}\right]$. Let $\eta_{1}<0<\eta_{2}$ be the roots of the quadratic equation $\frac{\sigma^{2}}{2} \eta^{2}-\left(m+\mu-\frac{\sigma^{2}}{2}\right) \eta-(r+m)=0$. Since $\delta>r$, it is easy to verify that $\eta_{2}<\xi-1$. We can derive the debt price for $x \in\left(x^{*}, \bar{x}\right)$ to be

$$
d_{c}(x)=\frac{\kappa+m}{r+m}+d_{1}\left(\frac{x}{\bar{x}}\right)^{\eta_{1}}+d_{2}\left(\frac{x}{\bar{x}}\right)^{\eta_{2}}
$$

where $\rho:=x^{*} / \bar{x} \in(0,1)$ and

$$
\begin{aligned}
& d_{1}=\frac{1}{\rho^{\eta_{1}}-\rho^{\eta_{2}}}\left[\frac{\kappa+m}{\delta+m}\left(1-\rho^{\xi-1}\right)-\frac{\kappa+m}{r+m}\left(1-\rho^{\eta_{2}}\right)\right] \\
& d_{2}=\frac{1}{\rho^{\eta_{1}}-\rho^{\eta_{2}}}\left[-\frac{\kappa+m}{\delta+m}\left(1-\rho^{\xi-1}\right)+\frac{\kappa+m}{r+m}\left(1-\rho^{\eta_{1}}\right)\right]
\end{aligned}
$$


In order for this to be an equilibrium, a necessary and sufficient condition is that the debt price $d_{c}$ is decreasing on $\left[x^{*}, \bar{x}\right]$. For this to be the case, a sufficient condition is that it is decreasing at $x=x_{+}^{*}$, i.e.,

$$
\eta_{1} d_{1} \rho^{\eta_{1}}+\eta_{2} d_{2} \rho^{\eta_{2}}=\frac{\rho^{\eta_{1}+\eta_{2}}}{\rho^{\eta_{1}}-\rho^{\eta_{2}}}\left[\left(\eta_{2} \rho^{-\eta_{1}}-\eta_{1} \rho^{-\eta_{2}}\right)\left(\frac{\kappa+m}{r+m}-\frac{\kappa+m}{\delta+m}\left(1-\rho^{\xi-1}\right)\right)-\frac{\kappa+m}{r+m}\left(\eta_{2}-\eta_{1}\right)\right]<0 .
$$

Let $F(\rho)$ be the function in brackets above. It can be shown that $F$ is convex, with limit $+\infty$ as $\rho \rightarrow 0$ and limit 0 when $\rho \rightarrow 1$. It can also be shown that $F^{\prime}(\rho) \rightarrow-\infty$ as $\rho \rightarrow 0$ and that $F^{\prime}(\rho) \rightarrow \frac{\kappa+m}{\delta+m}\left(\eta_{2}-\right.$ $\left.\eta_{1}\right)(\xi-1)>0$ as $\rho \rightarrow 1$. In other words, there is a unique $\rho^{*}$ that satisfies $F\left(\rho^{*}\right)=0$, with $F(\rho)>0$ when $\rho<\rho^{*}$ and $F(\rho)<0$ when $\rho>\rho^{*}$. In other words, our conjectured smooth equilibrium is indeed an equilibrium if and only if $x^{*}>\rho^{*} \bar{x}:=\bar{x}^{*}$.

What remains to discuss is the fact that the debt price function $d_{c}$ is continuous but not continuously differentiable at $x=x^{*}$. Suppose that $d_{c}$ exhibits a convex kink:

$$
\lim _{x \nearrow x^{*}} d_{c}^{\prime}(x)<\lim _{x \searrow x^{*}} d_{c}^{\prime}(x)
$$

To rule out arbitrages, the government uses an issuance policy such that the controlled debt-to-income ratio becomes a Skew Brownian motion (see Harrison and Shepp (1981)):

$$
d x_{t}=\left[g\left(x_{t}\right)-\left(m+\mu-\sigma^{2}\right) x_{t}\right] d t-\sigma x_{t} d B_{t}+(2 p-1) d L_{t}^{x^{*}}\left(x_{t}\right)
$$

In the above, $L_{t}^{x^{*}}\left(x_{t}\right)$ is the local time at $x^{*}$ of $x_{t}$ :

$$
L_{t}^{x^{*}}\left(x_{t}\right):=\lim _{\epsilon \searrow 0} \frac{1}{2 \epsilon} \int_{0}^{t} 1_{\left\{x^{*}-\epsilon<x_{s} \leq x^{*}+\epsilon\right\}} d s
$$

The probability $p \in(0,1)$ of "moving to the right" is equal to:

$$
p=\frac{\lim _{x \nearrow x^{*}} d^{\prime}(x)}{\lim _{x \nearrow x^{*}} d^{\prime}(x)+\lim _{x \searrow x^{*}} d^{\prime}(x)}
$$

$x_{t}$ is thus singular at $x^{*}$ only, and one can think of the Skew Brownian motion as a way to distort probabilities of moving up or down at $x=x^{*}$, so that in expectations debt investors do not realize infinite (or minus infinite) capital gains' rates.

\section{A.13.2 Reflecting Equilibrium}

Consider now $x^{*}<\bar{x}^{*}$ so that a smooth equilibrium does not exist. We conjecture that there is an equilibrium in which the debt-to-income ratio is evolving "uncontrolled" on $\left[x^{*}, \bar{x}_{c}\right]$, and is controlled at $x=x^{*}$ via singular control. In other words, $x_{t}$ is now a regulated Brownian motion, regulated at $x=x^{*}$. The default boundary $\bar{x}_{c}$ is now different from the smooth equilibrium default boundary $\bar{x}$. The government value function and the debt price are then pinned down on $\left[x^{*}, \bar{x}_{c}\right]$, independently of what happens when $x<x^{*}$.

For $x<x^{*}$, as we will see, two situations can arise.

1. If $d_{c}\left(x^{*}\right)<\frac{\kappa+m}{\delta+m}$ (in other words if $x^{*}$ is sufficiently close to $\bar{x}^{*}$ and if $\delta$ is not "too large") and under the condition that $\hat{x}$, defined in equation (A54), satisfies $0<\hat{x}<x^{*}$, then there exists a jump region $\left[\hat{x}, x^{*}\right]$, in which the government finds it optimal to jump immediately to $x^{*}$, and a "smooth" region $[0, \hat{x}]$, in which the government finds it optimal to follow a smooth debt issuance strategy.

2. If $d_{c}\left(x^{*}\right)>\frac{\kappa+m}{\delta+m}$, or if $\hat{x} \notin\left(0, x^{*}\right)$, then only the jump region exists. 
In both cases, the value function $v_{c}$ and the debt price $d_{c}$ satisfy the following. For $x \in\left(x^{*}, \bar{x}_{c}\right)$ :

$$
\begin{gathered}
(\delta-\mu) v_{c}(x)=1-(\kappa+m) x-(m+\mu) x v_{c}^{\prime}(x)+\frac{\sigma^{2} x^{2}}{2} v_{c}^{\prime \prime}(x) \\
(r+m) d_{c}(x)=\kappa+m-\left(m+\mu-\sigma^{2}\right) x d_{c}^{\prime}(x)+\frac{\sigma^{2} x^{2}}{2} d_{c}^{\prime \prime}(x)
\end{gathered}
$$

with the boundary conditions:

$$
\begin{array}{ll}
v_{c}\left(\bar{x}_{c}\right)=0 & d_{c}\left(\bar{x}_{c}\right)=0 \\
v_{c}^{\prime}\left(x^{*}\right)+d_{c}\left(x^{*}\right)=0 & d_{c}^{\prime}\left(x^{*}\right)=0
\end{array}
$$

The first two boundary conditions are standard, as they correspond to value-matching conditions are $x=\bar{x}_{c}$. The last two boundary conditions are standard boundary conditions for regulated Brownian motions.

Let $\xi_{1}<0<\xi_{2}$ be the roots of $\frac{\sigma^{2}}{2} \xi^{2}-\left(m+\mu+\frac{\sigma^{2}}{2}\right) \xi-(\delta-\mu)=0$, and $\eta_{1}<0<\eta_{2}$ be the roots of $\frac{\sigma^{2}}{2} \eta^{2}-\left(m+\mu-\frac{\sigma^{2}}{2}\right) \eta-(r+m)=0$. Since $\delta>r$, it is easy to verify that $\eta_{2}<\xi_{2}-1$. Note $\rho:=x^{*} / \bar{x}_{c}$. The debt price for $x \in\left(x^{*}, \bar{x}_{c}\right)$ thus satisfies:

$$
d_{c}(x)=\frac{\kappa+m}{r+m}+d_{1}\left(\frac{x}{\bar{x}_{c}}\right)^{\eta_{1}}+d_{2}\left(\frac{x}{\bar{x}_{c}}\right)^{\eta_{2}}
$$

The constants of integration $d_{1}, d_{2}$ satisfy:

$$
d_{1}=\frac{\kappa+m}{r+m}\left(\frac{\eta_{2} \rho^{\eta_{2}}}{\eta_{1} \rho^{\eta_{1}}-\eta_{2} \rho^{\eta_{2}}}\right) \quad d_{2}=\frac{\kappa+m}{r+m}\left(\frac{-\eta_{1} \rho^{\eta_{1}}}{\eta_{1} \rho^{\eta_{1}}-\eta_{2} \rho^{\eta_{2}}}\right)
$$

The value function $v_{c}$ satisfies:

$$
v_{c}(x)=\frac{1}{\delta-\mu}-\frac{\kappa+m}{\delta+m} x+v_{1}\left(\frac{x}{\bar{x}_{c}}\right)^{\xi_{1}}+v_{2}\left(\frac{x}{\bar{x}_{c}}\right)^{\xi_{2}}
$$

The constants of integration $v_{1}, v_{2}$ satisfy:

$$
\begin{aligned}
& v_{1}=\frac{\bar{x}_{c}}{\xi_{1} \rho^{\xi_{1}-1}-\xi_{2} \rho^{\xi_{2}-1}}\left[\frac{\kappa+m}{\delta+m}\left(1-\xi_{2} \rho^{\xi_{2}-1}\right)+\xi_{2} \rho^{\xi_{2}-1} \frac{1}{\bar{x}_{c}(\delta-\mu)}-\frac{\kappa+m}{r+m}\left(1+\frac{\left(\eta_{2}-\eta_{1}\right) \rho^{\eta_{1}+\eta_{2}}}{\eta_{1} \rho^{\eta_{1}}-\eta_{2} \rho^{\eta_{2}}}\right)\right] \\
& v_{2}=\frac{\bar{x}_{c}}{\xi_{1} \rho^{\xi_{1}-1}-\xi_{2} \rho^{\xi_{2}-1}}\left[\frac{\kappa+m}{\delta+m}\left(\xi_{1} \rho^{\xi_{1}-1}-1\right)-\xi_{1} \rho^{\xi_{1}-1} \frac{1}{\bar{x}_{c}(\delta-\mu)}+\frac{\kappa+m}{r+m}\left(1+\frac{\left(\eta_{2}-\eta_{1}\right) \rho^{\eta_{1}+\eta_{2}}}{\eta_{1} \rho^{\eta_{1}}-\eta_{2} \rho^{\eta_{2}}}\right)\right]
\end{aligned}
$$

Finally, the default optimality condition $v_{c}^{\prime}\left(\bar{x}_{c}\right)$ pins down $\bar{x}_{c}$ :

$$
-\frac{\kappa+m}{\delta+m} \bar{x}_{c}+v_{1} \xi_{1}+v_{2} \xi_{2}=0
$$

Now let us then focus on $x<x^{*}$. Imagine first that $d_{c}\left(x^{*}\right)<\frac{\kappa+m}{\delta+m}$. One can show that this condition is equivalent to:

$$
d_{c}\left(x^{*}\right)<\frac{\kappa+m}{\delta+m} \Leftrightarrow v_{1} \xi_{1} \rho^{\xi_{1}}+v_{2} \xi_{2} \rho^{\xi_{2}}>0
$$

In such case, one can construct an equilibrium in which the government follows a smooth issuance strategy for $x \in(0, \hat{x})$, and a jump strategy for $x \in\left(\hat{x}, x^{*}\right)$, for some cutoff $\hat{x}$ endogenously determined. 
In the jump region $\left[\hat{x}, x^{*}\right]$, the debt price must be constant and the value function must be linear in $x$ :

$$
\begin{aligned}
& v_{c}(x)=v_{c}\left(x^{*}\right)+\left(x^{*}-x\right) d_{c}\left(x^{*}\right) \\
& d_{c}(x)=d_{c}\left(x^{*}\right)
\end{aligned}
$$

On the interval $[0, \hat{x}]$, since we postulated that the government follows a smooth financing policy, the value function must satisfy:

$$
(\delta-\mu) v_{c}(x)=1-(\kappa+m) x-(m+\mu) x v_{c}^{\prime}(x)+\frac{\sigma^{2} x^{2}}{2} v_{c}^{\prime \prime}(x)
$$

with boundary conditions $v_{\mathcal{C}}(0)=\frac{1}{\delta-\mu}$ and $\lim _{x \searrow \hat{x}} v_{\mathcal{C}}(x)=\lim _{x} \gamma_{\hat{x}} v_{\mathcal{C}}(x)$. We can solve for $v_{\mathcal{C}}(x)$ as:

$$
v_{\mathcal{c}}(x)=\frac{1}{\delta-\mu}\left[1-\left(\frac{x}{\hat{x}}\right)^{\tilde{\xi}_{2}}\right]-\frac{\kappa+m}{\delta+m} x\left[1-\left(\frac{x}{\hat{x}}\right)^{\tilde{\xi}_{2}-1}\right]+v_{\mathcal{c}}(\hat{x})\left(\frac{x}{\hat{x}}\right)^{\tilde{\xi}_{2}}
$$

Since $d_{c}(x)=-v_{c}^{\prime}(x)$, we obtain the following expression for $d_{c}$ :

$$
d_{c}(x)=\frac{\kappa+m}{\delta+m}-\frac{\xi_{2}}{\hat{x}}\left[v_{c}(\hat{x})+\frac{\kappa+m}{\delta+m} \hat{x}-\frac{1}{\delta-\mu}\right]\left(\frac{x}{\hat{x}}\right)^{\xi_{2}-1}
$$

The threshold $\hat{x}$ is pinned down by the continuity of $d_{c}$ at $\hat{x}$. Since $d_{c}(\hat{x}-)+v_{c}^{\prime}(\hat{x}-)=0$ (due to the fact that the strategy is smooth on $[0, \hat{x}])$, and since $d_{c}(\hat{x}+)+v_{c}^{\prime}(\hat{x}+)=0$ (due to the fact that the value function is linear, with slope $-d_{c}(\hat{x}+)$, on $\left.\left[\hat{x}, x^{*}\right]\right)$, the requirement that $d_{c}$ is continuous at $\hat{x}$ is identical to the requirement that $v_{\mathcal{C}}$ is $\mathcal{C}^{1}$ at such point. This condition can be shown to lead to:

$$
\hat{x}=\frac{\xi_{2}}{1-\xi_{2}}\left(\frac{\left(1-\xi_{1}\right) \rho^{\xi_{1}} v_{1}+\left(1-\xi_{2}\right) \rho^{\xi_{2}} v_{2}}{\xi_{1} \rho^{\xi_{1}} v_{1}+\xi_{2} \rho^{\tau_{2}} v_{2}}\right) x^{*}
$$

If $\hat{x}$ in equation (A54) satisfies $0<\hat{x}<x^{*}$, then an MPE exists, in which (a) the financing policy of the government is smooth on $(0, \hat{x}),(b)$ the government jumps to $x^{*}$ if $x \in\left(\hat{x}, x^{*}\right)$, and (c) the debt-to-income ratio evolves with income shocks for $x>x^{*}$ and is reflected at $x=x^{*}$.

If instead (a) the constant $\hat{x}$ defined in equation (A54) is outside the interval $\left[0, x^{*}\right]$, or (b) $d_{c}\left(x^{*}\right)>$ $\frac{\kappa+m}{\delta+m}$, then the "smooth" region no longer exists, and one can construct an equilibrium in which the government follows a jump strategy for $x \in\left[0, x^{*}\right]$. On such interval, the debt price must be constant and the value function must be linear in $x$ :

$$
v_{\mathcal{c}}(x)=v_{\mathcal{c}}\left(x^{*}\right)+\left(x^{*}-x\right) d_{\mathcal{c}}\left(x^{*}\right), \quad d_{\mathcal{c}}(x)=d_{\mathcal{c}}\left(x^{*}\right)
$$

\section{A.14 Maximum Issuance Rate}

In this section, the issuance rate (per unit of income) is capped at some arbitrary constant $\bar{g}>0$. We look for an equilibrium where the constraint binds whenever the debt-to-income ratio is below an endogenously determined cutoff $x^{*}$. For $x \in\left(x^{*}, \bar{x}_{c}\right)$, the constraint is slack, where $\bar{x}_{c}$ is the optimal default boundary. We take $x^{*}, \bar{x}_{c}$ as given in the analysis below, and then discuss the two conditions that pin down both endogenous boundaries. 


\section{A.14.1 Constrained Region $\left[0, x^{*}\right]$}

In the region $x \in\left[0, x^{*}\right)$, the issuance rate is bounded above by $\bar{g}$. On this interval, the (incomenormalized) welfare for the government and the debt price satisfy:

$$
\begin{aligned}
& (\delta-\mu) v(x)=1+\bar{g} d(x)-(\kappa+m) x+[\bar{g}-(\mu+m) x] v^{\prime}(x)+\frac{1}{2} \sigma^{2} x^{2} v^{\prime \prime}(x) \\
& (r+m) d(x)=(\kappa+m)+\left[\bar{g}-\left(\mu+m-\sigma^{2}\right) x\right] d^{\prime}(x)+\frac{1}{2} \sigma^{2} x^{2} d^{\prime \prime}(x)
\end{aligned}
$$

Note that these ordinary differential equations are decoupled - we can solve for $d(\cdot)$ first, and reinject $d$ into the ODE that $v$ is solution of. The boundary conditions are as follows:

$$
\begin{array}{llrl}
(\delta-\mu) v(0) & =1+\bar{g}\left(d(0)+v^{\prime}(0)\right) & \lim _{x \nearrow x^{*}} v(x) & =\lim _{x \searrow x^{*}} v(x) \\
(r+m) d(0) & =\kappa+m+\bar{g} d^{\prime}(0) & \lim _{x \nearrow x^{*}} d(x) & =\lim _{x \searrow x^{*}} d(x)
\end{array}
$$

The boundary conditions at $x=0$ are standard Robin boundary conditions, linking the value of the function to its derivative at that point. In what follow, we are going to treat $d\left(x^{*}\right)$ and $v\left(x^{*}\right)$ as parameters, and will eventually obtain equations that will tie $d\left(x^{*}\right)$ and $v\left(x^{*}\right)$ to the boundaries $x^{*}, \bar{x}_{c}$. We then have the following lemma.

Lemma 6 Let $A, B, C \in \mathbb{R}_{+}^{3}$. Let $f(x ; A, B, C)$ be a $\mathcal{C}^{2}$ function defined on $\left[0 ; x^{*}\right]$ (and thus finite on that interval) that satisfies the second order ordinary differential equation:

$$
x^{2} f^{\prime \prime}(x)+(A-B x) f^{\prime}(x)-C f(x)=0
$$

Then $f$ takes the following form, for some coefficients $k_{1}, k_{2} \in \mathbb{R}$ :

$$
f(x ; A, B, C)=k_{1} x^{-\eta_{1}} U\left(\eta_{1} ; 2 \eta_{1}+B+2 ; A x^{-1}\right)+k_{2} x^{-\eta_{2}} U\left(\eta_{2} ; 2 \eta_{2}+B+2 ; A x^{-1}\right)
$$

In the above, $U$ is the Tricommi confluent hypergeometric function (see Abramowitz and Stegun (1964), chapter 13) and the constants $\eta_{1}>0>\eta_{2}$ are the roots of the polynomial:

$$
\eta^{2}+(B+1) \eta-C=0
$$

The proof of the above lemma is straight-forward once we remember that Kummer's confluent hypergeometric function $M(a ; b ; z)$ and Tricommi's confluent hypergeometric function $U(a ; b ; z)$ are independent solutions to the Kummer differential equation:

$$
z u^{\prime \prime}(z)+(b-z) u^{\prime}(z)-a u(z)=0
$$

It is then easy to check that $x^{-\eta} M\left(\eta ; 2 \eta+B+2 ; A x^{-1}\right)$ and $x^{-\eta} U\left(\eta ; 2 \eta+B+2 ; A x^{-1}\right)$ are solutions of equation (A57). Note that $M$ admits the asymptotic behavior $M(a ; b ; z) \sim e^{z} z^{a-b} / \Gamma(a)$ as $z \rightarrow+\infty$ and $U$ admits the asymptotic behavior $U(a ; b ; z) \sim z^{-a}$ as $z \rightarrow+\infty$. In particular, $f$ finite at $x=0$ allows us to rule out the Kummer function and work with the Tricommi function only.

Note $\eta_{d, 1}<0<1<\eta_{d, 2}$ the roots of:

$$
\frac{1}{2} \sigma^{2} \eta_{d}^{2}+\left(m+\mu-\frac{1}{2} \sigma^{2}\right) \eta_{d}-(r+m)=0
$$


We can use the previous lemma to show that:

$$
d(x)=\frac{\kappa+m}{r+m}+k_{d, 1} x^{-\eta_{d, 1}} U\left(\eta_{d, 1} ; 2 \eta_{d, 1}+\frac{2(m+\mu)}{\sigma^{2}} ; \frac{2 \bar{g}}{\sigma^{2} x}\right)+k_{d, 2} x^{-\eta_{d, 2}} U\left(\eta_{d, 2} ; 2 \eta_{d, 2}+\frac{2(m+\mu)}{\sigma^{2}} ; \frac{2 \bar{g}}{\sigma^{2} x}\right)
$$

The boundary conditions at $x=0$ and $x=x^{*}$ then allow us to pin down $k_{d, 1}, k_{d, 2}$ uniquely as a functions of the (yet unknown) value $d\left(x^{*}\right)$. Then, given the function $d$ fully specified on $\left[0, x^{*}\right]$, equation (A55) is a second order boundary value problem, and Baxley and Brown (1981) provides for the existence and uniqueness of a solution to this ordinary differential equation. Note $\eta_{v, 1}<0<1<\eta_{v, 2}$ the roots of:

$$
\frac{1}{2} \sigma^{2} \eta_{v}^{2}+\left(m+\mu+\frac{1}{2} \sigma^{2}\right) \eta_{v}-(\delta-\mu)=0
$$

The function $v$ takes the following form:

$$
v(x)=\frac{1}{\delta-\mu}\left(1-\frac{\kappa+m}{\delta+m} \bar{g}\right)-\frac{\kappa+m}{\delta+m} x+v_{p}(x)+k_{v, 1} v_{g, 1}(x)+k_{v, 2} v_{g, 2}(x)
$$

In the above, the general solutions $v_{g, i}$ take the following form:

$$
v_{g, i}(x):=v_{i} x^{-\eta_{v, i}} U\left(\eta_{v, i} ; 2 \eta_{v, i}+\frac{2(m+\mu)}{\sigma^{2}}+2 ; \frac{2 \bar{g}}{\sigma^{2} x}\right)
$$

$v_{p}$ is a particular solution to the ordinary differential equation:

$$
(\delta-\mu) v(x)=\bar{g} d(x)+[\bar{g}-(\mu+m) x] v^{\prime}(x)+\frac{1}{2} \sigma^{2} x^{2} v^{\prime \prime}(x)
$$

Some algebra can show that $v_{p}(x)=v_{g, 1}(x) u(x)$, with the function $u(x)$ satisfying:

$$
\begin{aligned}
H(x) & :=\exp \left[\int_{x^{*}}^{x} \frac{(\bar{g}-(m+\mu) s) v_{g, 1}(s)+\sigma^{2} s^{2} v_{g, 1}^{\prime}(s)}{\frac{\sigma^{2} s^{2}}{2} v_{g, 1}(s)} d s\right] \\
u(x) & :=\int_{x^{*}}^{x}\left(\int_{x^{*}}^{t} \frac{-2 \bar{g}}{\sigma^{2} s^{2} v_{g, 1}(s)} \frac{H(s)}{H(t)} d s\right) d t
\end{aligned}
$$

It is also easy to prove that those solutions $d$ and $v$ are strictly decreasing on the interval $\left(0, x^{*}\right)$, under the assumption - to be verified numerically - that $d\left(x^{*}\right)<d(0)$ and $d^{\prime}(0)<0$ (for $d$ ) and under the assumption that $v\left(x^{*}\right)<v(0)$ and $v^{\prime}(0) \leq 0$ for $v$. Indeed, assume for example by way of contradiction that $d$ was not strictly decreasing on that interval. This means that there exists $0<x_{1}<x_{2}<x^{*}$, such that $d\left(x_{1}\right)<d\left(x_{2}\right), d^{\prime}\left(x_{1}\right)=d^{\prime}\left(x_{2}\right)=0$, and $d^{\prime \prime}\left(x_{1}\right)>0>d^{\prime}\left(x_{2}\right)$. But in that case, using equation (A56), we have:

$$
\begin{aligned}
& \frac{1}{2} \sigma^{2} x_{1}^{2} d^{\prime \prime}\left(x_{1}\right)=(r+m) d\left(x_{1}\right)-(\kappa+m)>0 \\
& \frac{1}{2} \sigma^{2} x_{2}^{2} d^{\prime \prime}\left(x_{2}\right)=(r+m) d\left(x_{2}\right)-(\kappa+m)<0
\end{aligned}
$$

In other words, $d\left(x_{1}\right)>d\left(x_{2}\right)$, a contradiction. A similar proof holds for $v$. We thus have determined $v$ and $d$ on the interval $\left[0, x^{*}\right]$, subject to our knowledge of $x^{*}, d\left(x^{*}\right), v\left(x^{*}\right)$.

We can then verify that the issuance constraint is binding - in other words, that if the government was allowed to issue a non-zero measure of debt, it would find it optimal to do so - this is identical to verifying that $d(x)+v^{\prime}(x) \geq 0$. The unconstrained issuance policy $g_{u}(x)$ verifies $g_{u}(x):=\frac{d(x)}{-d^{\prime}(x)}(\delta-r)$, and since in $\left(0, x^{*}\right)$ the government is constrained to issue an amount $\bar{g}$, we must have in this particular 
part of the state space $\bar{g}<g_{u}(x)$. Differentiate equation (A55) to obtain:

$$
\begin{aligned}
& (\delta+m) v^{\prime}(x)=\bar{g} d^{\prime}(x)-(\kappa+m)+\left[\bar{g}-\left(\mu+m-\sigma^{2}\right) x\right] v^{\prime \prime}(x)+\frac{1}{2} \sigma^{2} x^{2} v^{\prime \prime \prime}(x) \\
& (r+m) d(x)=(\kappa+m)+\left[\bar{g}-\left(\mu+m-\sigma^{2}\right) x\right] d^{\prime}(x)+\frac{1}{2} \sigma^{2} x^{2} d^{\prime \prime}(x)
\end{aligned}
$$

Add those last two equations, introduce $h(x):=d(x)+v^{\prime}(x)$, and note that $h$ satisfies:

$$
(\delta+m) h(x)=\left[\bar{g}-g_{u}(x)\right] d^{\prime}(x)+\left[\bar{g}-\left(\mu+m-\sigma^{2}\right) x\right] h^{\prime}(x)+\frac{1}{2} \sigma^{2} x^{2} h^{\prime \prime}(x)
$$

Then use the boundary condition $(\delta-\mu) v(0)=1+\bar{g}\left(d(0)+v^{\prime}(0)\right)$, and remember that it must be the case that $v(0) \geq \frac{1}{\delta-\mu}$ (in other words, the welfare of a government that has no debt, but that has the option to borrow from more patient lenders must be at least as high as the autarky welfare) to conclude that $d(0)+v^{\prime}(0) \geq 0$, in other words $h(0) \geq 0$. At $x=x^{*}, v$ is $\mathcal{C}^{1}$ (to guarantee optimality of the endogenous threshold $\left.x^{*}\right)$ and $d$ is continuous, meaning that we must have $d\left(x^{*}\right)+v^{\prime}\left(x^{*}\right)=0$, in other words $h\left(x^{*}\right)=0$. Using Feynman-Kac, $h(x)$ admits the following integral representation:

$$
h(x)=\mathbb{E}^{x}\left[\int_{0}^{\tau} e^{-(\delta+m) t}\left(\bar{g}-g_{u}\left(x_{t}\right)\right) d^{\prime}\left(x_{t}\right) d t\right]
$$

The stopping time $\tau$ is the first time the state variable $x$ hits $x^{*}$. Since $g_{u}(x) \geq \bar{g}$ in that region of the state space, since $d$ is a decreasing functions of $x$, it must be the case that $h(x) \geq 0$.

\section{A.14.2 Unconstrained Region $\left[x^{*}, \bar{x}\right]$}

Given our postulated behavior, in $x \in\left(x^{*}, \bar{x}\right)$ the government financing policy is entirely unconstrained, meaning that the analysis we discussed in Section 4.5 and Section 4.6 is unchanged: the value function for the government behaves locally as if the government was committing not to issue any debt. Thus, the (income-normalized) welfare for the government, the debt price and the issuance policy satisfy:

$$
\begin{aligned}
(\delta-\mu) v(x) & =1-(\kappa+m) x-(\mu+m) x v^{\prime}(x)+\frac{1}{2} \sigma^{2} x^{2} v^{\prime \prime}(x) \\
d(x) & =-v^{\prime}(x) \\
g(x) & =\frac{d(x)}{-d^{\prime}(x)}(\delta-r)
\end{aligned}
$$

These equations are derived using steps identical to those used in Section A.5. The debt price function is thus entirely pinned down by the equation $d(x)=-v^{\prime}(x)$, and it can be showed that it satisfies the second order ordinary differential equation:

$$
(\delta+m) d(x)=\kappa+m-\left(m+\mu-\sigma^{2}\right) x d^{\prime}(x)+\frac{1}{2} \sigma^{2} x^{2} d^{\prime \prime}(x)
$$

As discussed previously, equation (A58) is the Feynman-Kac representation of the debt price computed using discount rate $\delta$ and under the assumption that the government never issues any additional bonds. Boundary conditions are as follows:

$$
\begin{aligned}
& v(\bar{x})=0 \\
& d(\bar{x})=0
\end{aligned}
$$

$$
\begin{aligned}
& \lim _{x \nearrow x^{*}} v(x)=\lim _{x \searrow x^{*}} v(x) \\
& \lim _{x \nearrow x^{*}} d(x)=\lim _{x \searrow x^{*}} d(x)
\end{aligned}
$$


We imposed continuity of the value function at $x=x^{*}$. The optimality of the endogenous boundary $x^{*}$ will be determined by "smoothing" $v$ at $x=x^{*}$ - i.e. by imposing that $v$ is continuously differentiable at such point. The government value function, debt price and issuance policy take the following form on $x \in\left[x^{*}, \bar{x}\right]:$

$$
\begin{aligned}
& v(x)=\frac{1}{\delta-\mu}-\left(\frac{\kappa+m}{\delta+m}\right) x+v_{1}\left(\frac{x}{\bar{x}}\right)^{\xi_{1}}+v_{2}\left(\frac{x}{\bar{x}}\right)^{\xi_{2}} \\
& d(x)=\frac{\kappa+m}{\delta+m}+d_{1}\left(\frac{x}{\bar{x}}\right)^{\xi_{1}-1}+d_{2}\left(\frac{x}{\bar{x}}\right)^{\xi_{2}-1} \\
& g(x)=(r-\delta) x \frac{\frac{\kappa+m}{\delta+m}+d_{1}\left(\frac{x}{\bar{x}}\right)^{\xi_{1}-1}+d_{2}\left(\frac{x}{\bar{x}}\right)^{\xi_{2}-1}}{\left(\xi_{1}-1\right) d_{1}\left(\frac{x}{\bar{x}}\right)^{\xi_{1}-1}+\left(\xi_{2}-1\right) d_{2}\left(\frac{x}{\bar{x}}\right)^{\xi_{2}-1}}
\end{aligned}
$$

Since $-v^{\prime}(x)=d(x)$, the constants $v_{1}, v_{2}, d_{1}, d_{2}$ are linked via $d_{i}=-\xi_{i} v_{i} / \bar{x} . \xi_{1}<0<1<\xi_{2}$ are the roots of the polynomial:

$$
\frac{1}{2} \sigma^{2} \xi^{2}-\left(\mu+m+\frac{1}{2} \sigma^{2}\right) \xi-(\delta-\mu)=0
$$

The boundary conditions for $d$ and for $v$ at $x=\bar{x}$ lead to:

$$
\begin{array}{r}
d_{1}+d_{2}+\frac{\kappa+m}{\delta+m}=0 \\
v_{1}+v_{2}+\frac{1}{\delta-\mu}-\frac{\kappa+m}{\delta+m} \bar{x}=0
\end{array}
$$

The boundary conditions for $d$ and for $v$ at $x=x^{*}$ lead to:

$$
\begin{array}{r}
\frac{\kappa+m}{\delta+m}+d_{1}\left(\frac{x^{*}}{\bar{x}}\right)^{\xi_{1}-1}+d_{2}\left(\frac{x^{*}}{\bar{x}}\right)^{\xi_{2}-1}=d\left(x^{*}\right) \\
\frac{1}{\delta-\mu}-\left(\frac{\kappa+m}{\delta+m}\right) x^{*}+v_{1}\left(\frac{x^{*}}{\bar{x}}\right)^{\xi_{1}}+v_{2}\left(\frac{x^{*}}{\bar{x}}\right)^{\xi_{2}}=v\left(x^{*}\right)
\end{array}
$$

Note that the boundary condition for $d$ at $x=\bar{x}$ is identical to the smooth-pasting default optimality condition at such point (this latter condition is thus redundant). At the boundary $x=x^{*}$, the debt issuance rate of the small open economy is equal to $\bar{g}$. This gives us the following equation:

$$
\bar{g}=(r-\delta) x \frac{\frac{\kappa+m}{\delta+m}+d_{1}\left(\frac{x^{*}}{\bar{x}}\right)^{\xi_{1}-1}+d_{2}\left(\frac{x^{*}}{\bar{x}}\right)^{\xi_{2}-1}}{\left(\xi_{1}-1\right) d_{1}\left(\frac{x^{*}}{\bar{x}}\right)^{\xi_{1}-1}+\left(\xi_{2}-1\right) d_{2}\left(\frac{x^{*}}{\bar{x}}\right)^{\xi_{2}-1}}
$$

We need to make sure our initial choices $x^{*}, \bar{x}$ are such that $d\left(x^{*}\right)<d(0)$, which insures that the function $d$ is monotone decreasing on $\left[0, x^{*}\right]$.

\section{A.14.3 Determination of $x^{*}$ and $\bar{x}$}

It remains to discuss how the boundaries $x^{*}, \bar{x}$ are optimally set by the government. To be able to apply a standard verification theorem, we need to smooth the value function $v$, in other words, $x^{*}, \bar{x}$ are determined via the two smooth pasting conditions:

$$
\begin{aligned}
\lim _{x \nearrow x^{*}} v^{\prime}\left(x ; x^{*}, \bar{x}\right) & =\lim _{x \searrow x^{*}} v^{\prime}\left(x ; x^{*}, \bar{x}\right) \\
\lim _{x \searrow \bar{x}} v^{\prime}\left(x ; x^{*}, \bar{x}\right) & =0
\end{aligned}
$$


Assuming that there exists a solution to this two-equation, two-unknown system, we then have our main result: when the government is constrained to use an issuance rate below a certain maximum level $\bar{g}$, an equilibrium exists, in which the issuance policy is unconstrained for $x>x^{*}$, and constrained at $\bar{g}$ when $x \in\left(0, x^{*}\right)$. It is optimal for the government to default as soon as $x$ reaches $\bar{x}$. In that equilibrium the welfare of a government that is not indebted is strictly greater than the autarky welfare.

\section{A.14.4 A Simplification: the Case $\sigma=0, \mu+m<0$}

In this particular case, we can solve for $v$ and $d$ in closed form. We have $\bar{x}=1 /(\kappa+m)$. When $x<x^{*}$, the debt price and government value function take the following expressions:

$$
\begin{aligned}
& d(x)=\frac{\kappa+m}{r+m}-\left(\frac{\kappa+m}{r+m}-d\left(x^{*}\right)\right)\left(\frac{\bar{g}-(\mu+m) x}{\bar{g}-(\mu+m) x^{*}}\right)^{-\frac{r+m}{\mu+m}} \\
& v(x)=a_{0}+a_{1} x+a_{2}\left(\frac{\bar{g}-(\mu+m) x}{\bar{g}-(\mu+m) x^{*}}\right)^{-\frac{r+m}{\mu+m}}+\left(v\left(x^{*}\right)-a_{0}-a_{1} x^{*}-a_{2}\right)\left(\frac{\bar{g}-(\mu+m) x}{\bar{g}-(\mu+m) x^{*}}\right)^{-\frac{\delta-\mu}{\mu+m}}
\end{aligned}
$$

In the above, the constants $a_{0}, a_{1}, a_{2}$ are equal to:

$$
\begin{aligned}
& a_{0}:=\frac{1}{\delta-\mu}\left[1+\frac{\bar{g}(\kappa+m)(\delta-r)}{(r+m)(\delta+m)}\right] \\
& a_{1}:=-\frac{\kappa+m}{\delta+m} \\
& a_{2}:=\frac{\bar{g}}{\delta-\mu-r-m}\left(d\left(x^{*}\right)-\frac{\kappa+m}{r+m}\right)
\end{aligned}
$$

When $x \in\left(x^{*}, \bar{x}\right)$, the debt price, government value function and issuance policy take the following expressions:

$$
\begin{aligned}
& d(x)=\frac{\kappa+m}{r+m}\left[1-\left(\frac{x}{\bar{x}}\right)^{-\frac{r+m}{\mu+m}}\right] \\
& v(x)=\frac{1}{\delta-\mu}-\frac{\kappa+m}{\delta+m} x-\left[\frac{1}{\delta-\mu}-\frac{\kappa+m}{\delta+m} \bar{x}\right]\left(\frac{x}{\bar{x}}\right)^{-\frac{\delta-\mu}{\mu+m}} \\
& g(x)=-\frac{(\delta-\mu)(\mu+m)}{\delta+m}\left[\left(\frac{\bar{x}}{x}\right)^{-\frac{\delta+m}{\mu+m}}-1\right] x
\end{aligned}
$$

Since $g\left(x^{*}\right)=\bar{g}, x^{*}$ is determined via:

$$
\bar{g}=-\frac{(\delta-\mu)(\mu+m)}{\delta+m}\left[\left(\frac{\bar{x}}{x^{*}}\right)^{-\frac{\delta+m}{\mu+m}}-1\right] x^{*}
$$

\section{A.15 First Best with Full Commitment}

We consider a particular issuance policy that achieve the first best outcome for the government. Given our income process specification, the autarky value $V_{0}$ for the government is equal to:

$$
V_{0}(Y)=\frac{Y}{\delta-\mu}
$$

Following a default, the government's income jumps from $Y_{\tau-}$ to $Y_{\tau}=\alpha Y_{\tau-}$, and the government is then stuck in financial autarky forever. Given this assumption, the government can only "pledge" cash-flows 
$(1-\alpha) Y_{t}$, and thus the first best value for the government is

$$
V^{*}(Y)=\frac{(1-\alpha) Y}{r-\mu}+\frac{\alpha Y}{\delta-\mu}
$$

We argue that a policy that guarantees that the debt-to-income ratio of the government stays constant at $x_{t}=x^{*}$ (for a parameter $x^{*}$ carefully chosen) achieves the first-best outcome. To see this, consider one particular cumulative debt issuance policy so that $d \Gamma_{0}=x^{*} Y_{0}-F_{0-}$ and for $t>0$,

$$
d \Gamma_{t}=(\mu+m) F_{t} d t+\sigma F_{t} d B_{t},
$$

which leads to a debt face value process that satisfies $d F_{t}=\mu F_{t} d t+\sigma F_{t} d B_{t}$ and hence $x_{t}=\frac{F_{t}}{Y_{t}}=x^{*}$. With full commitment, the government could employ a financing policy in Eq. (A59) with a strictly positive loading on the Brownian shock $d B_{t}$, so that the government issues debt if $d B_{t}>0$ while buys back if $d B_{t}<0$.

Let us then compute the government welfare $V^{*}$ under such policy. The expected value of consumption flows received between $t$ and $t+d t$ by the government are as follows:

$$
\mathbb{E}_{t}\left[d C_{t}\right]=Y_{t}\left(1-(\kappa+m) x^{*}+D_{t}(\mu+m) x^{*}\right] d t
$$

If one picks $x^{*}=\left(\frac{r+m}{\kappa+m}\right)\left(\frac{1-\alpha}{r-\mu}\right)$, then it is easy to verify that $\mathbb{E}_{t}\left[\int_{t}^{+\infty} e^{-\delta t} d C_{t}\right]=\alpha Y_{t} /(\delta-\mu)$. This implies that the government will never default, as its continuation value always equals to "reservation" value $\alpha Y_{t} /(\delta-\mu)$. This ensures that the debt price $D_{t}$ is equal to its risk-free value $D_{r f}:=\frac{\kappa+m}{r+m}$. Notice finally that our financing policy needs to have an initial impulse, such that the debt-to-income ratio at $t=0$ is equal to $x^{*}-$ in other words, $F_{0}=x^{*} Y_{0}$. This means that the no-debt welfare for a government that can fully commit is equal to:

$$
V^{*}\left(Y_{0}\right)=\alpha Y_{0} /(\delta-\mu)+F_{0} D_{r f}=\frac{(1-\alpha) Y_{0}}{r-\mu}+\frac{\alpha Y_{0}}{\delta-\mu}
$$

